\author{
UNIVERSIDADE DE SÃO PAULO \\ FACULDADE DE CIÊNCIAS FARMACÊUTICAS \\ Programa de Pós-Graduação em Farmácia \\ Área de Análises Clínicas
}

\title{
Caracterização molecular e fenotipica de amostras bacterianas pertencentes ao complexo Acinetobacter calcoaceticus- Acinetobacter baumannii
}

\author{
Elizabeth Harummyy Takagi
}

Tese apresentada para obtenção do grau de Doutor

Orientador: Profa Tit. Marina Baquerizo Martinez

Co-orientador: Prof ${ }^{a}$ Vanessa Sperandio

São Paulo 


\section{Ficha Catalográfica}

Elaborada pela Divisão de Biblioteca e

Documentação do Conjunto das Químicas da USP.

Takagi, Elizabeth Harummyy

T136c Caracterização molecular e fenotípica de amostras bacterianas pertencentes ao complexo Acinetobacter calcoaceticus-Acinetobacter baumannii / Elizabeth Harummyy Takagi. -- São Paulo, 2011. $92 \mathrm{p}$.

Tese (doutorado) - Faculdade de Ciências Farmacêuticas da Universidade de São Paulo. Departamento de Análises Clínicas e Toxicológicas.

Orientador: Martinez, Marina Baquerizo

Co-orientador: Sperandio, Vanessa

1. Microbiologia médica 2. Biologia molecular I. T. II. Martinez, Marina Baquerizo, orientador. III. Sperandio, Vanessa, coorientador. 


\title{
Elizabeth Harummyy Takagi
}

Caracterização molecular e fenotípica de amostras bacterianas pertencentes ao complexo Acinetobacter calcoaceticusAcinetobacter baumannii

\author{
Comissão Julgadora \\ da
}

Tese para obtenção do grau de Doutor

Profa. Dra. Marina Baquerizo Martinez orientador/presidente

\begin{tabular}{c}
\hline $1^{\circ} \cdot$ examinador \\
\hline $2^{\circ} \cdot$ examinador \\
\hline $3^{\circ} \cdot$ examinador \\
\hline $4^{\circ} \cdot$ examinador
\end{tabular}

São Paulo, de 
Aos meus pais, Mário e Regina, por todo amor, compreensão e apoio constantes.

À Cintia, minha irmã e meus sobrinhos, Gustavo e Benjamin. 
"Feliz aquele que transfere o que sabe e aprende o que ensina"

Cora Coralina 


\section{Agradecimentos}

À Profa. Tit. Marina Baquerizo Martinez, por me acolher em seu laboratório, pela oportunidade de desenvolver este trabalho, pela confiança, pelo apoio e amizade. Agradeço por ter contribuído em minha formação.

À Profa. Vanessa Sperandio pelo aceite da co-orientação.

À Profa. Rosário Hirata, pela disponibilização Bionumerics, pelo carinho e atenção.

À Silvia Yumi Bando, por todo o conhecimento compartilhado, pela atenção e carinho.

À Profa. Carla Taddei, pelo carinho, pela possibilidade de aprender um pouco sobre microbiota intestinal.

À Renata Albuquerque, por toda a atenção e auxílio dispensado, principalmente quando cheguei ao laboratório, pelo carinho e amizade.

À Lilian Ferri Passadore pela amizade, por sua alegria e auxílio em diversos momentos da minha pós-graduação.

À Silvia Regina Santos pela amizade, pela possibilidade de aprender um pouco sobre Streptococcus pneumoniae, pelo carinho.

À Stella, Angélica, Cristina, Fátima, Neide pelo carinho, atenção e pelo ótimo convívio durante os períodos de estágio durante a iniciação científica e para conclusão do curso.

Ao Lucas G. Ferreira, pela amizade, pelo carinho, todas as caronas .

À Fernanda F. Oliveira, pela amizade, pela atenção, pelos bons momentos compartilhados.

À Isabel I. R. Carvalho,pela amizade, pelo carinho e pelas eternas conversas, nas quais simples idéias ou sentimentos eram compreendidos, mesmo quando nenhuma palavra tivesse sido pronunciada. 
À Silvia T. Toledo, por todo auxilio, pela amizade, pelo apoio e incentivo em momentos tão delicados.

Às alunas de iniciação que estiveram em algum momento envolvidas nesse projeto: Tatiane Marques Carvalheiro, Juliana Coutinho Campos e Isis Pavão Andreatta.

Aos amigos Fabiana, Hadassa, Renée, Milton, pelo carinho, pelo apoio e atenção e bons momentos compartilhados no laboratório

Às secretárias do departamento de Ánalises Clínicas Ana, Sueli, Dora e Edna.

À todos os funcionários do Serviço de Laboratório Clínico do Hu-USP pelo carinho e bons momentos compartilhados.

Aos funcionários e docentes do Departamento de Análises Clínicas e Toxicológicas da Faculdade de Ciências Farmacêuticas da Universidade de São Paulo, pela cooperação técnica e por colocarem à minha disposição toda a infra-estrutura física de seus laboratórios.

À Fundação de Amparo à Pesquisa do Estado de São Paulo, ao CNPq e à Fundação Butantan, pelo apoio financeiro.

À toda minha família por acreditarem tanto em mim.

À minha tia Mickie por todas as intermináveis conversas, por todo o apoio e por despertar o meu encanto pela ciência.

Em especial à minha mãe Regina e meu pai Mário, por me apoiarem sempre em todos os momentos da minha vida, caso contrário nada disso seria possível. Amo muito voces. Muito obrigada!

À todos que contribuiram com esse trabalho. 
"Aqueles que passam por nós, não vão sós, não nos deixam sós. Deixam um pouco de si, levam um pouco de nós."

Antoine de Saint-Exupéry 


\section{SUMÁRIO}

RESUMO.

ABSTRACT III

LISTA DE FIGURAS VI

LISTA DE TABELAS V

LISTA DE ABREVIATURAS E SIGLAS VI

1 INTRODUÇÃO

1.1 Infecção hospitalar 1

1.2 Acinetobacter sp. 2

1.2.1 Identificação das espécies bacterianas 5

1.2.3. Resistência bacteriana aos antimicrobianos 7

1.2.3.1 Metalo- $\beta$-lactamases 9

1.2.3.2 Carbapenemases do tipo OXA 10

1.3 "Quorum sensing” e mecanismos de virulência 12

2 OBJETIVOS 16

$\begin{array}{ll}2.1 \text { Objetivo geral } & 16\end{array}$

$\begin{array}{ll}2.2 \text { Objetivo específicos } & 16\end{array}$

3 MATERIAL E METODOS

$\begin{array}{ll}3.1 \text { Amostras bacterianas } & 17\end{array}$

$\begin{array}{ll}3.2 \text { Extração do DNA } & 18\end{array}$

3.3 Identificação dos isolados pertencentes ao complexo ACB 18

3.3.1 Estudo do polimorfismo da regição intergênica 16S-23S rRNA 19

3.3.2 Esquema de identificação das espécies do complexo ACB e pesquisa de genes de resistência do tipo OXA 19

3.4 Tipagem molecular 23

3.4.1 Reação de RAPD 23

3.4.2 Eletroforese em gel de agarose em campo pulsado (PFGE) 25

3.4.3 Análise dos polimorfismos 26

3.5 Pesquisa de genes codificadores de carbapenemases 26 
3.6 Estudo da comunição celular bacteriana 28

3.6.1 Preparo dos meios pré-condificionados 28

3.6.2 Pesquisa de acil-homoserina lactona 28

3.6.2.1 Bioensaio pela indução de violaceína 28

3.6.2.2 Bioensaio pela inibição de violaceína 29

3.62.3 Análise do extrato orgânico do meio pré-condicionado por

LC-MS

$\begin{array}{ll}\text { 3.6.3 Pesquisa de autoindutor-2 } & 31\end{array}$

$\begin{array}{ll}\text { 3.6.4 Pesquisa de autoindutor-3 } & 31\end{array}$

3.7 Avaliação da produção de biofilmes 32

3.8 Ensaio de adesão bacteriana 33

3.9 Análise estatística 34

4 RESULTADOS $\quad 35$

4.1 Identificação das espécies do complexo ACB 35

4.2 Perfil das amostras estudadas 36

4.3 Pesquisa de genes codificadores de carbapenemases 41

4.4 Tipagem molecular 42

4.4.1 RAPD 42

$\begin{array}{ll}\text { 4.4.2 Tipagem por PFGE } & 46\end{array}$

4.5 Pesquisa de acil-homoserina lactonas $\quad 47$

4.6 Pesquisa de autoindutor-2 50

4.7 Pesquisa de autoindutor-3 50

4.8 Ensaio de adesão bacteriana em células eucarióticas 51

4.9 Avaliação da produção de biofilme 56

5 DISCUSSÃO

6 CONCLUSÕES

REFERÊNCIAS BIBLIOGRÁFICAS 


\section{RESUMO}

TAKAGI, E.H. Caracterização molecular e fenotípica de amostras bacterianas pertencentes ao complexo Acinetobacter calcoaceticus-Acinetobacter baumannii. 2011. 92p. Tese (Doutorado) - Faculdade de Ciências Farmacêuticas, Universidade de São Paulo, 2011.

Nos últimos 30 anos, Acinetobacter tornou-se um dos patógenos de maior preocupação clínica pela falta de terapias eficazes em virtude do fenótipo de multirresistência frequentemente apresentado. Dentre as espécies do gênero Acinetobacter, $A$. baumannii, $A$. genoespécie 3 e $A$. genoespécie $13 T U$ são as mais comumente encontradas a partir de amostras biológicas. Estas espécies ao lado de $A$. calcoaceticus constituem o complexo A. calcoaceticus-A. baumannii (ACB).

Este estudo propõe um esquema composto de duas PCRs para a identificação das espécies de interesse médico que fazem parte do complexo ACB. O método é simples, rápido e, além de identificar as espécies, permite pesquisar a presença de genes de resistência. Foram identificadas 515 amostras do complexo ACB, isoladas de pacientes no período de janeiro de 2005 a dezembro de 2010. A identificação das espécies do complexo ACB foi realizada por esquema composto de duas reações de PCR. Foram avaliados os perfis de sensibilidade por disco difusão e a pesquisa da

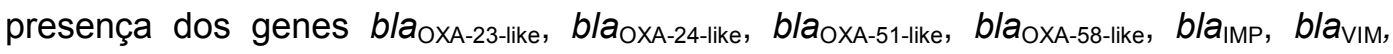
$b / a_{S I M}, b / a_{S P M}$ e bla $a_{G I M}$ foi realizada por PCR utilizando-se iniciadores específicos. No grupo de amostras estudas, $82,5 \%$ são $A$. baumannii (425), 11,5\% $A$. genoespécie 13TU (59) e 6,0\% $A$. genoespécie 3 (30), sendo $A$. baumannii mais isolado em pacientes internados em UTIs $(p=0,0407)$ e $A$. genoespécie $13 T \mathrm{~T}$ mais isolado em pacientes de outros ambientes hospitalares $(p=0,0204)$. A. baumannii apresentou menor sensibilidade a todos os antimicrobianos quando comparado com $A$. genoespécie 13TU e $A$. genoespécie. 3 ( $p<0,05)$. Foi possível observar ao longo do período estudado o aumento significativo da resistência aos carbapenêmicos e da sensibilidade a gentamicina por $A$. baumannii entre os isolados de pacientes de UTIs $(p<0.05)$. Nenhum dos genes codificadores para metalo-lactamases foi detectado nas amostras estudadas Dentre os cepas resistentes aos carbapenêmicos (176) o gene bla OXA -23 foi detectado em $81,25 \%$ e uma amostra de $A$. baumannii apresentou o gene codificador para OXA-72.

A tipagem molecular foi realizada por RAPD e para os isolados resistentes aos carbapenêmicos também por PFGE. Resultados obtidos por RAPD revelaram menor diversidade entre os isolados de pacientes internados em UTIs. O dendrograma obtido 
utilizando-se PFGE separou dois clones cujos componentes eram resistentes aos carbapenêmicos, no entanto não apresentavam o gene bla OXA-23-like. A produção de acil-homoserina lactona, autoindutor-2 e autoindutor-3 de três amostras de cada espécie clínica do complexo ACB foi pesquisada utilizando-se bioensaios. Apenas Autoindutor 3 foi detectado por bioensaio e em menor quantidade no meio précondicionados obtido a partir de $A$. genoespécie 3 quando comparado com $A$. genoespécie 13TU e $A$. baumannii $(p<0.05)$. Três cepas de cada espécie clínica do complexo ACB foi avaliada quanto a capacidade de adesão em monocamada de células Hep-2, MRC-5 e NCl-H292, sendo essa última a que revelou diferenças entre as espécies clínicas do complexo ACB. $A$. baumannii apresentou adesão difusa, $A$. genoespécie 13 TU adesão com formação de agrupamentos e $A$. genoespécie 3 não aderiu. Esse mesmo ensaio foi realizado na presença de propanolol e notou-se a diminuição de células aderidas por campo observado. Dez cepas de cada espécie clínica do complexo ACB foram pesquisadas quanto a produção de biofilme por ensaio colorimétrico utilizando cristal violeta e foi possível notar a produção significativa de biofilme por $A$. baumannii, quando comparado com $A$. genoespécie $3(p<0.05)$. Esse mesmo ensaio na presença de de fentolamina, mostrou a diminuição significativa na produção do biofilme por $A$. baumannii. A interferência no ensaio de adesão bacteriana e biofilme, na presença de fentolamina ou propanolol, sugerem o envolvimento do autoindutor-3 na regulação desses mecanismos de virulência.

Palavras-chaves: Identificação bacteriana, Acinetobacter baumannii, A. 3, A.13TU, biofilme, "quorum sensing", resistência bacteriana. 


\begin{abstract}
TAKAGI, E.H. Molecular and phenotypic characterization of Acinetobacter calcoaceticus-Acinetobacter baumannii isolates. 2011. 92p. Thesis (PhD) - Faculdade de Ciências Farmacêuticas. Universidade de São Paulo, São Paulo, 2011.
\end{abstract}

The genus Acinetobacter has emerged as one of the most troublesome pathogens for health care institutions globally. Its clinical significance, especially over the last 15 years, has been driven by its remarkable ability to up regulate or acquire resistance determinants, making it one of the organisms threatening the current antibiotic era. A. baumannii, $A$. 3 and $A$. 13TU are the most commonly species found from biological samples. These species beside $A$. calcoaceticus are very closely related and difficult to distinguish from each other by phenotypic properties. Therefore, it has been proposed to refer to these species as the A.calcoaceticus- $A$. baumannii complex(ACB). In the period from 2005 to 2009, the most frequent bacterial isolates among the nosocomial infection at the HU-USP was ACB (18\%). Due to the frequency with which species are involved in ACB outbreaks of infection in the HU-USP and the emergency clinic because of expression of the phenotype of resistance to several classes of antibiotics, this study aimed to identify and characterize the species of complex ACB by molecular methods, to study their mechanisms of resistance and to characterize the different clones from patients admitted to different hospital areas. Furthermore, the ability to characterize biofilm formation, adhesion to different cell lines as well as the mechanisms of cell-cell communication were analyzed. From the ACB complex, 515 samples were identified, isolated from patients from January 2005 to December 2010. The identification of clinical species of the ACB was performed by molecular methods that were developed and validated for identification of Acinetobacter sp. include two reactions of PCR.

The profiles of sensibility were evaluated by disc diffusion and the detection of the presence of genes bla OXA-23-like, bla $_{\text {OXA-24-like, bla }}$ OXA-51-like, bla OXA-58-like, bla ${ }_{I M P}$, blavIM, bla $_{S I M}, b_{a_{G I M}}$, and bla bPM $_{\text {w }}$ were performed using specific primers. Molecular typing was performed by RAPD and isolates resistant to carbapenems also by PFGE. The production of autoinducers of three clinical species complex was sought using bioassays with sensor strains. The ability adhesion was evaluated in monolayer of Hep-2 cells, MRC-5 and NCl-H292E. Ten clinical strains of each species of ACB complex were screened for the production of biofilms by colorimetric assay using 
crystal violet. Among all the strains studied, $82.5 \%$ were $A$. baumannii (425), $11.5 \%$ A.13TU (59) and 6.0\% A. 3 (30). A. baumannii strains were more isolated from intensive care unit $(\mathrm{ICU})$ patients $(\mathrm{p}=0.0407)$ and $A$. 13TU from other patients in different hospital settings $(p=0.0204)$. A. baumannii showed less sensitivity to all drugs when compared with $A .13 T U$ and $A .3(p<0.05)$. It was possible to observe during the study period a significant increase in carbapenem resistance and sensitivity to gentamicin by $A$. baumannii isolates from patients in ICUs $(p<0.05)$. No genes coding for metallo-lactamase was detected in the samples studied. bla detected in $81.25 \%$ among the 176 strains resistant to carbapenems. Results obtained by RAPD revealed less diversity among isolates from ICU patients compared to isolates from patients from other hospitals. The dendrogram obtained by PFGE showed less diversity than RAPD It was unable to detect homoserine lactone and autoinducer-2 by bioassay. The survey was positive of autoinducer-3 observed differences in yield among clinical species, smaller amount produced by strains of $A$. 3 when compared with $A$. 13TU and $A$. baumannii $(\mathrm{p}<0.05)$. Among the cells studied in adhesion testing, line $\mathrm{NCl}-\mathrm{H} 292$ showed the greatest power discrimination between adhesion pattern observed and species of the ACB. A. baumannii showed diffuse adherence, A. 13 TU strains showed adhesion clustering and $A$. 3 did not adhere. This experiment was repeated in the presence of $100 \mu \mathrm{M}$ of propranolol and it was noted a decrease in cell $A$. 13TU and $A$. baumannii adhered per field observed. The biofilm assay showed significantly higher production of biofilms by A.baumannii compared with $A$. $3(p<0.05)$. When the test was conducted in the presence of phentolamine at $100 \mu \mathrm{M}$, it was observed a significant decrease in the biofilm productions by $A$. baumannii, which revealing the involvement of the autoinducer-3 in biofilm production. The data obtained suggest that the proposed method of identification is a method for identification of species of medical interest belonging to the ACB complex which could be used in a routine laboratory. The method is simple, fast and beside the identification species, provides data about the resistance genes. Moreover, it revealed that the isolates of $A$. baumannii are more resistant and $\mathrm{OXA}_{\text {bla }}$ genes, that was restricted to the ACB complex studied in this work. $A$. baumannii has also increased capacity for adhesion and biofilm formation, which regulates the expression of the phenotype may be linked to the production of autoinducers-3.

Key-words: Acinetobacter baumannii, A. 3, A. 13TU, biofilm, quorum sensing, antimicrobial susceptibility. 


\section{LISTA DE FIGURAS}

Figura 1. Alinhamento das sequências nucleotídicas da região entre os genes codificadores do $16 \mathrm{~S}$ e $23 \mathrm{~S}$ rRNA

Figura 2 Esquema de identificação proposta para as espécies clínicas 36 do complexo ACB

$\begin{array}{lll}\text { Figura } 3 & \text { Distribuição das espécies por amostra biológica } & 37\end{array}$

Figura 4. Distribuição das espécies do complexo ACB isoladas de 38 pacientes de UTIs e outros ambientes hospitalar

Figura 5. Perfil de sensibilidade das espécies do complexo ACB 39

Figura 6. Perfil de sensibilidade de Acinetobacter baumannii isolado de 40 pacientes de UTIs e outros ambientes hospitalares

Figura 7. Análise temporal da porcentagem de amostras de $A$. 41 baumannii sensíveis a diferentes antibióticos (2005-2010

Figura 8. Exemplo do resultado obtido por RAPD 43

Figura 9. $\quad$ Comparação das matrizes de similaridade de Jaccard e Dice 44 pelo teste de correspondência de matriz de Mantel

Figura 10 Dendrograma obtido por análise dos polimorfismos obtidos por RAPD dos 425 isolados de $A$. baumannii

Figura 11 Dendrograma gerado pela análise dos polimorfismos obtidos por RAPD dos 59 isolados de $A$. 13TU e 31 isolados de $A .3$ estudados

Figura 12 Dendrograma obtido por RAPD e PFGE para isolados de $A$. baumannii resistentes aos carbapenêmicos

Figura 13 Cromatograma e espectros de massa para pesquisa de acilhomoserina lactona detectada em extrato de sobrenadante de A. baumannii

Figura 14 Atividade da $\beta$-galactosidade da cepa biossensora Escherichia coli TEVS 232 cultivada em meios pré-condicionados por cepas de A. 3, A. 13TU e A. baumanni

Figura 15 Ensaio de adesão em células MRC-5

Figura $16 \quad$ Ensaio de adesão bacteriana em células NCl-H292 53

Figura 17 Ensaio de adesão bacteriana em células $\mathrm{NCl}-\mathrm{H} 292$ sem ou 55 com propanolol

Figura 18 Produção de biofilme por amostras de A. baumannii, A. 13 TU 56 e $A$. 3 na presença e ausência de fentolamina

Figura 19 Estrutura geral de uma molécula de acil-homoserina-lactona 65

Figura $20 \quad$ Síntese de autoindutor-2 a partir do ciclo da metionina 65 


\section{LISTA DE TABELAS}

Tabela 1 Cepas utilizadas nos bioensaios para pesquisa de 18 autoindutores

Tabela 2. Iniciadores e condições de termociclagem utilizadas na 21 reação PCR multiplex para carbapenemases do tipo OXA

Tabela 3 Iniciadores e condições de termociclagem utilizados para identificação das espécies $A$. 3 e $A$. 13TU e amplificação da região intergênica $16 S-23 S$ rRNA

Tabela 4 Iniciadores e condições de termociclagem utilizados na 24 reação de RAPD

Tabela 5 Iniciadores e condições de termociclagem utilizados na 27 reação de multiplex PCR para metalo-lactamases

Tabela 6 Iniciadores utilizados para tipagem por RAPD e o resultado de amplificação

Tabela 7 Iniciadores usados na análise de RAPD e a quantidade de polimorfismos obtidos 


\section{LISTA DE ABREVIATURAS E SIGLAS}

\begin{tabular}{|c|c|}
\hline${ }^{\circ} \mathrm{C}$ & Graus Celsius \\
\hline$\mu g$ & Micrograma \\
\hline$\mu \mathrm{L}$ & Microlitros \\
\hline$\mu \mathrm{M}$ & Micromolar \\
\hline AFLP & "Amplified fragment length polymorphism" \\
\hline $\mathrm{AHL}$ & Acil-homoserina lactona \\
\hline $\mathrm{Al}-2$ & Autoindutor-2 \\
\hline Al-3 & Autoindutor-3 \\
\hline AIM & Austrália imipenemase \\
\hline ARDRA & "Amplified 16S ribosomal DNA restriction analysis" \\
\hline ATCC & "American type culture collection" \\
\hline $\mathrm{BHI}$ & "Brain Heart Infusion” \\
\hline CIM & Concentração inibitória minima \\
\hline CLS & "cell lysis buffer" \\
\hline CLSI & "Clinical and Laboratory Standards Institute" \\
\hline CRA & Acinetobacter resistente aos carbapenêmicos \\
\hline CSB & "cell suspension buffer" \\
\hline DMEM & "Dulbecco's modified eagle médium" \\
\hline DMSO & Dimetilsulfóxido \\
\hline DNA & Ácido desoxirribonucleico \\
\hline DO & Densidade óptica \\
\hline EDTA & Ácido etilenodiaminotetracético \\
\hline ESBL & "Extended-spectrum beta-lactamase" \\
\hline EUA & Estados Unidos da América \\
\hline FMUSP & Faculdade de Medicina da Universidade de São Paulo \\
\hline g. $\mathrm{L}^{-1}$ & grama por litro \\
\hline GIM & "Germany" imipenemase \\
\hline gyrB & Gene codificador da subunidade B da girase \\
\hline $\mathrm{h}$ & Hora \\
\hline $\mathrm{HC}$ & Hospital das Clinicas \\
\hline
\end{tabular}


HHL n-hexanoil-DL-homoserina lactona

HU-USP Hospital Universitário da Universidade de São Paulo

ICS Infecção de corrente sanguínea

IMP Imipenemase

IS Element de inserção

ITS "Intergenic sequence"

kDa Kilodalton

LB Luria Bertani

LBA Lavado-broquio-alveolar

LC-MS Cromatografia líquida- espectômetro de massa

$\mathrm{m} / \mathrm{z} \quad$ Relação massa carga

MBL Metalo-beta-lactamase

MEM Meio mínimo essencial de eagle

$\mathrm{mL} \quad$ Mililitros

$\mathrm{nm} \quad$ Nanômetro

NNIS "National Nosocomial Infections Surveilance"

OMP Protein de membrana externa

ONPG Orto-nitrofenil-galactopiranosídeo

OXA oxacilinase

$\mathrm{pb} \quad$ pares de bases

PBP "penicillin binding protein"

PCR Reação em cadeia polymerase

PFGE "Pulsed Field Gel Electrophoresis"

QS "Quorum sensing"

RAPD "Random amplified polymorphic DNA"

REP-PCR "repetitive element palindromic- polimerase chain reaction"

RND "Resistant Nodulation and Division"

rpm Rotações por minuto

rRNA RNA ribossômico

SFB Soro fetal bovino

SIM Seoul imipenemase

SPM São Paulo imipenemase

SSTF Solução salina tamponada com fosfato 


$\begin{array}{ll}\text { TBE } & \text { Tris-borato-EDTA } \\ \text { TE } & \text { Tris-EDTA } \\ \text { TSB } & \text { "tryptone soya broth" } \\ \text { TU } & \text { Tjernberg e Ursing } \\ \text { UPGMA } & \text { "unweighthed pair-group method using arithmetic average" } \\ \text { USP } & \text { Universidade de São Paulo } \\ \text { UTI } & \text { Unidade de terapia intensiva } \\ \text { UV } & \text { Ultra-violeta } \\ \text { V } & \text { Volts } \\ \text { VIM } & \text { Verona imipenemase }\end{array}$




\section{INTRODUÇÃO}

\subsection{Infeccção hospitalar}

Infecção hospitalar é uma síndrome infecciosa que o indivíduo adquire após a sua hospitalização ou realização de procedimentos ambulatoriais. Nos Estados Unidos, mais de dois milhões de pessoas adquirem infecção hospitalar, o que representa $5 \%$ dos indivíduos hospitalizados. Estima-se que no Brasil a incidência de infecções hospitalares atinge valor superior a 1,2 milhões por mês (PANNUTI \& GRIMBAUM, 1993). Com este alto índice, desde 1983 o Ministério da Saúde tem estabelecido um programa nacional para o controle da infecção hospitalar (IH) (Ministério da Saúde, 1983), porém, embora atualmente a maioria dos hospitais brasileiros tenha constituído formalmente comissões de controle de infecção hospitalar ainda são poucos os centros que desenvolvem um programa efetivo para essa finalidade (ANVISA, 2004).

Embora fungos, vírus e parasitas são reconhecidos como fontes de infecções hospitalares, as bactérias são os agentes etiológicos mais envolvidos em infecções adquiridas após procedimentos hospitalares. Bactérias multirresistentes são os principais problemas destes pacientes e inúmeros fatores de riscos são frequentemente descritos, entre eles podemos citar as condições debilitantes das doenças de base como diabetes, falência renal e malignidades (SIROY et al., 2005; SLAMA, 2008). Tempo longo de hospitalização, procedimentos cirúrgicos e antibioticoterapias prévias são outros importantes fatores de risco (SIROY et al., 2005). Entre os bacilos Gram negativos não fermentadores Pseudomonas aeruginosa e Acinetobacter baumannii são os mais envolvidos em casos de surtos de infecções hospitalares (BERGOGNE-BÉRÉZIN \& TOWNER, 1996; DIJKSHOORN et al., 2007; SLAMA; 2008).

A partir da década de 70, Acinetobacter tornou-se uma crescente preocupação em hospitais. Esta bactéria é o segundo bacilo Gram-negativo não-fermentador mais freqüente em infecções hospitalares, sendo superado apenas pelo gênero Pseudomonas. Relatos de surtos causados por 
Acinetobacter são descritos mundialmente, sendo $A$. baumannii a espécie clínica mais importante (DIJKSHOORN et al., 2007; PELEG et al., 2008).

\subsection{Acinetobacter sp.}

São patógenos oportunistas, acomete principalmente pacientes imunodeprimidos e internados em unidades de terapia intensiva (DIJKSHOORN et al., 2007). Na grande maioria das infecções, a terapia é difícil em virtude da expressão do fenótipo de resistência às diversas classes de antimicrobianos, inclusive aos carbapenêmicos, o que representa uma grande preocupação pela falta de terapias eficazes, sendo considerada uma urgência clínica e epidemiológica global (PELEG et al, 2008). Adicionalmente, este patógeno possui uma capacidade surpreendente de adaptação a ambientes hostis. Utiliza diferentes fontes de carbono, cresce em diferentes condições de temperatura e pH (JUNI, 1978); apresenta resistência a desinfetantes (WISPLINGHOFF et al., 2007) e tolerância a baixas taxas de umidade (JAWAD et al., 1998). Essas características somadas à habilidade de A. baumannii em aderir e formar biofilmes em superfícies, bióticas e abióticas, contribui com a persistência deste microrganismo no ambiente hospitalar, e com a possibilidade de ocorrência de surtos recorrentes (PELEG et al., 2008).

A colonização por $A$. baumannii é mais comum que a infecção, até mesmo em pacientes suscetíveis, revelando que geralmente essa espécie apresenta baixo potencial de patogenicidade (DIJKSHOORN et al., 2007). Entretanto, quando a infecção ocorre, pode evoluir severamente. A taxa de mortalidade para casos de bacteremias por $A$. baumannii é maior significativamente, quando comparada com casos de bacteremias envolvendo outros patógenos Gram negativos, incluindo Klebsiella pneumoniae (JERASSY et al., 2006; ROBENSHTOK et al., 2006). Além disso, a taxa de mortalidade, para casos de colonização ou infecção por $A$. baumannii, é maior significativamente, mesmo quando comparada com casos semelhantes envolvendo isolados de $P$. aeruginosa multirresistentes (GKRANIA-KLOTSAS \& HERSHOW, 2006). 
$\mathrm{Na}$ última década, Acinetobacter tornou-se um importante agente etiológico em infecções oportunistas, principalmente pneumonias relacionadas à ventilação mecânica, infecções de feridas causadas por queimaduras, bacteremias, infecções do trato urinário, em pacientes da unidade de terapia intensiva (UTI) (BERGONE-BÉRÉZIN \& TOWNER, 1996). Porém, mais de 100 casos de infecções adquiridas na comunidade já foram relatados por diversos autores (ANSTEY et al., 2002; BICK \& SEMEL, 1993; LEUNG et al., 2006) e têm sido associado também a infecções em militares e civis feridos em conflitos como a guerra do Iraque (DAVIS et al., 2005; DIJKSHOORN et al., 2007; PELEG et al., 2008).

O gênero Acinetobacter pertence à família Moraxellaceae, sendo esta pertencente à ordem Grammaproteobacteria. Este gênero é compreendido por cocobacilos Gram-negativos, aeróbios estritos, não fermentadores de glicose, imóveis, produtores de catalase, não apresentam a enzima citocromo $\mathrm{C}$ oxidase e apresentam DNA com porcentagem de citosina e guanidina que varia entre 39 a 47\% (BERGOGNE-BÉRÉZIN \& TOWNER, 1996; PELEG et al., 2008). Espécies do gênero Acinetobacter apresentam bom crescimento em meio sólido, rotineiramente utilizados em laboratórios de microbiologia clínica, como ágar sangue de carneiro ou TSA (triple soy agar), quando incubados a $37^{\circ} \mathrm{C}$ por 18 a 24 horas. $\mathrm{O}$ crescimento bacteriano de isolados pertencentes ao complexo Acinetobacter calcoaceticus-Acinetobacter baumannii (ACB) nesses meios sólidos apresenta-se com colônias lisas, cremosas, algumas vezes mucóide, com coloração branca acinzentada e por vezes apresentam semelhanças com as de algumas bactérias da família Enterobacteriaceae, com colônias de diâmetro de 1,5 a 3,0 mm após incubação de 12 horas, enquanto a maioria das outras espécies de Acinetobacter produzem colônias menores e são mais translúcidas (BERGOGNE-BÉRÉZIN \& TOWNER, 1996; PELEG et al., 2008).

Diferentemente das enterobactérias, algumas espécies de Acinetobacter que não pertencem ao complexo $\mathrm{ACB}$ podem não crescer em ágar MacConkey. Isolados das espécies de $A$. haemolyticus e outras espécies como as espécies Acinetobacter genoespécie 6, A. genoespécie 13BJ, $A$. genoespécie $14 \mathrm{BJ}, A$ genoespécie $15 \mathrm{BJ}, A$. genoespécie 16 e $A$. genoespécie 
17, podem apresentar hemólise em ágar sangue de carneiro, uma característica até o momento nunca relatada em cepas pertencentes ao complexo ACB (PELEG et al., 2008).

A história do gênero Acinetobacter remonta ao início do século XX com a descrição de um micro-organismo isolado de solo por Beijerinck, um microbiologista holandês, e nomeado de Micrococcus calcoaceticus (BEIJERINK, 1911 apud PELEG et al., 2008, p.539). Ao longo das décadas seguintes, organismos similares foram descritos e atribuídos a pelo menos 15 gêneros e espécies diferentes (PELEG et al., 2008).

Em 1954, Brisou e Prevout, propuseram o nome Acinetobacter (oriundo do grego akinetos, não móveis) para designar o gênero, permitindo separar os microrganismos não móveis daqueles que apresentam motilidade composto pelo gênero Achromobacter, no entanto apenas a partir de 1968 é que essa nomenclatura tornan-se mais aceita (BRISOU \& PREVOT, 1954 apud PELEG et al., 2008, p. 539).

O reconhecimento oficial do gênero Acinetobacter foi realizado pelo Subcomitê em Taxonomia de Moraxella e outras bactérias similares em 1971, após a publicação de resultados obtidos por Baumann e colaboradores que revelaram que diferentes espécies bacterianas pertenciam a um mesmo gênero, Acinetobacter. (BAUMANN, 1968 apud PELEG et al.; 2008, p. 539). Em 1974, o gênero Acinetobacter é listado pela primeira vez no Manual Bergey de Bacteriologia Sistemática, sendo a cepa $A$. calcoaceticus a cepa padrão tanto para o gênero quanto para a espécie (LAUTROP, 1974 apud PELEG et al., 2008, p. 539).

Em 1986, Bouvet e Grimont descrevem a presença de 12 grupos distintos de espécies genômicas por hidribização DNA-DNA, alguns dos quais receberam nomes formais, incluindo $A$. baumannii, $A$. calcoaceticus, $A$. haemolyticus, A. johnsonii, A. junii e A. Iwoffii (BOUVET \& GRIMONT, 1986 apud PELEG et al., 2008, p. 540). Posteriormente, trabalhos realizados por Bouvet e Jeanjean, Tjernberg e Ursing; Nishimura e colaboradores resultaram na descrição de novas espécies genômicas de Acinetobacter (NISHIMURA \& IIZUKA, 1988; BOUVET \& JEANJEAN, 1989; TJERNBERG \&; URSING, 1989). 
No entanto, essas descrições foram realizadas de modo independente uma das outras e algumas delas são atribuídas a uma mesma espécie, como por exemplo, Acinetobacter genoespécie 14 descrita por Bouvet e Jeanjean ( $A$. genoespécie 14BJ) e Acinetobacter genoespécie 13 descrito por Tjernberg e Ursing (A. genoespécie 13TU) (PELEG et al, 2008).

\subsubsection{Identificação das espécies bacterianas}

Atualmente, o gênero Acinetobacter é composto por, pelo menos, 37 espécies diferentes, sendo 26 espécies com nomes oficialmente reconhecidos (http://www.bacterio.cict.fr/a/acinetobacter.html Acesso em 25/08/2011) e 15 espécies descritas como genoespécies, delineadas por hibridação DNA-DNA (DIJKSHOORN et al., 2007). Quatro espécies bacterianas, $A$. calcoaceticus, $A$. baumannii, $A$. genoespécie 3 e $A$. genoespécie $13 T \mathrm{~T}$ são intimamente relacionadas, sendo difícil de distinguir por características fenotípicas, uma das outras. Deste modo, em 1992 foi proposto o agrupamento dessas espécies no complexo Acinetobacter calcoaceticus-Acinetobacter baumannii (GERNERSMIDT et al., 1991; GERNER-SMIDT, 1992).

O complexo Acinetobacter calcoceticus-Acinetobacter baumannii (ACB) não é composto apenas pelas três espécies de maior relevância clínica do gênero Acinetobacter, envolvidas na grande maioria das infecções nosocomiais e infecções adquiridas na comunidade - $A$. baumannii, $A$. genoespécie 3 e $A$. genoespécie 13TU, mas também por uma espécie ambiental, $A$. calcoaceticus, que é comumente isolada de amostras de solo e água, mas até o momento não há descrição de casos que envolva essa espécie em processos infecciosos (PELEG et al., 2008). Recentemente, foram propostas as denominações de $A$. pittii e $A$. nosocomialis para as espécies $A$. genoespécie 3 e $A$. genoespécie 13TU, respectivamente (NEMEC et al., 2011), porém até o momento não foram validadas formalmente.

A nomenclatura do complexo A. calcoaceticus-A. baumannii pode ser enganosa e não adequada quando utilizada no contexto clínico, pelo fato do nome de uma espécie bacteriana, de origem ambiental, estar presente no 
nome do complexo (PELEG et al., 2008). Talvez este tenha sido o motivo pelo qual, muitos pesquisadores e laboratórios ignoram o termo complexo $A C B$ e passam a denominar os isolados deste complexo apenas por $A$. baumannii, o que muito provavelmente é uma das causas de diferenças, e por vezes, contradições em pesquisas de similaridade genética, estudos epidemiológicos e caracterização de mecanismos de resistência associados a esta espécie. Alguns trabalhos científicos já relataram diferenças no perfil de susceptibilidade aos antimicrobianos entre as diferentes espécies do complexo ACB (HOUANG et al., 2003; BOO et al., 2009; LEE et al., 2009; VAN DEN BROEK et al., 2009; SHENG et al., 2011).

A identificação de espécies bacterianas pertencentes ao gênero Acinetobacter baseada apenas em esquemas compostos por provas fenotípicas é geralmente insuficiente (BERGONE-BÉRÉZIN \& TOWNER, 1996; DIJKSHOORN et al., 2007). Nos últimos anos, buscando suprir a falha na caracterização das espécies bacterianas do gênero Acinetobacter, técnicas e métodos de biologia molecular tem sido explorados por diversos pesquisadores (NEMEC et al., 2003; DIJKSHOORN et al., 2007; PELEG et al., 2008; NEMEC et al., 2011).

Os métodos moleculares para a identificação baseam-se: (i) no perfil de informações gerado a partir de todo o DNA genômico, como na técnica de hidridação DNA-DNA, ainda é o padrão de referência, porém este processo é trabalhoso e insustentável para se pesquisar rotineiramente (BOUVET \& GRIMONT, 1986; PELEG et al., 2008); ou como na técnica de AFLP (amplified fragment lenght polymorphism), que consiste na digestão do DNA por duas enzimas de restrição e posterior amplificação dos fragmentos pelo uso de adaptadores aos fragmentos obtidos, por dificuldades de padronização os resultados não podem ser comparados entre laboratórios (JANSSEN et al., 1997; DIJKSHOORN et al.; 2007) ; (ii) no perfil de informações gerado a partir da amplificação de um gene específico e posterior restrição enzimática deste material genético, como na técnica de ARDRA que apresenta como fundamento a análise dos fragmentos de restrição obtidos a partir da restrição enzimática do produto resultante da amplificação do DNA codificador do RNA ribossômico da subunidade 16S (ARDRA) (DIJKSHOORN et al., 1998; 
VANEECHOUTTE et al., 1995). Já foi observada, porém, a ocorrência de múltiplos perfis entre diferentes cepas pertencentes à mesma espécie, sugerindo diversidade intra-espécie, sendo necessário, um banco extenso de perfis apresentando variações intra e inter-espécies para a identificação da espécie em questão (DIJKSHOORN et al., 1998); (iii) na análise da sequência de um gene particular ou parte de um região genética, como o gene codificador do RNA ribossômico 16S (IBRAHIM et al., 1997); a região intergênica entre os genes codificadores do RNA ribossômico 16S e 23S (ITS) (CHANG et al., 2005), o operon ribossomal completo (GARCíA-ARATA et al., 1997) o gene recA (KRAWCZYK et al., 2002), o gene gyrB (YAMAMOTO \& HARAYAMA, 1996) e o gene rpoB (LA SCOLA et al., 2006).

A região ITS apresenta-se como uma boa candidata para a identificação das espécies bacterianas, por apresentar menor similaridade entre espécies do complexo $\mathrm{ACB}$, quando comparada com a sequência nucleotídica do gene codificador da subunidade $16 \mathrm{~S}$ do RNA ribossômico (BARRY et al., 1991; CHEN et al., 2004; DOLZANI et al., 1995; GONÇALVES et al., 2002; GUASP et al., 2000). Além disso, comparado com o gene 16S rRNA (aproximadamente $1.5 \mathrm{~kb}$ ), o fragmento correspondente ao ITS no complexo ACB é relativamente pequeno (607 a 638pb), o que torna fácil o seqüenciamento destes fragmentos (CHANG et al., 2005).

Em 2007, é descrita uma PCR modificada para identificação das espécies Acinetobacter baumannii e Acinetobacter genoespécie 13TU baseando-se na heterogeneidade da sequência nucleotídica do gene codificador da subunidade B da DNA girase ( $g y r B)$, entre essas espécies (HIGGINS et al., 2007). E em 2010, tendo o gyrB como alvo é descrito outra PCR para a identificação entre as espécie $A$. calcacoeticus e $A$. genoespécie 3 (HIGGINS et al., 2010).

\subsubsection{Resistência bacteriana aos antimicrobianos}

Relatos de $A$. baumannii multirresistente relacionados às infecções hospitalares no exterior e no Brasil. nos últimos dez anos, constitui um sério 
problema de saúde pública (DALLA-COSTA, et al., 2003; CARVALHO et al., 2009; MARTINS, et al; 2009; SCHIMITH BIER et al., 2010; GROSSO et al., 2011). O termo multirresistente (MR) para Acinetobacter sp., assim como para outros bacilos Gram negativos, não apresenta uma definição padrão, sendo geralmente empregado na caracterização de isolados resistentes a três ou mais classes de antimicrobianos usados no tratamento (PEREZ et al., 2007).

A emergência de amostras bacterianas do complexo ACB com perfil de multirresistência aos antimicrobianos passou a ter como tratamento de escolha o imipenem, um carbapenêmico. Antimicrobianos pertencentes à classe dos carbapenêmicos são beta-lactâmicos de amplo espectro derivados da tienamicina e apresentam considerável estabilidade frente à maioria das betalactamases, inclusive às beta-lactamases de amplo espectro (ESBL). Por esta razão carbapenêmicos são empregados no tratamento de infecções nosocomiais ocasionadas por bactérias Gram-negativas multirresistentes (RODLOFF et al., 2006).

Entretanto, o aumento da taxa de resistência aos carbapenêmicos tem sido relatado em várias regiões pelo mundo, inclusive no Brasil. Sader e colaboradores analisaram o perfil de sensibilidade aos antimicrobianos de bactérias isoladas do trato respiratório inferior de pacientes internados em hospitais brasileiros, a partir de resultados do programa SENTRY dos anos 1997 e 1998 (SADER et al., 2001). Relatam Acinetobacter sp. como a terceira espécie mais prevalente entre as amostras isoladas de espécimes respiratórios de pacientes com pneumonia hospitalar em comparação com o total de amostras brasileiras. Os autores mostraram que apenas os carbapenêmicos eram opções terapêuticas adequadas para o tratamento empírico de infecções por Acinetobacter sp nos hospitais por eles avaliados (SADER et al., 2001).

Os mecanismos de resistência aos carbapenêmicos mais descritos em Acinetobacter sp. são alterações de permeabilidade, principalmente por perda de porinas (COSTA et al., 2000; FERNANDES-CUENCA et al., 2003; DUPON et al., 2005; SIROY et al., 2005; TAKAGI et al., 2009) e inativação enzimática pela hidrólise do anel beta-lactâmico, por carbapenemases, como $\beta$-lactamases da classe B de Ambler (metalo- $\beta$-lactamases) e da classe D de Ambler (OXA- 
carbapenemases), sendo essa última, a mais frequente neste gênero bacteriano (LIVERMORE, 1995; RASMUSSEN \& BUSH, 1997; LIVERMORE \& WOODFORD, 2000; POIREL \& NORMANN, 2006; WALTER-RASMUSSEN \& HOIBY, 2006; QUEENAN \& BUSH, 2007; GUPTA, 2008).

O sucesso das carbapenemases, entre os isolados de Acinetobacter resistentes aos carbapenêmicos, é em virtude dos genes codificadores dessas enzimas estarem frequentemente associados a elementos genéticos móveis como plasmídeos, integrons e transposons, estruturas que atuam como protagonistas na disseminação horizontal dessas enzimas entre diferentes cepas da mesma espécie e também entre espécies distintas (LIVERMORE \& WOODFORD, 2000; QUEENAN \& BUSH, 2007).

Surtos ocasionados por $A$. baumannii que apresentam resistência aos carbapenêmicos relacionadas à produção de carbapenemases apresentam significativo impacto clínico e epidemiológico e são amplamente descritos (POIREL \& NORDMAN, 2006; DIJKSHOORN et al., 2007; PELEG et al., 2088).

\subsubsection{Metalo- $\beta$-lactamases}

As metalo- $\beta$-lactamases (MBL) são pertencentes à classe $B$ de Ambler e caracterizam-se por apresentarem sítio ativo dependente do cátion divalente do elemento zinco $\left(\mathrm{Zn}^{2+}\right)$ o principal cofator. Essa propriedade bioquímica é útil para a detecção fenotípica desse mecanismo de resistência pela comparação do resultado de ensaio de sinergismo entre o antimicrobiano carbapenêmico na presença de quelantes de íons como, por exemplo, o EDTA e a susceptibilidade da amostra bacteriana apenas ao antimicrobiano avaliado. $\mathrm{Na}$ presença de EDTA, há a diminuição da quantidade de íons disponíveis, sendo insuficiente para que ocorra a atividade hidrolítica do anel beta-lactâmico pelas metalo- $\beta$-lactamases (QUEENAN \& BUSH, 2007)

Inibidores convencionais de $\beta$-lactamases, como ácido clavulâmico, tazobactam e sulbactam não apresentam ação sobre a atividade enzimática das metalo- $\beta$-lactamases (QUEENAN \& BUSH, 2007) Além disso, essas enzimas possuem maior afinidade por carbapenêmicos que por cefalosporinas 
e penicilinas, não atuando sobre os monobactâmicos (LIVERMORE \& WOODFORD, 2000).

Até o momento, foram identificadas as seguintes famílias de metalo- $\beta$ lactamases: IMP no Japão (WATANABE et al., 1991), VIM na Itália (LAURETTI et al., 1999), SPM no Brasil (TOLEMAN et al., 2002), GIM (CASTANHEIRA et al., 2004), SIM em Seoul (LEE et al., 2005), AIM na Austrália (YONG et al., 2007) e KHM no Japão (SEKIGUCHI et al., 2008). Essas famílias de carbapenemases, pertencentes à classe $\mathrm{B}$ de Ambler, parecem estar restritas aos seus países de origem, exceto as famílias IMP e VIM que se encontram disseminadas por diversos países (QUEENAN \& BUSH, 2007).

Dentre as cinco famílias de metalo- $\beta$-lactamases capazes de ocasionar resistência adquirida aos carbapenêmicos - GIM-1, SPM-1, SIM-1 e as variantes de IMP e VIM - apenas três destas já foram descritas em $A$. baumannii. A primeira descrição foi de IMP-1 na Itália (CORGNALIA et al, 1999), seguida por IMP-1 no Japão (SHIBATA et al., 2003; NISHIO et al, 2004; TAKAHASHI et al., 2000) e na Coréia do Sul (LEE et al., 2003); IMP-2 na Itália (RICCIO et al., 2000) e no Japão (SHIBATA et al., 2003); IMP-4 em Hong Kong (CHU et al., 2004); IMP-5 em Portugal (DA SILVA et al., 2002); IMP-6 no Brasil (GALES et al., 2003); IMP-11 no Japão (WALSH et al., 2005); VIM-2 na Coréia do Sul (LEE et al., 2003; YUM et al.; 2002) e SIM-1 na Coréia do Sul (LEE et al., 2005). No entanto, a frequência deste tipo de mecanismo de resistência em A. baumannii é menor quando comparado os outros, como a presença de carbapenemases do tipo OXA (DIJKSHOORN et al., 2007; PELEG et al., 2008).

\subsubsection{Carbapenemases do tipo OXA}

As oxacilinases (OXA) são enzimas que pertencem à classe $D$ de Ambler e apresentam o grupamento serina no seu sítio ativo, inativam principalmente os carbapenêmicos, possuem afinidade também por algumas cefalosporinas, como a cefepima, no entanto não há ação hidrolítica quando o 
substrato é a ceftazidima (NAAS \& NORDMANN, 1999; BROWN \& AMYES, 2006; WALTER-RASMUSSEN \& HOIBY, 2006).

Mais de 120 variantes distintas de enzimas da class $D$ já foram descritas, contudo apenas 45 destas exibem a capacidade de hidrolisar o anel $\beta$-lactâmico dos carbapenêmicos (WALTER-RASMUSSEN \& HOIBY, 2006). Avaliando a identidade entre as sequências de aminoácidos das variantes das enzimas do tipo OXA, é possível identificar oito subgrupos. Até o momento, cinco desses subgrupos já foram descritos em $A$. baumannii, OXA-23-like; OXA-24-like; OXA-51-like; OXA-58-like e OXA-143 (BROWN \& AMYES, 2006; HIGGINS et al., 2009). Todos os subgrupos são relacionados com resistência aos carbapenêmicos adquirida, exceto o subgrupo OXA-51-like que é composto por enzimas intrínsecas em $A$. baumannii e essa característica é utilizada para a identificação desta espécie bacteriana pela deteç̧ão da presença desses genes codificadores de enzimas pertencentes a esse subgrupo (HERITIER et al., 2005). Enzimas do tipo OXA-51-like apresentam importância na resistência aos carbapenêmicos quando possuem o elemento de inserção IsAba1 à montante do gene codificador dessa enzima, ocorrendo a hiperexpressão e contribuindo para o fenótipo de menor susceptibilidade a esse antimicrobiano (TURTON et al., 2006a).

A resistência aos carbapenêmicos mediada por enzimas do tipo OXA é a mais prevalente entre os isolados de A. baumannii (PELEG et al., 2008). No Brasil, no final da década de 90 , foram descritos os primeiros oito casos de $A$. baumannii resistentes a carbapenêmicos isolados de pacientes do Hospital de Clínicas e do Hospital Universitário Evangélico de Curitiba. Esses isolados de A. baumannii eram produtores de OXA-23 e pertencentes a um mesmo clone (DALLA-COSTA et al., 2003).

Em 2009, foi relatado a disseminação de $A$. baumannii portadores do gene codificador da enzima OXA-23 entre hospitais do Rio de Janeiro (CARVALHO et al.; 2009) e nesse mesmo ano, há o registro da transmissão e disseminação clonal de $A$. baumannii, produtor de OXA-23, entre profissionais de saúde, equipamentos médico e paciente (MARTINS et al., 2009). Em 2010, Schimith-Bier e colaboradores descreveram a presença de três clones 
diferentes produtores de OXA-23 em isolados bacterianos obtidos entre $2002 \mathrm{e}$ 2005, em Curitiba, revelando a transferência horizontal desse mecanismo de resistência codificado por um gene primordialmente plasmidial (SCHIMITH BIER et al., 2010).

\section{3 "Quorum sensing" e mecanismos de virulência}

Até o presente momento são escassos os trabalhos voltados para a compreensão dos mecanismos de virulência envolvidos na infecção causada por bactérias pertencentes ao complexo ACB. Um importante processo de regulação de fatores de virulência é o "quorum sensing" (QS) ou comunicação celular.

A comunicação celular desempenha uma função central na fisiologia e no desenvolvimento de organismos vivos. Mesmo organismos unicelulares como as bactérias, frequentemente coordenam suas atividades de forma semelhante a entidades multicelulares (SHAPIRO, 1998). Essa coordenação necessariamente requer a comunicação célula-célula, o que o ocorre por meio da produção e liberação de moléculas específicas, chamados de autoindutores, que são liberados no ambiente. $\mathrm{O}$ acúmulo extracelular desses sinais denota a presença de população relativamente densa e faz com que as células apresentem um comportamento coordenado (FUQUA et al, 1994; GRAY \& GAREY, 2001).

O "quorum sensing" (QS), portanto, é um sistema de comunicação entre bactérias dependente de densidade populacional. Quando uma quantidade crítica de autoindutores é atingida, as bactérias detectam a presença de um número suficiente (quorum de bactérias) e respondem por meio da ativação ou repressão de certos genes.

Atualmente, sabe-se que existem diversas interações entre as células. As bactérias produzem um repertório extensivo de metabólitos secundários e respondem a várias substâncias químicas presentes no meio ambiente. Grupos particulares de metabólitos secundários têm sido caracterizados quanto à sua 
função na regulação da expressão de genes de um modo dependente da densidade populacional (FUQUA et al., 2001; KELLER \& SURETTE, 2006).

O QS bacteriano é um fenômeno comum que favorece o acesso a nutrientes ou a nichos ambientais mais favoráveis, permite que as bactérias organizem respostas defensivas contra hospedeiros eucarióticos, além de aperfeiçoar a capacidade das bactérias se diferenciarem em formas mais bem adaptadas a sobreviverem em ambientes hostis, onde as condições de crescimento são restritivas (WILLIAMS et al., 2000):

Muitos estudos demonstram que o QS regula uma série de características fenotípicas, incluindo a produção de antimicrobianos, formação de biofilme, bioluminescência, diferenciação celular, competência para captação de DNA, crescimento, produção de pigmento, transferência de plasmídeos, produção de enzimas hidrolíticas celulares, esporulação, motilidade, produção de toxina e expressão de genes de virulência (SMITH et al., 2004).

Ainda não está completamente elucidado como a comunicação celular ocorre nas bactérias. Pesquisas sobre a sinalização celular baseada no autoindutor $\mathrm{N}$-acil-homoserinas lactonas mostram que esse sistema é muito comum. Entretanto, os tipos de moléculas potenciais que as bactérias produzem e às quais respondem para se adaptarem em seu ambiente, incluindo ambientes competitivos, ainda são pouco exploradas e o número de moléculas sinalizadoras identificadas é crescente (KELLER \& SURETTE, 2006).

O sistema de sinalização por autoindutores baseia-se na ligação dessas moléculas, quando em concentrações elevadas, moléculas sensoras estão presentes na superfície ou no interior das bactérias. Essas moléculas sensoras, chamadas em geral de 'proteínas R', atuam como reguladores transcricionais, ou seja, regulam a expressão de genes específicos, direta ou indiretamente. Cada uma dessas proteínas $\mathrm{R}$ responde a um autoindutor específico e em geral só é ativada quando estimulada por essa molécula. Autoindutores inespecíficos, embora capazes de se ligar às proteínas $R$, não provocam ativação ou provocam uma ativação mais fraca. 
As moléculas sinalizadoras podem ser divididas em quatro categorias: (i) derivados de ácidos graxos, conhecidos como autoindutores-1 (Al-1), geralmente $\mathrm{N}$-acil homoserinas lactonas (AHLs), usados por bactérias Gramnegativas para comunicação intraespécie (MILLER \& BASSLER, 2001; WHITEHEAD et al., 2001); (ii) furanosil boratodiéster autoindutor-2 (AI-2), produzidos por bactérias Gram-positivas e Gram-negativas e utilizados para comunicação intra e interespécies (SCHAUDER \& BLASSER, 2001; CHEN et al., 2002), (iii) autoindutor-3 (Al-3), de estrutura desconhecida, até o momento e foi descrito em bactérias Gram-negativas (SPERANDIO et al., 2003), (iv) aminoácidos e peptídeos pequenos utilizados por bactérias Gram-positivas (MILLER \& BLASSLER, 2001; WHITEHEAD et al., 2001).

Em bactérias Gram-negativas, os principais autoindutores são: as acilhomoserina lactonas, autoindutor-2 e autoindutor-3. Esse último apresenta a estrutura muito parecida com as catecolaminas, noradrenalina e adrenalina, tornando-se um mecanismo não apenas para a comunicação entre as células procarióticas como entre o parasita e o hospedeiro (CLARKE et al., 2006).

Em patógenos oportunistas como $A$. baumannii o fenômeno "quorum sensing" provavelmente atue como um dos mecanismos capaz de ativar múltiplos fatores de virulência (JOLY-GUILLOU, 2005). Niu e colaboradores (2008) descreveram a identificação de seis possíveis estruturas químicas de autoindutor do tipo acil homoserina lactona em extratos orgânicos de sobrenandante de cultura de A. baumannii (NIU et al., 2008).

Em A. baumannii, moléculas de autoindutores apresentam influência na formação de biofilme (GADDY \& ACTIS, 2009). A importância médica da formação de biofilmes bacterianos reside no fato destes serem usualmente relacionados a infecções persistentes, como nos casos de infecções por cateteres e por implantes cirúrgicos, sendo uma causa comum de infecções hospitalares. Além de contribuir para a persistência no ambiente hospitalar (DONLAN \& COSTERTON, 2002).

A participação de autoindutores, como $\mathrm{AHL}$, em outros mecanismos de virulência ainda não foi estabelecida (GONZALEZ et al., 2009). Deste modo baseando-se principalmente nos trabalhos divulgados por Lee e colaboradores, 
em 2005, que relata a capacidade de cepas de Acinetobacter baumannii aderirem às células de epitélio de brônquio humano; e outro por Choi e colaboradores, em 2008, que relata a capacidade de Acinetobacter baumannii invadir células epiteliais, buscou-se neste trabalho avaliar a adesão bacteriana, das diferentes espécies clínicas do complexo ACB, na presença e ausência de possíveis interferentes do fenômeno quorum sensing, em monocamada de células utilizando fibroblastos de pulmão MRC-5, células epiteliais HEp-2 e células epiteliais de pulmão NCl-H292 (LEE et al., 2005; CHOI et al., 2008).

Em decorrência da emergência de cepas, pertences ao complexo ACB, multirresistentes isoladas de pacientes atendidos no Hospital Universitário da USP, nos propusemos a padronização de um método de identificação das espécies bacterianas do complexo $A C B$ de fácil execução, baixo custo, permitindo avaliar a epidemiologia, relação dessas espécies com o perfil de susceptiblidade aos antimicrobianos, com a presença de genes codificadores de metalo- $\beta$-lactamases e carbapenemases do tipo OXA. E ainda, a pesquisa de possíveis diferenças, entre as espécies do complexo $A C B$, quanto à produção de autoindutores, produção de biofilme e aderência bacteriana em superfícies bióticas. Pretendemos desta forma, gerar conhecimentos que possam vir a auxiliar no desenvolvimento de medidas racionais no controle da disseminação do micro-organismo, bem como em medidas de controle de infecção hospitalar e uso racional de antimicrobianos. 


\section{OBJETIVOS}

\subsection{Objetivo Geral}

Caracterizar molecular e fenotípicamente as amostras bacterianas do complexo ACB isoladas de pacientes atendidos no Hospital Universitário da Universidade de São Paulo.

\subsection{Objetivos específicos}

Com as amostras bacterianas pertencentes às espécies clínicas do complexo ACB iremos:

- Padronizar método molecular para a identificação das espécies

- Avaliar a sensibilidade bacteriana aos antimicrobianos e comparar os perfis entre as espécies.

- Avaliar a clonalidade por RAPD.

- Avaliar a clonalidade das amostras bacterianas resistentes aos carbapenêmicos por PFGE.

- Investigar a presença de genes codificadores de $\beta$-lactamases

- Pesquisar a produção dos autoindutores acil-homoserina lactona, autoindutor-2 e autoindutor-3.

- Avaliar comparativamente a adesão bacteriana em células eucarióticas.

- Analisar comparativamente a produção de biofilme 


\section{MATERIAL E MÉTODOS}

Estudo retrospectivo de amostras bacterianas pertencentes ao complexo Acinetobacter calcoaceticus -A. baumannii (ACB), depositadas no banco de amostras biológicas do Hospital Universitário da Universidade de São Paulo.

\subsection{Amostras bacterianas}

A identificação e o antibiograma foram realizados no Laboratório de Microbiologia Clínica do Hospital Universitário da USP. A identificação das amostras pertencentes ao complexo $A C B$ foi realizada pelo sistema automatizado Vitek- $2^{\circledR}$ software versão 04.02 (Biomerieux, França) e o perfil de sensibilidade pelo método de disco-difusão segundo as normas preconizadas pelo Clinical and Laboratory Standards Institute (CLSI vigente na época).

Para a identificação das espécies do complexo ACB pela técnica de biologia molecular, a avaliação da diversidade genética e a determinação da sensibilidade aos antimicrobianos, 515 cepas, isoladas de pacientes atendidos pelo Hospital Universitário da USP, no período de janeiro de 2005 a dezembro de 2010, foram estudadas (Anexo 1). Apenas uma única amostra bacteriana de cada paciente foi selecionada, quando havia mais de uma, a amostra mais invasiva foi selecionada.

Para o estudo de "quorum sensing" e adesão bacteriana foram avaliadas três amostras de cada espécie bacteriana de importância clínica do complexo ACB (Anexo

2), enquanto para os ensaios de biofilme foram dez amostras de cada espécie (Anexo 3).

Para a pesquisa do fenômeno "quorum sensing" biosensores foram empregados (Tabela 1). 
Tabela 1 Cepas utilizadas nos bioensaios para pesquisa de autoindutores

\begin{tabular}{ccc}
\hline Cepa biossensora & Autoindutor & Referência \\
\hline Chromobacterium violaceum CV026 & acil-homoserina lactona & MCCLEAN et al., 1997 \\
Vibrio harveyi BB170 & autoindutor-2 & TUROVSKIY \& CHINKIDAS, 2006 \\
Escherichia coli TEVS232 & autoindutor-3 & SPERANDIO et al., 1999 \\
\end{tabular}

Os isolados bacterianos foram mantidos em caldo LB contendo $15 \%$ de glicerol e mantidos a $-80^{\circ} \mathrm{C}$. Antes de cada experimento, as células foram reativadas por duas semeaduras consecutivas em caldo LB com incubação a $37^{\circ} \mathrm{C}$ por 18 horas.

\subsection{Extração do DNA}

Para extração do DNA foi utilizado o método de fervura descrito por Vaneechoutte et al. (1995). Foram ressuspensas 2 a 3 colônias de tamanho médio, de uma cultura pura, em $100 \mu \mathrm{L}$ de água estéril, ultrapura (MilliQ, Millipore, São Paulo, SP), em microtubos. As suspensões foram submetidas a banho fervente por 15 minutos e em seguida, a choque térmico, em banho de gelo por 15 minutos. Homogeneizou-se cuidadosamente o conteúdo de cada microtubo e este material foi armazenado a $-20^{\circ} \mathrm{C}$ até o momento de uso.

\subsection{Identificação dos isolados bacterianos pertencentes ao complexo ACB}

Para a identificação das espécies $A$. baumannii, $A$. genoespécie $13 T U$ e A. genoespécie 3 foram empregadas a reação de amplificação em cadeia pela polimerase da região intergênica $16 \mathrm{~S}-23 \mathrm{~S}$ do gene $r R N A$ para detecção do polimorfismo presente entre essas espécies. 


\subsubsection{Estudo do polimorfismo da região intergênica 16S-23S rRNA}

Para o estudo do polimorfismo da região intergênica 16S-23S rRNA foram avaliadas dez amostras do complexo ACB, sendo quatro amostras portadoras do gene bla OXA-51-like e seis amostras que não apresentavam este gene. A reação de amplificação em cadeia polimerase para a região intergênica 16S-23S rRNA foi realizada utilizando DNA polimerase de alta fidelidade (Taq Platinum High Fidelity, Invitrogen, EUA), em volume final de $20 \mu \mathrm{L}$. As condições de reação e as sequências dos iniciadores encontram-se na Tabela 2.

Os produtos de $\mathrm{PCR}$ foram submetidos à eletroforese em gel de agarose a $0,8 \%$. Em seguida, foram corados por solução de brometo de etídio, visualizados em um transiluminador de luz ultravioleta (UV) e então registrados por fotografia digital.

Os amplicons foram purificados utilizando o kit GFX PCR DNA and Gel Band Purification kit (GE healthcare, Reino Unido) e sequenciados pela técnica de Sager utilizando um sequenciador MegaBace ${ }^{\circledR}$ (GE healthcare, Reino Unido) no Centro de Estudos do Genoma Humano do Instituto de Biociências da Universidade de São Paulo. Os iniciadores utilizados para as reações de dideoxi-terminal de sequenciamento para ITS foram os mesmos empregados na amplificação, descritos na Tabela 2.

As sequências nucleotídicas obtidas para cada cepa foram comparadas uma com a outra por alinhamento utilizando o software de domínio público (BioEdit 7.0.9 - HALL, 1999) e comparadas com o banco de dados do GenBank, utilizando a ferramenta BLAST (ALTSCHUL et al., 1990).

Após a análise da diferença interespécies da sequência de intergênica 16S-23S rRNA, foi desenhado um iniciador, descrito na Tabela 2, com polaridade antisense em uma região heterogênea para a identificação de Acinetobacter genoespécie 3 .

3.3.2 Esquema de identificação das espécies do complexo ACB e pesquisa de genes de resistência do tipo OXA

Foram utilizadas duas reações de PCR. A primeira é uma reação multiplex para a detecção dos quatro subgrupos dos genes codificadores de oxacilinas proposta por Woodford e colaboradores (2006), permitindo a 
identificação de $A$. baumannii pela presença do gene intrínseco bla $a_{\text {oxa-51 }}$ (TURTON et al., 2006b) e detectar a possível presença de outros genes de resistências como bla OXA-23-like, blaOXA-24-like, bla OXA-58-like (WOODFORD et al., 2006). O gene codificador da enzima OXA-143 não foi pesquisado nesse trabalho. Os iniciadores e as condições da PCR estão descritos na Tabela 3. $\mathrm{Na}$ segunda PCR, as amostras que não apresentaram amplificação para bla OXA-51 foram analisadas. Para 0 desenvolvimento desta segunda PCR multiplex foram utilizados os iniciadores previamente descritos por Higgins e colaboradores (2007), que permitem identificar as espécies $A$. baumannii e Acinetobacter genoespécie 13TU, baseando-se na heterogeneidade da sequência nucleotídica codificadora as subunidade $B$ da girase; para a identificação de Acinetobacter genoespécie 3 foi utilizado o iniciador ITS-16S e também um iniciador com polaridade antisense em uma região heterogênea identificada no estudo da região ITS. Como controle interno, iniciadores que amplificam um fragmento do gene codificador de 16S RNAr foram adicionados à reação. Os iniciadores e as condições das reações encontram-se na Tabela 2.

Os produtos de PCR foram submetidos à eletroforese em gel de agarose a 1\%, voltagem de $100 \mathrm{~V}$, por $40 \mathrm{~min}$. Em seguida, foram corados em solução de brometo de etídio e visualizados em um transiluminador de luz UV e então registrados por fotografia digital. 
Tabela 2 Iniciadores e condições de termociclagem utilizados para identificação das A.genoespécie 3 e $A$. genoespécie 13TU e amplificação da região intergênica 16S-23S rRNA.

\begin{tabular}{|c|c|c|c|c|c|c|c|}
\hline Oligoiniciadores & Alvo & Sequência $\left(5^{\prime} \rightarrow 3^{\prime}\right)$ & $\mu \mathrm{M}^{*}$ & Referência & $\begin{array}{l}\text { Conjunto de } \\
\text { iniciadores }\end{array}$ & $\begin{array}{l}\text { Tamanho } \\
\text { do } \\
\text { fragmento }\end{array}$ & $\begin{array}{l}\text { Programação de } \\
\text { termociclagem }\end{array}$ \\
\hline ITS-16S rRNAf & ITS-16S rRNA & GTC GTA ACA AGG TAG CCG TA & 0,2 & & \multirow{3}{*}{ ITS-16Sf/ITS-23Sr } & \multirow{3}{*}{$730 \mathrm{pb}$} & \multirow{3}{*}{$\begin{array}{l}94^{\circ} \mathrm{C} \text { min, } 30 \text { ciclos, } \\
94^{\circ} \mathrm{C} \quad 1 \mathrm{~min}, 50^{\circ} \mathrm{C} \\
30 \mathrm{~s}, \quad 68^{\circ} \mathrm{C} 1 \mathrm{~min}, \\
68^{\circ} \mathrm{C} 10 \mathrm{~min} 1,5 \mathrm{mM} \\
\mathrm{MgSO}_{4}\end{array}$} \\
\hline \multirow[t]{2}{*}{ ITS-23S rRNAr } & \multirow[t]{2}{*}{ ITS-23S rRNA } & \multirow[t]{2}{*}{ GGG TTY CCC CRT TCR GAA AT } & \multirow[t]{2}{*}{0,2} & $\begin{array}{l}\text { CHANG, et } \\
\text { al., } 2005\end{array}$ & & & \\
\hline & & & & & & & \\
\hline sp4F & gyrB & CAC GCC GTA AGA GTG CAT TA & 0,2 & $\begin{array}{l}\text { HIGGINS et } \\
\text { al., } 2007\end{array}$ & $\mathrm{sp} 4 \mathrm{~F} / \mathrm{sp} 4 \mathrm{~F}$ & $294 \mathrm{pb}$ & \\
\hline $\mathrm{sp} 4 \mathrm{R}$ & gyrB & AAC GGA GCT TGT CAG GGT TA & 0,2 & & & & \multirow{3}{*}{$\begin{array}{l}94^{\circ} \mathrm{C} \min , 25 \text { ciclos, } \\
94^{\circ} \mathrm{C} 1 \mathrm{~min}, 60^{\circ} \mathrm{C} \\
30 \mathrm{~s}, 72^{\circ} \mathrm{C} 1 \mathrm{~min} 30 \mathrm{~s}, \\
72^{\circ} \mathrm{C} 10 \min 1,5 \mathrm{mM}\end{array}$} \\
\hline $16 S-63 F$ & $16 \mathrm{~S}$ rRNA & CAG GGC TAA CAC ATG CAA GTC & 0,3 & & & & \\
\hline 16S-1387R & 16S rRNA & GGG CGG WGT GTA CAA GG & 0,3 & $\begin{array}{l}\text { MARCHESI et } \\
\text { al., } 1998\end{array}$ & 16S-63F/16S-1387R & $1300 \mathrm{pb}$ & \\
\hline ITS-3 & $\begin{array}{l}\text { ITS 16S-23S } \\
\text { rRNA }\end{array}$ & $\begin{array}{c}\text { AAG TGA GTG TTG TCC GTG CGA } \\
\text { TT }\end{array}$ & 0,2 & este trabalho & ITS-3/ITS-16S & $700 \mathrm{pb}$ & $\mathrm{MgSO}_{4}$ \\
\hline
\end{tabular}

ITS - sequência intergênica, gyrB - subunidade B da girase, * concentração do iniciador na PCR em $\mu \mathrm{M}$ 
Tabela 3 Iniciadores e condições de termociclagem utilizadas na reação PCR multiplex para carbapenemases do tipo OXA

\begin{tabular}{|c|c|c|c|c|c|c|c|}
\hline Iniciadores * & Alvo & Sequência $\left(5^{\prime} \rightarrow 3^{\prime}\right)$ & $\mu \mathrm{M}$ & $\begin{array}{l}\text { Conjunto de } \\
\text { iniciadores }\end{array}$ & $\begin{array}{l}\text { Tamanho do } \\
\text { fragmento }\end{array}$ & Condições de reação & $\begin{array}{l}\text { Programação de } \\
\text { termociclagem }\end{array}$ \\
\hline OXA-23F & & GAT CGG ATT GGA GAA CCA GA & 0,2 & \multirow{3}{*}{ OXA-23F-OXA-23R } & \multirow{3}{*}{501} & \multirow{10}{*}{$\begin{array}{l}\text { 1X tampão de Taq com } \\
\mathrm{KCl}, 2,5 \mathrm{mM} \mathrm{MgCl}, 20 \\
\mu \mathrm{M} \text { dNTP, } 1,5 \cup \mathrm{Taq} \\
\text { polimerase. Volume final } \\
20 \mu \mathrm{L}\end{array}$} & \multirow{10}{*}{$\begin{array}{l}94^{\circ} \mathrm{C} \min , 30 \text { ciclos, } \\
94^{\circ} \mathrm{C} 1 \mathrm{~min}, 55^{\circ} \mathrm{C} 30 \mathrm{~s}, \\
72^{\circ} \mathrm{C} 1 \mathrm{~min} 30 \mathrm{~s}, 72^{\circ} \mathrm{C} \\
10 \mathrm{~min}\end{array}$} \\
\hline & bla $\mathrm{OXA-23-like}$ & & & & & & \\
\hline OXA-23R & & ATT TCT GAC CGC ATT TCC AT & 0,2 & & & & \\
\hline OXA-24F & & GGT TAG TTG GCC CCC TTA AA & 0,2 & \multirow{4}{*}{$\begin{array}{l}\text { OXA24F-OXA24R } \\
\text { OXA51F-OXA51R }\end{array}$} & \multirow[b]{2}{*}{246} & & \\
\hline OXA-24R & $b / a_{O X A-24-l i k e}$ & AGT TGA GCG AAA AGG GGA TT & 0,2 & & & & \\
\hline OXA-51F & bla $\mathrm{OXA-51- \text {like }}$ & TAA TGC TTT GAT CGG CCT TG & 0,2 & & 353 & & \\
\hline OXA-51R & & TGG ATT GCA CTT CAT CTT GG & 0,2 & & & & \\
\hline OXA-58F & & AAG TAT TGG GGC TTG TGC TG & 0,2 & & & & \\
\hline & bla $\mathrm{OXA-58-like}$ & & & OXA58F-OXA58R & 599 & & \\
\hline OXA-58R & & ССС CTC TGC GCT СTA CAT AC & 0,2 & & & & \\
\hline
\end{tabular}

*WOODFORD et al., 2006 


\subsection{Tipagem molecular}

A tipagem molecular das 515 cepas pertencentes ao complexo ACB foi realizada utilizando-se o método de RAPD preconizado por Williams e colaboradores (1990). Os isolados resistentes aos carbapenêmicos foram tipados também pelo método de PFGE.

\subsubsection{Reação de RAPD}

Tomou-se como base o protocolo desenvolvido por Williams e colaboradores (1990).

Foram testados nove iniciadores descritos na Tabela 3. Foram selecionados os iniciadores que revelaram o maior número de polimorfismos e um bom padrão de amplificação (bandas reprodutíveis e bem nítidas). Para essa seleção, foram utilizadas dez amostras de DNA de Acinetobacter baumannii em estudo.

Após a reação, os produtos de amplificação foram separados em eletroforese horizontal, em gel de agarose a 1,4\%, voltagem de $150 \mathrm{~V}$, por $2 \mathrm{~h}$. Utilizou-se TBE (Trisma-base 0,1 M, ácido bórico 0,09 M e EDTA $1 \mathrm{mM}$ ) como tampão de corrida do gel. As bandas foram detectadas por coloração com brometo de etídio e visualizadas em um transiluminador de luz ultravioleta e a imagem registrada por fotografia digital. O controle negativo continha todos os componentes exceto DNA.

Para a tipagem molecular dos 515 isolados bacterianos foram utilizados quatro iniciadores opb 15, opd 07, opd 11 e opd 13, descritos na Tabela 4. 
Tabela 4. Iniciadores e condições de termociclagem utilizados na reação de RAPD

\begin{tabular}{|c|c|c|c|c|}
\hline Iniciadores & Sequência $\left(5^{\prime} \rightarrow 3^{\prime}\right)$ & $\begin{array}{l}\text { Concentração do } \\
\text { iniciador }(\mu \mathrm{M})\end{array}$ & Condições da reação & $\begin{array}{l}\text { Programação de } \\
\text { termociclagem }\end{array}$ \\
\hline OPA - 08 & GTGACGTAGG & 0,4 & \multirow{9}{*}{$\begin{array}{l}\text { 1X tampão de Taq com } \mathrm{KCl}, 2,5 \mathrm{mM} \\
\mathrm{MgCl}_{2}, 20 \mu \mathrm{M} \text { dNTP, } 1,5 \mathrm{U} \text { Taq } \\
\text { polimerase. Volume final } 20 \mu \mathrm{L}\end{array}$} & \multirow{9}{*}{$\begin{array}{c}94^{\circ} \mathrm{C} \text { min, } 40 \text { ciclos, } 94^{\circ} \mathrm{C} 45 \mathrm{~s}, \\
36^{\circ} \mathrm{C} 45 \mathrm{~s}, 72^{\circ} \mathrm{C} 2 \mathrm{~min}, 72^{\circ} \mathrm{C} 7 \mathrm{~min}\end{array}$} \\
\hline OPB - 13 & TTCCCCCGCT & 0,4 & & \\
\hline OPB - $15^{*}$ & GGAGGGTGTT & 0,4 & & \\
\hline OPB - 20 & GGACCCTTAC & 0,4 & & \\
\hline OPC - 17 & TTCCCCCCAG & 0,4 & & \\
\hline OPD - $07^{*}$ & TTGGCACGGG & 0,4 & & \\
\hline OPD - 05 & TGAGCGGACA & 0,4 & & \\
\hline OPD - $11^{*}$ & AGCGCCATTG & 0,4 & & \\
\hline OPD - $13^{*}$ & GGGGTGACGA & 0,4 & & \\
\hline
\end{tabular}

* Iniciadores escolhidos para tipagem por RAPD 


\subsubsection{Eletroforese em gel de agarose em campo pulsado (PFGE)}

Foi utilizado o protocolo rápido descrito por Durmaz e colaboradores (2009) com algumas modificações. Foi realizada a cultura dos isolados em TSA (triptone soy agar) por 12 a 18 horas, a $37^{\circ} \mathrm{C}$. Preparou-se suspensão bacteriana $\mathrm{DO}_{600} 1.0 \mathrm{em}$ "cell suspension buffer" (CSB) (100 mM TrisHCl, $10 \mathrm{mM}$ EDTA pH 8,0). O volume de $100 \mu \mathrm{L}$ desta suspensão foi homogenizado delicadamente com $100 \mu \mathrm{L}$ de agarose de baixo ponto de fusão (BioRad,EUA) a $2 \%$, preparada em CSB e transferidas para o molde de preparação dos blocos de agarose. $\mathrm{O}$ molde foi mantido por $10 \mathrm{~min}$ a $4^{\circ} \mathrm{C}$, e os blocos de agarose foram transferidos para microtubos com $500 \mu \mathrm{L}$ de solução CLS-1 ("cell lysis solution"-1; $50 \mathrm{mM}$ Tris-HCl, $50 \mathrm{mM}$ EDTA, 2,5 mg.mL ${ }^{-1}$ lisozima, 1,5 $\mathrm{mg} \cdot \mathrm{mL}^{-1}$ proteinase $\mathrm{K}, \mathrm{pH} 8,0$ ) e incubados por 1 hora, a $37^{\circ} \mathrm{C}$. Os blocos de agarose foram transferidos para novos microtubos com $500 \mu \mathrm{L}$ de CLS-2 ("cell lysis solution"-2; 0,5M EDTA pH 8,0; $1 \%$ sarcosil; $400 \mu \mathrm{g} \cdot \mathrm{mL}^{-1}$ proteinase $\mathrm{K}$ ) incubados por 2 horas a $55^{\circ} \mathrm{C}$. Os blocos foram lavados três vezes com $1 \mathrm{~mL}$ de água ultra pura (MilliQ, Millipore, USA) e três vezes com $1 \mathrm{~mL}$ de TE (10mM Tris-HCl, 0,1 mM EDTA pH 7,6), a cada lavagem foi incubado por 15 minutos a $50^{\circ} \mathrm{C}$. Após a última lavagem, adicionou-se nova alíquota de $1 \mathrm{~mL}$ de $\mathrm{TE}$ e os blocos de agarose foram mantidos a $4^{\circ} \mathrm{C}$ até o momento de uso.

Os blocos de agarose, contendo DNA cromossomal, foram cortados ao meio e este fragmento foi utilizado na restrição enzimática. O pedaço do bloco de agarose foi incubado em $100 \mu \mathrm{L}$ no tampão da enzima diluído para $1 \mathrm{X}$ com 2,5 $\mu \mathrm{L}$ da enzima Apal "Fast Digest" (Fermentas, Lituânia) por $30 \mathrm{~min}, 37^{\circ} \mathrm{C}$.

Os produtos da digestão enzimática foram submetidos à eletroforese em gel de agarose ( $1,0 \%$ agarose Sigma, EUA) com 0,2X de Gel Red (Biotium, EUA) em tampão (0,9M Tris base, 0,9 M ácido bórico, 0,02 M EDTA), sendo os fragmentos separados em um aparelho CHEF-DR II (BioRad), em temperatura de $14^{\circ} \mathrm{C}$, durante período de 20 horas a $6 \mathrm{~V} . \mathrm{cm}^{-1}$. O tempo de pulso inicial foi de 5 segundos e o tempo final de 30 segundos. Após a corrida, o gel foi visualizado em um transiluminador de luz ultravioleta e a imagem registrada por fotografia digital. 


\subsubsection{Análise dos polimorfismos}

A análise estatística dos dados foi feita utilizando-se os programas NTSYS-pc (Numerical Taxonomy and Multivariate Analysis System), versão 1,7 (Exeter Software, Setauked, NY) e Bionumerics, versão 5.1 (Applied Maths, Sint-Martens-Latem, Bélgica).

A similaridade entre as amostras foi estimada mediante a utilização dos coeficientes de Jaccard e Dice. As matrizes de similaridade geradas pelos dois coeficientes foram comparadas utilizando-se o teste de correspondência de matrizes de Mantel. Pela matriz de similaridade foi possível determinar os grupos a partir do método de UPGMA (unweighthed pair-group method using arithmetic average), que foi representado na forma de dendrograma.

\subsection{Pesquisa de genes codificadores de carbapenemase}

A pesquisa de genes codificadores para as quatro subclasses de OXAs (OXA-23, OXA-24, OXA-51 e OXA-58) foi realizada por PCR utilizando-se

iniciadores específicos para os genes blaOXA-23-like, blaOXA-24-like, blaOXA-51-like e blaOXA-58-like (WOODFORD et al., 2006). Os iniciadores e as condições da PCR estão descritos na Tabela 3.

Em isolados resistentes aos carbapenêmicos, também, foram pesquisados genes codificadores de metalo-lactamases por PCR multiplex conforme proposto por Ellington e colaboradores (ELLINGTON et al., 2007) descritos na Tabela 5.

Os produtos de PCR foram submetidos à eletroforese em gel de agarose a $1 \%$, voltagem constante de $100 \mathrm{~V}$, por $1 \mathrm{~h}$. Em seguida, foram corados por brometo de etídio ( $10 \mu \mathrm{g} / \mathrm{mL}$ ), visualizados em um transiluminador de luz UV e registrados por fotografia digital. 
Tabela 5 Iniciadores e condições de termociclagem utilizados na reação de multiplex PCR para metalo-lactamases

\begin{tabular}{|c|c|c|c|c|c|c|c|}
\hline Iniciadores* & Alvo & Sequência $\left(5^{\prime} \rightarrow 3^{\prime}\right)$ & $\mu \mathrm{M}$ & $\begin{array}{l}\text { Conjunto de } \\
\text { iniciadores }\end{array}$ & $\begin{array}{l}\text { Tamanho do } \\
\text { fragmento }\end{array}$ & $\begin{array}{l}\text { Condições da } \\
\text { reação }\end{array}$ & $\begin{array}{c}\text { Programação de } \\
\text { termociclagem }\end{array}$ \\
\hline IMP-F & & GGA ATA GAG TGG CTT AAY TCT C & 0,2 & & & \multirow{7}{*}{$\begin{array}{l}\text { 1X tampão de Taq } \\
\text { com } \mathrm{KCl}, 1,5 \mathrm{mM} \\
\mathrm{MgCl}_{2}, 20 \mu \mathrm{M} \mathrm{dNTP} \\
1,5 \cup \text { Taq polimerase. } \\
\text { Volume final } 20 \mu \mathrm{L}\end{array}$} & \multirow{7}{*}{$\begin{array}{l}94^{\circ} \mathrm{C} \min , \quad 30 \\
\text { ciclos, } 94^{\circ} \mathrm{C} \quad 1 \\
\min 58^{\circ} \mathrm{C} \quad 30 \mathrm{~s}, \\
72^{\circ} \mathrm{C} \quad 1 \min 30 \mathrm{~s}, \\
72^{\circ} \mathrm{C} \quad 10 \min 1,5 \\
\mathrm{mM} \mathrm{MgSO}_{4}\end{array}$} \\
\hline IMP-R & bla & CCA AAC YAC TAS GTT ATC T- & 0,2 & IMP-F/IMP-R & 188 & & \\
\hline VIM-F & & GAT GGT GTT TGG TCG CAT A & 0,2 & & & & \\
\hline VIM-R & blavim & CGA ATG CGC AGC ACC AG & 0,2 & VIM-F/VIM-R & 390 & & \\
\hline $\begin{array}{l}\text { GIM-F } \\
\text { GIM-R }\end{array}$ & $b / a_{G I M}$ & $\begin{array}{l}\text { TCG ACA CAC CTT GGT CTG AA } \\
\text { AAC TTC CAA CTT TGC CAT GC- }\end{array}$ & $\begin{array}{l}0,2 \\
0,2\end{array}$ & GIM-F/GIM-R & 477 & & \\
\hline $\begin{array}{l}\text { SPM-F } \\
\text { SPM-R }\end{array}$ & bla & $\begin{array}{l}\text { AAA ATC TGG GTA CGC AAA CG } \\
\text { ACA TTA TCC GCT GGA ACA GG }\end{array}$ & $\begin{array}{l}0,2 \\
0,2\end{array}$ & SPM-F/SPM-R & 271 & & \\
\hline $\begin{array}{l}\text { SIM-F } \\
\text { SIM-R }\end{array}$ & blasım & $\begin{array}{l}\text { TAC AAG GGA TTC GGC ATC G } \\
\text { TAA TGG CCT GTT CCC ATG TG- }\end{array}$ & $\begin{array}{l}0,2 \\
0,2\end{array}$ & SIM-F/SIM-R & 570 & & \\
\hline
\end{tabular}

${ }^{*}$ ELLINGTON et al., 2007 


\subsection{Estudo da comunicação celular bacteriana}

\subsubsection{Preparo dos meios pré-condicionados}

Três cepas (Anexo 2) de cada espécie clínica do complexo ACB estudadas foram inoculadas em $50 \mathrm{~mL}$ de meio $\mathrm{LB}$, LB $0,4 \mathrm{M} \mathrm{NaCl}$, LB com 50mM MOPS pH 7.0, TSB, ou $\mathrm{BHI}$ a $37^{\circ} \mathrm{C}$. Ao atingir a $\mathrm{DO}_{600} 1,2$, as culturas foram centrifugadas $6.600 \times \mathrm{g}$ por 15 minutos, o sobrenadante foi filtrado em membrana com poros de $0.22 \mu \mathrm{m}$. Esse filtrado foi denominado como meio précondicionado. O mesmo procedimento foi realizado para as amostras controle positiva ou negativa para cada ensaio

O meio de cultura utilizado para a obtenção do meio pré-condicionado variou de acordo com o autoindutor a ser pesquisado. LB, LB com 50mM MOPS pH 7.0, TSB, BHI para pesquisa do acil homoserina lactonas; LB 0,4 M $\mathrm{NaCl}$ para pesquisa de autoindutor 3 e meio LB para pesquisa de autoindutor2.

\subsubsection{Pesquisa de acil-homoserina lactonas}

Para a pesquisa de acil-homoserina foi utilizado o método preconizado por McClean e colaboradores (MCCLEAN et al., 1997). Três cepas de cada espécie clínica do complexo ACB foram utilizadas nesse ensaio. Foram utilizados dois métodos de bioensaio.indução e inibição de violaceína.

\subsubsection{Bioensaio pela indução de violaceína}

As amostras de Acinetobacter sp. e P. aeruginosa ATCC 27853, controle positivo para a produção de acil-homoserina lactonas (AHLs). foram cultivadas em $50 \mathrm{~mL}, 200 \mathrm{~mL}$ ou $500 \mathrm{~mL}$ de meio LB ou LB com $50 \mathrm{mM}$ MOPS pH 7,0 ou TSB ou $\mathrm{BHI}$ a $37^{\circ} \mathrm{C}$ sob agitação constante de $150 \mathrm{rpm}$ até atingir a $\mathrm{DO}_{600} 1.0$, fase exponencial tardia. O crescimento foi centrifugado a $6.600 \times g$ por 10 minutos e o sobrenadante foi filtrado em membrana de celulose com poros de $0.22 \mu \mathrm{m}$. O sobrenadante livre de células foi submetido à extração orgânica 
com $100 \mathrm{~mL}$ de diclorometano ou em dois volumes de $50 \mathrm{~mL}$ de acetato de etila com $0,01 \%$ de ácido acético, concentrou-se a fase orgânica em rota-vapor até total evaporação do solvente. $O$ resíduo, quando a extração foi feita com diclorometano, foi solubilizado em $1 \mathrm{~mL}$ de acetonitrila, contudo, o resíduo obtido com acetato de etila, foi solubilizado neste solvente. Os extratos foram armazenados a $-20^{\circ} \mathrm{C}$ até o momento de uso.

Os extratos dos sobrenadantes de culturas de Acinetobacter sp. e $P$. aeruginosa ATCC 27853, controle positivo, foram analisados quanto à presença de AHL. Foi realizado também a extração orgância do meio de cultura, sem inoculo bacteriano, empregado como controle negativo. A cepa sensora Chromobacterium violaceum CV026, gentilmente cedida pela Profa. Dra. Vanessa Sperandio, foi cultivada em $10 \mathrm{~mL}$ de meio LB (peptona $10 \mathrm{~g} \cdot \mathrm{L}^{-1}$, extrato de levedura $\left.5 \mathrm{~g} \cdot \mathrm{L}^{-1}, \mathrm{NaCl} 5 \mathrm{~g} \cdot \mathrm{L}^{-1}\right)$, contendo canamicina $\left(50 \mu \mathrm{g} \cdot \mathrm{mL}^{-1}\right)$, por $18 \mathrm{~h}$ a $30^{\circ} \mathrm{C}$. A $3 \mathrm{~mL}$ de ágar Soft-top (triptona $10 \mathrm{~g} \cdot \mathrm{L}^{-1}$, NaCl $5 \mathrm{~g} \cdot \mathrm{L}^{-1}$, Agar $6,5 \mathrm{~g} \cdot \mathrm{L}^{-1}$ ) foram adicionados $100 \mu \mathrm{L}$ da cultura. Esse volume foi cuidadosamente vertido em uma placa de Petri contendo agar LB ou agar nutriente (extrato de carne $3 \mathrm{~g} \cdot \mathrm{L}^{-1}$, peptona $5 \mathrm{~g} . \mathrm{L}^{-1}$, agar $15 \mathrm{~g} \cdot \mathrm{L}^{-1}$ ) com canamicina $\left(50 \mu \mathrm{g} \cdot \mathrm{mL}^{-1}\right)$. Após a geleficação do ágar Soft-top, as placas foram perfuradas utilizando-se uma pipeta Pasteur. Aos orifícios formados, adicionaram-se $10 \mu \mathrm{L}$ de LB ou extrato de sobrenadante de um caldo de cultivo a ser testado. Como controle positivo, $5 \mu \mathrm{L}$ de solução $1 \mu \mathrm{M}$ de $\mathrm{AHL}$ sintética $\mathrm{N}$-hexanoil-DL-homoserina foram adicionados a uma das perfurações. As placas foram mantidas a $30^{\circ} \mathrm{C}$ por 18 horas. A atividade de AHL foi detectada pela presença de pigmentação violeta ao redor das perfurações no agar.

\subsubsection{Bioensaio pela inibição de violaceína}

A presença de $\mathrm{AHL}$ de cadeia longa foi avaliada em ensaio de inibição da produção de violaceína em meio suplementado com $\mathrm{N}$-hexanoil-DLhomoserina lactona $(\mathrm{HHL})$. As $\mathrm{AHL}$ com cadeias laterais entre 10 e 14 carbonos não induzem a produção de violaceína por C. violaceum CV026. Entretanto, em presença de AHL ativadoras desse pigmento, as AHL de cadeia longa podem ser detectadas, pela sua capacidade de inibir a produção do 
mesmo (MCCLEAN et al., 1997). A cepa a ser testada, portanto, foi estriada em LB ágar suplementado com $75 \mathrm{nM}$ de N-hexanoil-DL-homoserina lactona $(\mathrm{HHL})$. As placas foram incubadas por 24 horas a $37^{\circ} \mathrm{C}$ e, logo após este período de incubação, a cepa monitora $C$. violaceum CV026 foi estriada em paralelo à cepa teste. Após reincubação a $26^{\circ} \mathrm{C}$ por mais 24 horas, a ausência de pigmentação de $C$. violaceum $C V 026$, em razão da inibição da produção de violaceína, foi considerada um indicativo da produção de $A H L$ de cadeia longa pela cepa avaliada. Como controle negativo, foi utilizada a própria cepa monitora e, como o controle positivo, $P$. aeruginosa ATCC 27853 , que além de produzir AHL com cadeia curta de carbonos, é capaz de sintetizar esse autoindutor com cadeia longa de carbono com mais de dez átomos desse elemento químico.

\subsubsection{Análise do extrato orgânico de meio pré-condicionado por LC-MS}

Uma amostra de Acinetobacter baumannii foi cultivada em $500 \mathrm{~mL}$ de meio LB a $37^{\circ} \mathrm{C}$ sob agitação constante de $150 \mathrm{rpm}$ até atingir a $O D_{600}$ de 1.0 , fase exponencial tardia. $O$ meio de cultura foi centrifugado a $6600 \mathrm{~g}$ por 10 minutos e o sobrenadante foi filtrado em membrana de celulose com poros de $0.22 \mu \mathrm{m}$. O sobrenadante livre de células foi submetido a um extração orgânica com 2 volumes de $50 \mathrm{~mL}$ de acetato de etila com $0,01 \%$ de ácido acético. Concentrou-se a fase orgânica em rota-vapor até total evaporação do solvente e o resíduo foi solubilizado em $1 \mathrm{~mL}$ de acetato de etila. $\mathrm{O}$ extrato foi mantido a $-20^{\circ} \mathrm{C}$ até o momento de uso.

O extrato orgânico concentrado foi analisado por cromatografia líquida acoplado a detector de massa, LC-MS íontrap. Essa análise foi realizada com o auxílio do especialista Felipe Döor, no laboratório do Prof $^{\circ}$ Dr. Ernani Pinto. Buscou-se por picos que apresentaram no espectro de massa pico de com a relação massa carga $(\mathrm{m} / \mathrm{z})$ 102, característico do anel principal de acilhomoserina lactona, em seguida foi realizada a busca por substâncias que geraram a relação m/z 102 na fragmentação ocasionada pela ionização do material analisado nesse equipamento. 


\subsubsection{Pesquisa de autoindutor-2}

Para a pesquisa do autoindutor - 2 foi utilizado o biossensor Vibrio harveyi BB170 (gentilmente cedido pela Profa. Dra. Vanessa Sperandio) que em contato com o autoindutor apresenta o fenômeno da bioluminescência. Como controle positivo utilizou-se meio pré-condicionado obtido a partir de Vibrio harveyi BB120 ou Vibrio harveyi BB152 e como controle negativo meio de cultura estéril.

A amostra de $V$. harveyi BB170 foi inoculada em meio AB ("autoinducer bioassay medium" $\mathrm{NaCl}$ 17,5 g.L $\mathrm{L}^{-1}, \mathrm{MgSO}_{4}$ 12,3 g.L $\mathrm{L}^{-1}$, casaminoácidos 2,0 g.L ${ }^{-1}$ ) e incubada a $30^{\circ} \mathrm{C}$ por aproximadamente 18 horas. Após diluição 1:5.000 em meio $A B, 10 \mu \mathrm{L}$ foram adicionados a $90 \mu \mathrm{L}$ do meio pré-condicionado, preparado em meio LB, em microplacas de polivinil de fundo chato e feita incubação a $30^{\circ} \mathrm{C}$ por 3,6 e 12 horas para a detecção de atividade de bioluminescência (SURETTE \& BASSLER, 1998). A atividade de bioluminescência foi quantificada em aparelho luminômetro (Berthlod MicroLumat Plus, Califórnia, EUA) em $450 \mathrm{~nm}$. Todos os ensaios foram realizados em triplicata.

\subsubsection{Pesquisa de autoindutor-3}

A pesquisa da produção de autoindutor-3 foi realizada pelo uso da cepa biosensora Escherichia coli TEVS 232, cedida pela Profa. Dra. Vanessa Sperandio, contendo a fusão $L E E 1:: / a c Z$, que na presença de autoindutor-3 induz o gene codificador de $\beta$-galactosidase. Como controle positivo utilizou-se o meio pré-condicionado obtido a partir de Escherichia coli 0157:H7 e como controle negativo o meio pré-condicionado obtido a partir de Escherichia coli DH5a.

A cepa TEVS232 foi inoculada em $3 \mathrm{~mL}$ de meio pré-condicionado e incubada $37^{\circ} \mathrm{C}$ sob agitação de $250 \mathrm{rpm}$ até atingir a $\mathrm{DO}_{600} \quad 0,2$. Após esse período, as amostras foram incubadas em gelo por aproximadamente $20 \mathrm{~min}$. Foi feita a transferência de $100 \mu \mathrm{L}$ do crescimento para um tubo contendo 900 $\mu \mathrm{L}$ de tampão $\mathrm{Z}\left(\mathrm{Na}_{2} \mathrm{HPO}_{4} .7 \mathrm{H}_{2} \mathrm{O} \quad 0,06 \mathrm{M} / \mathrm{NaH}_{2} \mathrm{PO}_{4} \cdot \mathrm{H}_{2} \mathrm{O} \quad 0,04 \mathrm{M} / \mathrm{MgSO}_{4} .7 \mathrm{H}_{2} \mathrm{O}\right.$ 
$0,001 \mathrm{M} / \beta$-mercaptoetanol $0,05 \mathrm{M}$, pH 7,0 ). Para a ruptura das células bacterianas foi adicionada uma gota de SDS $10 \%$ e duas gotas de clorofórmio. Após a homogeneização e a ruptura celular (aproximadamente 5 minutos), foram adicionados $200 \mu \mathrm{L}$ de orto-nitrofenil- $\beta$-galactopiranosídeo (ONPG) $4 \mathrm{mg} / \mathrm{mL}$, em tampão fosfato $0,1 \mathrm{M} \mathrm{e}$ incubado a $37^{\circ} \mathrm{C}$ por $20 \mathrm{~min}$. A reação foi interrompida com adição de $500 \mu \mathrm{L}$ de $\mathrm{Na}_{2} \mathrm{CO}_{3} 1 \mathrm{M}$. O volume da reação foi centrifugado a $14.800 \mathrm{x} g$ por 5 minutos e o sobrenadante foi separado para quantificação da absorbância em comprimento de onda de $420 \mathrm{~nm}$. A atividade de $\beta$-galactosidase foi medida da seguinte maneira: Miller Units (Unidade de Miller $)=1000^{*} \mathrm{DO}_{420} / \mathrm{t}^{*} \mathrm{v}^{*} \mathrm{DO}_{600}$ onde $\mathrm{t}=$ tempo da reação, $\mathrm{v}=$ volume inicial da cultura $(100 \mu L)$ (MILLER, 1972).

\subsection{Avaliação da produção de biofilmes}

A pesquisa de biofilmes foi realizada segundo protocolo proposto por O'Toole (2011). Dez cepas de cada espécie do complexo ACB foram utilizadas nesse ensaio (Anexo 3). Como controle positivo para produção de biofilme utilizou-se a cepa de Escherichia coli E2348/69 e como controle negativo apenas o meio de cultura sem inóculo bacteriano. $O$ ensaio foi realizado em placas de 96 poços, cada amostra foi avaliada em triplicata. Como controle, seis poços de cada placa não receberam inóculo bacteriano, nos demais foram inoculadas $1.10^{8}$ células bacterianas por poço em volume final de $100 \mu \mathrm{L}$ de meio LB com e sem $100 \mu \mathrm{M}$ de fentolamina. A placa foi incubada a $37^{\circ} \mathrm{C}$ por 24 horas.

Após o período de incubação, o meio de cultura foi removido e os poços foram lavados 3 vezes com tampão fosfato $\mathrm{pH} 7$,2. Em seguida, o biofilme foi corado com cristal violeta $0,1 \%$ por 15 minutos. Os poços foram lavados até a completa remoção do excesso de corante. A placa foi seca em temperatura ambiente. Para a solubilização do cristal violeta, foram adicionados $125 \mu \mathrm{L}$ de ácido acético $30 \%$ e as placas foram incubadas por $20 \mathrm{~min}$ a $25^{\circ} \mathrm{C}$. Foi realizada a medida de absorbância em comprimento de onda de $570 \mathrm{~nm}$.

Todos os ensaios foram realizados em triplicata e repetidos três vezes. 


\subsection{Ensaio de adesão bacteriana}

Foram utilizadas células MRC-5 (ATCC CCL - 171), célula diploide derivada de pulmão de um feto de 14 semanas de idade, do sexo masculino, de origem caucasiana. Elas foram mantidas em Meio Mínimo Essencial de Eagle (MEM) acrescido de Meio Lebovitz $n^{\circ} 15$ (L-15) v/v, suplementado de $40 \%$ de soro fetal bovino e de $10 \%$ de dimetilsulfóxido (DMSO) a $-80^{\circ} \mathrm{C}$. Do mesmo modo foram mantidas as células NCl-H292 (ATCC CRL-1848), células oriundas de um nódulo linfático em metástase de um carcinoma mucoepidermoide de pulmão humano, com o meio de cultura o RPMI e células HEp-2 (ATCC CCL-23), células epitelias derivadas de uma linhagem contaminada de células HeLa, utilizando o meio de cultura DMEM.

A cultura de célula foi realizada em placas de 24 poços sobre lamínula de vidro, utilizando o meio de cultura apropriado e suplementado com $10 \%$ de soro fetal bovino. As células foram incubadas a $37^{\circ} \mathrm{C}$ em atmosfera $5 \%$ de $\mathrm{CO}_{2}$, por dois dias para se obter uma monocamada homogênea.

O ensaio foi realizado de acordo com a metodologia descrita por CRAVIOTO et al. (1979), com algumas modificações. As amostras bacterianas de Acinetobacter sp., foram cultivadas em placa de TSA a $37^{\circ} \mathrm{C}$ por $16 / 18 \mathrm{~h}$. Foi feita uma suspensão bacteriana correspondendo à escala 0,5 McFarland, em espectrofotômetro.

A placa contendo a monocamada de células foi lavada seis vezes com solução salina tamponada com fosfato (SSTF) $0,01 \mathrm{M} \mathrm{pH} \mathrm{7,2} \mathrm{e} \mathrm{em} \mathrm{seguida}$ adicionadas de $0,99 \mathrm{~mL}$ do meio de cultura apropriado, contendo SFB a $2 \%$ e $10 \mu \mathrm{L}$ da suspensão bacteriana. A placa foi incubada por $3 \mathrm{~h}$ a $37^{\circ} \mathrm{C}$, em atmosfera de $5 \% \mathrm{CO}_{2}$. Trocou-se o meio de cultura e a placa foi incubada por mais 3 horas. Em seguida, foi lavada seis vezes com SSTF e fixada com metanol por pelo menos 30 minutos. Após a fixação, as lamínulas foram coradas com Giemsa diluído em tampão Sörensen $0,33 \mathrm{M}$ pH 7,3 por 20 minutos e lavadas para retirar o excesso de corante. Após a secagem, as lamínulas foram montadas em lâminas de vidro para microscopia e observadas e microscópio óptico em aumento de 400X e 1000X. 
Todos os ensaios foram feitos em duplicata e repetidos por três vezes.

\subsection{Análise estatística}

Utilizou-se o programa Statistica versão 9.1 (Stat Soft, 2010). Para os dados obtidos para distribuição das espécies do complexo ACB e perfil de sensibilidade foram utilizados o teste qui-quadrado e teste de comparação de porcentagens. Os dados obtidos nos ensaio de biofilme e pesquisa de autoindutor-3 foram testados quanto à distribuição normal (teste de ShapiroWilk) e à homogeneidade das variâncias (teste de Levene e Brown-Forysthe). Nos conjuntos de dados que não foram observadas distribuição normal e principalmente, a homogeneidade das variâncias, os testes estatísticos nãoparamétricos de Mann-Whitney ou Kruskal-Wallis foram utilizados para comparação de dois ou mais grupos, respectivamente. 


\section{RESULTADOS}

\subsection{Identificação das espécies do complexo ACB}

Por PCR obteve-se um único amplicon de aproximadamente 790pb referente a um pequeno fragmento da região do gene que codifica o RNA ribossômico 16S, a região intergênica, e um pequeno fragmento da região do gene que codifica a subunidade $23 \mathrm{~S}$ do RNA ribossômico.

Inicialmente, sequências da região intergênica (ITS) 16S-23S rRNA de 10 amostras bacterianas pertencentes ao complexo ACB foram comparadas com as depositadas no GenBank, utilizando-se a ferramenta BLAST (ALTSCHUL et al., 1990). O alinhamento das sequências da região ITS, representado na Figura 1, permitiu avaliar os polimorfismos entre as espécies, sendo possível o desenho do iniciador específico para Acinetobacter 3, descrito na Tabela 2.

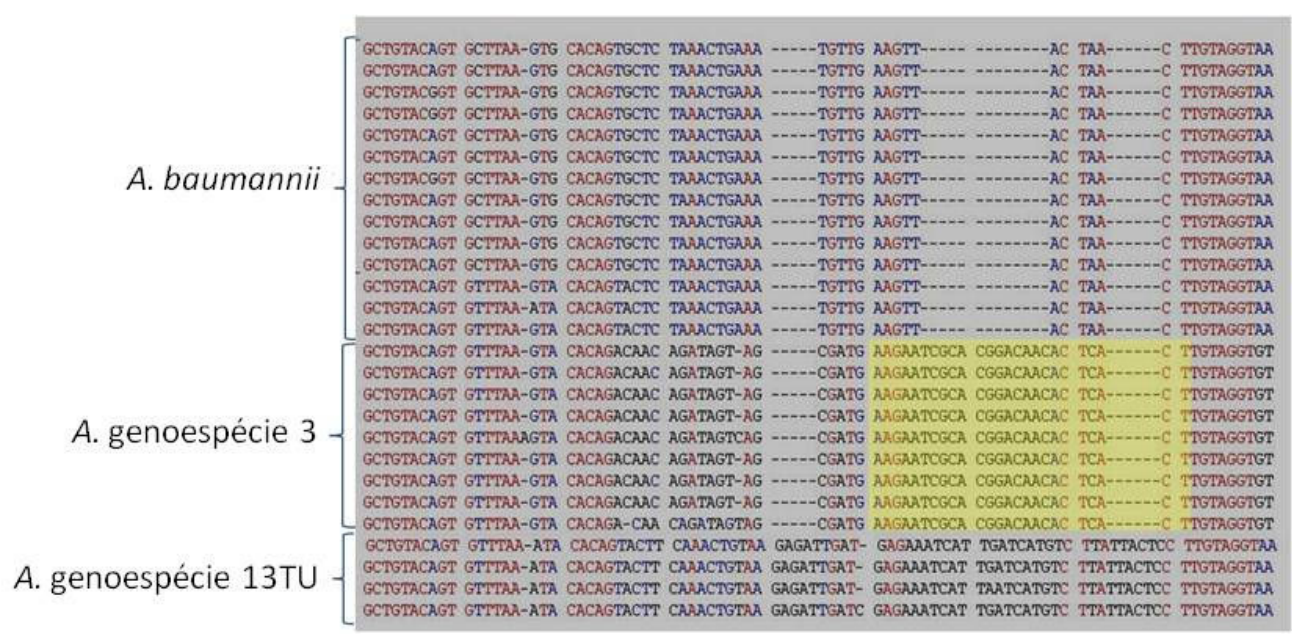

Figura 1. Alinhamento das sequências nucleotídicas da região entre os genes codificadores do $16 S$ e 23S rRNA das diferentes espécies do complexo ACB, em destaque a região de alinhamento do iniciador específico para $A$. genoespécie 3.

Todas as amostras identificadas pelo método proposto como $A$. genoespécie 3 e $A$. genoespécie 13TU, tiveram os amplicons da região intergênica 16S-23S rRNA sequenciados. As sequências foram analisadas em banco de dados GenBank (ALTSCHUL et al., 1990) que confirmaram o resultado obtido pelo método proposto, apresentando $100 \%$ de concordância . (Figura 2). 


\section{Multiplex PCR para bla oxA}

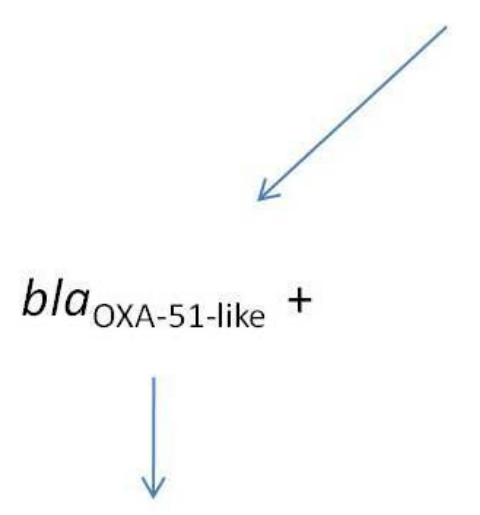

A. baumannii

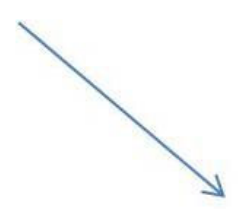

bla $_{\text {OXA-51-like }}-$

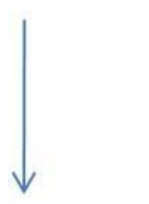

PCR multiplex identificação

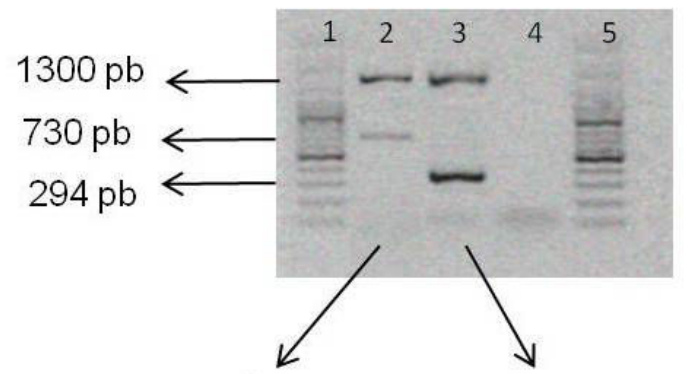

A. genoespécie 3

A. genoespécie $13 T \mathrm{TU}$

Figura 2. Esquema de identificação proposta para as espécies clínicas do complexo ACB. Gel de agarose $0,8 \%$ TAE $1 \mathrm{X}, 100 \mathrm{~V}, 1$ hora. Linha 1 e 5 padrão de 100 pb plus Fermentas, linha 2 - perfil para $A$. genoespécie 3 , linha 3 perfil para $A$. genoespécie $13 T U$ e Linha 4 controle negativo.

\subsection{Perfil das amostras estudadas}

Foram estudadas 515 amostras bacterianas pertencentes ao complexo ACB isoladas de pacientes atendidos pelo Hospital Universitário da Universidade de São Paulo, no período de janeiro de 2005 a dezembro de 2010.

Os isolados bacterianos foram obtidos das seguintes amostras biológicas: secreção traqueal $(39,2 \%)$, urina $(11,8 \%)$, sangue $(9,1 \%)$, lavado brônquico alveolar (5,6\%), prega axilar (5,1\%), secreção de orofaringe $(4,7 \%)$, 
ponta de cateter $(4,5 \%)$, secreção de ferida $(3,1 \%)$, prega inguinal $(1,9 \%)$, e outras amostras (menos de $1 \%$ de representatividade), como: abscesso, secreção purulenta, escara, escarro, celulite, líquido ascítico, osso, secreção abdominal, biópsia, ferimento de coxa, secreção de gastrostomia, queimadura e ouvido.

Dentre os 515 isolados pertencentes ao complexo $A C B$, foi possível observar que $82,5 \%$ (425) pertenciam à espécie $A$. baumannii, $11,5 \%$ (59) à A.genoespécie $13 \mathrm{TU}$ e $6,0 \%$ (31) à $A$. genoespécie 3 . O predomínio de isolamento $A$. baumannii ocorreu independentemente da amostra clínica como mostrado na Figura 3, com exceção dos isolados bacterianos obtidos a partir das três amostras de celulite, que pertenciam a $A$. genoespécie 3 . É possível observar maior percentual de amostras de $A$. genoespécie 3 e $A$. genoespécie 13TU em secreção de orofaringe quando comparado com o percentual de isolados de secreção traqueal $p<0,05$.

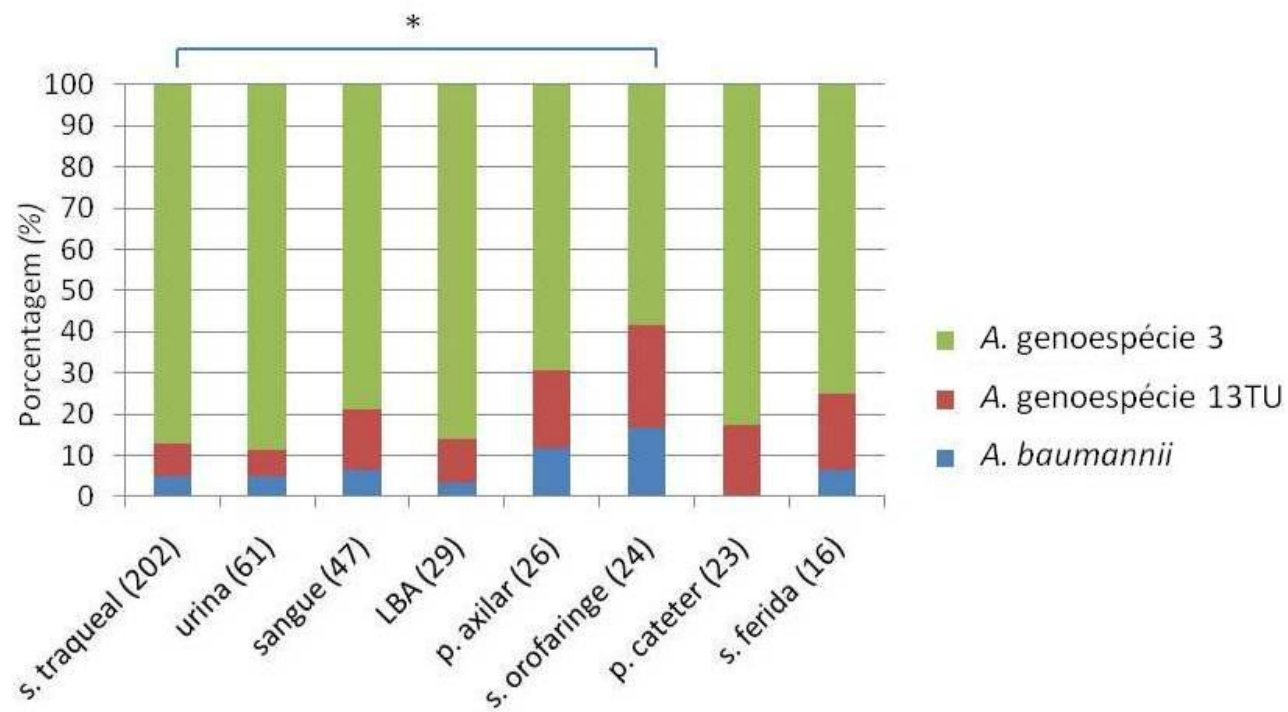

Figura 3. Distribuição das espécies por amostra biológica. * $p<0,05$ ( ) número de amostras biológicas.

Dentre os 515 pacientes atendidos que apresentaram cultura positiva para o complexo ACB, $311(60,15 \%)$ eram pacientes internados em unidades de terapia intensiva (UTI). A distribuição das espécies do complexo, representada na Figura 4, mostra que a espécie $A$ baumannii foi mais isolada 
em pacientes internados em UTI $(p<0,05)$, enquanto A.genoespécie 13TU apresentou maior frequência em pacientes fora de UTI $(p<0,05)$.

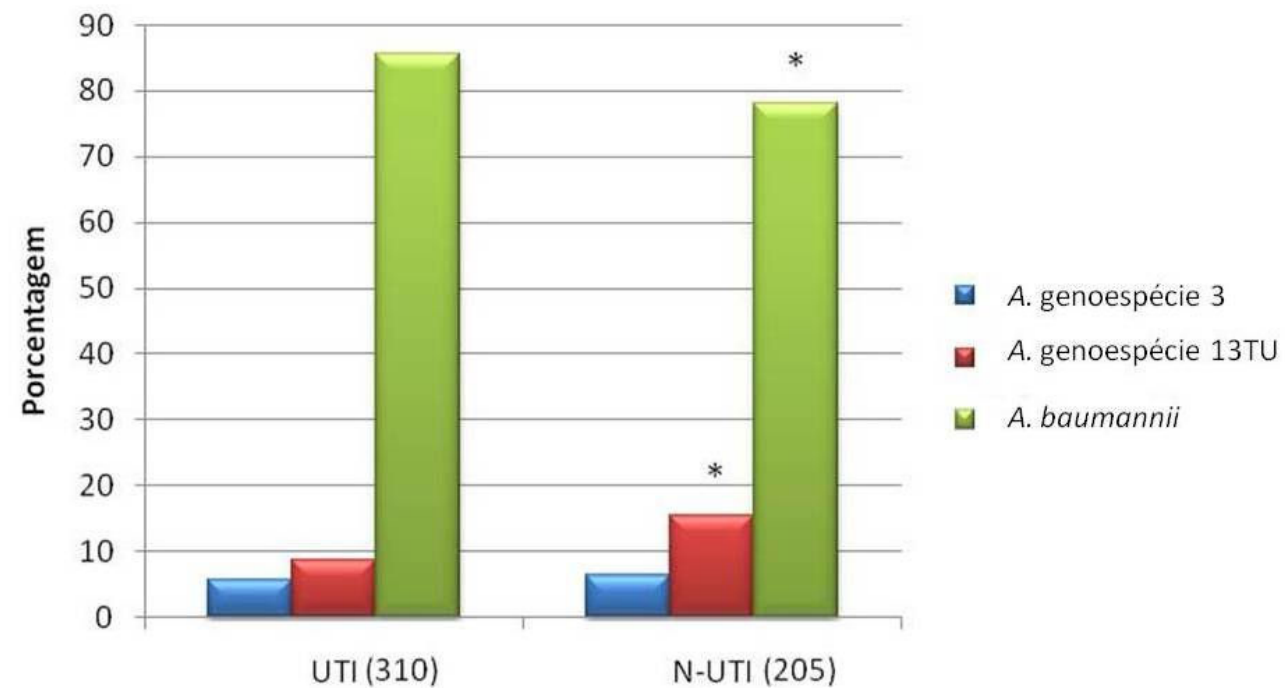

Figura 4. Distribuição das espécies do complexo ACB isoladas de pacientes de UTIs e outros ambientes hospitalares. A. genoespécie 3 não apresentou diferença estatística entre a frequência dentro de UTls e fora desse ambiente hospitalar $(p=0,9554)$. A. baumannii $(p=0.0407)$ e $A$. genoespécie 13TU $(p=0,0204)$. ( ) Número absoluto de isolados bacterianos. * $p<0,05$.

A susceptibilidade aos antimicrobianos foi avaliada por teste de discodifusão no Laboratório de Microbiologia Clínica do Hospital Universitário da USP de acordo com as normas preconizadas pelo CLSI (2010). Foi possível observar que as espécies $A$. genoespécie 3 e $A$. genoespécie 13TU apresentaram-se mais sensíveis a todos os antimicrobianos testados quando comparadas com A. baumannii $(p<0,05)$, dados apresentados na Figura 5. 


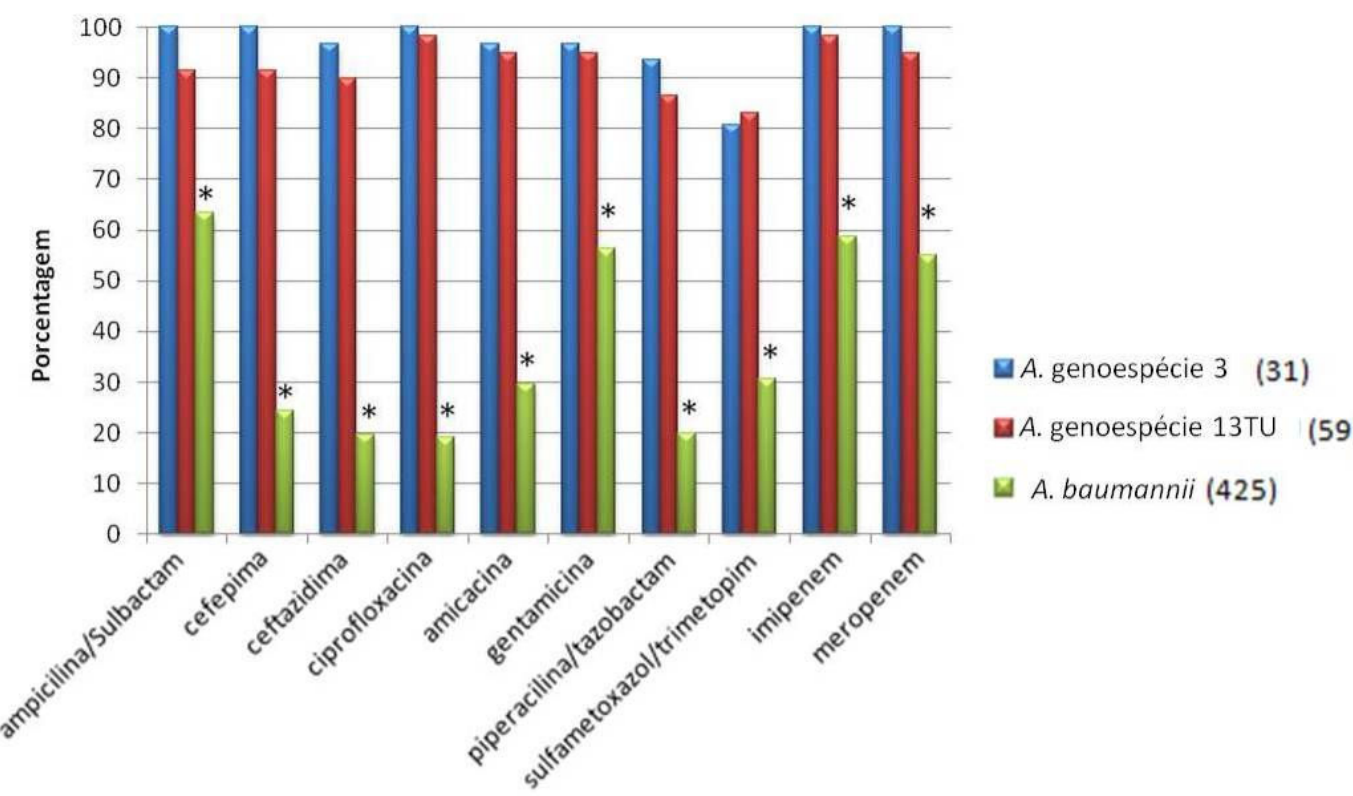

Figura 5. Perfil de sensibilidade das espécies do complexo ACB. ( ) número de isolados de cada espécie bacteriana. ${ }^{*} p<0,05$.

A análise dos perfis de sensibilidade entre isolados de $A$. baumannii de pacientes de UTI e fora desse ambiente hospitalar revelou diferenças significativas para os seguintes antimicrobianos: ampicilina/sulbactam, cefepima, ceftazidima, ciprofloxacina, piperacilina/tazobactam, imipenem e meropenem $(p<0,05)$ como apresentado na Figura 6. 


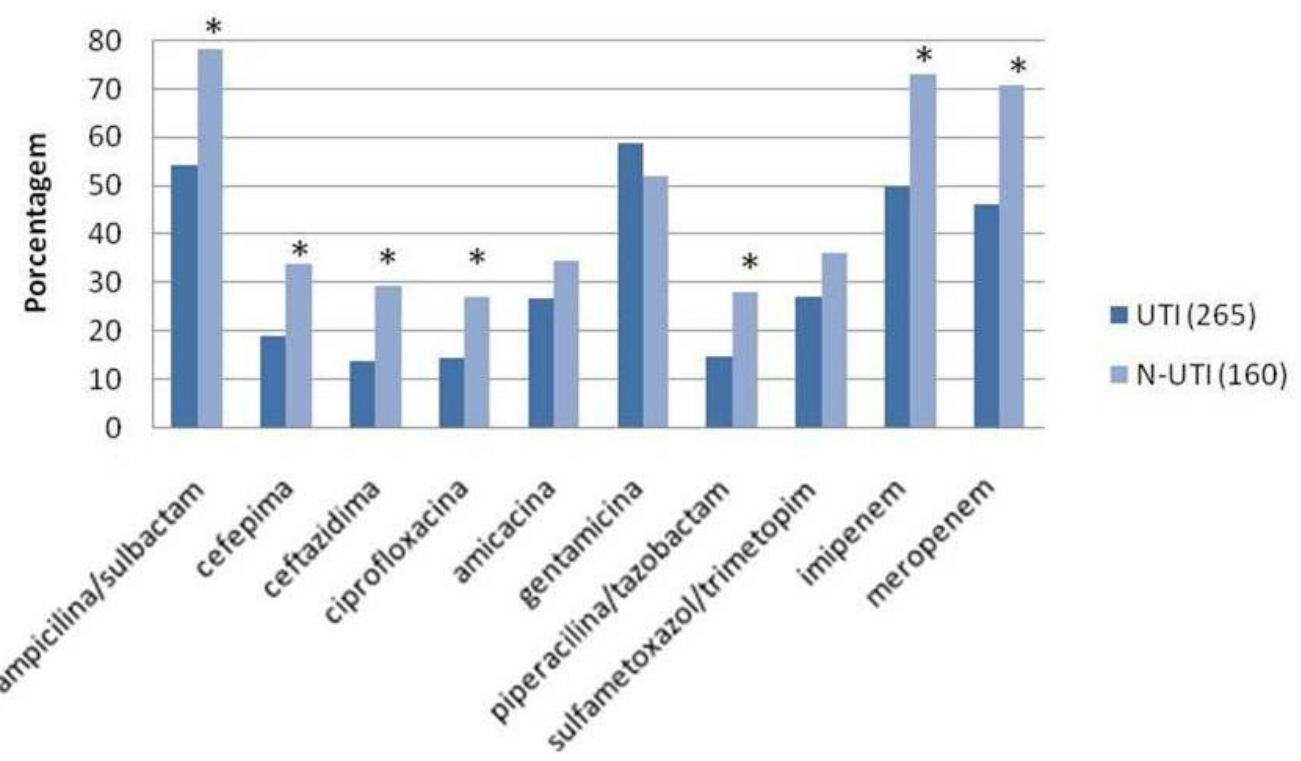

Figura 6. Perfil de sensibilidade de Acinetobacter baumannii isolado de pacientes de UTIs e outros ambientes hospitalares.

( ) número absoluto de isolados. ${ }^{*} p<0,05$

Avaliando o perfil de sensibilidade de $A$. baumannii aos antimicrobianos por ano estudado, foi possível acompanhar a diminuição da sensibilidade aos carbapenêmicos (imipenem e meropenem), acompanhada do aumento da sensibilidade à gentamicina, como apresentado na Figura 7. A partir de 2008, nota-se a associação da diminuição de sensibilidade aos carbapenêmicos e o aumento de sensibilidade à gentamicina sendo estatisticamente significativa entre os isolados bacterianos de pacientes internados em UTI nos anos de 2009 e 2010 ( $p=0.001$ e $p=0.004$, respectivamente). 


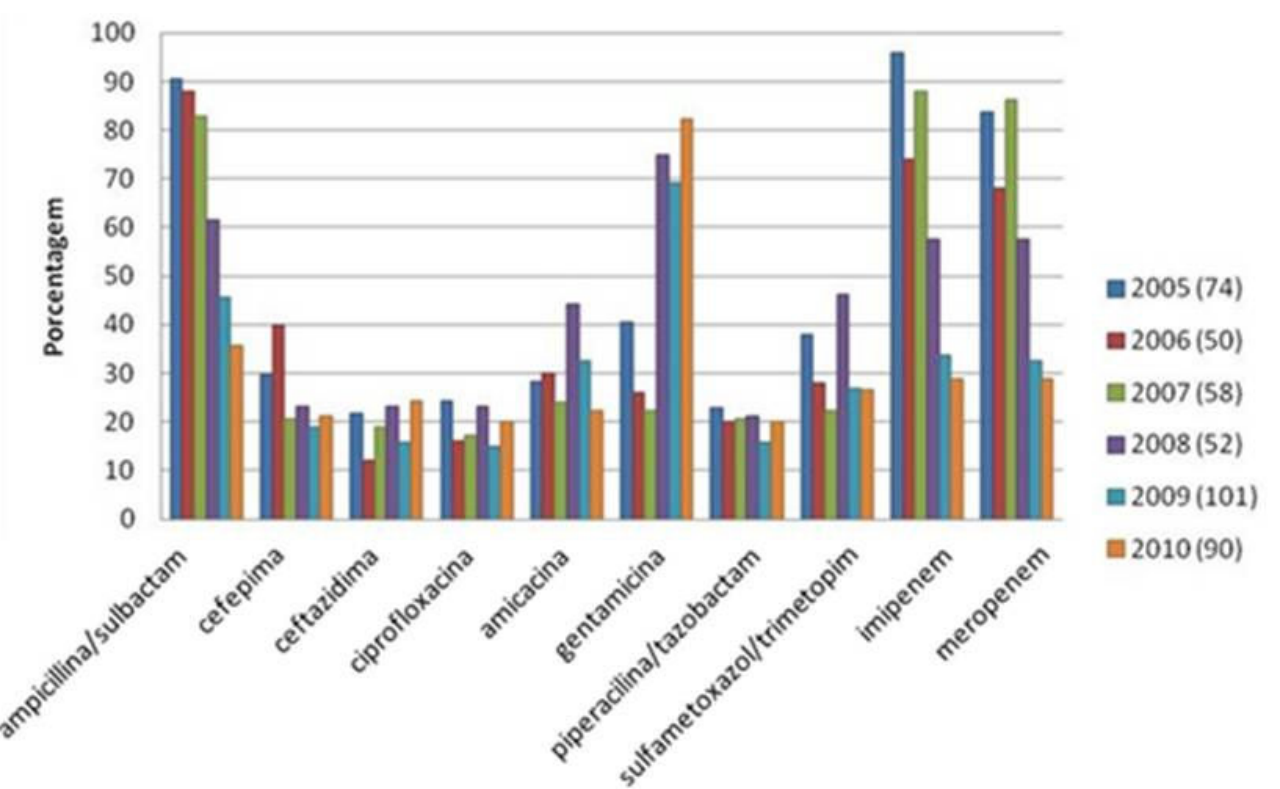

Figura 7. Análise temporal da porcentagem de amostras de $A$. baumannii sensíveis a diferentes antimicrobianos (2005-2010); ( ) - número de isolados.

\subsection{Pesquisa de genes codificadores de carbapenemases}

Dentre os 515 isolados bacterianos estudados, bla oxa-51-like, gene intrínseco para $A$. baumannii, foi detectado em 82,5\% (425). Dentre os isolados resistentes aos carbapenêmicos $41,4 \%$ (176), bla oxa-23-like foi detectado em $81,2 \%$ destes isolados e bla $a_{\text {oxa-24-like }}$ foi encontrado em um único isolado de $A$. baumannii que por análise da sequência de DNA do amplicon obtido para $b_{\text {bxa-24-like }}$ foi confirmado como bla oxA-72. Nenhum dos isolados apresentaram amplificação para bla IMP $_{\text {, bla }}$, bla SIM $_{1}$ bla $a_{\mathrm{GIM}}, b_{\mathrm{SPM}}$, bla $\mathrm{O}_{\mathrm{OXA}-58-\mathrm{like}}$. Neste trabalho não foi pesquisado o gene codificador da enzima OXA-143.

A cepa de $A$. baumannii portadora de bla de 84 anos, sexo masculino, em janeiro de 2009. O paciente esteve internado na clínica médica e desenvolveu infecção do trato urinário relacionada à sondagem vesical. Recebeu tratamento por dez dias com ampicilina-sulbactam e teve alta. Apresentou infecções urinárias de repetição e em outubro de 2009, foi novamente isolado $A$. baumannii com mesmo gene de resistência anteriormente encontrado e mesmo perfil molecular tanto por RAPD, quanto por PFGE. Este dado sugere a persistência deste clone neste paciente. 


\subsection{Tipagem molecular}

\subsubsection{RAPD}

Foram testados nove iniciadores com dez isolados bacterianos do complexo ACB e selecionados aqueles que geraram o maior número de polimorfismos e um padrão de amplificação com bandas reprodutíveis e nítidas, dados apresentados na Tabela 6.

Tabela 6. Iniciadores utilizados para tipagem por RAPD e o resultado de amplificação

\begin{tabular}{|c|c|c|}
\hline Iniciadores & Sequência (5' - 3') & Resultado \\
\hline OPA - 08 & GTGACGTAGG & ++ \\
\hline OPB - 13 & TTCCCCCGCT & ++ \\
\hline OPB $-15^{*}$ & GGAGGGTGTT & ++++ \\
\hline OPB - 20 & GGACCCTTAC & + \\
\hline OPC - 17 & TTCCCCCCAG & ++ \\
\hline OPD $-07^{*}$ & TTGGCACGGG & +++ \\
\hline OPD - 05 & TGAGCGGACA & ++ \\
\hline OPD - $11^{*}$ & AGCGCCATTG & ++++ \\
\hline OPD - $13^{*}$ & GGGGTGACGA & +++ \\
\hline
\end{tabular}

$(++++)$ ótima amplificação e grande número de polimorfismos; (+++) boa amplificação e razoável número de polimorfismos; $(++)$ boa amplificação, mas pequeno número de polimorfismos; (+) pouca amplificação; * iniciadores selecionados.

Os quatro iniciadores escolhidos OPD07, OPD11, OPD 13 E OPB15 geraram 156 polimorfismos e nenhum monomorfismo, dados apresentados na Tabela 7. Esse conjunto de iniciadores originou perfis de RAPD ("fingerprints") que permitiram identificar cada uma das linhagens sob estudo (Figura 8). 
Tabela 7. Iniciadores usados na análise de RAPD e a quantidade de polimorfismos obtidos

\begin{tabular}{cc}
\hline Iniciadores & polimorfismo \\
\hline OPB -15 & 48 \\
OPD -07 & 23 \\
OPD -11 & 50 \\
OPD -13 & 35 \\
\hline Total & 156 \\
\hline
\end{tabular}

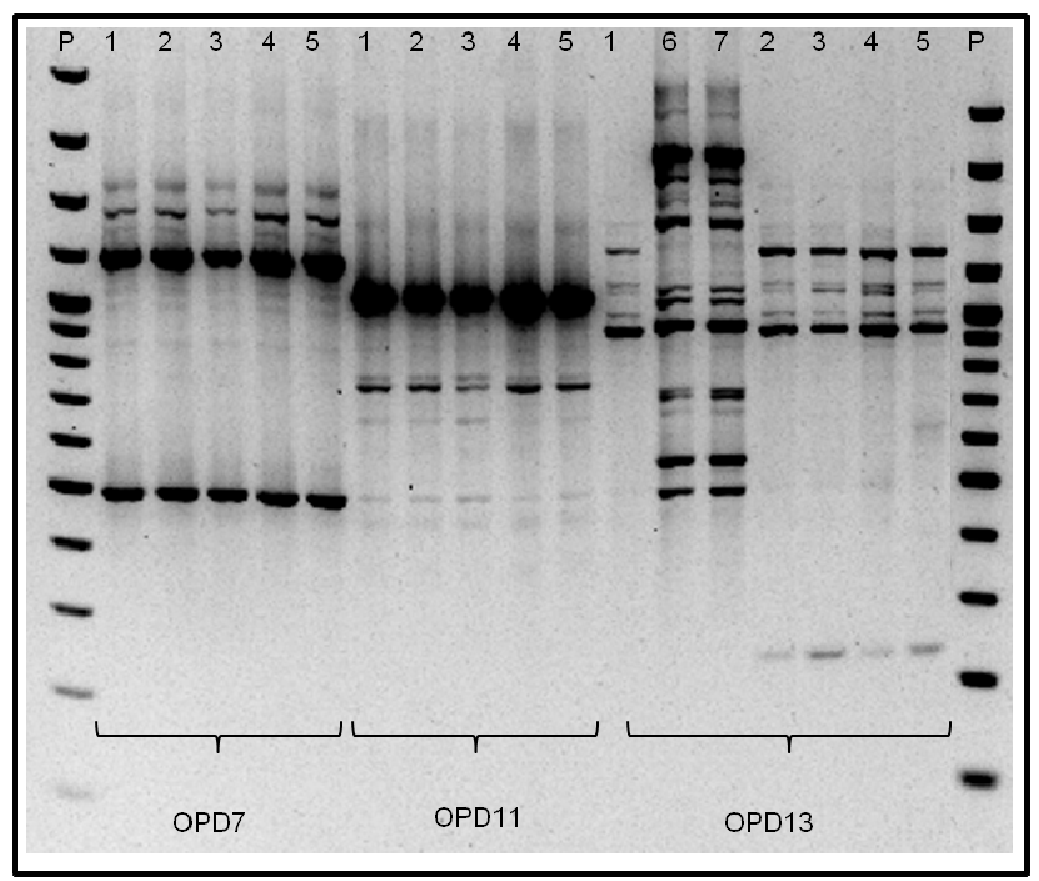

Figura 8. Exemplo do resultado obtido por RAPD. Gel de agarose 1,4\%, TAE 1X, 100V, 2 h. P. padrão de 100 pb plus Fermentas. 1 - 7 amostras de $A$. baumannii

Os polimorfismos foram utilizados para construir a matriz binária de presença e ausência de bandas. Pela matriz e pelo programa NTSYS-pc foram estimados os índices de similaridade (Jaccard e Dice) para todas as amostras bacterianas. 
As matrizes de similaridades obtidas pelos dois índices foram comparadas pelo teste estatístico de Mantel (Figura 9).

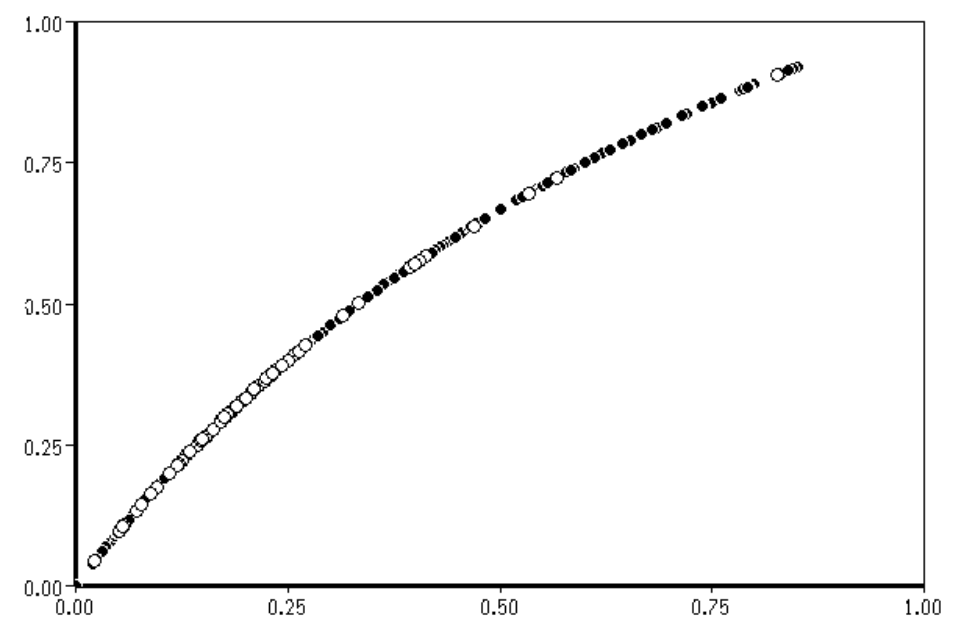

Figura 9. Comparação das matrizes de similaridade de Jaccard e Dice pelo teste de correspondência de matriz de Mantel. Eixo x - índice de Jaccard; eixo y - índice de Dice; $(r=0,98557)$

Este teste mostrou que as matrizes geradas pelos coeficientes de Jaccard e Dice foram correlacionadas ( $r=0,98557)$. Os dois índices utilizados apresentaram alta correlação.

A análise dos grupos e a construção do dendrograma foram realizadas pelo programa Bionumerics (Applied Maths, Sint-Martens-Latem, Bélgica), utilizando Dice, como coeficiente de similaridade.

O dendrograma obtido por RAPD para os 515 isolados não foi capaz de agrupar cepas pertencentes a uma mesma espécie e revelou diversidade entre as amostras (dados não mostrados). Analisando os resultados da tipagem molecular obtida com amostras de $A$. baumannii isoladas de pacientes de UTI e fora desse ambiente (N-UTI), foi possível observar menor diversidade entre os isolados de pacientes de UTI e a formação de agrupamentos compostos apenas por isolados obtidos em determinado período, como os agrupamentos destacados em amarelo, compostos apenas por isolados bacterianos obtidos no ano de 2008 e os destacados em verde isolados bacterianos obtidos nos anos de 2009 e 2010, o que não foi observado entre bactérias isoladas em anos anteriores. (Figura 10) 


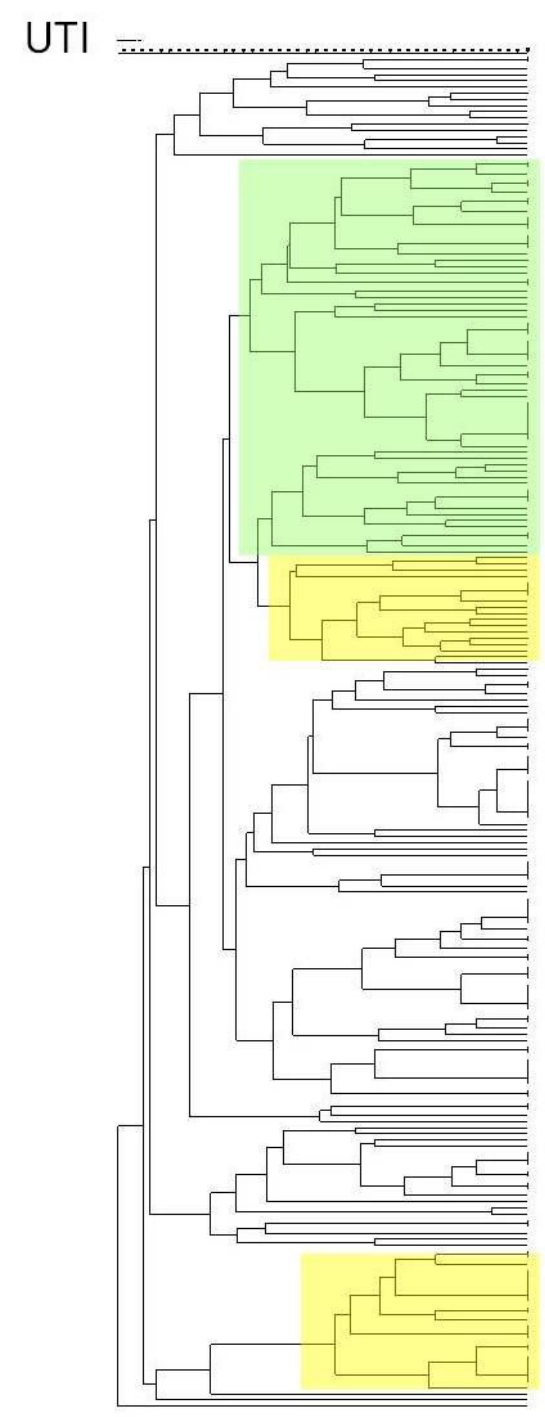

$\mathrm{N}-\mathrm{UTI}$

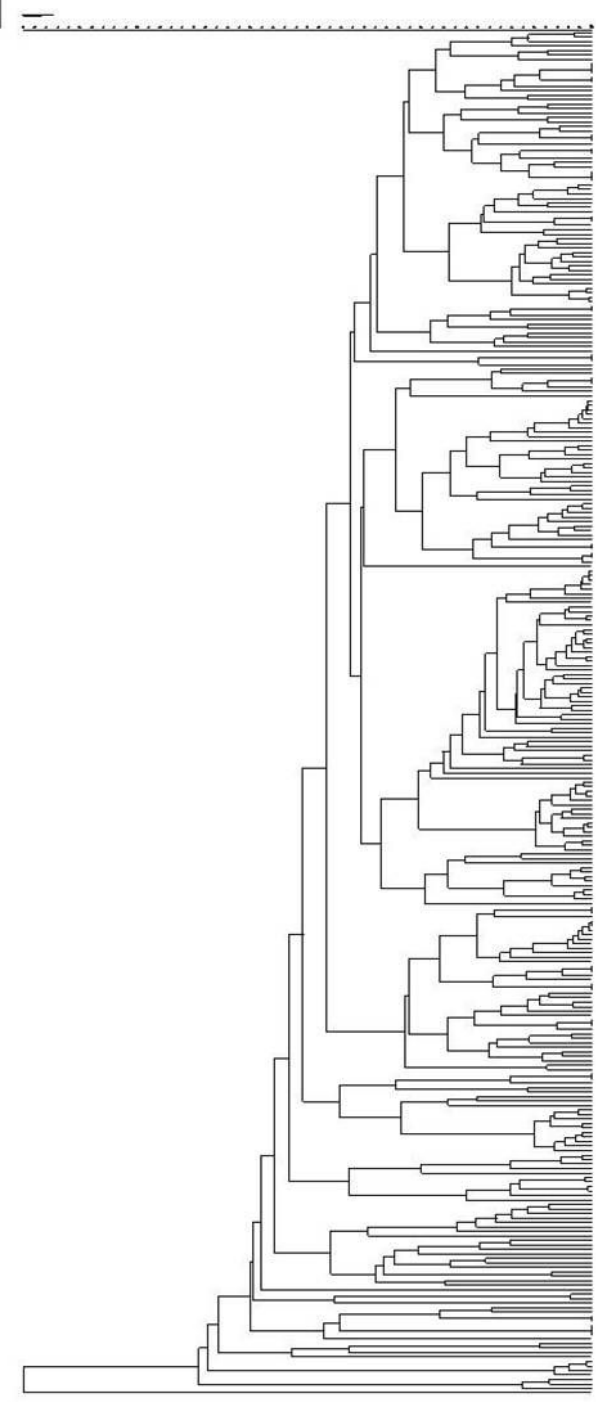

Figura 10 Dendrograma obtido por análise dos polimorfismos obtidos por RAPD dos 425 isolados de A. baumannii. Método de UPGMA, coeficiente de similaridade Dice. Dendrograma de isolados de pacientes internados em UTI e fora desse ambiente hospitalar (NUTI). Agrupamentos destacados em amarelo compostos exclusivamente, por isolados do ano de 2008. Agrupamentos destacados em verde, compostos por isolados dos anos de 2009 e 2010.

Nos dendrogramas obtidos para as espécies $A$. genoespécie 3 e $A$. genoespécie 13TU, apresentados na Figura 11, não foi possível observar agrupamentos formados por isolados de um determinado período ou tipo de amostra biológica. Observa-se diversidade entre os isolados de cada espécie A. genoespécie 13TU e A. genoespécie 3 . 
A. genoespécie 13TU

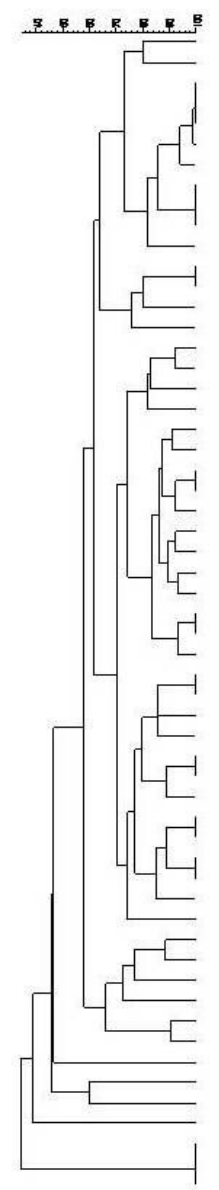

A. genoespécie 3

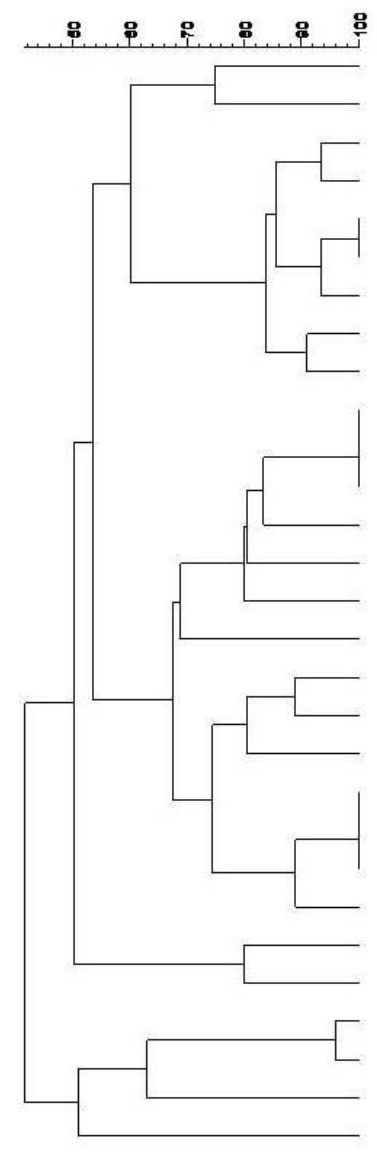

Figura 11. Dendrograma gerado pela análise dos polimorfismos obtidos por RAPD dos 59 isolados de $A$. genoespecie 13TU e 31 isolados de $A$. genoespécie 3 estudados. Método de UPGMA, utilizando o coeficiente de similaridade Dice.

\subsubsection{Tipagem por PFGE}

Avaliando visualmente os resultados obtidos pela tipagem molecular realizada por PFGE para os 176 isolados resistentes aos carbapenêmicos pelo critério de Ternover (1995) obteve-se 25 perfis diferentes distribuídos em três clusters principais, sendo que dois destes compreendem mais de $95 \%$ dos isolados analisados, apresentado na Figura 12. Além disso, nota-se que os agrupamentos A1 e C são formados por isolados que não apresentaram amplificação para bla OXA-23. Quando comparado com o dendrograma obtido por RAPD apenas para os isolados resistentes aos carbapenêmicos nota-se a maior capacidade discriminatória desta técnica, apresentando mais agrupamentos que os encontrados no dendrograma obtido por PFGE, além de 
mudanças quanto ao agrupamento de alguns isolados.Considerando que as cepas com similaridade maior que $80 \%$ são relacionadas entre si (SINGH et al., 2006) observa-se seis agrupamentos, revelando a disseminação do gene blaoxA23 em $A$. baumannii, não sendo o fenótipo de resistência aos carbapenêmicos relacionado a um único agrupamento clonal.

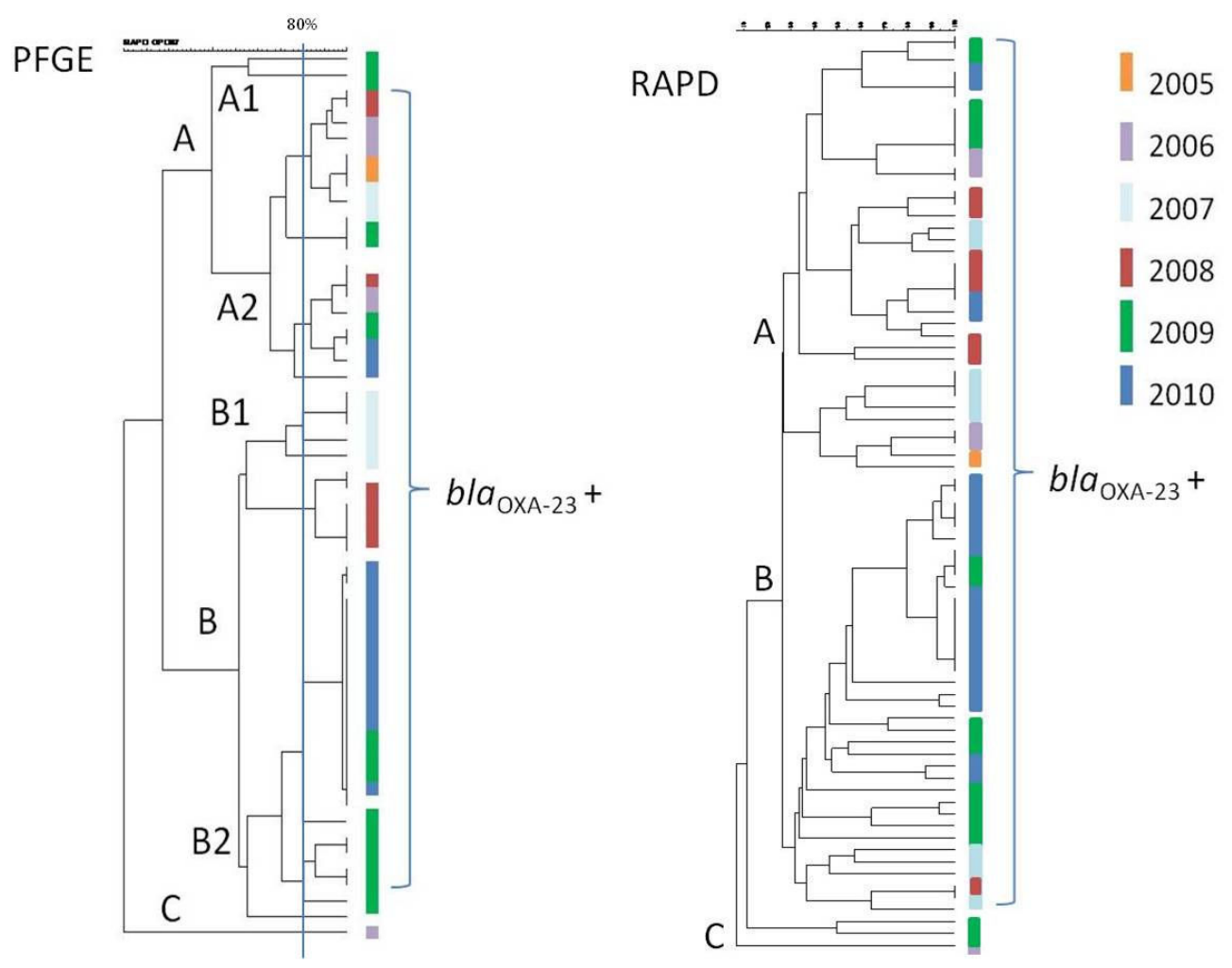

Figura 12. Dendrograma obtido por RAPD e PFGE para isolados de $A$. baumannii resistentes aos carbapenêmicos. UPGMA, coeficiente de Dice. A linha traçada no dendrograma obtido por PFGE indica a similaridade de $80 \%$.

\subsection{Pesquisa de acil-homoserina lactonas}

A produção de acil-homoserina lactonas (AHL) foi avaliada utilizando o bioensaio com a cepa Chromobacterium violaceum CV026 a partir da indução ou inibição do pigmento violaceína. Foram realizados cultivos em diferentes meios de cultura - TSB, LB e BHI - para verificar em qual meio a expressão de AHL seria maior e também dois solventes - diclorometano e acetato de etila foram empregados para realizar a extração orgânica de $\mathrm{AHL}$ dos sobrenadantes livre de células. 
Nenhum ensaio fenotípico quando se utilizou os extratos dos sobrenadantes de Acinetobacter sp.foram positivos para a produção ou inibição de violaceína utilizando a cepa biosensora CV026. Enquanto o extrato do sobrenadante do controle positivo - $P$. aeruginosa ATCC 27853 - foi positivo em ambos os ensaios.

Dados obtidos pela análise do extrato orgânico do sobrenadante livre de células de uma cultura de $A$. baumannii em caldo LB por cromatografia líquida com detector de espectrômetro de massa (LC-MS íontrap), revelaram um pico característico do anel principal da estrutura de acil-homoserina lactona que apresenta a relação massa carga $\mathrm{m} / \mathrm{z}$ 102. Realizou-se a pesquisa de íons que geraram m/z 102 na fragmentação e com base nos compostos já conhecidos e foi possível encontrar íons compatíveis com: AHL-C14, AHL-3-oxo-C14 e AHLC10 (Figura 13). Niu e colaboradores (2008) descreveram a identificação de AHL-C14 e AHL-C10 em extratos orgânicos de sobrenandante de cultura de $A$. baumannii, além de outras possíveis estruturas como AHL-3-OH-C12, AHLC12, AHL-3-oxo-C13 e AHL-C16. Estes dados precisam ser confirmados por análise em equipamento LC-MS íon quadrupolo que permitirá confirmar a presença e realizar um estudo mais adequado quanto à estrutura molecular desses autoindutores. 

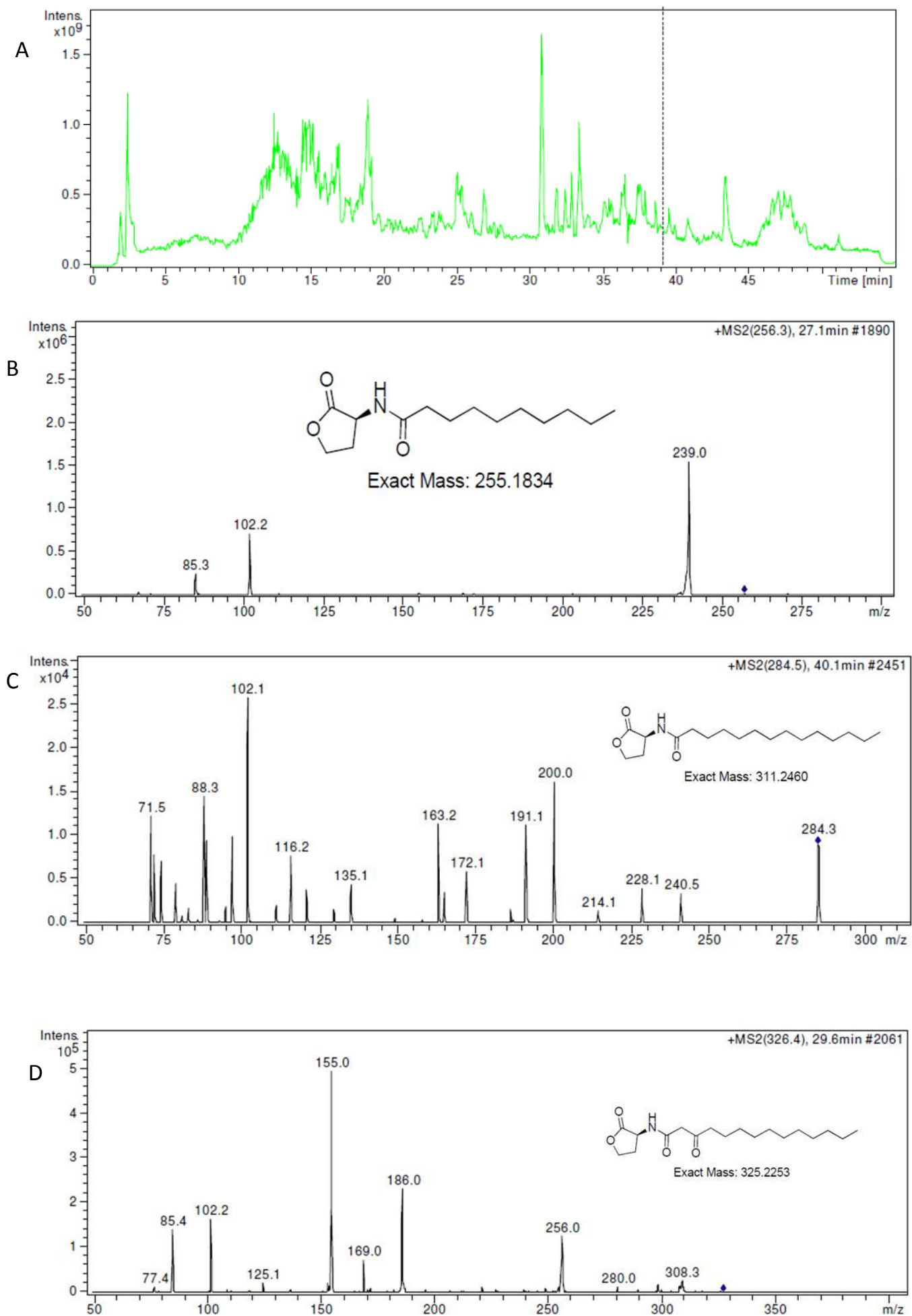

Figura 13. A - Cromatograma obtido a partir do extrato orgânico do sobrenadante livre de células de Acinetobacter baumannii. B - Espectro MS/MS m/z 256 - possivelmente AHL-C10. C - Espectro MS/MS m/z 284 - possivelmente AHL-C14. D- Espectro MS/MS m/z 326 possivelmente AHL-3-oxo-C14 


\subsection{Pesquisa de autoindutor-2}

Na pesquisa realizada utilizando $V$. harveyi BB170, nenhum dos meios pré-condicionados avaliados foi capaz de induzir bioluminescência na biossensora, independente do tempo de incubação da cepa sensora com o meio pré-condicionado. Como controle positivo foi utilizado meio précondicionado por E. coli O157:H7.

\subsection{Pesquisa de autoindutor-3}

Foi possível observar a maior presença do autoindutor-3, pela atividade de $\beta$-galactosidase em meios pré-condicionados obtidos das espécies $A$.13TU e $A$. baumannii em relação $A$ genoespécie. 3 . $(p<0,05)$ como apresentado na Figura 13. Na presença de propanolol, houve completa inibição da atividade de $\beta$-galactosidase, revelando a especificidade da atividade enzimática com a presença do autoindutor-3 (Figura 14).

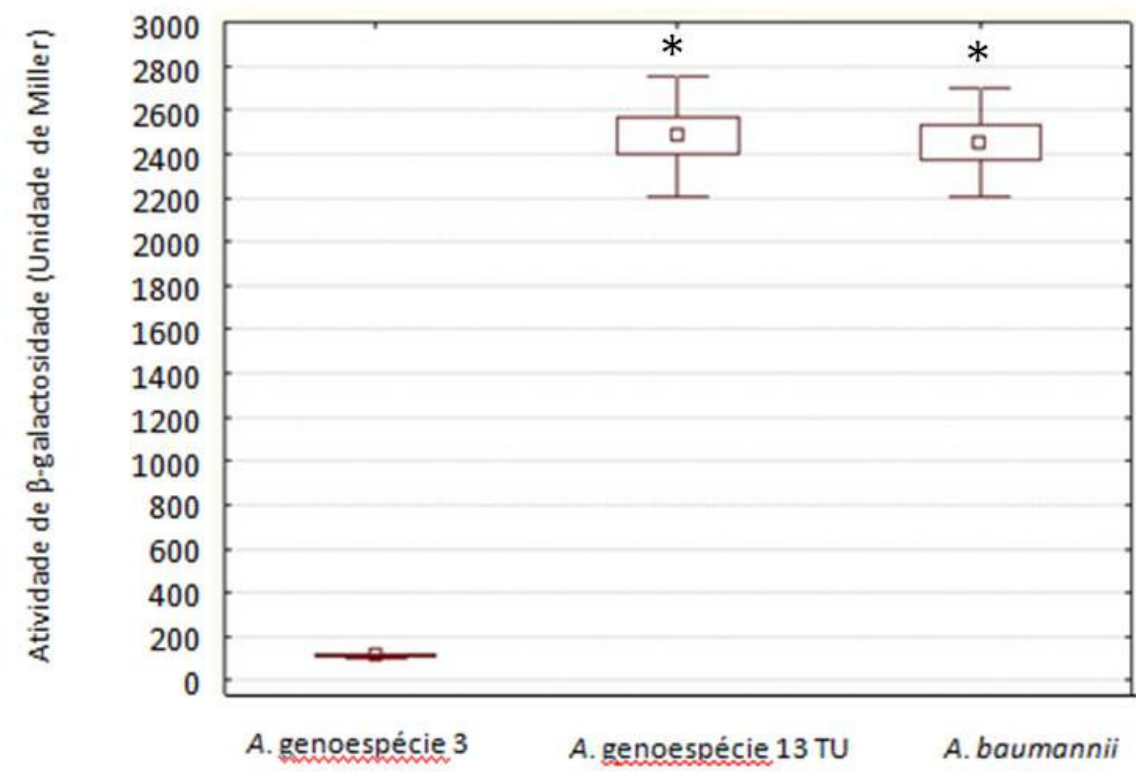

Figura 14. Atividade da $\beta$-galactosidade da cepa biosensora Escherichia coli TEVS 232 cultivada em meios pré-condicionados por cepas de $A$. genoespécie $3, A$. genoespécie 13TU e A. baumannii 


\subsection{Ensaio de adesão bacteriana em células eucarióticas}

Foi padronizado o ensaio de adesão em monocamadas de cultura de células MRC-5, HEp-2 e NCl-H292. Os ensaios foram realizados em duplicata e utilizando três cepas da mesma espécie não pertencentes ao mesmo clone, dado obtido pela técnica de RAPD. O tempo de contato da célula bacteriana com a monocamada de células eucarióticas foi de seis horas. Nenhuma das cepas avaliadas foi capaz de aderir às células HEp-2. Em células MRC-5 todas as amostras de $A$. baumannii aderiram apresentando padrão difuso, assim como A.genoespécie 3 e A.genoespécie 13TU. Porém, essas duas últimas apresentaram menos células bacterianas aderidas por campo observado (Figura 15). Já com ensaio de adesão em linhagem celular NCl-H292, pode-se observar características diferentes de adesão entre as espécies, A.genoespécie 3 não é capaz de aderir, enquanto $A$. baumannii adere difusamente e $A$. genoespécie 13TU apresenta-se agrupada (Figura 16). 


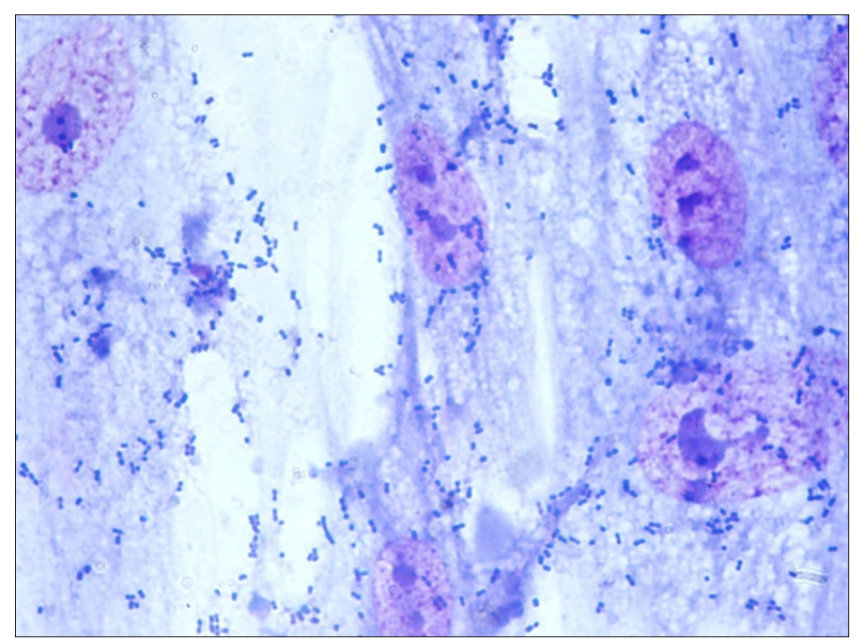

A. baumannii

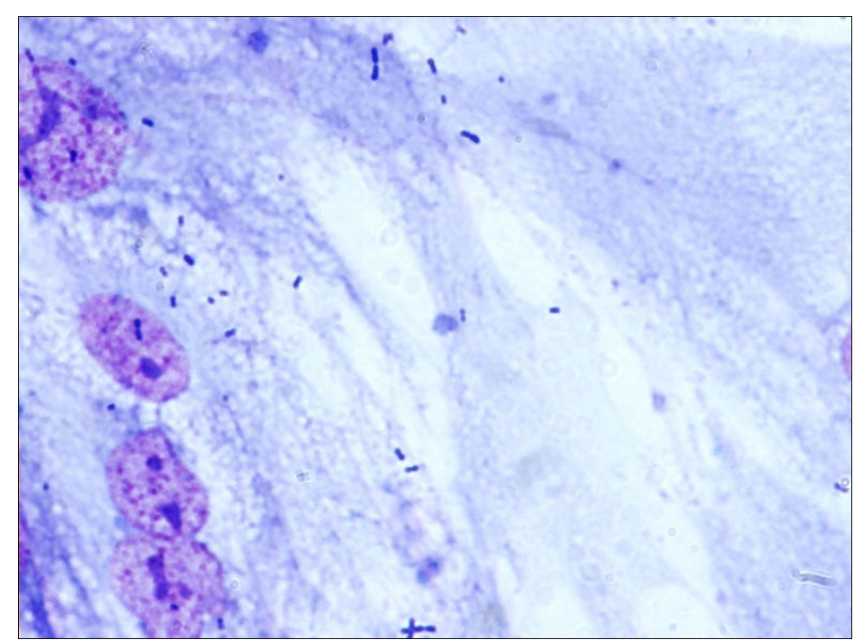

A. genoespécie 3

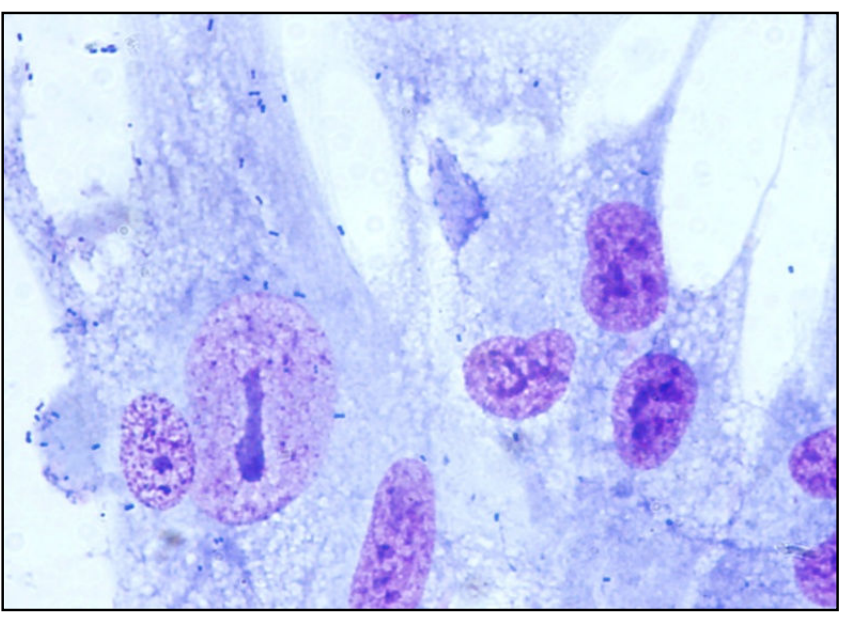

A. genoespécie 13TU

Figura 15. Ensaio de adesão bacteriana em células MRC-5 por 6 horas de incubação, $37^{\circ} \mathrm{C}$, $5 \% \mathrm{CO}_{2}$. (microscópio óptico 1000x). 


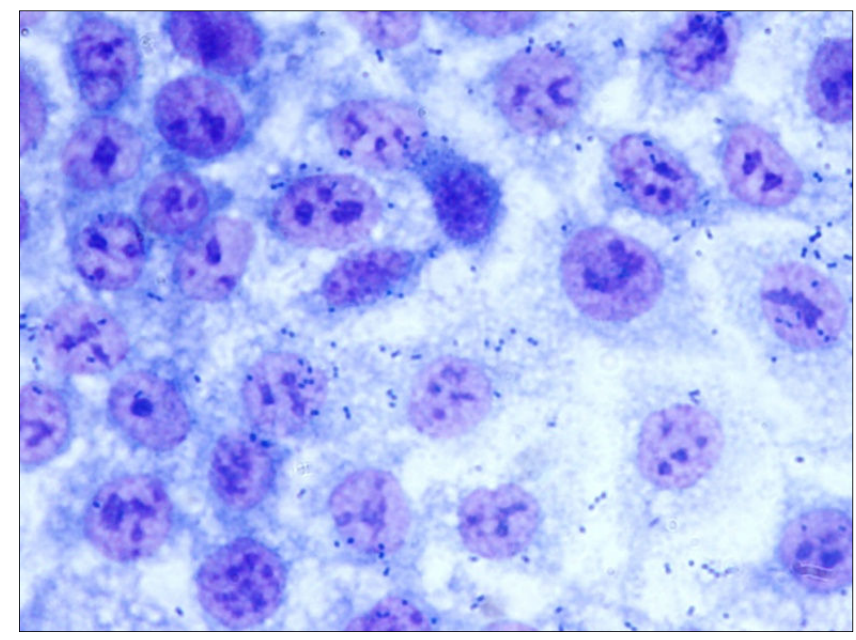

\section{A. baumannii}

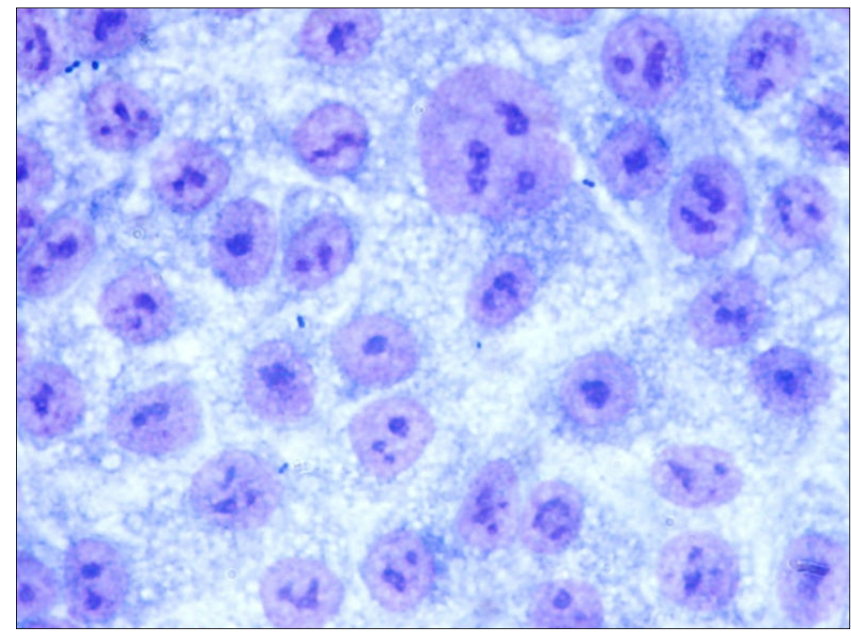

A. genoespécie 3

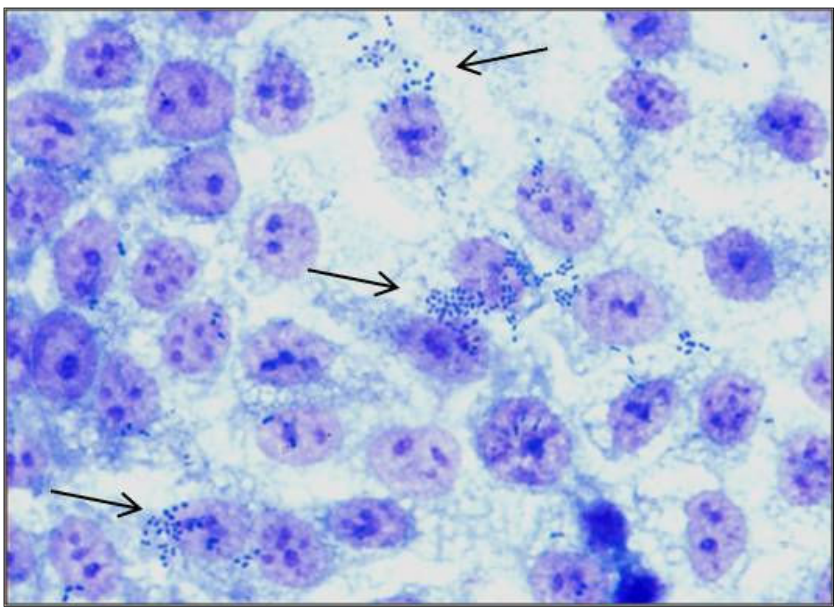

A. genoespécie13TU

Figura 16. Ensaio de adesão bacteriana em células $\mathrm{NCl}-\mathrm{H} 292$ por 6 horas de incubação, $37^{\circ} \mathrm{C}$, $5 \% \mathrm{CO}_{2}$. $A$. genoespécie 3 não é capaz de aderir, enquanto $A$. baumannii adere difusamente e A. genoespécie 13TU apresenta-se em agrupados, "clusters" sinalizado pelas setas (microscópio óptico 1000x). 
Visto que os ensaios de adesão utilizando as células $\mathrm{NCl}-\mathrm{H} 292$ apresentaram melhores resultados para a caracterização das espécies do

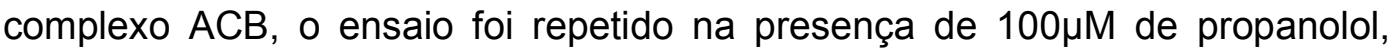
buscando avaliar a possível interferência no mecanismo de adesão.

Foi possível observar a diminuição da adesão bacteriana pelas espécies de $A$. baumannii e $A$. genoespécie $13 \mathrm{TU}$ na presença de $100 \mu \mathrm{M}$ de propanolol. Enquanto, para A.genoespécie 3 não houve diferenças na adesão com ou sem propanolol (Figura 17). 
ausência de propanolol
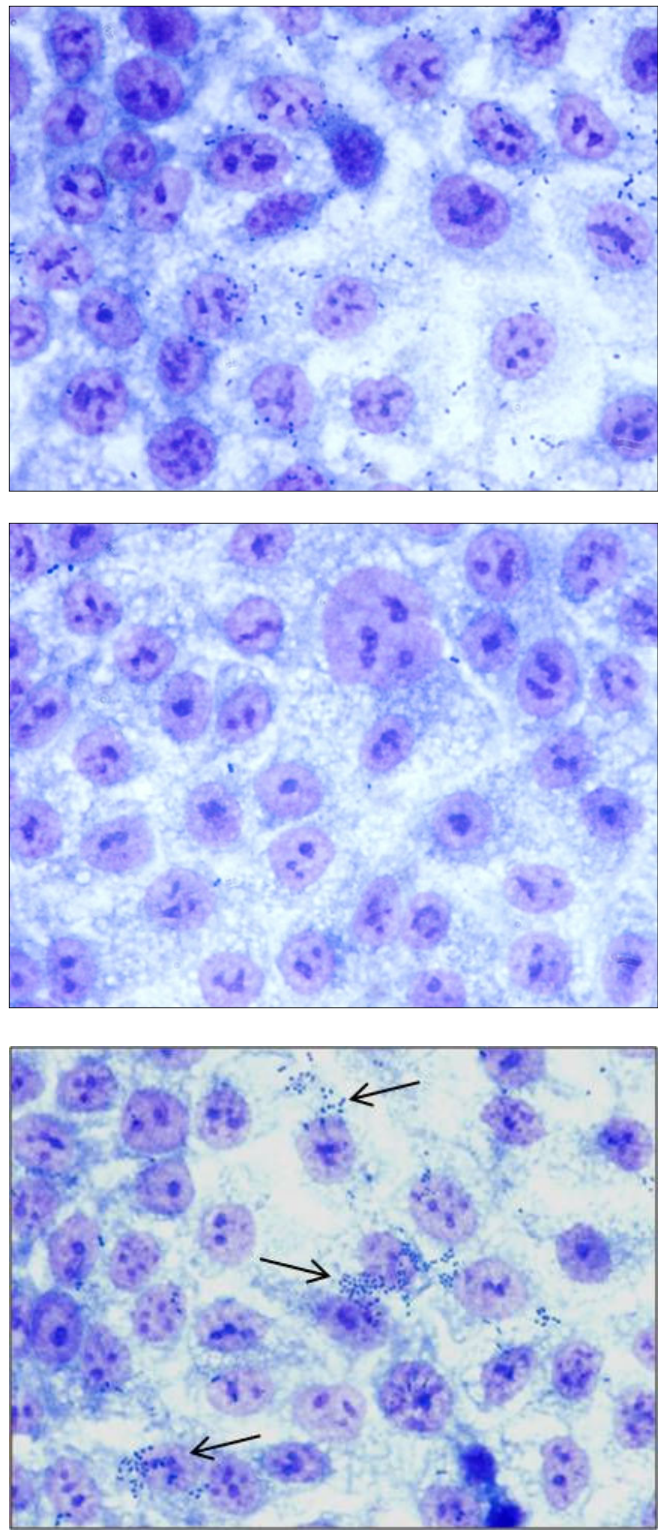

Figura 17. Ensaio de adesão em células $\mathrm{NCl}-\mathrm{H} 292$ por 6 horas de incubação, $37^{\circ} \mathrm{C}, 5 \% \mathrm{CO}_{2}$; Ensaio sem ou com propanolol. (microscópio óptico 1000X). Setas indicam a formação de agrupados bacterianos
$100 \mu \mathrm{M}$ propanol

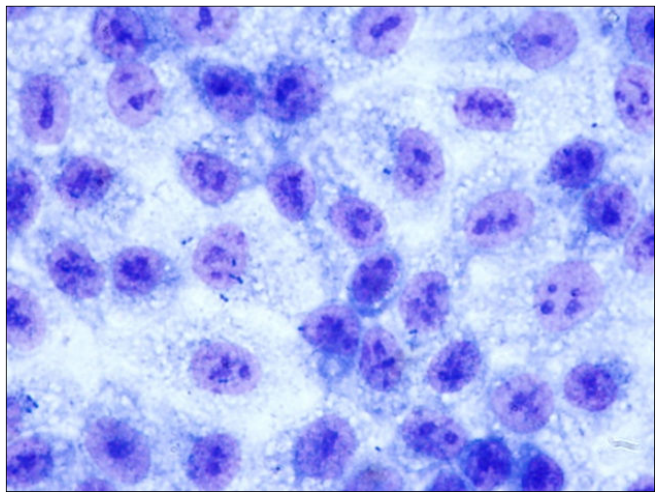

A. baumannii

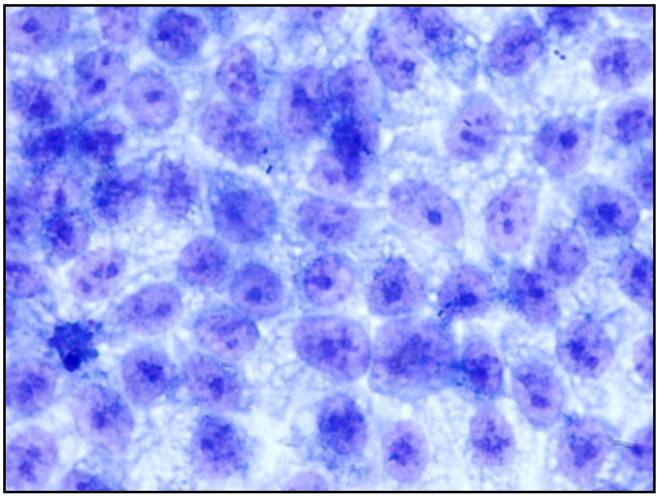

A. genoespécie 3

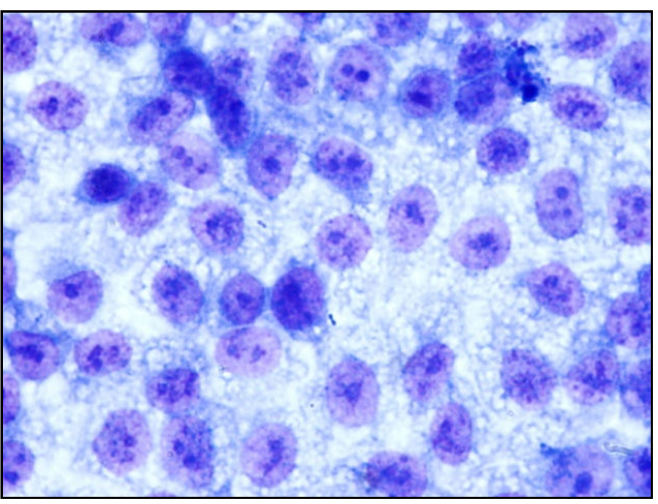

A. genoespécie 13TU 


\subsection{Avaliação da produção de biofilme}

O resultado do ensaio de biofilme, representado na Figura 18, revelou maior produção por $A$. baumannii, quando comparado com $A$.genoespécie 3 $(p<0.05)$. A produção de biofilme por $A$. genoespécie 13TU não apresentou diferença estatística quando comparado a $A$. baumannii ou $A$ genoespécie. 3 $(p>0,05)$. Já quando realizado o ensaio na presença de $100 \mu \mathrm{M}$ de fentolamina notou-se a diminuição significativa na produção do biofilme por $A$. baumannii $(p<0.05)$.

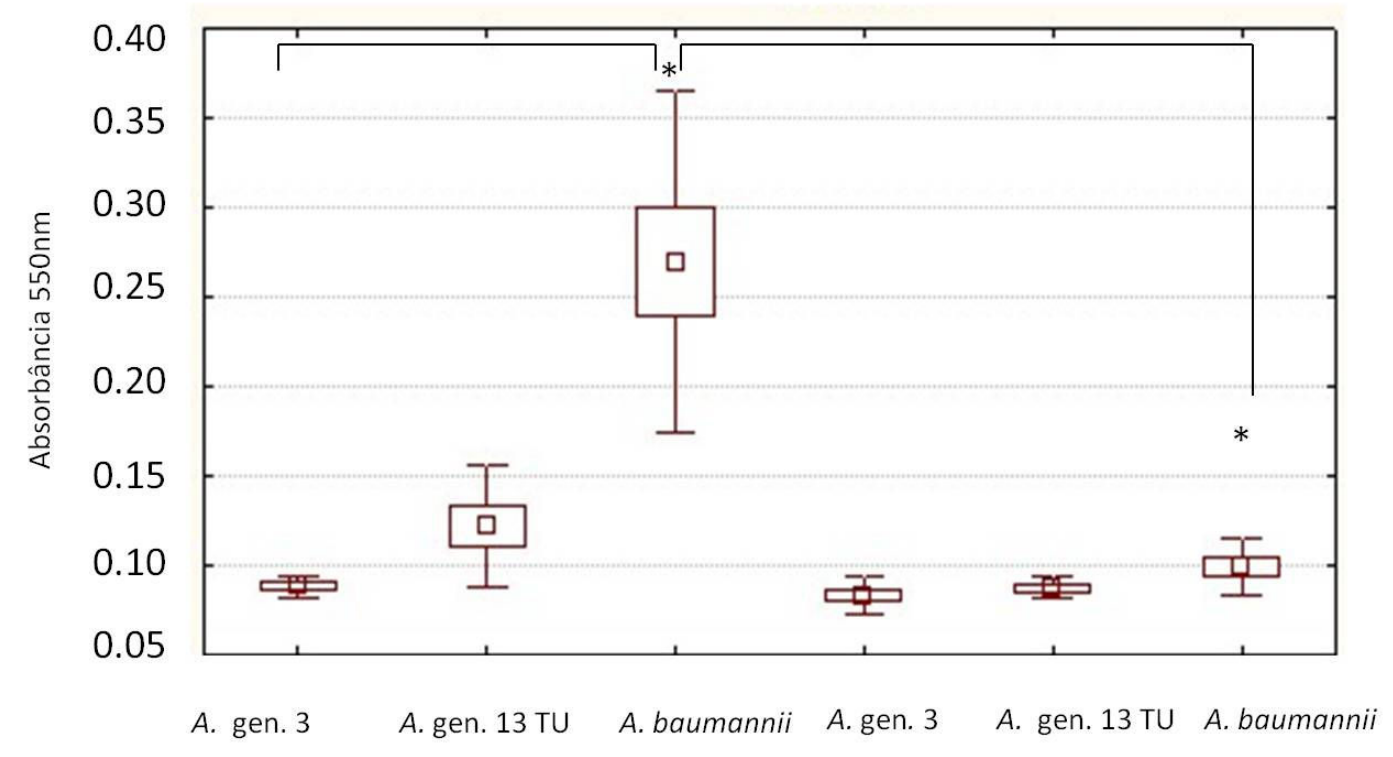

Ausência de fentolamina

100uM fentolamina

Figura 18. Produção de biofilme por amostras de $A$. baumannii, $A$. genoespécie 13 TU e $A$. genoespécie 3 na presença e ausência de fentolamina Ensaio realizado em caldo LB na presença e ausência de $100 \mu \mathrm{M}$ fentolamina. Tempo de incubação 24 horas. * $p<0,05$. 


\section{DISCUSSÃO}

O gênero Acinetobacter é composto por patógenos oportunistas que acomete principalmente imunocomprometidos e pacientes com prolongado período de internação hospitalar (JOLY-GUILOU, 2005). Apesar de ser um micro-organismo que apresenta pouca virulência, tornou-se um problema para muitos hospitais devido a sua resistência intrínseca a vários antimicrobianos, assim como a sua facilidade em acumular mecanismos de resistência e sua habilidade em sobreviver por longos períodos em superfícies inanimadas (JOYGUILOU, 2005). Deste modo, a vigilância deste patógeno tornou-se uma necessidade e a combinação de esforços de equipes multidisciplinares locais, nacionais e internacionais se fez necessário (PELEG et al., 2008).

As principais infecções relacionadas ao gênero Acinetobacter, como agente etiológico, são principalmente pneumonias relacionadas à ventilação mecânica, infecções de feridas causadas por queimaduras, bacteremias, infecções do trato urinário, em pacientes em UTI (BERGONE-BÉRÉZIN \& TOWNER, 1996; DIJKSHOORN et al., 2007; PELEG et al., 2008).

As espécie bacterianas de maior relevância clínica são $A$. baumannii, $A$. genoespécie 3 e $A$. genoespécie 13TU (DIJKSHOORN et al., 2007; PELEG et al., 2008). Essas espécies, juntamente com a espécie ambiental $A$. calcoaceticus, são intimamente relacionadas, sendo difícil de distinguir, uma das outras, por características fenotípicas. Em 1992, foi proposto o agrupamento dessas espécies no complexo Acinetobacter calcoaceticusAcinetobacter baumannii (GERNER-SMIDT et al., 1991; GERNER-SMIDT, 1992).

A nomenclatura do complexo A. calcoaceticus-A. baumannii pode ser enganosa e não adequada quando utilizada no contexto clínico, pelo fato do nome de uma espécie bacteriana, de origem ambiental, estar presente no nome do complexo (PELEG et al., 2008). Talvez este tenha sido o motivo pelo qual, muitos pesquisadores e laboratórios ignoram o termo complexo ACB e passaram a denominar os isolados deste complexo apenas por $A$. baumannii, sendo, provavelmente, a principal causa de diferenças, e por vezes, contradições em pesquisas científicas a respeito da similaridade genética, 
estudos epidemiológicos e caracterização de mecanismos de resistência associados a esta espécie.

Inicialmente, foram analisadas as sequências da região intergênica 16S$23 S$ rRNA de dez cepas bacterianas do complexo ACB, sendo seis portadoras do gene blaxa-51. As dez sequências foram comparadas com o banco de dados GenBank, utilizando-se a ferramenta BLAST (ALTSCHUL et al., 1990) e avaliadas quanto a presença de polimorfismos. Foi possível desenhar um iniciador específico para a espécie $A$.genoespécie 3 .

Neste estudo, a identificação genotípica das espécies do complexo ACB revelou predomínio de $A$. baumannii $82,5 \%$ (425), seguido por $A$. genoespécie 13TU, identificada em $11,5 \%$ (59) e $A$. genoespécie $36,0 \%$ (31) dos 515 isolados pertencentes ao complexo ACB. Um dos primeiros relatos da distribuição das espécies bacterianas, por hibridação DNA-DNA, do gênero Acinetobacter, isoladas de amostras biológicas de humanos, foi realizada na Suécia e revelou $A$. genoespécie 3 como a espécie predominante (TJERBERG \& URSING, 1989). Em 1993, na Dinamarca, foi relatado a distribuição homogênea das espécies $A$. baumannii, $A$. genoespécie 3 e $A$. genoespécie 13TU, também identificadas por hibridação DNA-DNA (GERNER-SMIDT \& TJERBERG,1993), enquanto outros estudos descrevem o predomínio de $A$. baumannii na Bélgica pela técnica de SDS-PAGE, na Alemanha e na Holanda por testes fenotípicos (DIJKSHOORN et al., 1993; SEIFERT et al., 1993; STRUELENS et al.,1993).

Outros estudos descrevem o predomínio de A. baumannii amostras biológicas como na Alemanha (SEIFERT et al., 1994), Estados Unidos (WISPLINGHOFF et al., 2000; HUJER et al., 2006), Coréia (LEE et al., 2007; LIM et al., 2007) e França (GUNDI et al., 2009; DONNARUMMA et al., 2010). Entretanto, há relatos na Irlanda (HORREVORTS et al., 1995) e em Hong Kong (CHU et al., 1999) que descrevem a maior frequência de $A$. genoespécie 3 entre os isolados bacterianos avaliados.

No presente estudo, $A$. genoespécie 13TU foi a segunda espécie mais frequente, assim como nos estudos de Lee e colaboradores (2007) com 25,8\% 
das 232 amostras de Acinetobacter sp. e de Lim e colaboradores (2007), com $15,5 \%$ das amostras de um total de 58 obtidas de hospitais coreanos.

A espécie $A$. genoespécie 3 foi a menos frequente entre os 515 isolados pertencentes ao complexo $\mathrm{ACB}$. Diferentes estudos mostraram $A$ genoespécie. 3 como a segunda espécie mais frequente entre amostras clínicas, cuja frequência variou de 5,6\% a 27,5\% (DONNARUMMA et al., 2010; GUNDI et al., 2009; SEIFERT et al., 1993).

Até o momento, não há uma proposta simples e de baixo custo para a identificação das três espécies de relevância clínica, que compõem o complexo ACB e que, simultaneamente, possibilitaria a pesquisa de genes codificadores de enzimas do tipo OXA, mecanismo de resistência aos carbapenêmicos mais frequente em bactérias do gênero Acinetobacter.

Atualmente, a identificação das espécies clínicas do complexo ACB é trabalhosa e de custo elevado (Hibridação DNA-DNA) ou de baixa acurácia (fenotípica). Com a nossa proposta, a identificação das espécies do complexo ACB é realizada utilizando-se um esquema composto de duas PCRs. A primeira é uma PCR multiplex capaz de identificar os quatro subgrupos de genes que codificam oxacilinases bla OXA-23-like, bla OXA-24-like, bla OXA-51-like, b/aOXA-58like descrita por Woodford e colaboradores (2006), sendo possível a identificação de A. baumannii com a detecção do gene bla OXA-51-like, que é intrínseco à espécie. A segunda $\mathrm{PCR}$ é composta de três conjuntos de iniciadores, um deles tem como alvo a heterogeneidade da subunidade $B$ da girase (HIGGINS et al., 2007) para a identificação de $A$. genoespécie 13TU; outro é constituído pelos iniciadores específico para $A$ genoespécie. 3 e o último composto pelos iniciadores que tem como alvo o controle interno $16 \mathrm{~S}$ rRNA. Os amplicons, obtidos para cada alvo, apresentaram tamanhos distintos o que permitiu o desenvolvimento de uma PCR multiplex para as três espécies. A identificação das espécies $A$. genoespécie 3 e A. genoespécie 13TU foi confirmada pela análise nucleotídica da região intergênica 16S-23S rRNA. O conjunto de reações de forma ímpar auxilia o Laboratório de Microbiologia na identificação bacteriana com maior acurácia e rapidez, permitindo também a melhor escolha de tratamento empírico para cada espécie bacteriana. 
Nas amostras pertencentes ao complexo ACB estudadas, foi possível observar a maior susceptibilidade a todos os antimicrobianos pelas espécies $A$. genoespécie 3 e A.genoespécie 13TU quando comparado com $A$. baumannii, sendo apenas 1 isolado da espécie $A$. genoespécie 13TU resistente ao imipenem. Alguns trabalhos científicos já relataram diferenças no perfil de susceptibilidade aos antimicrobianos entre as diferentes espécies do complexo ACB. (HOUANG et al., 2003; LEE et al., 2009; VAN DEN BROEK et al., 2009; SHENG et al., 2001). A emergência da resistência aos carbapenêmicos por outras espécies que não $A$. baumannii tem sido relatada na Irlanda (BOO et al., 2009) e Taiwan (CHEN et al., 2010; SHENG et al., 2011).

A resistência apresentada aos antimicrobianos por $A$. baumannii foi significativamente maior quando comparada as outras espécies. A análise temporal do perfil de sensibilidade de $A$. baumannii aos antimicrobianos revelou a diminuição da sensibilidade aos carbapenêmicos (imipenem e meropenem) e o aumento da sensibilidade à gentamicina, sendo esta associação significativa entre os isolados bacterianos de pacientes internados em UTI nos anos de 2009 e 2010 ( $p=0,001$ e $p=0,004$, respectivamente). O aumento da sensibilidade a gentamicina já foi relatada em outras espécies como E. coli, por aumento da expressão de proteína ligadora de oligopeptídeo (OppA) (KASHIGAWI et al., 1992). É provável que estas cepas resistentes aos carbapenêmicos apresentem este fenótipo não só por produção de carbapemases como pela alteração de expressão de proteínas relacionadas à membrana externa, o que poderia conferir maior susceptibilidade à gentamicina, permitindo maior entrada deste antibiótico ou pela manutenção de maior concentração no interior da célula bacteriana.

O gene blaOXA-51-like é intrínseco para A. baumannii (BROWN \& AMYES, 2006) e é normalmente pouco expresso, mas pode ocorrer uma hiperexpressão pela inserção da sequência do elemento ISAba1 a montante deste gene e associado a outros mecanismos como alteração de permeabilidade ou hiperexpressão de bombas de efluxo pode conferir resistência aos carbapenêmicos (TURTON et al., 2006). Neste trabalho a detecção da presença do gene bla oxa-51-like foi usada para a identificação de $A$. baumannii e a presença de IsAba1 não foi avaliada. 
Os genes blaOXA-23-like, blaOXA-24-like, bla OXA-58-like, são associados a resistência aos carbapenêmicos (WOODFORD et al., 2006.). O gene codificador do gene OXA-23 foi encontrado em $81,2 \%$ dos 176 isolados resistentes aos carbapenêmicos, revelando o predomínio desse mecanismo de resistência, sendo a primeira descrição de OXA-23 em isolados de $A$. baumannii no Brasil, em Curitiba, no final da década de 90 (DALLA-COSTA et al., 2003). A primeira cepa resistente aos carbapenêmicos isolado no HU-USP foi em 2005, portadora de blaంXA-23. No início do ano de 2006 ocorreu o primeiro surto por A.baumannii resistente aos carbapenêmicos por alteração de permeabilidade de membrana externa (TAKAGI et al., 2009) e a partir do segundo semestre de 2006 houve a emergência da isolados multirresistentes por presença de blaOXA-23.

A enzima OXA-23 foi a primeira descrita em $A$. baumannii, originalmente denominada de ARI-1 a partir de um isolado de amostra clínica em 1985 (PATON et al., 1993) e atualmente contribui com a resistência aos carbapenêmicos mundialmente (BOO et al., 2006; COELHO et al 2006; CORVEC et al., 2003; CORVEC et al., 2007; JEON, et al., 2005; $\mathrm{KOH}$ et al., 2007; NAAS et al., 2005; VALENZUELA et al., 2007; VILLEGAS et al., 2007; ZHOU et al., 2007), inclusive no Brasil (DALLA-COSTA et al., 2003; CARVALHO et al., 2009; MARTINS et al., 2009; SCHIMITH BIER et al., 2010; GROSSO et al., 2010). Na população de amostras estudadas nesse trabalho nota-se que a resistência aos carbapenêmicos mediada pela enzima OXA-23 é a mais frequente, o que corrobora com os diversos relatos de surtos por $A$. baumannii que apresentam esse mecanismo de resistência, provavelmente por uma maior capacidade de transferência horizontal de elementos genéticos móveis contendo o gene codificador de OXA-23.

No presente estudo, foi encontrada uma única cepa de $A$. baumannii portadora de blaoxA-72 foi isolada de um paciente de 84 anos, sexo masculino, em janeiro de 2009. O paciente esteve internado na clínica médica e desenvolveu infecção do trato urinário relacionada à sondagem vesical. Recebeu tratamento por dez dias com ampicilina-sulbactam e teve alta. Apresentou infecções urinárias de repetição e em outubro de 2009, foi novamente isolado $A$. baumannii com mesmo gene de resistência 
anteriormente encontrado e mesmo perfil molecular tanto por RAPD, quanto por PFGE. Este dado sugere a persistência deste clone neste paciente.

No Brasil, o primeiro relato da presença do gene bla०XA-72 em $A$. baumannii corresponde a um isolado obtido de hemocultura de um paciente idoso, dez dias após ser submetido a processo cirúrgico (WERNECK et al., 2010). O gene bla OXA-72 foi primeiramente descrito em $A$. baumannii na Tailândia, em 2004; posteriormente ocorreram relatos na China, Coréia do Sul, Taiwan, Itália, Espanha e França (BARNAUD et al., 2010; DI POPOLO et al., 2010; POIREL et al., 2010), surtos já foram descritos em Taiwan (LIN et al., 2011), e Croácia (GOIC-BARISIC et al., 2011).

Alguns estudos têm demonstrado a ocorrência de mais de uma enzima do tipo OXA adquirida em um mesmo isolado (WALTER-RASMUSSEN, 2006; PELEG et al., 2008; MENDES et al., 2009). Entretanto, a ocorrência de OXAcarbapenemases com MBL em $A$. baumannii, somente foi evidenciada em um único trabalho em Singapura até o momento ( $\mathrm{KOH}$ et al., 2007). No presente estudo não foram encontrados isolados bacterianos com genes codificadores para MBL.

As diferenças encontradas quanto a distribuição das espécies de relevância clínica assim como a respeito da suscetibilidade aos antimicrobianos ressaltam a importância desse conhecimento, possibilitando compreender melhor a patogênese, a epidemiologia, bem como na orientação de diretrizes de uso racional de antimicrobianos.

Ferramentas para o estudo da similaridade genética de agentes etiológicos são de fundamental importância para a melhor compreensão da epidemiologia da doença infecciosa, tais ferramentas são denominadas métodos de tipagem molecular que possibilitam a caracterização de surtos, situações de transmissão cruzada, fatores associados à infecção hospitalar, auxiliando no monitoramento e controle da infecção hospitalar (SINGH, et al., 2006).

Para a representação gráfica dos resultados obtidos RAPD ou PFGE foi escolhido o método de agrupamento por média aritmética não-ponderada para a construção de dendrogramas. Para calcular a similaridade entre os isolados, 
coeficientes matemáticos Dice e ou Jaccard que levam em conta a presença e ausência de polimorfismos foram utilizados.

Para a obtenção de capacidade de discriminação satisfatória na tipagem por RAPD é necessário o uso de vários iniciadores (KOELEMAN et al., 1998), assim em nosso estudo foram estudados polimorfismos obtidos por quatro iniciadores e os dados analisados forneceram apenas uma única possibilidade de dendrograma. $O$ uso do RAPD possibilita principalmente a avaliação da similaridade genética dentro de um grupo de amostras, visando avaliar se seriam cepas indistinguíveis entre si ou não, possibilitando que laboratórios que não dispõe do equipamento de PFGE possam caracterizar essas amostras por uma técnica rápida e de menor custo, fornecendo informações para que as medidas de controle de infecção hospitalar possam ser tomadas com maior eficiência.

Não há registro na literatura quanto ao percentual de similaridade adequado para análise de dados obtidos por RAPD, deste modo neste trabalho análise destes dados foi realizada a pela análise dos agrupamentos e a possível relação com características comuns entre essas amostras.

A construção de um único dendrograma para todos os isolados da espécie $A$. baumannii não agrupou os isolados por período, ambiente hospitalar ou área hospitalar de onde tenha sido isolado. Já ao analisar separadamente as cepas de $A$. baumannii isoladas de pacientes internados em UTI e fora desse ambiente, é possível observar maior diversidade entre as cepas isoladas de pacientes atendidos em outro ambiente que não UTI. No dendrograma obtido para A. baumannii isolados de pacientes internados em UTI, nota-se o agrupamento de isolados em 2008, destacado em amarelo e os destacados em verde isolados bacterianos obtidos nos anos de 2009 e 2010 (Figura 10). Além disso, há mais cepas indistinguíveis entre os isolados de pacientes de UTI que fora deste ambiente. Este dado sugere que em ambientes onde a pressão seletiva frente aos antimicrobianos é maior, os clones permanecem por mais tempo circulando.

Já nos dendrogramas obtidos para $A$. genoespécie 3 e $A$. genoespécie 13TU nota-se a presença de algumas cepas indistinguíveis, porém não é possível a formação de agrupamentos por qualquer característica desses isolados bacterianos, como ambiente hospitalar, amostras biológicas ou época 
de isolamento. Esses dados mostram que provavelmente que a rotatividade dos isolados das espécies $A$. genoespécie 13TU e $A$. genoespécie 3 no ambiente é maior quando comparado $A$. baumannii. Os dados obtidos da sensibilidade aos antimicrobianos, adesão e formação de biofilmes podem contribuir com a maior rotatividade destas espécies.

As cepas resistentes aos carbapenêmicos foram tipadas por PFGE e RAPD. A comparação entre as matrizes de similaridade obtidas por RAPD e PFGE para isolados resistentes aos carbapenêmicos apresentou a correlação linear de $R=0,874$, dado obtido por teste de Mantel. Considerando relação de percentual de similaridade, descrita por Singh e colaboradores, sendo cepas com $100 \%$ de similaridade genética são consideradas indistinguíveis e cepas com mais de $80 \%$ de similaridade genética são consideradas relacionadas e as cepas com similaridade genética menor a $80 \%$ são consideradas distintas (SINGH et al., 2006), para análise do dendrograma obtido por PFGE nota-se a presença de pelo 6 agrupamentos de cepas relacionadas entre si e todas apresentam o gene blaOXA-23-like, revelando ao longo do período a emergência e a disseminação de diferentes clones resistentes aos carbapenêmicos (Figura 12).

Comparando os dendrogramas obtidos por RAPD e PFGE, foi possível observar que por RAPD houve a diferenciação de isolados que se apresentaram indistinguíveis por PFGE. Este fato poderia ser explicado pelo material genético envolvido na análise de tipagem molecular. Enquanto por PFGE os fragmentos analisados são os obtidos por digestão enzimática, a análise por RAPD é realizada a partir de fragmentos obtidos por amplificação e deste modo pequenas quantidades de material genético (DNA plasmidial) podem ser detectadas, gerando perfis diferentes nas amostras com diferentes perfis de plasmídeos.

Em 2005, um estudo realizado na Índia comparou os resultados de tipagem molecular obtidos com RAPD e PFGE e observaram poder discriminatório do RAPD menor do que o PFGE, principalmente para diferenciar os subtipos de um mesmo clone; mas para diferenciar entre as cepas envolvidas nos surtos daquelas não relacionadas a técnica de RAPD foi útil, apesar de ter sido utilizado um único iniciador (PRASHANTH \& BADRINATH, 2005). 
Durante a investigação de um surto em Madri, Bou e colaboradores (2000) compararam os resultados do RAPD com amplificação de sequências repetidas por PCR (REP-PCR) e PFGE na definição da relação genética entre os isolados obtidos antes, durante e após o surto. Os autores constataram a presença de oito diferentes grupos por REP-PCR e PFGE e somente sete grupos por RAPD revelando a menor capacidade discriminatória que pode ser justificada pelo uso de apenas um iniciador para a realização desta tipagem (BOU et al., 2000).

A resistência aos antimicrobianos tornou-se um dos grandes desafios do século XXI, na área da saúde. Entretanto, o estudo do fenômeno "quorum sensing" na regulação de fatores de virulência, como adesão bacteriana, biofilme dentre outros, tem permitido a melhor compreensão da patogenicidade bacteriana e da interação parasita-hospedeiro, além de ser um alvo atraente para o desenvolvimento de novas terapias antibacterianas (RASKO et al., 2008; RASKO \& SPERANDIO, 2010)

$\mathrm{Na}$ análise dos genomas de $A$. baumannii depositados no banco de dados GenBank (ALTSCHUL et al., 1990) foi encontrado genes homólogos ao gene codificador da N-acil-homoserina lactona sintase (gene ID 6002690 ABAYE3761) e ao gene codificador do regulador transcricional ligante de autoindutor (gene ID 6002688 ABAYE3758), sugerindo a produção de moléculas de AHLs. Em 2008, o gene responsável pela síntese de autoindutor do tipo AHL foi caracterizado, passando a ser denominado de abal (NIU et al., 2008).

A pesquisa do autoindutor de AHL seja por bioensaio direto e reverso utilizando a cepa Chromobacterium violaceum CV026, não revelou a presença deste autoindutor em meios pré-condicionados ou extratos orgânicos dos sobrenadantes livres de células de culturas a partir de qualquer uma das três amostras de cada espécie bacteriana do complexo ACB. A ausência de resultados para a presença de $A H L$ por bioensaios utilizando-se $C$. violaceum CV026 pode ser explicada pela produção de AHL que apresente algum tipo de modificação em sua estrutura, como substituições ou ramificações ao longo da cadeia de carbonos de sua estrutura, apresentada na Figura 19, não sendo detectada pela cepa biosensora que apesar de reconhecer um amplo espectro 
de $A H L$, responde melhor a $A H L$ de seis carbonos e fracamente àquelas que se apresentam oxidadas na posição três da cadeia de carbonos.

A análise do extrato orgânico por cromatografia líquida com detector de espectrômetro de massa (LC-MS íontrap), permitiu detectar picos sugestivos compatíveis com AHL-C14, AHL-3-oxo-C14 e AHL-C10. Niu e colaboradores (2008) descreveram a identificação de AHL-C14 e AHL-C10 em extratos orgânicos de sobrenadante de cultura de $A$. baumannii, além de outras possíveis estruturas como AHL-3-OH-C12, AHL-C12, AHL-3-oxo-C13 e AHLC16. Revelando que o fenômeno "quorum sensing" mediada por autoindutores do tipo AHL é presente em $A$. baumannii e que apresentam variações quando ao tamanho da cadeia de carbonos e presença ou não de substituições, sendo a ausência de detecção por bioensaio um viés da técnica e da cepa biosensora utiilzada nesse estudo.

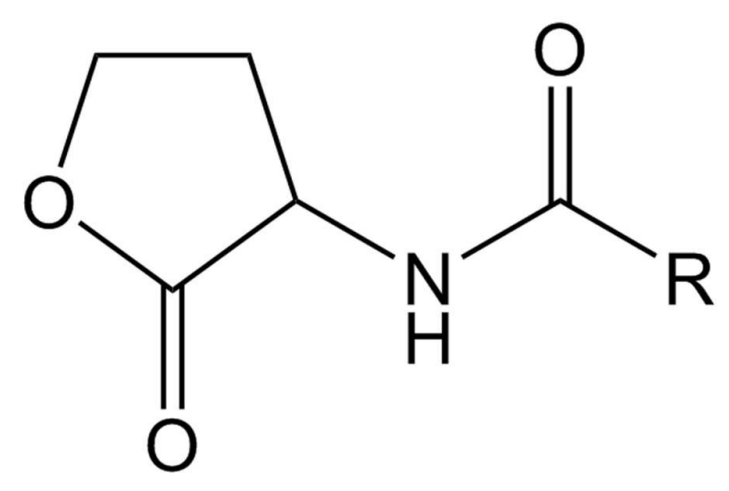

Figura 19. Estrutura geral de uma molécula de acil-homoserina-lactona (AHL) - o radical "R" é uma cadeia acil lateral.

A presença de autoindutor-2 em meio pré-condicionado foi pesquisada por bioluminescência na cepa biosensora $V$. harveyi BB170. Os resultados mostraram que os meios pré-condicionados, obtidos por três amostras de cada espécie clínica do complexo ACB, não continham moléculas de autoindutor-2 suficiente para promover a bioluminescência na cepa $V$. harveyi BB170.

Analisando a rota metabólica da reciclagem de S-adenosil-homocisteína (SAH) para homocisteína, o autoindutor 2 pode ser gerado por uma das duas rotas metabólicas presentes (Figura 20). 


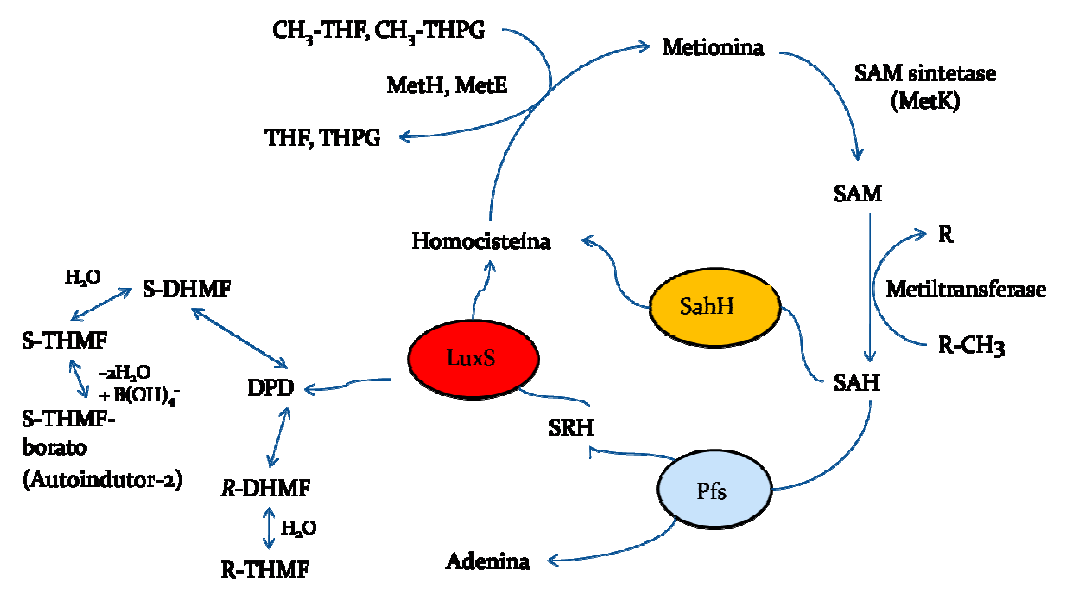

Figura 20 - Síntese de autoindutor-2 a partir do ciclo da metionina. Figura modificada de Keersmaecker e colaboradores. (DE KEERSMAECKER et al., 2006).

Ao pesquisar a presença de genes homólogos no genoma depositado no banco de dados GenBank, utilizando a ferramenta BLAST (ALTSCHUL et al., 1990), não há descrito gene hómologo ao gene codificador para LuxS e sim para SahH (S-adenosil-homocisteína hidrolase), revelando assim a ausência da rota metabólica que resultaria na produção do autoindutor-2. Há o relato de apenas duas espécies bacterianas, Bifidobacterium longum NCCC2705 e Escherichia blattae, que apresentem ambas as rotas metabólicas para a reciclagem de SAH (SUN et al.,2004).

A pesquisa da produção de autoindutor-3 foi realizada pelo uso da cepa biosensora Escherichia coli TEVS 232, contendo a fusão $L E E 1:: / a c Z$, que na presença de autoindutor-3 induz o gene codificador de $\beta$-galactosidase (SPERANDIO et al, 1999). Foi possível detectar a presença significativamente maior de autoindutor-3 em meios pré-condicionados obtidos a partir de cepas de $A$. baumannii e $A$. genoespécie 13TU, quando comparados com A.genoespécie 3. O autoindutor-3 apresenta atividade similar com noradrenalina e adrenalina (CLARKE et al., 2006), esta semelhança facilitaria a comunicação entre parasita e hospedeiro, uma vez que ele pode mimetizar a ação destes hormônios. O conhecimento da presença deste autoindutor, envolvido na regulação de diversos mecanismos de virulência, possibilita a melhor compreensão da patogenicidade do micro-organismo, além da possibilidade de ser utilizado como alvo para o desenvolvimento de novas estratégias terapêuticas que permitam a interferência desta comunicação, o 
que pode ser uma alternativa bastante interessante na situação atual e global da disseminação de cepas resistentes aos antimicrobianos disponíveis.

Um dos importantes fatores de virulência relacionado a "quorum sensing" é o biofilme. A habilidade das cepas de Acinetobacter sp. produzir biofilme foi estudada pelo ensaio colorimétrico de cristal violeta, que indiretamente mede o número de células bacterianas baseado na coloração da camada de peptideoglicano. Observou-se que A. baumannii, apesar da heterogeneidade na produção de biofilme, produz maior quantidade de biofilme quando comparado com $A$. genoespécie 3 . A diferença na produção de biofilme entre amostras de $A$. baumannii já foi relatada por diversos outros trabalhos (KING et al., 2009; WROBLEWSKA et al., 2008). O ensaio de biofilme na presença de $100 \mu \mathrm{M}$ fentolamina, antagonista $\beta$-adrenérgico, diminuiu significativamente a produção do biofilme por $A$. baumannii revelando 0 envolvimento do autoindutor-3 na formação de biofilmes. Este dado sugere que este indutor tenha papel importante na formação de biofilmes.

A adesão bacteriana às células epiteliais é uma das etapas essenciais para a colonização e infecção. Deste modo, optamos por avaliar adesão de três cepas de cada espécie clínica do complexo ACB à monocamada de células.

Ensaios de adesão bacteriana foram realizados em monocamada de células HEp-2 (ATCC CCL - 23), MRC-5 (ATCC CCL - 171) e NCl-H292 (ATCC CRL-1848) por seis horas a $37^{\circ} \mathrm{C}, 5 \%$ de $\mathrm{CO}_{2}$. Notou-se que nenhuma das espécies bacterianas foi capaz de aderir em células HEp-2, que são células derivadas de células HeLa contaminadas, mostrando que não há moléculas de adesão para essas bactérias em sua superfície.

A utilização de células MRC-5 para adesão de Acinetobacter sp. ainda não foi descrita. Optou-se por utilizá-la por ser uma linhagem diplóide, obtida de pulmão de feto humano. A. genoespécie 3 não aderiu a estas células, enquanto a .A. baumannii e A.13TU aderiram e apresentaram padrão difuso.

Em ensaios com $\mathrm{NCl}-\mathrm{H} 292$, células oriundas de um nódulo linfático em metástase de um carcinoma mucoepidermóide de pulmão humano, foi possível observar diferenças nos padrões de adesão entre as três espécies clínicas do complexo ACB. A. genoespécie 3TU não é capaz de aderir, enquanto $A$. baumannii adere apresentando padrão difuso e $A$. genoespécie 13TU 
apresenta-se em agrupados. Sendo a cultura de células $\mathrm{NCl}-\mathrm{H} 292$ a melhor para diferenciar as espécies do complexo ACB. CHOI e colaboradores (2008) descreveram a adesão apenas $A$. baumannii nessa cultura celular. Observouse também o papel do indutor 3 na adesão nessa linhagem celular, a adesão foi inibida por $100 \mu \mathrm{M}$ propanol. Devido a semelhança estrutural do indutor 3 com a adrenalina e noradrenalina, pode-se conjeturar a ação destes hormônios na manutenção do micro-organismo no tecido.

A maior susceptibilidade aos antimicrobianos por $A$. genoespécie 3 e $A$. genoespécie 13TU pode explicar a menor frequência dessas espécies no grupo de amostras estudadas. Sendo mais facilmente tratadas e mostram-se menos adaptáveis à pressão seletiva do ambiente hospitalar.

A. genoespécie 3 apresentou maior susceptibilidade aos antimicrobianos, menor produção de biofilme e a não adesão a qualquer monocamada de células eucarióticas estudadas. Essa diferença encontrada para $A$. genoespécie 3 pode estar relacionada à menor frequência dessa espécie em UTI (DONNARUMMA et al., 2010; GUNDI et al., 2009; SEIFERT et al., 1993). Os resultados obtidos nos ensaios em células NCl-H292, juntamente com os obtidos na avaliação da diferença de susceptibilidade dos antimicrobianos e os dados obtidos na adesão em células MRC-5, vão ao encontro dos resultados encontrados referentes à menor frequência de cepas das espécies A.genoespécie 3 e $A$. genoespécie 13 TU nas amostras bacterianas, isoladas de pacientes de unidade de terapia intensiva, do banco de cepas do Hospital Universitário da USP. 


\section{CONCLUSÕES}

- O esquema proposto para a identificação das espécies do complexo ACB é simples e rápido, além de possibilitar a detecção de genes codificadores de carbapenemases do tipo OXA, mecanismo de resistência mais prevalente em Acinetobacter sp.

- A população de amostras de $A$. baumannii apresentou menor taxa de sensibilidade aos antimicrobianos quando comparada com $A$. genoespécie 3 e A. genoespécie 13TU. Essa característica parece contribuir com a melhor adaptação de $A$. baumannii pressão seletiva do ambiente hospitalar, sendo a espécie mais frequentemente encontrada entre os isolados bacterianos pertencentes ao complexo ACB.

- Nesse estudo, genes relacionados à resistência aos carbapenêmicos foram encontrados apenas em isolados da espécie $A$. baumannii, sendo $81,2 \%$ dos 176 , isolados resistentes aos carbapenêmicos, portadores do gene codificador da enzima OXA-23 e um único isolado portador de OXA-72. Nenhum isolado bacteriano apresentou amplificação para b/a $a_{\mathrm{IMP}}$, blaviM, b/a $a_{\mathrm{SIM}}, b / a_{\mathrm{GIM}}, b / a_{\mathrm{SPM}}$, bla OXA-58-like.

- As amostras de A. baumannii isoladas de pacientes internados em UTI apresentaram menor diversidade quando comparadas com os isolados de $A$. baumannii de pacientes de outros ambientes hospitalares, revelando a frequência maior de cepas com relação de clonalidade entre as amostras bacterianas expostas a maior pressão seletiva, sendo possível observar a presença de clones relacionados a surtos, principalmente nos anos de 2009 e 2010.

- Na pesquisa em três amostras de cada espécie do complexo ACB de autoindutores por bioensaio, apenas foi possível detectar a presença de autoindutor-3 em meios pré-condicionados, sendo encontrado em maior quantidade nos meios obtidos por A. baumannii e $A$. genoespécie 13TU. A detecção de $\mathrm{AHL}$ foi possível apenas pela análise do extrato orgânico, do sobrenadante livre de células obtido de uma cultura de $A$. baumannii, por LC- 
MS iontrap, sendo possível detectar picos sugestivos referentes a três AHLs: AHL-C14, AHL-3-oxo-C14 e AHL-C10.

- Os ensaios de adesão bacteriana, utilizando as células epiteliais de pulmão $\mathrm{NCl}-\mathrm{H} 292$, sugerem que as três espécies clínicas do complexo ACB estudadas possuem padrões de aderência bacteriana distintos.

- A maior susceptibilidade aos antimicrobianos, a não aderência em monocamadas de células eucarióticas e a menor produção de biofilme por A.genoespécie 3 podem explicar a menor frequência dessa espécie no ambiente hospitalar.

- As diferença encontradas na frequência das espécies clínicas do complexo ACB e na susceptibilidade aos antimicrobianos ressaltam a importância da identificação dessas espécies que neste trabalho é realizada por uma prospota composta de duas PCRs que possibilita também avaliar a presença de genes codificadores de enzimas do tipo OXA, mecanismo de resistência aos carbapenêmicos mais frequente no gênero Acinetobacter.

- O fenômeno de "quorum sensing" parece estar relacionado a dois tipos de autoindutores: acil-homoserina lactona e autoindutor-3, sendo este último um importante comunicante não apenas na comunicação entre bacterianas como também na relação patógeno-hospedeiro por apresentar característica de função similar às catecolaminas, adrenalina e nor-adrenalina.

- Dados obtidos, na presença de antagonistas adrenérgicos, sugerem que autoindutor-3 está envolvido na regulação da produção de biofilme e aderência de células bacterianas em células $\mathrm{NCl}-\mathrm{H} 292$, nas amostras de $A$. baumannii estudadas. 


\section{REFERÊNCIAS BIBLIOGRÁFICAS}

ALTSCHUL, S.F.; GISH, W.; MILLER, W. MYERS, E.W.; LIPMAN, D.J. Basic local aligment search tool. Journal of Molecular Biology, v.215, p.403-410, 1990.

ANVISA - Agência Nacional de Vigilância Sanitária. Anvisa intensifica controle de infecção em serviços de saúde. Revista de Saúde Pública, v. 38; 475-478, 2004.

ANSTEY, N.M.; CURRIE, B.J.; HASSELL, M.; PALMER, D.; DWYER, B.; SEIFERT, H. Community-acquired bacteremic Acinetobacter pneumonia in tropical Australia is caused by diverse strains of Acinetobacter baumannii, with carriage in the throat in at-risk groups. Journal of Clinical Microbiology, v.40, p.685-686, 2002.

BARNAUD, G.; ZIHOUNE, N.; RICARD, J.D.; HIPPEAUX, M.C.; EVEILLARD, M.; DREYFUSS, D.; BRANGER, C. Two sequential outbreaks caused by multidrug-resistant Acinetobacter baumannii isolates producing OXA-58 or OXA-72 oxacillinase in an intensive care unit in France. Journal of Hospital Infection, v. 76, p.358-360, 2010.

BARRY, T.; COLLERAN, G.; GLENNON, M.; DUNICAN, K.; GANNON, F. The 16S/23S ribossomal spacer region as a target for DNA probes to identify eubacteria. PCR Methods and Applications, v.1, n.1, p.51-56, 1991.

BAUMANN, P.; DOUDOROFF, M.; STANIER, R.Y. A study of the Moraxella group. II. Oxidative-negative species (genus Acinetobacter). Journal Bacteriology, v.95, p.1520-1541, 1968 apud PELEG, A.Y.; SEIFERT, H.; PATERSON, D.L. Acinetobacter baumannii: emergence of a successful pathogen. Clinical Microbiology Reviews, v.21, n.3, p.538-582, 2008.

BEIJERINCK, M. Pigmenten als oxydatieproducten govermd door bacterien. Verls. Koninklijke Akad. Wetensch, v.19, p.102-1103 apud PELEG, A.Y.; SEIFERT, H.; PATERSON, D.L. Acinetobacter baumannii: emergence of a successful pathogen. Clinical Microbiology Reviews, v.21, n.3, p.538-582, 2008.

BERGOGNE-BÉRÉZIN, E.; TOWNER, K.J. Acinetobacter spp. as noscomial pathogens: microbiological, clinical and epidemiologia features. Clinical Microbiological Review, v.9, n.2, p.148-165, 1996.

BERNARDS, A.T.; VAN DER TOOR, J.; VAN BOVEN, C.P.; DIJKSHOORN, L. Evaluation of the ability of a commercial system to identify Acinetobacter 
genomic species. European Journal of Clinical Microbiology and Infectious Diseases, v.15, p.303-308, 1996.

BICK, J.A.; SEMEL, J.D. Fulminant community-acquired Acinetobacter pneumonia in a healthy woman. Clinical and Infection Diseases, v. 17, p.820821.

BOO, T.W.; WALSH, F.; CROWLEY, B. First report of OXA-23 carbapenemase in clinical isolates of Acinetobacter species in the Irish Republic. Journal of Antimicrobial Chemotherapy, v.58, p.1101-1102, 2006.

BOO, T.W.; WALSH, F.; CROWLEY, B. Molecular characterization of carbapenem-resistant Acinetobacter species in an Irish university hospital: predominance of Acinetobacter genomic species 3. Journal of Medical Microbiology, v.58, p.209-216, 2009.

BOU, G.; CERVERO, G.; DOMINGUEZ, M.A.; QUEREDA, C.; MARTINEZBELTRAN, J. Characterization of nosocomial outbreak caused by a multiresistant enzyme: high level carbapenem resistance in $A$. baumannii is not due solely to the presene of beta-lactmases. Journal of Clinical Microbiology, v. 38, p.3299-3305, 2000.

BOUVET, P.J.; GRIMONT, P.A. Taxonomy of the genus Acinetobacter with the recognition of Acinetobacter baumannii sp. nov., Acinetobacter haemolyticus sp. nov., Acinetobacter johnsonii sp. nov., and Acinetobacter junii sp. nov., and emended description of Acinetobacter calcoaceticus and Acinetobacter Iwoffi. International Journal of Systematic Bacteriology, v. 36, p.228-240, 1986 apud PELEG, A.Y.; SEIFERT, H.; PATERSON, D.L. Acinetobacter baumannii: emergence of a successful pathogen. Clinical Microbiology Reviews, v.21, n.3, p.538-582, 2008

BOUVET, P.J.; GRIMONT, P.A. Identification and biotyping of clinical isolates of Acinetobacter. Annales de I'Institut Pasteur/Microbiology, v.138, n.5, p.569578, 1987.

BOUVET, P.J.; JEANJEAN, S. Delineation of new proteolytic genomic species in the genus Acinetobacter. Research in Microbiology, v. 140, p. 291-299,. 1989.

BRISOU, J.; PREVOT, A.R. Studies on bacterial taxonomy. X. The revision of species under Achromobacter group. Annales de I'Institut Pasteurl Microbiology, v.86, p. 722-728, 1954 apud PELEG, A.Y.; SEIFERT, H.; PATERSON, D.L. Acinetobacter baumannii: emergence of a successful pathogen. Clinical Microbiology Reviews, v.21, n.3, p.538-582, 2008. 
BROWN, S.; AMYES, S. OXA \{beta\}-lactamases in acinetobacter: the story so far. Journal of Antimicrobial Chemotherapy, v.57, p.1-3, 2006.

CANDEL, F.J.; CALVO, N.; HEAD, J. CARVALHO, K.R.; CARVALHO-ASSEF, A.P.; PEIRANO, G.; SANTOS, L.C.; PEREIRA, M.J.; ASENSI, M.D. Dissemination of multidrug resistant Acinetobacter baumannii genotypes carrying bla(OXA-23) collected from hospitals in Rio de Janeiro, Brazil. International Journal of Antimicroial Agents, v.34, p.25-28, 2009.

CARVALHO, K.R.; CARVALHO-ASSEF, A.P.; PEIRANO, G.; SANTOS, L.C.; PEREIRA, M.L.; ASENSI, M.D. Dissemination of multidrug-resistant Acinetobacter baumannii genotypes carrying bla(OXA-23) collected from hospitals in Rio de Janeiro, Brazil. International Journal Od Antimicrobial Agents, v.34, p.25-28, 2009.

CASTANHEIRA, M.; TOLEMAN, M.A.; JONES, R.N.; SCHMIDT, F.J.; WALSH, T.R. Molecular chracterization of beta-lactmase gene, blaGIM-1, enconding a new subclass of metallo-beta-lactmase. Antimicrobial Agents and Chemotherapy, v. 48, p 4654-4661, 2004.

CHANG, H.C.; WEI, Y.F.; DIJKSHOORN, L.; VANEECHOUTTE, M.; TANG, C.T.; CHANG, T.C. Species-level identification of isolates of the Acinetobacter calcoaceticus-Acinetobacter baumannii complex by sequence analysis of the 16S-23S rRNA gene spacer region. Journal of Clinical Microbiology, v.43, p.1632-1639, 2005.

CHEN, C.C.; TENG, L.J.; CHANG, T.C. Identification of clinically relevant viridas streptococci by sequence analysis of the 16S-23S rDNA spacer region. Journal of Clinical Microbiology, v.42, n.6, p.2651-2657, 2004.

CHEN, X.; POTIER, N.; VANDOUSSElAER, A.; PELCZER, L.; BASSLER, B.L.; HUGHSON, F.M. Structural identification of bacterial quorum-sensing signal containing boron. Nature, v.415, p.545-549, 2002.

CHOI, C.H.; LEE, J.S.; LEE, Y.C.; PARK, T.I.; LEE, J.C. Acinetobacter baumannii invades epithelial cells and outer membrane protein $A$ mediates interactions with epithelial cells. BMC Microbiology, v.8, p.216-218, 2008.

CHU, Y.W.; AFZAL-SHAH, M.; HOUANG, E.T.; PALEPOU, M.I.; LYON, D.J.; WOODFORD, N.; LIVERMORE, D.M. IMP-4, a novel metallo-beta-lactamase from nosocomial Acinetobacter spp. Collected in Hong Kong between 1994 and 1998. Antimicrobial Agents Chemotherapy, v. 45, p.710-714, 2001.

CHU, Y.W.; LEUNG, C.M.; HOUANG, E.T.; NG, K.C.; LEUNG, C.B.; LEUNG, H.Y.; CHENG, A.F. Skin carriage of acinetobacters in Hong Kong. Journal of Clinical Microbiology, v.37, p.2962-2967, 1999. 
CISNEROS, J.M; RODRÍGUEZ-BAÑO, J.; FERNÁNDEZ-CUENCA, F.; RIBERA, A.; VILA, J.; PASCUAL, A.; MARTÍNEZ-MARTÍNEZ, L.; BOU, G.; PACHÓN, J.; SPANISH GROUP FOR NOSOCOMIAL INFECTION (GEIH) FOR THE SPANISH SOCIETY OF INFECTIOUS DISEASES AND CLINICAL MICROBIOLOGY (SEIMC). Risk-factors for the acquisition of imipenemresistant Acinetobacter baumannii in Spain: a nationwide study. Clinical Microbiology and Infection, v.11, p.874-879, 2005.

CLARKE, M.B.; HUGHES, D.T.; ZHU, C.; BOEDEKER, E.C.; SPERANDIO, V. The QseC sensor kinase: a bacterial adrenergic receptor. Proceedings of the National Academy of Sciences of the United States of America, v.103, p.10420-10425, 2006.

Clinical and Laboratory Standards Institute M100-S20 Performance standards for antimicrobial susceptibility testing, $20^{\text {th }}$ informational supplement, CLSI M100-S20, Wayne, 153p, 2010.

COELHO, J.M.; TURTON, M.E.; KAUFMAN, M.E.; GLOVER, J.; WOODFORD, N.; WARNER, M.; PALEPOI, M.F.; PIKE, R.; PITT, T.L.; PATEL, B.C.; LIVERMORE, D.M. Occurrence of carbapenem-resistant Acinetobacter baumannii clones at multiple hospitals in London and Southeast England. Journal of Clinical Microbiology, v.44, p.3623, 2006.

CORNAGLIA, G.; RICCION, M.L.; MAZZARIOL, A.; LAURETTI, L.; FONTANA, R.; ROSSOLINI, G.M. Appearance of IMP-1 metallo-beta-lactamase in Europe. Lancet, v.353, p.899-900, 1999.

CORVEC, S.; CAROFF, N.; ESPAZE, E.; GIRAUDEAU, C.; DRUGEON, H.; REYNAUD, A. AmpC cephalosporinase hyperproduction in Acinetobacter baumannii clinical strains. Journal Antimicrobial Chemotherapy, v. 52, p. 629-635, 2003.

CORVEC, S.; POIREL, L.; NAAS, T.; DRUGEON, H.; NORDMANN, P. Genetics and expression of the carbapenem-hydrolyzing oxacillinase gene blaOXA-23 in Acinetobacter baumannii. Antimiicrobial Agents and Chemotherapy, v.51, p.1530-1533, 2007.

COSTA, S.F.; WOODCOCK, J.; GRILL, M.; WISE, R.; BARONE, A.A.; CAIAFFA, H.; LEVIN. Outer-membrane proteins pattern and detection of betalactamases in clinical isolates of imipenem-resisant Acinetobacter baumannii from Brazil. International Journal of Antimicrobial Agents, v.13, p.175-182, 2000.

CRAVIOTO, A.; GROSS, R.J.; SCOTLAND, S.M.; ROWE, B. An adhesive factor bound in strains of Escherichia coli belonging to the traditional infantile enteropathogenic serotypes. Current Microbiology, v.3, p.95-99, 1979. 
DA SILVA, G.J.; CORREIA, M.; VITAL, C.; RIBEIRO, G.; SOUSA, J.C.; LEITÃO, R.; PEIXE, L.; DUARTE, A. Molecular characterization of bla(IMP-5), a new integron-borne metallo-beta-lactamase gene from as Acinetobacter bauamannii nosocomial isolate in Portugal. FEMS Mirobiology Letters, v. 215, p.33-39, 2002.

DALLA-COSTA, L.M.; COELHO, J.M.; SOUZA, H.A.; CASTRO, M.E.; STIER, C.J.; BRAGAGNOLO, K.L.; REA-NETO, A.; PENTEADO-FILHO, S.R.; LIVERMORE, D.M.; WOODFORD, N. Outbreak of carbapenem-resistant Acinetobacter baumannii producing the OXA-23 enzyme in Curitiba, Brazil. Journal of Clinical Microbiology, v.41, n.7, p.3403-3406, 2003.

DAVIS, K.A.; MORAN, K.A.; MCALLISTER, C.K.; GRAY, P.J. Multidrugresistant Acinetobacter extremity infections in soldiers. Emerging Infectious Diseases, v.11, p.1218-1224, 2005.

DE KEERSMAECKER, S.C.J.; SONCK, K.; VANDERLEYDEN, J. Let LuXS speak up in Al-2 signaling. Trends in Microbiology, v.14, p.114-119, 2006.

DI POPOLO, A.; GIANNOULI, M.; TRIASSI, M.; BRISSE, S.; ZARRILLI, R. Molecular epidemiological investigation of multidrug-resistant Acinetobacter baumannii strains in four Mediterranean countries with a multilocs sequence typing scheme. Clinical Microbiology and Infection, v.17, p.197-201; 2011.

DIJKSHOORN, L.; AUCKEN, H.M.; GERNER-SMIDT, P.; KAUFMANN, M.E.; URSNG, J.; PITT, T.L. Correlation of typing methods for Acinetobacter isolates from hospital outbreaks. Journal of Clinical Microbiology, v.31, p.702-705, 1993.

DIJKSHOORN, L.; NEMEC, A.; SEIFERT, H. An increasing threat in hospitals multidrug-resistant Acinetobacter baumannii. Nature Reviews Microbiology, v.5, p.939-951, 2007.

DIJKSHOORN, L.; VAN HARSSELAAR, B.; TJERNBERG, I.; BOUVET, P.J.; VANEECHOUTTE, M. Evaluation of amplified ribossomal DNA restriction analysis for identification of Acinetobacter genomic species. Systematic and Applied Microbiology, v.21, n.1, p.33-9, 1998.

DIJKSHOORN, L.; VAN AKEN, E.; SHUNBURNE, T.J.; VAN DER REIJDEN, BERNARDS, A.T.; NEMED, A.; TOWNES, K.J. Prevalence of Acinetobacter baumannii and other Acinetobacter spp. In faecal samples from nonhospitalised individuals. Clinical Microbiology and Infection, v.11, p.329-332, 2005.

DOLZANI, L.; TONIN, E.; LAGATOLLA, C.; PRANDIN, L.; MONTI-BRAGADIN, C. Identification of Acinetobacter isolates in the $A$. calcoaceticus- $A$. baumannii complex by restriction analysis of the 16S-23S rRNA intergenic-spacer sequences. Journal of Clinical Microbiology, v.33, n.5, p.1108-1113, 1995. 
DONLAN, R.M.; COSTERTON, J.W. Biofilms: survival mechanism of clinically relevant microorganisms. Clinical Microbiology Reviews, v.15, p.167-193, 2002.

DONNARUMMA, F.; SERGI, S.; INDORATO, C.; MASTROMEI, G.; MONNANNI, R.; NICOLETTI, P.; PECILE, P.; CECCONI, D.; MANNINO, R.; BENCINI, S.; FANCI, R.; BOSI, A.; CASALONE, E. Molecular characterization of Acinetobacter isolates collected intesive care units of six hospitals in Florence, Italy, during a 3-year surveillance program: a population structure analysis. Journal of Clinical Microbiology, v.48, p.1297-1304, 2010.

DUPONT, M.; PAGES, J.M.; LAFITTE, D.; SIROY, A.; BOLLET, C. Identification of an OprD homologue in Acinetobacter baumannii. Journal of Proteome Research, v.4, p.2386-2390, 2005.

DURMAZ, R.; OTLU, B.; KOKSAL, F.; HOSOGLU, S.; OZTURK, R.; ERSOY, Y.; AKTAS, E.; GURSOY, N.C.; CALISKAN, A. The optimization of a rapid pulsed-field gel electrophoresis protocol for the typing of Acinetobacter baumannii, Escherichia coli and Klebsiella spp. Japanese Journal of Infectious Diseases, v.62, p.372-377, 2009.

DURMAZ, R.; OTLU, B.; KOKSAL, F.; HOSOGLU, S.; OZTURK, R.; ERSOY, Y.; AKTAS, E.; GURSOY, N.C.; CALISKAN, A. The optimization of a rapid pulsed-field gel electrophoresis protocol for the typing of Acinetobacter baumannii, Escherichia coli and Klebsiella spp. Japanese Journal of Infectious Diseases, v.62, p.372-377, 2009.

ELLINGTON, M.J.; KISTLER, J.; LIVERMORE, D.M.; WOODFORD, N. Multiplex PCR for rapid detection of genes encondig acquired metallo-betalactamases. Journal of Antimicrobial Chemotherapy, v.59, p.321-322, 2007.

FALAGAS, M.E.; BLIZIOTIS, I.A.; SIEMPOS, I.I. Attributable mortality of Acinetobacter baumannii infections in critically ill patients: a systematic review of matched cohort an case-control studies. Critical Care, v.10, R48, 2006.

FALAGAS, M.E.; BLIZIOTIS, I.A. Pandrug-resistant gram-negative bacteria: the dawn of the post-antibiotic era? International Journal of Antimicrobial Agents, v.29, p.630-636, 2007.

FERNANDEZ-CUENCA, F.; MARTINEZ-MARTINEZ, L.; CONEJO, M.C.; AYALA, J.A.; PEREA, E.J.; PASCUAL, A. Relationship between beta-lactamase production, outer membrane protein and penicillin-binding protein profiles on the activity of carbapenems against clinical isolates of Acinetobacter baumannii. Journal of Antimicrobial Chemotherapy, v.51, p.565-574, 2003. 
FUQUA, W.C.; WINANS, S.C.; GREENBERG, E.P. Quorum sensing in bacteria: the LuxR-Luxl family of cell density-responsive transcriptional regulators. Journal of Bacteriology, v.176, v.2, p.269-275, 1994

FUQUA, W.C.; PARSEK, M.R.; GREENBERG, E.P. Regulation of gene expression by cell-to-cell communication: acyl-homoserine lactone quorum sensing. Annual Review of Genetics, v.35, p.439-468, 2001.

GADDY, J.A.; ACTIS, L.A. Regulation of Acinetobacter baumannii biofilm formation. Future Microbiology, v.4, p.273-278, 2009.

GALES, A.C.; TOGNIM, M.C.; REIS, A.O.; JONES, R.N.; SADERM H.S. Emergence of an IMP-like metallo-enzyme in an Acinetobacter baumannii clinical strain from a Brazilian teaching hospital. Diagnostic Microbiology and Infectious Disease, v.45, p.77-79, 2003.

GARCIA-ARATA, M.O.; GERNER-SMIDT, P.; BAQUERO, F.; IBRAHIIM, A. PCR-amplified $16 S$ and 23S rDNA restriction analysis for the identification of Acinetobacter strains at the DNA group levels. Research Microbiology, v.148, p.777-784, 1997.

GERNER-SMIDT, P. Ribotyping of the Acinetobacter calcoaceticusAcinetobacter baumannii complex. Journal of Clinical Microbiology, v.30, n.10, p.2680-2685, 1992.

GERNER-SMIDT, P.; TJERNBERG, I. Acinetobacter in Denmark: II. Molecular studies of the Acinetobacter calcoaceticus-Acinetobacter baumannii complex. APMIS, V.101, P.826-832, 1993.

GERNER-SMIDT, P.; TJERNBERG, I.; URSING, J. Reliability of phenotypic tests for identification of Acinetobacter species. Journal of Clinical Microbiology, v. 2, p.277-282, 1991.

GKRANIA-KLOTSAS, E.; HERSHOW, R.C. Colonization or infection with multidrug-resistant Acinetobacter baumannii may be an independent risk factor for increased mortality. Clinical Infectious Disease, v. 43, p.1224-1225, 2006.

GOIC-BARISIC, I.; TOWNER, K.J.; KOVACIC, A.; SISKO-KRALJEVIC, K.; TONKIC, M.; NOVAK, A.; PUNDA-POLIC, V. Outbreak in Croatia caused by new carbapenem-resistant clone of Acinetobacter baumannii producinf OXA-72 carbapenemase. Journal of Hospital Infection, v.77, p.368-369, 2011.

GONÇALVES, E.R.; ROSATO, Y.B. Phylogenetic analysis of Xanthomonas species based upon 16S-23S rDNA intergenic spacer sequences. International Journal of Systematic Evolutionary Microbiology, v.52, n.2, p.355-361, 2002. 
GONZÁLEZ, R.H.; DIJKSHOORN, L.; VAN DEN BARSELAAR, M.; NUDEL, C. Quorum sensing signal profile of Acinetobacter strains from nosocomial and environmental sources. Revista Argentina de Microbiología, v.41, p.73-78, 2009.

GOUBY, A.; CARLES-NURIT, M.J.; BOUZIGES, N.; BOURG, G.; MESNARD, R.; BOUVET, P.J. Use of pulsed-field gel electrophoresis for investigation on hospital outbreaks of Acinetobacter baumannii. Journal of Clinical Microbiology, v.30, p.1588-1591, 1992.

GRAY, K.M.; GAREY, J.R. The evolution of bacterial Luxl and LuxR quorum sensing regulators. Microbiology, v.147, n.8, p.2379-2387, 2001.

GROSSO, F, CARVALHO, K.R.; QUINTEIRA, S. RAMOS, A.; CARVALHOASSEF, A.P.; ASENSI, M.D.; PEIXE, L. OXA-23-producing Acinetobacter baumannii: a new hotspot of diversity in Rio de Janeiro? Journal of Antimicrobial Chemotherapy, v. 66, p.62-65, 2011.

GUASP, C.; MORRE, E.R.B.; LALUCAT, J.; BENNASAR, A. Utility of internally transcribed 16S-23S rDNA spacer regions for the definition of Pseudomonas stutzeri genomovars and other Pseudomonas species. International Journal of Systematic Evolutionary Microbiology, v.50, n.4, p.1629-1639, 2000.

GUNDI, V.A.; DIJKSHOORN, L.; BURIGNAT, S.; RAOULT, D.; LA SCOLA, B. Validation of partial rpoB gene sequence analysis for the identification of clinically important and emerging Acinetobater species. Microbiology, v.55, p.2333-2341, 2009.

GUPTA, V. Metallo-beta-lactamases in Pseudomonas aeruginosa and Acinetobacter species. Expert Opinion on Investigational Drugs, v.17, p.131143, 2008.

HALL, T.A. Bioedit: a user-friendly biological sequence aligment editor and analysis program for Windows 95/98/NT. Nucleic Acids Symposium Series, v.41, p.95-98, 1999.

HERITIER, C. DUBOUIX, A. POIREL, L. MARTY, N.; NORDMANN, P. A nosocomial outbreak of Acinetobacter baumannii isolates expressing the carbapenem-hydrolysing oxacillinase OXA-58. Journal of Antimicrobial Chemotherapy, v.55, p.115-118, 2005.

HIGGINS, P.G.; POIREL, L.; LEHMANN, M.; NORDMANN, P.; SEIFERT, H. OXA-143, a novel carbapenem-hydrolyzing class $D$ beta-lactamase in Acinetobacter baumannii. Antimicrobial Agents and Chemotherapy, v.53, p.5035-5038, 2009. 
HIGGINS, P.G.; WISPLINGHOFF, H.; KRUT, O.; SEIFERT, H. A PCR-based method to differentiate between Acinetobacter baumannii and Acinetobacter genomic species 13TU. Journal of Clinical Microbiology and Infection, v.13, p.1199-1201, 2007.

HIGGINS, P.G.; LEHMANN, M.; WISPLINGHOFF, H.; SEIFERT, H. gyrB multiplex PCR to differentiate between Acinetobacter calcaoceticus and Acinetobacter genomic species 3. Journal of Clinical Microbiology, v.48, p.4592-4594, 2010.

HORREVORTS, A.; BERGMAN, K.; KOLLEE, I.; BREUKER, I.; TJERNBERG, I.; DIJKSHOORN, I. Clinical and epidemiological investigations of Acinetobacter genomospecies 3 in a neonatal intensive care unit. Journal of Clinical Microbiology, v.33, n.6, p.1567-1572, 1995.

HOUANG, E.T.; CHU, Y.M.; CHU, K.Y.; NQ, K.C.; LEUNG, C.M.; CHENG, A.F. Significance of genomic DNA group delineation in comparative sutides of antimicrobial susceptibility of Acinetobacter spp. Antimicrobial Agents Chemotherapy, v. 47, p.1472-1475, 2003.

HOUANG, E.T.; CHU, Y.W.; LEUNG C.M.; CHU, K.Y.; BERLAU, J.; NG, K.C.; CHENG, A.F. Epidemiology and infection control implications of Acinetobacter spp. In Hong Kong. Journal of Clinical Microbiology, v.39, p.228-234, 2001.

HUJER, K.M.; HUJER, A.M.; HULTEN, E.A.; BAJAKSOUZIAN, S.; ADAMS, J.M.; DONSKEY, C.J.; ECKER, D.J.; MASSIRE, C.; ESHOO, M.W.; SAMPATH, R.; THOMSON, J.M.; RATHER, P.N.; CRAFT, D.W.; FISHBAIN, J.T.; EWELL, A.J.; JACOBS, M.R.; PATERSON, D.L.; BONOMO, R.A. Analysis of antibiotic resistance genes in multidrug-resistant Acinetobacter sp. isolates from military and civilian patients treated at the Walter Reed Army Medical Center. Antimicrobial Agents Chemotherapy, v. 50, p.4114-4123, 2006.

IBRAHIM, A.; GERNER-SMIDT, P.; LIESACK, W. Phylogenetic relationship of the twenty-one DNA groups of the genus as revealed by $16 \mathrm{~S}$ ribosomal DNA sequence analysis. International Journal of Systematic Bacteriology, v.47, n.3, p.837-841, 1997.

JANSSEN, P.; MAQUELIN, K.; COOPMAN, R.; TJERNBERG, I.; BOUVET, P.; KERSTERS, K.; DIJKSHOORN, L. Discrimination of Acinetobacter genomic species by AFLP fingerprinting. International Journal of Systematic Bacteriology, v.47, p.1179-1187, 1997.

JAWAD, A., SEIFERT, H., SNELLING, A.M., HERITAGE, J., HAWKEY, P.M. Survival of Acinetobacter baumannii on dry surfaces: comparison of outbreak and sporadic isolates. Journal of Clinical Microbiology, v.36, n.7, p.19381941, 1998. 
JEON, B.C.; JEONG, S.H.; BAE, I.K.; KWON, S.B.; LEE, K.; YOUNG, D.; LEE, J.H.; SONG, J.S.; LEE, S.H. Investigationof a nosocomial outbreak of imipenem-resistant Acinetobacter baumannii producing the OXA-23 betalactmase in Korea. Journal of Clinical Microbiology, v. 43, p. 2241-2245, 2005.

JERASSY, Z.; YINNON, A.M.; MAZOUZ-COHEN, S.; BENENSON, S.; SCHLESINGER, Y.; RUDENSKY, B.; RAVEH, D. Prospective hospital-wide studies of 505 patients with nosocomial bacteraemia in 1997 and 2002. Journal of Hospital Infection, v.62, p.230-236, 2006.

JOLY-GUILLOU, M.L. Clinical impact and pathogenicity of Acinetobacter. Clinical Microbiology and Infection, v.11, p.868-873, 2005.

JUNI, E. Genetics and physiology of Acinetobacter. Annual Review of Microbiology, v.32, p.349-371, 1978.

KASHIWAGI, K.; MIYAJI, A.; IKEDA, S.; TOBE, T.; SASAKAWA, C.; IGARASHI, K. Increase of sensitivity to aminoglycoside antibiotics by polyamine-induced protein (oligopeptide-binding protein) in Escherichia coli. Journal of Bacteriology, v. 174, p.4331-4337, 1992.

KELLER, L.; SURETTE, M.G. Communication in bacteria: an ecological and evolutionary perspective. Nature Review Microbiology, v.4, n.4, p.249-58, 2006.

KING, L.B.; SWIATLO, E.; SWIATLO, A.; MCDANIEL, L.S. Serum resistance and biofilm formation in clinical isolates of Acinetobacter baumannii. FEMS Immunology and Medical Microbiology, v.55, p.414-421, 2009.

KOH, T.H.; SNG, L.H.; WANG, G.C.; HSU, L.Y.; ZHAO, Y. IMP-4 and OXA beta-lactamases in Acinetobacter baumannii from Singapore. Journal of Antimicrobial Chemotherapy, v. 59, p.627-632, 2007.

KOELEMAN, J.G.; STOOF, J.; BIESMANS, D.J.; SAVELKOUL, P.H.; VANDENBROUCKE-GRAULS, C.M. Comparison of amplified ribosomal DNA restriction analysis, random amplified polymorphic DNA analysis, and amplified fragment length polymorphism fingerprinting for identification of Acinetobacter genomic species and typing of Acinetobacter baumannii, Journal of Clinical Microbiology, v. 36, p.2522-2529, 1998.

KRAWCZYK, B.; LEWANDOWSKI, K; KUR, J. Comparative studies of Acinetobacter genus and the species identification method based on the recA sequences. Molecular Cell Probes, v.16, p.1-11, 2002. 
LA SCOLA, B.; GUNDI, V.A.; KHAMIS, A.; RAOULT, D. Sequencing of the rpoB gene and flanking spacers for molecular identification of Acinetobacter species. Journal of Clinical Microbiology, v. 44, p. 827-832, 2006.

LAURETTI, L.; RICCIO, M.L.; MAZZAQRIOL, A.; CORNAGLIA, G.; AMICOSANTE, G.; FONTANA, R.; ROSSOLINI, G.M. Cloning and characterization of blaVIM, a new integron-borne metallo-beta-lactamase gene from a Pseudomonas aerugionsa clinical isolate. Antimicrobial Agents Chemotherapy, v.43, p.1584-1590, 1999.

LAUTROP, H. Bergey's manual of determinative bacteriology. Williams \& Wilkins Co, Baltimore, MD apud PELEG, A.Y.; SEIFERT, H.; PATERSON, D.L. Acinetobacter baumannii: emergence of a successful pathogen. Clinical Microbiology Reviews, v.21, n.3, p.538-582, 2008.

LEE, H.W.; KOH, Y.M.; LEE, J.C.; LEE, Y.C.; SEOL, S.Y.; CHO, D.T.; KIM, J. Capacity of multidrug-resistant clinical isolates of Acinetobacter baumannii to form biofilm adhere to epithelial cell surfaces. Clinical Microbiology and Infection, v.14, n.1, p.49-54, 2008.

LEE, J.H.; CHOI, C.H.; KANG, H.Y.; LEE, J.Y.; KIM, J.; LEE, Y.C.; SEOL, S.Y.;CHO, D.T.; KIM, K.W.; SONG, D.Y.; LEE, J.C. Differences in phenotypic and genotypic traits against antimicrobial agents between Acinetobacter baumannii and Acinetobacter genomic species 13TU. Journal of Antimicrobial Chemotherapy,v.59, p.633-639, 2007.

LEE, K.; LEE, W.G.; UH, Y.; HA, G.Y.; CHO, J.; CHONG, Y.; KOREAN NATIONWIDE SURVEILLANCE OF ANTIMICROBIAL RESISTANCE GROUP. VIM- and IMP-type metallo-B-lactamase-producing Pseudomonas spp. and Acinetobacter sp. In Korean Hospitals. Emergence Infectious Diseases, v.9, p.868-871, 2003.

LEE, K.; YUM, J.H.; YONG, D.; LEE, H.M.; KIM, H.D.; DOCQUIER, J.D.; ROSSOLINI, G.M.; CHONG, Y. Novel acquired metallo-beta-lactamase gene, bla(SIM-1), in a class 1 integron from Acinetobacter baumannii clinical isolates from Korea. Antimicrobial Agents and Chemotherapy, v.49, p.4485-4491, 2005.

LEUNG, W.S., CHU, C.M.; TASANG, K.Y.; LO, F.H.; LO, K.F.; HO, P.L. Fulminant community-acquired Acinetobacter baumannii pneumonia as a distinct clinical synfrome. Chest, v.129, p.213-214, 2006.

LIN, Y.M.;SHIN, K.S.; KIM, J. Distinct antimicrobial resistance patterns and antimicrobial resistance-harboring genes according to genomic species of Acinetobacter isolates. Journal of Clinical Microbiology, v.45, p.902-905, 2007. 
LIN, W.R.; LU, P.L.; SIU, L.K.; CHEN, T.C.; LIN, C.Y.; HUNG, C.T.; CHEN, Y.H. Rapid control of a hospital-wide outbreak caused by extensively drug-resistant OXA-72 producing Acinetobacter baumannii. The Kaohsiung Journal of Medical Science, v.27, p.207-214, 2011.

LIVERMORE, D.M. Beta-lactamses in laboratory and clinical resistance. Clinical Microbiology Reviews, v.8, p.557-584, 1995.

LIVERMORE, D.; WOODFORD, N. Carbapenemases: a problem in waiting? Current Opinion in Microbiology, v.3, p.489-495, 2000.

MAK, J.K.; KIM, M.J.; PHAM, J.; TAPSALL, J.; WHITE, P.A. Antibiotic resistance determinants in nosocomial strains of multidrug resistant Acinetobacter baumannii. Journal of Antimicrobial Chemotherapy, v.63, p.47-54, 2009.

MAIDEN, M.C.; BYGRAVES, J.A.; FEIL, E.; MORELLI, G.; RUSELL, J.E.; URWIN, R.; ZHANG, Q.; ZHOU, J.; ZURTH, K.; CAUGANT, D.A.; FEAVERS, I.M.; ACHTMAN, M.; SPRATT, B.G. Multilocus sequence typing: a portable approach to the identification of clones within populations of pathogenic microorganisms. Proceedings of the National Academy of Sciences of the United States of America, v.95, p.3140-3145, 1998.

MANDELL, L.A.; CAMPBELL Jr., G.D. Nosocomial pneumonia guidelines: an international perspective. Chest, v.113, suppl.3, p.188-193, 1998.

MARCHESI, J.R.; SATO, T.; WEIGHTMAN, A.J.; MARTIN, T.A.; FRY, J.C.; HIOM, S.J.; DYMOCK, D.; WADE, W.G. Design and evaluation of useful bacterium-specific PCR primers that amplify genes coding for bacterial $16 \mathrm{~S}$ rRNA. Applied and Environmental Microbiology, v.64, p.795-799, 1998.

MARTINS, A.F.; KUCHENBECKER, R. SUKIENNIK, T.; BOFF, R.; REITER, K.C.; LUTZ, L.; MACHADO, A.B.; BARTH, A.L. Carbapenem-resistant Acinetobacter baumannii producing the OXA-23 enzyme dissemination in Southern Brazil. Infection, v. 37, p.474-476, 2009.

MCCLEAN, K.H.; WINSON, M.K.; FISH, L.; TAYLOR, A.; CHHABRA, S.R.; CAMARA, M.; DAYKIN, M.; LAMB, J.H.; SWIFT, S.; BYCROFT, B.W.; STEWART, G.S.; WILLIAMS, P. Quorum sensing and Chromobacterium violaceum: exploitation of violacein production and inhibition for the detection of $\mathrm{N}$-acyl-homoserine lactones. Microbiology, v.143, p.3703-3711, 1997.

MILLER, J.H. Experiments in molecular genetics. Cold Spring Harbor: Cold Spring Harbor Laboratory, 1972. 466p. 
MILLER, M.B.; BASSLER, B.L. QS in bacteria. Annual Review of Microbiology, v.55, p.165-199, 2001.

Ministério da Saúde Brasil. Portaria n.196, de 24 de junhode 1983. Diário oficial da União, Brasília, 28 de junho de 1983. Seção 1. Dispõe sobre o controle e prevenção das infecções hospitalares.

MOLINA, J.; CISNEROS, J.M.; FERNÁNDEZ-CUENCA, F.; RODRÍGUZ-BAÑO, J.; RIBERA, A.; BECEIRO, A.; MARTÍNEZ-MARTÍNEZ, L.; PASCAL, A.; BOU, G.; VILA, J.; PACHÓN, J.; SPANISH GROP OF NOSOCOMIAL INFECTION (GEIH). Clinical features of infections and colonization by Acinetobacter genospecies 3. Journal of Clinical Microbiology, v.48, p.4623-4626, 2010.

NAAS, T.; LEVY, M.; HIRSCHAUER, C.; MARCHANDIN, H.; NORDMANN, P. Outbreak of carbapenem-resistant Acinetobacter baumannii producing the carbapenemase OXA-23 in a tertiary care hospital of Papeete, French, Polynesia. Journal of Clinical Microbiology, v. 43, p.4826-4829, 2005.

NAAS, T.; NORDMANN, P. OXA-type beta lactmases. Current Pharmaceutical Design, v.5, p.865-879, 1999.

NEMEC, A.; DIJKSHOORN, L.; CLEENWERCK, I.; DE BAERE, T.; JANSSENS, D.; VAN DER REIJDEN, T.J.; JEZEK, P.; VANEECHOUTTE, M. Acinetobacter parvus sp. nov., a small-colony-forming species isolated from human clinical specimens. International Journal of Systematic and Evolutionary Microbiology, v. 53, p.1563-1567, 2003.

NEMEC, A.; JANDA, L.; MELTER, O.; DIJKSHOORN, L. Genotypic and phenotypic similarity of multiresistant Acinetobacter baumannii isolates in the Czech Republic. Journal of Medical Microbiology, v.48, p.287-296, 1999.

NEMEC, A.; KRIZOVA, L.; MAIXNEROVA, M.; VAN DER REIJDEN, T.J.; DESCHAGHT, P.; PASSET, V.; VANEECHOUTTE, M.; BRISSE, S.; DIJKSHOORN, L. Genotypic and phenotypic characterization of the Acinetobacter calcaoceticus-Acinetobacter baumannii complex with the proposal of Acinetobacter pittii sp. nov. (formely Acinetobacter genomic species 3 ) and Acinetobacter nosocomialis sp. nov. (formerly Acinetobacter genomic species 13TU). Research in Microbiology, v.162, p.393-404, 2011.

NISHIMURA, Y.; INO, T.; IIZUKA, H. Acinetobacter radioresistens sp. nov. isolated from cotton and soil. International Journal of Systematic Bacteriology, v. 38, p.209-211, 1988.

Nishio, H.; KOMATSU, M. SHINATA, N.; SHIMAKAWA, K.; SUEYOSHI, N.; URA, T. SATOH, K.; TOYOKAWA, M.; NAKAMURA, T.; WADA, Y.; ORITA, T.; KOFUKU, T.; YAMASAKI, K.; SAKAMOTO, M.; KINOSHITA, S.; AIHARA, M.; 
ARAKAWA, Y. Metallo-beta-lactamase-producing gram-negative bacilli: labnoratory-based surveillance in cooperation with 13 clinical laboratories in the Kinki region of Japan. Journal of Clinical Microbiology, v. 42, p.5256-5263, 2004.

NIU, C.; CLEMMER, K.M.; BONOMO, R.A.; RATHER, P.N. Isolation and characterization of an autoinducer synthase from Acinetobacter baumannii. Journal of Bacteriology, v.190, p.3386-3392, 2008.

NOWAK, A.; KUR, J. Differentiation of seventeen genospecies of Acinetobacter by multiplex polymerase chains reaction and restriction fragment length polymorphism analysis. Molecular Cell Probes, v. 10, p.405-411, 1996.

O'TOOLE, G.A.Microtiter dish biofilm formation assay. Journal of Visualized Experiments, v.30, p. 2437, 2011.

PANNUTI, C.S.; GRINBAUM, R.S. An overview of nosocomial infection control infection control in Brazil. Infectin Control Hospital Epidemiology,v.16, p.170174, 1995.

PATON, R.; MILES, R.S.; HOOD, J.; AMYES, S.G.B. ARI-1: $\beta$-lactamasemediated imipenem resistance in Acinetobacter baumannii. International Journal of Antimicrobial Agents, v.2, p.81-87, 1993.

PELEG, A.Y.; SEIFERT, H.; PATERSON, D.L. Acinetobacter baumannii: emergence of a successful pathogen. Clinical Microbiology Reviews, v.21, n.3, p.538-582, 2008.

PEREZ, F.; HUJER, A.M.; HUJER, K.M.; DECKER, B.K.; RATHER, P.N.; BONOMO, R.A. Global challenge of multidrug-resistant Acinetobacter baumannii. Antimicrobial Agents and Chemotherapy, v.51, n.10, p.34713484, 2007.

POIREL L.; FIGUEIREDO, S.; CATTOIR, V.; CARATTOLI, A.; NORDMANN, P. Acinetobacter radioresistens as a silent source of carbapenem resistance for Acinetobacter spp. Antimicrobial Agents and Chemotherapy, v.52, p.12521256, 2008.

POIREL, L. NAAS, T.; NICOLAS, D.; COLLET, L.; BELLAIS, S.; CAVALLO, J.D.; NORDMANN, P. Characterization of VIM-2, a carbapenem-hydrolyzing metallo-betalamase and its plasmis and integron-borne gene from a Psedomonas aeruginosa clinical isolate in France. Antimicrobial Agents and Chemotherapy, v.44, p.891-897, 2000. 
POIREL, L.; NAAS, T.; NORDMANN, P. Diversity, epidemiology, and genetics of class $D \beta$-lactamases. Antimicrobial Agents and Chemotherapy, v.54, p24-38, 2010.

POIREL, L.; NORDMANN, P. Carbapenem resistance in Acinetobacter baumannii: mechanisms and epidemiology. Clinical Microbiology Reviews, v.12, p.826-836, 2006.

PRASHANTH, K.; BADRINATH, S. Epidemiological investigation of nosocomial Acinetobacter infections using arbitrarily primed PCR \& pulse field gel electrophoresis. The Indian Journal of Medical Research, v. 122, p.408-418, 2005.

QUEENAN, A.M.; BUSH, K. Carbapenemases: the versatile beta-lactamases. Clinical Microbiology Reviews, v.20, p.440-458, 2007.

RASKO, D.A.; MOREIRA, C.G.; LI, R.; READING, N.C.; RITCHIE, J.M.; WALDOR, M.K.; WILLIANS,N.; TAUSSIG, R.; WEI, S.; ROTH, M.; HUGHES, D.T.; HUNTLEY, J.F.; FINA, M.W.; FALCK, J.R.; SPERANDIO, V. Targeting QseC signaling and virulence for antibiotic development. Science, v.321, p.1078-1080, 2008.

RASKO, D.A.; SPERANDIO, V. Anti-virulence strategies to combat bacteriamediated disease. Nature Reviews. Drug Discovery, v.9, p.117-128, 2010.

RAMUSSEN, B.A; BUSH, K. Carbapenem-hydrolyzing beta-lactamases. Antimicrobial Agents Chemotherapy, v.41, p.223-232, 1997.

RAVN, L.; CHRISTENSEN, A.B.; MOLIN S.; GIVSKOV, M.; GRAM, L. Methods for detecting acylated homoserine lactones produced by Gram-negative bacteria and their application in studies of AHL-production kinetics. Journal of Microbiological Methods, v.44, p.239-251, 2001.

RICCIO, M.L.; FRANCESCHINI, N.; BOSCHI, L.; CARAVELLI, B.; CORNAGLIA, G.; FONTANA, R.; AMICOSANTE, G.; ROSSOLINI, GM.M. Characterization of the matello-beta-lacamase determinant of Acinetobacter baumannii AC-54/97 reveals the existentce of bla (IMP) allelic variants carried by gene cassettes of different phylogeny. Antimicrobial Agents Chemortherapy, v.44, p.1229-1235.

ROBENSHTOK, E.; PAUL, M.; LEIBOVICI, L.; FRASER, A.; PITLIK, S.; OSLFELD, I.; SAMRA, Z.; PEREZ, S.; LEV, B.; WEINBERGER, M. The significance of Acinetobacter baumannii bacteremias compared with Klebsiella pneumonia bacteraemia: risk factors and outcomes. Journal of Hospital Infection, v.64, p.282-287, 2006. 
RODLOFF, A.C.; GOLDSTEINM E.J.; TORRES, A. Two decades of imipenem therapy. Journal of Antimircobial Chemotherapy, v. 58, p.916-929, 2006.

SADER, H.S.; JONES, R.N.; GALES, A.C.; SILVA, J.B.; PIGNATARI, A.C. SENTRY Antimicrobial Surveillance Program Report: Latin American and Brazilian results for 1997 through 2001. Brazilian Journal of Infection Diseases, v.8, n.1, p.25-79, 2004.

SADER, H.S.; MENDES, R.E.; GALES, A.C.; JONES, R.N.; PFALLER, M.A.; ZOCCOLI, C.; SAMPAIO, J. Perfil de sensibilidade a antimicrobianos de bactérias isoladas do trato respiratório baixo de pacientes com pneumonia internado em hospitais brasileiros - Resultado do programa SENTRY, 1997 e 1998. Jornal de Pneumologia, v. 27, p.59-67, 2001.

SCHAUDER, S.; BASSLER, B.L. The languages of bactéria. Genes \& Development, v.15, p.1468-1480, 2001.

SCHIMITH-BIER, K.E.; LUIZ, S.O.; SCHEFFER, M.C.; GALES, A.C.; PAGANINI, M.C.; NASCIMENTO, A.J.; CARIGNANO, E; DALLA COSTA, L.M. Temporal evolution of carbapenem-resistant Acinetobacter baumannii in Curitiba, southern Brazil.American Journal of Infection Control., v.38, p.308314, 2010.

SEGAL, H. GARNY, S.; ELISHA, B.G. Is IS(ABA-1) customized for Acinetobacter? FEMS Microbiology Letters, v.243, p.425-429, 2005.

SEIFERT, H.; BAGINSKI, R.; SCHULZE, A.; PULVERER, G. The distribution of Acinetobacter species in clinical culture materials. Zentralblatt für. Bakteriologie, v.279, p.544-552, 1993.

SEIFERT, H.; STRATE, A.; SCHULZE, A.; PULVERER, G. Bacteremia due to Acinetobacter species other than Acinetobacter baumannii. Infection, v.22, p.379-385, 1994.

SEKIGUCHI, J.; MORITA, K.; KITAO, T. WATANABE, N.; OKAZAKI, M.; MIYOSHI-AKIYAMA, T.; KANAMORI, M.; KIRIKAE, T. KHM-1, a novel plasmidmediated metallo-beta-lactamase from a Citrobacter freundii clinical isolate. Antimicrobial Agents and Chemotherapy, v.52, p.4194-4197.

SHAPIRO, J.A. Thinking about bacterial populations as multicellular organisms. Annual Review of Microbiology, v.52, p.81-104, 1998.

SHENG, W.; WANG, J.; LI, S.; LIN, Y.; CHENG, A.; CHEN, Y.; CHANG, S. Comparative in vitro antimicrobial susceptibilities and synergistic activities of antimicrobial combinations against carbapenem-resistant Acinetobacter 
species: Acinetobacter baumannii versus Acinetobacter genospecies 3 and 13TU. Diagnostic Microbiology and Infectiou Disease, 2011. [No Prelo].

SHIBATA, N.; DOI, Y.; YAMANE, K.; YAGI, T.; KUROKAWA, H.; SHIBAYAMA, K.; KATO, H.; KAI, K.; ARAKAWA, Y. PCR typing of genetic determinants for metallo-beta-latamases and integrases carried by gram-negative bacteria isolated in Japana, with focus on the class 3 integron. Journal of Clinical Microbiology. v.41, p.5407-5013, 2003.

SINGH, A.; GOERING, R.V.; SIMJEE, S.; FOLEY, S.L.; ZERVOS, M.J. Application of molecular techniques to the study of hospital infection. Clinical Microbiology Reviews, v. 19, p.512-530.

SIROY, A.; MOLLE, V.; LEMAITRE-GILLIER, C.; VALLENET, D.; PESTELCARON, M.; COZZONE, A.J.; JOUENNE, T.; DE, E. Channel formation by CarO, the carbapenem resistance-associated outer membrane protein of Acinetobacter baumannii. Antimicrobial Agents and Chemotherapy, v.49, p.1432-1440, 2005.

SLAMA, T.G. Gram-negative antibiotic resistance: there is a price to pay. Critical Care, S.4, 2008.

SMITH, J.L.; FRATAMICO, P.M.; NOVAK, J.S. Quorum sensing: a primer for food microbiologists. Journal of Food Protection, v.67, n.5, p.1053-1070, 2004.

SPERANDIO, V.; MELLIES, J.L.; NGUYEN, W.; SHIN, SOOAN, KAPER, J.B. Quorum sensing controls expression of type III secrete gene transcription and protein secretion in enterohemorragic and enteropathogenic Escherichia coli. Proceedings of the National Academy of Science of the United States of America, v.96, p.15196-15201, 1999.

SPERANDIO, V.; TORRES, A.G.; JARVES, B.; NATARO, J.P.; KAPER, J.B. Bacteria-host communication: the language of hormones. Proceedings of the National Academy of Science, v.100, p.8951-8956, 2003.

StatSoft. Statistica: data analysis software system. Version 9.1. Pittsburg: StatSoft Event Center, 2010.

STRULENS, M.J.; CARLIER, E.; MAES, N.; SERRUYS, E.; QUINT, W.G; VAN BELKUM, A. Nosocomial colonization and infection with multiresistant Acinetobacter baumannii: outbreak delineation using DNA macrorestriction analysis and PCR-fingerprinting. Journal of Hospital Infection, v.25, p.15-32, 1993. 
SUN, J.; DANIEL, R.; WAGNER-DÖBLER, I.; ZENG, A.P. Is autoinducer-2 a universal signal for interspecies communication: a comparative genomic and phylogenetic analysis of the synthesis and signal transduction pathways. BMC Evolutionary biology, v.4, p.36, 2004.

SURETTE, M.G.; BASSLER, B.L. Quorum sensing in Escherichia coli and Salmonella typhymurium. Proceedings of the National Academy of Science of the United States of America, v.95, p.7046-7050, 1998.

TAKAHASHI, A.; YOMODA, S.; KOBAYASHI, I.; OKUBO, T.; TSUNODA, M.; IYOBE, S. Detection of carbapenemase-producing Acinetobacter baumannii in a hospital. Journal of Clinical Microbiology, v.38, p.526-529, 2000.

TAKAGI, E.H.; LINCOPAN, N.; CASSETTARI, V.C.; PASSADORE, L.F.; MAMIZUKA, E.M.; MARTINEZ, M.B. Carvapenem-resistant Acinetobacter baumannii outbreak at university hospital. Brazilian Journal of Microbiology, v.40, p.339-341, 2009.

TJERNBERG, I.; URSING, J. Clinical strains of Acinetobacter classified by DNA-DNA hydribidization. Acta Patholologica, Microbiologica, et Immunologica Scandinavica, v.97, n.7, p.595-605, 1989.

TOGNIM, M.C.; GALES, A.C.; PENTEADO, A.P.; SILBERT, S.; SADER, H.S. Dissemination of IMP-1 metallo-beta-lactamase-producing Acinetobacter species in a Brazilian teaching hospital. Infection Control and Hospital Epidemiology, v.27, p.742-747, 2006.

TOLEMAN, M.A.; SIMM, A.M.; MURPHY, T.A.; GALES, A.C.; BIEDENBACH, D.J.; JONES, R.N.; WALSH, T.R. Molecular characterization of SPM-1, a novel metallo-betalactamse isoalted in Latin America: report from the SENTRY antimicrobial surveillance programme. Journal of Antimicrobial Chemotherapy, v.50, p.673-679, 2002.

TUROVSKIY, Y.; CHINKIDAS, M. Autoinducer-2 bioassay is a qualitative, not quantitative method influenced by glucose. Journal of Microbiology Methods, v.66, p.497-503, 2006.

TURTON, J.F.; SHAH, J.; OZONGWU, C.; PIKE, R. Incidence of Acinetobacter species other than $A$. baumannii among isolates of Acinetobacter: evidence for emerging species. Journal of Clinical Microbiology, v.48, p.1445-1449, 2010.

TURTON, J.F., WARD, M.E.; WOODFORD, N.; KAUFMANN, M.E.; PIKE, R.; LIVERMORE, D.M.; PITT, T.L. The role of ISAba1 in expression of OXA carbapenemase genes in Acinetobacter baumannii. FEMS Microbiology Letters, v.258, p.72-77, 2006a.

TURTON, J.F.; WOODFORD, N.; GLOVER, J.; YARDE, S.; KAUFMANN, M.E.; PITT, T.L. Identification of Acinetobacter baumannii by detection of the blaOXA- 
51-like carbapenemase gene intrinsic to this species. Journal of Clinical Microbiology, v.44, p.2974-2976, 2006b.

VALENZUELA, J.K.; THOMAS, L.; PARTRIDGE, S.R.; VAN DER REIJDEN T.; DIJKSHOORN, L.; IREDELL, J. Horizontal gene transfer in a polyclonal outbreak of carbapenem-resistant Acinetobacter baumannii. Journal of Clinical Microbiology., v.45, p.453-460, 2007.

VAN DEN BROEK, P.J.; VAN DER REIJDEN, T.J.K.; VAN STRIJEN, E.; HELMIG-SCHURTER, A.V.; BERNARDS, A.T.; DIJKSHOORN. Endemic and epidemic Acinetobacter species in a university hospital: an 8-year survey. Journal of Clinical Microbiology, v.47, p.3593-3599, 2009.

VAN DESSEL, H.; KAMPP-HOPMANS, T.E.M.; FLIT, A.C.; BRISSE, S.; SMET, A.M.G.A.; DIJKSHOORN, L.; TROELSTRA, A.; VERHOEF, J.; MASCINI, E.M. Outbreak of susceptible strains of Acinetobacter species 13 (sensu Tjernberg and Ursing) in an adlt neurosurgical intensive care unit. Journal of Hospital Infection, v.51, p.89-95, 2002.

VANEECHOUTTE, M.; DIJKSHOORN, L.; TJERNBERG, I., ELAICHOUNI, A.; DE VOS, P.; CLAEYS, G.; VERSCHRAEGEN G. Identification of Acinetobacter genomic species by amplified ribossomal DNA restriction analysis. Journal of Clinical Microbiology, v.33, n.1, p.11-15, 1995.

VILLEGAS, M.V.; KATTAN, J.N.; CORREA, A.; LOLANS, K.; GUZMAN, A.M.; WOODFORD, N.; LIVERMORE, D.; QUINN, J.P. Dissemination of Acinetobacter baumannii clones with OXA-23 carbapenemase in Colombian hospitals. Antimicrobial Agents and Chemotherapy, v.51, p.2001-2004, 2007.

WALSH, T.R.; TOLEMAN, M.A.; POIREL, L. NORDMANN, P. Metallo-betalactamases: the quiet before the storm? Clinical Microbiology Reviews, v.18, p.306-325.

WALTHER-RASMUSSEN, J.; HOIBY, N. OXA-type carbapenemases. Journal of Antimicrobial Chemotherapy, v.57, p.373-383, 2006.

WALTERS, M.; SIRCILI, M.P.; SPERANDIO, V. Al-3 synthesis is not dependent on luxS in Escherichia coli. Journal of Bacteriology, v.188, p.56685681, 2006.

WATANABE, M.; IYOBEM S.; INOUE,, M.; MITSUASHI S. Transferable imipenem resistance in Pseudomonas aerginosa. Antimicrobial Agents and Chemotherapy, v. 35, p.147-151, 1991.

WENDT, C.; DIETZE, B.; DIETZ, E.; RUDEN, H. Survival of Acinetobacter baumannii on dry surfaces. Journal of Clinical Microbiology, v.35, n.6, p.1394-1397, 1997. 
WERNECK, J.S.; PICÃO, R.C.; CARVALHAES, C.G.; CARDOSO, J.P.; GALES, A.C. OXA-72-producing Acinetobacter baumannii in Brazil: a case report. Journal of Antimicrobial Chemotherapy, v.66, p.452-454, 2010.

WHITEHEAD, N.A.; BARNARD, A.M.; SLATER, H.; SIMPSON, N.J.; SALMOND, G.P. Quorum sensing in gram negative bacteria. FEMS Microbiology Reviews, v.25, p.365-404, 2001.

WILLIAMS, P.; CAMARA, M.; HARDMAN, A.; SWIFT, S.; MILTON, D.; HOPE, V.J.; WINZER, K.; MIDDLETON, B.; PRITCHARD, D.J.; BYCROFT, B.W. Quorum sensing and the population-dependent control of virulence. Philosophical Transactions of the Royal Society of London, Series B: Biological Sciences, v.355, n.1397, p.667-680, 2000.

WILLIAMS, J.G.K.; KUBELIK, A.R.; LIVAK, K.J.; RAFALSKI, J.A.; TINGEY, S.V. DNA polymorphisms amplified by arbitrary primers are useful as genetic markes. Nucleic Acids Research, v. 18, p.6531-6535, 1990.

WISPLINGHOFF, H.; SCHMITT, R.; WOHRMANN, A,. STEFANIK, D.; SEIFERT, H. Resistance to disinfectants in epidemiologically definied clinical isolates of Acinetobacter baumannii. Journal of Hospital Infection, v.66, n.2, p174-181, 2007.

WISPLINGHOFF, H.; EDMOND, M.B.; PFALLER, M.A.; JONES, R.N.; WENZEL, R.P.; SEIFERT, H. Nosocomial bloodstream infections caused by Acinetobacter species in United States hospitals: clinical features, molecular epidemiology, and antimicrobial susceptibility. Clinical Infectious Diseases, v. 31, p.690-697, 2000.

WOODFORD, N., ELLINGTON, M.J.; COELHO, J.M.; TURTON, J.F.; WARD, M.E.; BROWN, S.; AMYES, S.G.B.; LIVERMORE, D.M. Multiplex PCR for genes encoding prevalent OXA carbapenemases in Acinetobacter spp. International Journal of Antimicrobial Agents, v.27, p.351-353, 2006.

WROBLEWSKA, M.M.; SAWICKA-GRZELAK, A.; MARCHEL, H.; LUCZAK, M.; SIVAN, A. Biofilm production by clinical strains of Acinetobacter baumannii isolated from patients hospitalized in two tertiary care hospitals. FEMS Immunology and Medical Microbiology, v.53, p.140-144, 2008.

YAMAMOTO, S.; HARAYAMA, S. Phylogenetic analysis of Acinetobacter strains based on the nucleotide sequences of gyrB genes and on the amino acid sequences of their products. International Journal of Systematic Bacteriology, v. 43, p.1632-1639, 2005.

YONG D.R.; PRATT, R.; TOLEMAN, M.; WALSH, T. A novel sub-group metallo-b-lactamase (MBL), AIM-1 emerges in Pseudomonas aeruginosa from Australia. In $47^{\text {th }}$ ICAAC. Vol abstract C1-593. Chicago, USA:47 th ICAACp.75, 2007. 
YUM, J.H.; YONG, D.; LEE, K.; KIM, H.S.; CHONG, Y. A new integron carrying VIM-2 metallo-B-lactamase gene cassete in a Serratia marcescens isolate. Diagnostic Microbiology of Infectious Disease, v.42, p.217-219, 2002

ZAVASCKI, A.P.; CARVALHAES, C.G.; PICAO, R.C.; GALES, A.C. Multidrug resistant Pseudomonas aerugiona and Acinetobacter baumannii:resistance mechanisms and implications for therapy. Expert review of Anti-Infective Therapy, v. 8, p.71-93.

ZHOU, H.; PI, B.R.; YANG, Q.; YU, Y.S.; CHEN, Y.G.; LI, L.J.; ZHENG, S.S. Dissemination of imipenem-resistant Acinetobacter baumannii strains carrying the ISAba1 blaoxA-23 genes in a Chinese hospital. Journal of Medical Microbiology, v.56, p.1076-1080, 2007. 
ANEXOS 
Anexo 1 - Relação das 515 amostras bacterianas identificadas e o perfil de susceptibilidade aos antimicrobianos

\begin{tabular}{|c|c|c|c|c|c|c|c|c|c|c|c|c|c|c|c|c|}
\hline Número & identificação & OXAs & Amostra & Ano & Clínica & idade & SAM & FEP & CAZ & CIP & AK & CN & TZP & SXT & IPM & MEM \\
\hline $003 / 05$ & A. baumannii & 23,51 & Secreção & 2005 & Pediatria & 3 & $\mathrm{~S}$ & I & $\mathrm{R}$ & $\mathrm{R}$ & $\mathrm{R}$ & $\mathrm{R}$ & $\mathrm{R}$ & $\mathrm{S}$ & $\mathrm{S}$ & $S$ \\
\hline $007 / 05$ & A. baumannii & 51 & Urina & 2005 & Ambulatório & 71 & S & $\mathrm{R}$ & $\mathrm{R}$ & $\mathrm{R}$ & $\mathrm{R}$ & $\mathrm{R}$ & $\mathrm{R}$ & $\mathrm{R}$ & S & S \\
\hline $008 / 05$ & A. gen. 3 & $\ldots$ & Sangue & 2005 & UTI neonatal & 0 & $S$ & $S$ & $S$ & $S$ & $S$ & $S$ & $S$ & $S$ & $S$ & $S$ \\
\hline $021 / 05$ & A. baumannii & 51 & Urina & 2005 & Pronto socorro & 80 & $S$ & $\mathrm{R}$ & $\mathrm{R}$ & $\mathrm{R}$ & $\mathrm{R}$ & $\mathrm{R}$ & $\mathrm{R}$ & $\mathrm{R}$ & S & $\mathrm{R}$ \\
\hline $022 / 05$ & A. gen. 3 & $\ldots$ & Urina & 2005 & Pronto socorro & 90 & $S$ & $S$ & $S$ & $S$ & $S$ & $S$ & $S$ & $\mathrm{~S}$ & $S$ & $S$ \\
\hline 027/05 & A. gen. $13 \mathrm{TU}$ & $\ldots$ & Urina & 2005 & Ambulatório & 70 & $S$ & $S$ & $S$ & $S$ & $S$ & $S$ & $S$ & $\mathrm{~S}$ & $S$ & $S$ \\
\hline $028 / 05$ & A. gen. 3 & $\ldots$ & Celulite & 2005 & Pronto socorro & 53 & S & S & $\mathrm{S}$ & $\mathrm{S}$ & $\mathrm{S}$ & S & $\mathrm{S}$ & S & S & $\mathrm{S}$ \\
\hline 030/05 & A. baumannii & 51 & Urina & 2005 & Pronto socorro & 80 & $S$ & $S$ & $S$ & $\mathrm{R}$ & $S$ & $S$ & $S$ & $\mathrm{R}$ & $\mathrm{S}$ & $\mathrm{S}$ \\
\hline $043 / 05$ & A. baumannii & 51 & S. traqueal & 2005 & Pediatria & 5 & S & $\mathrm{R}$ & $\mathrm{R}$ & $\mathrm{R}$ & $\mathrm{R}$ & $\mathrm{R}$ & $\mathrm{R}$ & $\mathrm{R}$ & $\mathrm{S}$ & $\mathrm{S}$ \\
\hline 068/05 & A. gen. 3 & $\ldots$ & P. axilar & 2005 & UTI Pediatria & 1 & $S$ & $S$ & $S$ & $S$ & $S$ & $S$ & $S$ & $\mathrm{~S}$ & $\mathrm{~S}$ & $S$ \\
\hline $190 / 05$ & A. gen. 3 & $\ldots$ & S. biliar & 2005 & Clínica cirúrgica & 76 & S & $\mathrm{S}$ & $\mathrm{S}$ & $S$ & $S$ & S & $S$ & $\mathrm{~S}$ & $\mathrm{~S}$ & $S$ \\
\hline $200 / 05$ & A. baumannii & 23,51 & L. peritoneal & 2005 & UTI adulto & 46 & S & I & $\mathrm{R}$ & $\mathrm{R}$ & $\mathrm{R}$ & S & $\mathrm{R}$ & $\mathrm{R}$ & $\mathrm{R}$ & S \\
\hline $202 / 05$ & A. gen. $13 \mathrm{TU}$ & $\ldots$ & Escarro & 2005 & Pronto socorro & 81 & $S$ & $S$ & $S$ & $S$ & $S$ & $S$ & $S$ & $S$ & $S$ & $S$ \\
\hline $203 / 05$ & A. gen. $13 \mathrm{TU}$ & $\ldots$ & Sangue & 2005 & Pronto socorro & meses & $S$ & $S$ & S & S & $S$ & $S$ & $S$ & S & S & S \\
\hline $267 / 05$ & A. gen. $13 \mathrm{TU}$ & ausente & S. traqueal & 2005 & UTI adulto & 64 & $S$ & $S$ & $S$ & $\mathrm{~S}$ & $S$ & $S$ & $S$ & S & $\mathrm{S}$ & $S$ \\
\hline $271 / 05$ & A. baumannii & 51 & T. necrótico & 2005 & Clínica cirúrgica & 25 & $S$ & $\mathrm{R}$ & $\mathrm{R}$ & S & $\mathrm{R}$ & $\mathrm{R}$ & $\mathrm{R}$ & $\mathrm{R}$ & $\mathrm{S}$ & S \\
\hline $272 / 05$ & A. baumannii & 51 & F. coxa & 2005 & Clínica cirúrgica & 18 & $S$ & $\mathrm{R}$ & $\mathrm{R}$ & $\mathrm{R}$ & $\mathrm{R}$ & $R$ & $R$ & $\mathrm{R}$ & $\mathrm{S}$ & $\mathrm{S}$ \\
\hline $273 / 05$ & A. baumannii & 23,51 & Sangue & 2005 & UTI adulto & 60 & $S$ & $\mathrm{R}$ & $\mathrm{R}$ & $\mathrm{R}$ & $\mathrm{R}$ & $S$ & $\mathrm{R}$ & $\mathrm{R}$ & S & $\ldots$ \\
\hline $275 / 05$ & A. baumannii & 51 & Urina & 2005 & Clínica cirúrgica & 76 & $S$ & $\mathrm{R}$ & $\mathrm{R}$ & $\mathrm{R}$ & $\mathrm{R}$ & I & $\mathrm{R}$ & $\mathrm{S}$ & $\mathrm{S}$ & $\mathrm{S}$ \\
\hline $276 / 05$ & A. baumannii & 51 & s. dreno & 2005 & UTI adulto & 80 & $S$ & $\mathrm{R}$ & $\mathrm{R}$ & $\mathrm{R}$ & $\mathrm{R}$ & $S$ & $\mathrm{R}$ & $S$ & S & S \\
\hline $279 / 05$ & A. baumannii & 51 & Sangue & 2005 & UTI adulto & 59 & $S$ & $\mathrm{R}$ & $\mathrm{R}$ & $\mathrm{R}$ & $\mathrm{R}$ & $S$ & $\mathrm{R}$ & $\mathrm{R}$ & $\mathrm{S}$ & $S$ \\
\hline $284 / 05$ & A. baumannii & 51 & LBA & 2005 & UTI adulto & 62 & $S$ & $\mathrm{R}$ & $\mathrm{R}$ & $\mathrm{R}$ & $\mathrm{R}$ & 1 & $\mathrm{R}$ & $S$ & $\mathrm{~S}$ & 1 \\
\hline $285 / 05$ & A. baumannii & 51 & P. cateter & 2005 & UTI adulto & 68 & S & $\mathrm{R}$ & $\mathrm{R}$ & $\mathrm{R}$ & $\mathrm{R}$ & $\mathrm{R}$ & $\mathrm{R}$ & $\mathrm{R}$ & S & S \\
\hline $286 / 05$ & A. baumannii & 51 & Sangue & 2005 & UTI neonatal & 0 & $S$ & $S$ & $S$ & S & $\mathrm{S}$ & $S$ & $\mathrm{~S}$ & $S$ & $\mathrm{~S}$ & $S$ \\
\hline $288 / 05$ & A. baumannii & 51 & S. parede & 2005 & Clínica cirúrgica & 48 & $\mathrm{~S}$ & $\mathrm{R}$ & $\mathrm{R}$ & $\mathrm{R}$ & $\mathrm{R}$ & 1 & $\mathrm{R}$ & $\mathrm{R}$ & $\mathrm{S}$ & $\mathrm{S}$ \\
\hline $291 / 05$ & A. gen. 3 & $\ldots$ & Celulite & 2005 & Pronto socorro & 60 & $\mathrm{~S}$ & $\mathrm{~S}$ & $\mathrm{~S}$ & $\mathrm{~S}$ & $\mathrm{~S}$ & S & $\mathrm{S}$ & $S$ & $\mathrm{~S}$ & $\mathrm{~S}$ \\
\hline $299 / 05$ & A. baumannii & 51 & S. abdominal & 2005 & UTI adulto & 29 & S & $\mathrm{R}$ & $\mathrm{R}$ & $\mathrm{R}$ & $\mathrm{R}$ & $\mathrm{R}$ & $\mathrm{R}$ & $\mathrm{R}$ & $\mathrm{S}$ & S \\
\hline $302 / 05$ & A. baumannii & 51 & S. traqueal & 2005 & UTI adulto & 62 & $\mathrm{~S}$ & $S$ & $\mathrm{R}$ & $\mathrm{R}$ & S & $\mathrm{R}$ & 1 & $\mathrm{R}$ & $\mathrm{S}$ & $S$ \\
\hline $324 / 05$ & A. baumannii & 51 & Urina & 2005 & Pronto socorro & 20 & $S$ & $S$ & $S$ & $S$ & $S$ & $S$ & $S$ & $S$ & $S$ & $S$ \\
\hline
\end{tabular}




\begin{tabular}{|c|c|c|c|c|c|c|c|c|c|c|c|c|c|c|c|c|}
\hline Número & identificação & OXAs & Amostra & Ano & Clínica & idade & SAM & FEP & CAZ & CIP & AK & $\mathrm{CN}$ & TZP & SXT & IPM & MEM \\
\hline $325 / 05$ & A. baumannii & 51 & S. traqueal & 2005 & UTI adulto & 57 & $S$ & I & $\mathrm{R}$ & $\mathrm{R}$ & $\mathrm{R}$ & $\mathrm{R}$ & $\mathrm{R}$ & $\mathrm{R}$ & $S$ & $S$ \\
\hline $326 / 05$ & A. gen. $13 \mathrm{TU}$ & $\ldots$ & Sangue & 2005 & UTI neonatal & 0 & $S$ & $\mathrm{R}$ & $\mathrm{R}$ & $S$ & $\mathrm{R}$ & $\mathrm{S}$ & I & $\mathrm{R}$ & $\mathrm{R}$ & $\mathrm{R}$ \\
\hline $343 / 05$ & A. baumannii & 51 & S. ferida & 2005 & Pronto socorro & 83 & $S$ & $S$ & I & $\mathrm{R}$ & $\mathrm{R}$ & $\mathrm{R}$ & 1 & $S$ & $S$ & $S$ \\
\hline $344 / 05$ & A. baumannii & 51 & LBA & 2005 & UTI adulto & 87 & $S$ & 1 & $\mathrm{R}$ & $S$ & $\mathrm{R}$ & $S$ & I & $S$ & $S$ & $\ldots$ \\
\hline $346 / 05$ & A. baumannii & 51 & S. traqueal & 2005 & UTI adulto & 78 & $S$ & $\mathrm{R}$ & $\mathrm{R}$ & $\mathrm{R}$ & $\mathrm{R}$ & $\mathrm{R}$ & 1 & $\mathrm{R}$ & $S$ & $S$ \\
\hline $351 / 05$ & A. baumannii & 51 & S. traqueal & 2005 & UTI adulto & 42 & $S$ & $S$ & I & $\mathrm{R}$ & $\mathrm{R}$ & $S$ & $\mathrm{R}$ & $S$ & $\mathrm{~S}$ & $S$ \\
\hline $354 / 05$ & A. baumannii & 51 & Urina & 2005 & Ambulatório & 62 & $S$ & $\mathrm{R}$ & $\mathrm{R}$ & $\mathrm{R}$ & $\mathrm{R}$ & $\mathrm{R}$ & $\mathrm{R}$ & $\mathrm{R}$ & $S$ & $S$ \\
\hline $355 / 05$ & A. baumannii & 51 & S. abdominal & 2005 & UTI adulto & 72 & $S$ & I & $\mathrm{R}$ & $\mathrm{R}$ & $\mathrm{R}$ & $S$ & $\mathrm{R}$ & $\mathrm{R}$ & $S$ & $S$ \\
\hline $369 / 05$ & A. baumannii & 51 & S. traqueal & 2005 & UTI adulto & 47 & $S$ & $\mathrm{R}$ & $\mathrm{R}$ & $\mathrm{R}$ & $\mathrm{R}$ & $\mathrm{R}$ & $\mathrm{R}$ & $\mathrm{R}$ & $S$ & $S$ \\
\hline $370 / 05$ & A. baumannii & 51 & S. traqueal & 2005 & UTI adulto & 73 & $S$ & $S$ & 1 & $\mathrm{R}$ & $\mathrm{R}$ & $S$ & 1 & $S$ & $S$ & $S$ \\
\hline $371 / 05$ & A. baumannii & 51 & Sangue & 2005 & UTI adulto & 59 & $S$ & $\mathrm{R}$ & $\mathrm{R}$ & $\mathrm{R}$ & $\mathrm{R}$ & $\mathrm{R}$ & $\mathrm{R}$ & $\mathrm{R}$ & $S$ & $S$ \\
\hline $376 / 05$ & A. baumannii & 51 & Ouvido & 2005 & Berçario & 0 & $S$ & $S$ & $S$ & $S$ & $S$ & $S$ & $S$ & $S$ & $S$ & $S$ \\
\hline $380 / 05$ & A. baumannii & 51 & LBA & 2005 & UTI adulto & 68 & $S$ & $\mathrm{I}$ & $\mathrm{R}$ & $\mathrm{R}$ & $\mathrm{R}$ & $\mathrm{R}$ & 1 & $\mathrm{R}$ & $S$ & $\ldots$ \\
\hline $382 / 05$ & A. baumannii & 51 & LBA & 2005 & UTI adulto & 16 & $\mathrm{~S}$ & $\mathrm{R}$ & $\mathrm{R}$ & $\mathrm{R}$ & $\mathrm{R}$ & $\mathrm{R}$ & $\mathrm{R}$ & $\mathrm{S}$ & $S$ & $\mathrm{~S}$ \\
\hline $385 / 05$ & A. baumannii & 51 & S. purulenta & 2005 & Clínica médica & 83 & $\mathrm{I}$ & $\mathrm{R}$ & $\mathrm{R}$ & $\mathrm{R}$ & $\mathrm{R}$ & $\mathrm{R}$ & $\mathrm{R}$ & $\mathrm{R}$ & $S$ & $S$ \\
\hline $407 / 05$ & A. gen. $13 \mathrm{TU}$ & $\ldots$ & S.ferida & 2005 & Clínica obstétrica & 18 & $S$ & $S$ & $S$ & $S$ & $S$ & $S$ & $S$ & $S$ & $S$ & $S$ \\
\hline $408 / 05$ & A. baumannii & 51 & LBA & 2005 & UTI adulto & 32 & $S$ & $\mathrm{R}$ & 1 & $\mathrm{R}$ & $\mathrm{R}$ & $\mathrm{R}$ & $\mathrm{R}$ & $\mathrm{R}$ & $S$ & \\
\hline $409 / 05$ & A. baumannii & 51 & S. traqueal & 2005 & UTI adulto & 34 & $S$ & $\mathrm{R}$ & $\mathrm{R}$ & $\mathrm{R}$ & $\mathrm{R}$ & I & $\mathrm{R}$ & $S$ & $S$ & $S$ \\
\hline $440 / 05$ & A. baumannii & 51 & Urina & 2005 & Clínica cirúrgica & 52 & $S$ & $\mathrm{R}$ & $\mathrm{R}$ & $\mathrm{R}$ & $\mathrm{R}$ & $\mathrm{R}$ & $\mathrm{R}$ & $S$ & $S$ & $\ldots$ \\
\hline $448 / 05$ & A. baumannii & 51 & Sangue & 2005 & Clínica médica & 79 & $S$ & $\mathrm{I}$ & $\mathrm{R}$ & $\mathrm{R}$ & $\mathrm{R}$ & $S$ & $\mathrm{R}$ & $\mathrm{R}$ & $S$ & $S$ \\
\hline $452 / 05$ & A. baumannii & 51 & S. traqueal & 2005 & UTI adulto & 69 & $\mathrm{~S}$ & $S$ & I & $S$ & $\mathrm{~S}$ & $S$ & 1 & $S$ & $\mathrm{~S}$ & $S$ \\
\hline $476 / 05$ & A. baumannii & 51 & LBA & 2005 & UTI adulto & 76 & $S$ & $\mathrm{R}$ & $\mathrm{R}$ & $\mathrm{R}$ & $\mathrm{R}$ & $S$ & $\mathrm{R}$ & $S$ & $S$ & $S$ \\
\hline $478 / 05$ & A. baumannii & 51 & outros & 2005 & Berçario & 0 & $\mathrm{~S}$ & $\mathrm{~S}$ & $S$ & $S$ & $\mathrm{~S}$ & $\mathrm{~S}$ & $\mathrm{~S}$ & $\mathrm{~S}$ & $\mathrm{~S}$ & $S$ \\
\hline $479 / 05$ & A. gen. 13 TU & $\ldots$ & $\mathrm{MI}$ & 2005 & Pronto socorro & 75 & $S$ & $S$ & $S$ & $S$ & $S$ & $S$ & $S$ & $S$ & $\mathrm{~S}$ & $S$ \\
\hline $488 / 05$ & A. baumannii & 51 & S. traqueal & 2005 & UTI adulto & 70 & $S$ & $\mathrm{R}$ & $\mathrm{R}$ & $\mathrm{R}$ & $\mathrm{R}$ & $\mathrm{R}$ & $\mathrm{R}$ & $\mathrm{R}$ & $S$ & I \\
\hline $505 / 05$ & A. baumannii & 51 & P. axilar & 2005 & UTI Pediatria & 0 & $S$ & $S$ & $\mathrm{~S}$ & $S$ & $\mathrm{~S}$ & $S$ & $S$ & $S$ & $S$ & $S$ \\
\hline $517 / 05$ & A. baumannii & 51 & S. traqueal & 2005 & UTI adulto & 62 & S & S & S & $S$ & $\mathrm{~S}$ & S & $S$ & $\mathrm{R}$ & $S$ & $S$ \\
\hline $522 / 05$ & A. baumannii & 51 & Abscesso & 2005 & Clínica cirúrgica & 29 & $S$ & $\mathrm{R}$ & $\mathrm{R}$ & $\mathrm{R}$ & $\mathrm{R}$ & $\mathrm{R}$ & $\mathrm{R}$ & $\mathrm{R}$ & $S$ & $\mathrm{R}$ \\
\hline $523 / 05$ & A. baumannii & 51 & LBA & 2005 & UTI adulto & 33 & $\mathrm{~S}$ & $\mathrm{R}$ & $\mathrm{R}$ & $\mathrm{R}$ & $\mathrm{R}$ & $\mathrm{R}$ & $\mathrm{R}$ & $\mathrm{R}$ & $S$ & $S$ \\
\hline $524 / 05$ & A. baumannii & 51 & S. traqueal & 2005 & UTI neonatal & meses & $S$ & $S$ & $S$ & $S$ & $S$ & $S$ & $S$ & $S$ & $S$ & $S$ \\
\hline $551 / 05$ & A. gen. $13 \mathrm{TU}$ & diferente & S. traqueal & 2005 & UTI adulto & 68 & $S$ & $S$ & $S$ & $S$ & $S$ & $S$ & $S$ & $S$ & $S$ & $S$ \\
\hline
\end{tabular}




\begin{tabular}{|c|c|c|c|c|c|c|c|c|c|c|c|c|c|c|c|c|}
\hline Número & identificação & OXAs & Amostra & Ano & Clínica & idade & SAM & FEP & CAZ & CIP & AK & $\mathrm{CN}$ & TZP & SXT & IPM & MEM \\
\hline $553 / 05$ & A. baumannii & 51 & S. traqueal & 2005 & UTI adulto & 89 & $\mathrm{R}$ & $\mathrm{R}$ & $\mathrm{R}$ & $\mathrm{R}$ & $\mathrm{R}$ & $\mathrm{R}$ & $\mathrm{R}$ & $\mathrm{R}$ & $S$ & $S$ \\
\hline $567 / 05$ & A. baumannii & 51 & Urina & 2005 & Pronto socorro & 73 & $S$ & $\mathrm{R}$ & $\mathrm{R}$ & $\mathrm{R}$ & $\mathrm{R}$ & $\mathrm{R}$ & $\mathrm{R}$ & $\mathrm{R}$ & $\mathrm{R}$ & $\ldots$ \\
\hline $577 / 05$ & A. gen. 3 & $\ldots$ & S. traqueal & 2005 & UTI Pediatria & 0 & $S$ & $S$ & $S$ & $S$ & $S$ & $S$ & $S$ & $S$ & $S$ & $S$ \\
\hline $579 / 05$ & A. baumannii & 51 & S. orofaringe & 2005 & Berçario & 5 meses & $S$ & $S$ & $S$ & $S$ & $S$ & $S$ & $S$ & $S$ & $S$ & $S$ \\
\hline $588 / 05$ & A. baumannii & 23,51 & S. purulenta & 2005 & UTI adulto & 74 & $\mathrm{R}$ & $\mathrm{R}$ & $\mathrm{R}$ & $\mathrm{R}$ & $S$ & $S$ & $\mathrm{R}$ & $S$ & $\mathrm{R}$ & $\mathrm{R}$ \\
\hline $595 / 05$ & A. baumannii & 51 & S. traqueal & 2005 & UTI adulto & 68 & S & $\mathrm{R}$ & $\mathrm{R}$ & $\mathrm{R}$ & $\mathrm{S}$ & $S$ & 1 & $\mathrm{R}$ & $S$ & $S$ \\
\hline $603 / 05$ & A. baumannii & 51 & S. traqueal & 2005 & UTI adulto & 55 & $\mathrm{~S}$ & $\mathrm{R}$ & $\mathrm{R}$ & $\mathrm{R}$ & $\mathrm{R}$ & $\mathrm{R}$ & $\mathrm{R}$ & $S$ & $S$ & $S$ \\
\hline $606 / 05$ & A. baumannii & 51 & Ulcera & 2005 & Clínica cirúrgica & 77 & $\mathrm{~S}$ & $S$ & $S$ & $S$ & $\mathrm{~S}$ & $S$ & $S$ & $S$ & $S$ & $\mathrm{~S}$ \\
\hline $608 / 05$ & A. gen. 3 & $\ldots$ & S. orofaringe & 2005 & Berçario & meses & $S$ & $S$ & $S$ & $S$ & $S$ & $S$ & $S$ & $S$ & $S$ & $S$ \\
\hline $611 / 05$ & A. gen. $13 \mathrm{TU}$ & $\ldots$ & Abscesso & 2005 & Clínica médica & 37 & $S$ & $S$ & $S$ & $S$ & $S$ & $S$ & $S$ & $S$ & $S$ & $S$ \\
\hline $617 / 05$ & A. baumannii & 51 & LBA & 2005 & UTI adulto & 69 & $S$ & $\mathrm{R}$ & $\mathrm{R}$ & $\mathrm{R}$ & $\mathrm{R}$ & $\mathrm{R}$ & $\mathrm{R}$ & $\mathrm{R}$ & $S$ & $S$ \\
\hline $623 / 05$ & A. baumannii & 51 & S. traqueal & 2005 & Clínica médica & 39 & $S$ & $\mathrm{R}$ & $\mathrm{R}$ & $\mathrm{R}$ & $\mathrm{R}$ & $\mathrm{R}$ & $\mathrm{R}$ & $\mathrm{R}$ & $S$ & $S$ \\
\hline $629 / 05$ & A. baumannii & 51 & c. membro infer & 2005 & Pronto socorro & 18 & $\ldots$ & $S$ & $S$ & $S$ & $S$ & $S$ & $S$ & $S$ & $S$ & $S$ \\
\hline $638 / 05$ & A. baumannii & 51 & S. traqueal & 2005 & UTI adulto & 33 & $\ldots$ & $\mathrm{R}$ & $\mathrm{R}$ & $\mathrm{R}$ & $\mathrm{R}$ & $\mathrm{R}$ & $\mathrm{R}$ & $\mathrm{R}$ & $S$ & $S$ \\
\hline $647 / 05$ & A. baumannii & 51 & LBA & 2005 & UTI adulto & 36 & $S$ & $\mathrm{R}$ & $\mathrm{R}$ & $\mathrm{R}$ & $\mathrm{R}$ & $\mathrm{R}$ & $\mathrm{R}$ & $\mathrm{R}$ & $S$ & $S$ \\
\hline $651 / 05$ & A. baumannii & 51 & Sangue & 2005 & UTI adulto & 46 & $\mathrm{R}$ & $\mathrm{R}$ & $\mathrm{R}$ & $\mathrm{R}$ & $\mathrm{R}$ & $\mathrm{R}$ & $\mathrm{R}$ & $\mathrm{R}$ & $S$ & $S$ \\
\hline $656 / 05$ & A. baumannii & 51 & S. orofaringe & 2005 & UTI Pediatria & 2 & $S$ & $S$ & $S$ & $S$ & $S$ & $S$ & $S$ & $\mathrm{R}$ & $S$ & $S$ \\
\hline $662 / 05$ & A. baumannii & 51 & $P$. inguinal & 2005 & Clínica cirúrgica & 25 & $\mathrm{~S}$ & $\mathrm{~S}$ & $\mathrm{~S}$ & $\mathrm{~S}$ & $\mathrm{~S}$ & $\mathrm{~S}$ & $\mathrm{~S}$ & $\mathrm{~S}$ & $\mathrm{~S}$ & $\mathrm{~S}$ \\
\hline $663 / 05$ & A. baumannii & 51 & S. traqueal & 2005 & UTI adulto & 79 & $S$ & $\mathrm{R}$ & $\mathrm{R}$ & $\mathrm{R}$ & $\mathrm{R}$ & $\mathrm{R}$ & $\mathrm{R}$ & $\mathrm{R}$ & $S$ & $\ldots$ \\
\hline $678 / 05$ & A. baumannii & 51 & LBA & 2005 & UTI adulto & 69 & $\mathrm{~S}$ & $\mathrm{R}$ & $\mathrm{R}$ & $\mathrm{R}$ & $\mathrm{R}$ & $\mathrm{R}$ & $\mathrm{R}$ & $\mathrm{R}$ & $\mathrm{S}$ & $\mathrm{S}$ \\
\hline $685 / 05$ & A. gen. $13 \mathrm{TU}$ & $\ldots$ & S. traqueal & 2005 & UTI Pediatria & 0 & $S$ & $S$ & $S$ & $S$ & $S$ & $S$ & $S$ & $S$ & $S$ & $\ldots$ \\
\hline $688 / 05$ & A. gen. $13 \mathrm{TU}$ & $\ldots$ & S. orofaringe & 2005 & Ambulatório & 1 & $\mathrm{~S}$ & $\mathrm{~S}$ & $\mathrm{~S}$ & $\mathrm{~S}$ & $\mathrm{~S}$ & & $\mathrm{~S}$ & $\mathrm{~S}$ & $\mathrm{~S}$ & $\mathrm{~S}$ \\
\hline $695 / 05$ & A. baumannii & 51 & Urina & 2005 & Clínica médica & 67 & $S$ & $\mathrm{R}$ & $\mathrm{R}$ & $\mathrm{R}$ & $\mathrm{R}$ & $\mathrm{R}$ & $\mathrm{R}$ & $\mathrm{R}$ & $S$ & $S$ \\
\hline $698 / 05$ & A. gen. $13 \mathrm{TU}$ & $\ldots$ & P. cateter & 2005 & Clínica médica & 18 & $\mathrm{~S}$ & $\mathrm{~S}$ & $\mathrm{~S}$ & $\mathrm{~S}$ & $\mathrm{~S}$ & $\mathrm{~S}$ & $\mathrm{~S}$ & $\mathrm{R}$ & $\mathrm{S}$ & $\mathrm{S}$ \\
\hline $705 / 05$ & A. gen. 13 TU & $\ldots$ & Pele & 2005 & Clínica médica & 17 & $\mathrm{R}$ & $S$ & $S$ & $S$ & $S$ & $S$ & $S$ & $S$ & $S$ & $S$ \\
\hline $709 / 05$ & A. gen. $13 \mathrm{TU}$ & $\ldots$ & S. orofaringe & 2005 & Pronto socorro & 1 & $\mathrm{~S}$ & $\mathrm{~S}$ & $\mathrm{~S}$ & $\mathrm{~S}$ & $\mathrm{~S}$ & $\mathrm{~S}$ & $\mathrm{~S}$ & $\mathrm{~S}$ & $\mathrm{~S}$ & $\mathrm{~S}$ \\
\hline $742 / 05$ & A. baumannii & 51 & S. traqueal & 2005 & UTI adulto & 30 & $S$ & $\mathrm{R}$ & $\mathrm{R}$ & $\mathrm{R}$ & $\mathrm{R}$ & $\mathrm{R}$ & $\mathrm{R}$ & $\mathrm{R}$ & $S$ & $S$ \\
\hline $749 / 05$ & A. baumannii & 51 & Urina & 2005 & Clínica médica & 46 & $S$ & I & $\mathrm{R}$ & $\mathrm{R}$ & $\mathrm{R}$ & $\mathrm{R}$ & $\mathrm{R}$ & $\mathrm{R}$ & $S$ & $S$ \\
\hline $759 / 05$ & A. baumannii & 51 & LBA & 2005 & UTI adulto & 44 & $S$ & $S$ & $S$ & $S$ & $S$ & $S$ & $S$ & $S$ & $S$ & $S$ \\
\hline $760 / 05$ & A. baumannii & 51 & S. orofaringe & 2005 & Pronto socorro & 1 & $S$ & $S$ & $S$ & $S$ & $S$ & $S$ & $S$ & $S$ & $S$ & $S$ \\
\hline $766 / 05$ & A. baumannii & 51 & S. traqueal & 2005 & UTI adulto & 42 & $S$ & $\mathrm{R}$ & $\mathrm{R}$ & $\mathrm{R}$ & $\mathrm{R}$ & $\mathrm{R}$ & $\mathrm{R}$ & $\mathrm{R}$ & $S$ & $S$ \\
\hline
\end{tabular}




\begin{tabular}{|c|c|c|c|c|c|c|c|c|c|c|c|c|c|c|c|c|}
\hline Número & identificação & OXAs & Amostra & Ano & Clínica & idade & SAM & FEP & CAZ & CIP & AK & $\mathrm{CN}$ & TZP & SXT & IPM & MEM \\
\hline $776 / 05$ & A. baumannii & 51 & S. traqueal & 2005 & UTI adulto & 70 & $S$ & $S$ & $\mathrm{R}$ & $\mathrm{R}$ & $\mathrm{S}$ & $S$ & $S$ & $\mathrm{R}$ & $\mathrm{S}$ & $S$ \\
\hline $782 / 05$ & A. baumannii & 51 & S. orofaringe & 2005 & Berçario & meses & $\mathrm{S}$ & $S$ & $S$ & $S$ & $\mathrm{~S}$ & $\mathrm{~S}$ & $S$ & $S$ & $S$ & $\mathrm{~S}$ \\
\hline $808 / 05$ & A. baumannii & 51 & LBA & 2005 & UTI adulto & 31 & $S$ & $\mathrm{R}$ & $\mathrm{R}$ & $\mathrm{R}$ & $\mathrm{R}$ & $\mathrm{R}$ & $\mathrm{R}$ & $\mathrm{R}$ & $S$ & $S$ \\
\hline $809 / 05$ & A. gen. $13 \mathrm{TU}$ & $\ldots$ & Queimadura & 2005 & Clínica pediátrica & 1 & $S$ & $S$ & $S$ & $S$ & $S$ & $S$ & 1 & $S$ & $S$ & $S$ \\
\hline $810 / 05$ & A. baumannii & 51 & L. ascítico & 2005 & Pronto socorro & 38 & $\mathrm{~S}$ & $\mathrm{R}$ & $\mathrm{R}$ & $\mathrm{R}$ & $\mathrm{R}$ & $\mathrm{R}$ & $\mathrm{R}$ & $\mathrm{R}$ & $S$ & $S$ \\
\hline $813 / 05$ & A. baumannii & 51 & S. traqueal & 2005 & UTI adulto & 67 & $\mathrm{R}$ & $\mathrm{R}$ & $\mathrm{R}$ & $\mathrm{R}$ & $\mathrm{R}$ & $\mathrm{R}$ & $\mathrm{R}$ & $\mathrm{R}$ & $S$ & .. \\
\hline $007 / 06$ & A. baumannii & 51 & P. cateter & 2006 & Clínica médica & 35 & $S$ & $\mathrm{R}$ & $\mathrm{R}$ & $\mathrm{R}$ & $\mathrm{R}$ & $\mathrm{R}$ & $\mathrm{R}$ & $\mathrm{R}$ & $S$ & $S$ \\
\hline $011 / 06$ & A. baumannii & 51 & S. traqueal & 2006 & UTI adulto & 28 & $\mathrm{R}$ & $\mathrm{R}$ & I & $\mathrm{R}$ & 1 & $\mathrm{R}$ & $\mathrm{R}$ & $\mathrm{R}$ & $\mathrm{R}$ & $\mathrm{R}$ \\
\hline $012 / 06$ & A. gen. $13 \mathrm{TU}$ & $\ldots$ & S. orofaringe & 2006 & Pronto socorro & 8 & $S$ & $S$ & $S$ & $S$ & $S$ & $S$ & $S$ & $S$ & $S$ & $S$ \\
\hline $019 / 06$ & A. baumannii & 51 & $P$. ing. & 2006 & UTI adulto & 23 & $S$ & $S$ & 1 & $S$ & $S$ & $S$ & $S$ & $S$ & $S$ & $\ldots$ \\
\hline $022 / 06$ & A. gen. $13 \mathrm{TU}$ & ausente & S. traqueal & 2006 & UTI adulto & 57 & $S$ & 1 & $\mathrm{R}$ & $S$ & $S$ & $\mathrm{R}$ & $S$ & $\mathrm{R}$ & $S$ & $\ldots$. \\
\hline $024 / 06$ & A. gen. $13 \mathrm{TU}$ & $\ldots$ & S. ferida & 2006 & UTI Pediatria & 13 & $S$ & $S$ & $S$ & $S$ & $S$ & $S$ & $S$ & $S$ & $S$ & $S$ \\
\hline $026 / 06$ & A. baumannii & 51 & Sangue & 2006 & UTI adulto & 57 & $S$ & 1 & $\mathrm{R}$ & $\mathrm{R}$ & $\mathrm{R}$ & $\mathrm{R}$ & $\ldots$ & $\mathrm{R}$ & $\mathrm{R}$ & $\ldots$ \\
\hline 053/06 & A. baumannii & 51 & S. traqueal & 2006 & UTI adulto & 59 & $S$ & $S$ & $\mathrm{R}$ & $\mathrm{R}$ & $\mathrm{R}$ & $\mathrm{R}$ & $\mathrm{R}$ & $\mathrm{R}$ & $\mathrm{R}$ & $\mathrm{R}$ \\
\hline $058 / 06$ & A. baumannii & 51 & Urina & 2006 & Ambulatório & 80 & $S$ & $\mathrm{R}$ & $\mathrm{R}$ & $\mathrm{R}$ & $\mathrm{R}$ & $\mathrm{R}$ & $\mathrm{R}$ & $\mathrm{R}$ & $S$ & $\mathrm{R}$ \\
\hline $078 / 06$ & A. baumannii & 51 & S. vaginal & 2006 & UTI adulto & 18 & $S$ & $S$ & $\mathrm{R}$ & $\mathrm{R}$ & $\mathrm{R}$ & $\mathrm{R}$ & $\mathrm{R}$ & $\mathrm{R}$ & $\mathrm{R}$ & $\ldots$. \\
\hline $101 / 06$ & A. gen. 3 & $\ldots$ & S. orofaringe & 2006 & UTI neonatal & 0 & $S$ & $S$ & $S$ & $S$ & $S$ & $S$ & $S$ & $S$ & $S$ & $S$ \\
\hline $105 / 06$ & A. baumannii & 51 & S. traqueal & 2006 & UTI adulto & 82 & $\mathrm{~S}$ & $\mathrm{~S}$ & 1 & $\mathrm{~S}$ & $\mathrm{~S}$ & $\mathrm{~S}$ & $\mathrm{~S}$ & $\mathrm{~S}$ & $\mathrm{~S}$ & $\mathrm{~S}$ \\
\hline $110 / 06$ & A. baumannii & 51 & P. ing. & 2006 & Clínica médica & 32 & $S$ & $S$ & $S$ & $S$ & $S$ & $S$ & $S$ & $S$ & $S$ & $S$ \\
\hline $127 / 06$ & A. baumannii & 51 & S. traqueal & 2006 & UTI Pediatria & 1 & $\mathrm{~S}$ & $\mathrm{~S}$ & $S$ & $\mathrm{~S}$ & $\mathrm{~S}$ & $\mathrm{~S}$ & $\mathrm{~S}$ & $S$ & $\mathrm{~S}$ & $\mathrm{~S}$ \\
\hline $137 / 06$ & A. baumannii & 51 & Sangue & 2006 & Pronto socorro & 84 & $S$ & $\mathrm{R}$ & $\mathrm{R}$ & $\mathrm{R}$ & $\mathrm{R}$ & $\mathrm{R}$ & $\mathrm{R}$ & $\mathrm{R}$ & $S$ & $S$ \\
\hline $144 / 06$ & A. baumannii & 51 & S. coto & 2006 & Clínica cirúrgica & 76 & $\mathrm{~S}$ & $\mathrm{R}$ & $\mathrm{R}$ & $\mathrm{R}$ & $\mathrm{R}$ & $\mathrm{R}$ & $\mathrm{R}$ & $\mathrm{R}$ & $\mathrm{S}$ & $\mathrm{S}$ \\
\hline $146 / 06$ & A. baumannii & 51 & S. traqueal & 2006 & UTI adulto & 65 & $S$ & $S$ & $\mathrm{R}$ & $\mathrm{R}$ & $\mathrm{R}$ & $\mathrm{R}$ & 1 & $\mathrm{R}$ & $\mathrm{R}$ & $\mathrm{R}$ \\
\hline $147 / 06$ & A. baumannii & 51 & S. traqueal & 2006 & UTI adulto & 42 & $\mathrm{~S}$ & $\mathrm{R}$ & $\mathrm{R}$ & $\mathrm{R}$ & $\mathrm{R}$ & $\mathrm{S}$ & $\mathrm{R}$ & $\mathrm{R}$ & $\mathrm{S}$ & $\mathrm{S}$ \\
\hline $160 / 06$ & A. gen. 13 TU & ausente & LBA & 2006 & UTI adulto & 66 & $S$ & $S$ & 1 & $S$ & $S$ & $S$ & $S$ & $S$ & $S$ & $S$ \\
\hline $164 / 06$ & A. baumannii & 51 & Sangue & 2006 & Clínica cirúrgica & 62 & $\mathrm{~S}$ & $\mathrm{R}$ & $\mathrm{R}$ & $\mathrm{R}$ & $\mathrm{R}$ & $\mathrm{R}$ & $\mathrm{R}$ & $\mathrm{R}$ & $S$ & $S$ \\
\hline $174 / 06$ & A. gen. $13 \mathrm{TU}$ & $\ldots$ & P. axilar & 2006 & Berçario & meses & $\mathrm{S}$ & $S$ & $S$ & $S$ & $S$ & $S$ & $S$ & $S$ & $S$ & $S$ \\
\hline $182 / 06$ & A. baumannii & 51 & Urina & 2006 & Ambulatório & 69 & $S$ & $S$ & $S$ & $\mathrm{R}$ & $S$ & $S$ & $S$ & $S$ & $S$ & $S$ \\
\hline $190 / 06$ & A. baumannii & 51 & LBA & 2006 & UTI adulto & 80 & $S$ & $S$ & $\mathrm{R}$ & $\mathrm{R}$ & $\mathrm{R}$ & $\mathrm{R}$ & $\mathrm{R}$ & $\mathrm{R}$ & $\mathrm{R}$ & $\mathrm{R}$ \\
\hline $192 / 06$ & A. baumannii & 51 & Urina & 2006 & Pronto socorro & 54 & $S$ & $S$ & $\mathrm{R}$ & $\mathrm{R}$ & $\mathrm{R}$ & $\mathrm{R}$ & $\mathrm{R}$ & $\mathrm{R}$ & $S$ & $S$ \\
\hline $204 / 06$ & A. baumannii & 51 & S. traqueal & 2006 & UTI adulto & 58 & $S$ & $S$ & $\mathrm{R}$ & $\mathrm{R}$ & $\mathrm{R}$ & $\mathrm{R}$ & $\mathrm{R}$ & $\mathrm{R}$ & $\mathrm{R}$ & $\mathrm{R}$ \\
\hline
\end{tabular}




\begin{tabular}{|c|c|c|c|c|c|c|c|c|c|c|c|c|c|c|c|c|}
\hline Número & identificação & OXAs & Amostra & Ano & Clínica & idade & SAM & FEP & CAZ & CIP & AK & CN & TZP & SXT & IPM & MEM \\
\hline $228 / 06$ & A. baumannii & 51 & S. traqueal & 2006 & UTI adulto & 65 & $\mathrm{R}$ & $S$ & $\mathrm{R}$ & $\mathrm{R}$ & $\mathrm{S}$ & $\mathrm{R}$ & $S$ & $\mathrm{R}$ & $S$ & $S$ \\
\hline $229 / 06$ & A. baumannii & 51 & S. traqueal & 2006 & UTI adulto & 39 & $\mathrm{~S}$ & $S$ & $\mathrm{R}$ & $\mathrm{R}$ & $\mathrm{R}$ & $\mathrm{R}$ & 1 & $\mathrm{R}$ & $\mathrm{R}$ & $\mathrm{R}$ \\
\hline $251 / 06$ & A. gen. $13 \mathrm{TU}$ & $\ldots$ & Sangue & 2006 & UTI Pediatria & meses & $S$ & $S$ & $S$ & $S$ & $S$ & $S$ & $\mathrm{~S}$ & $S$ & $S$ & $S$ \\
\hline $253 / 06$ & A. gen. $13 \mathrm{TU}$ & $\ldots$ & LBA & 2006 & UTI Pediatria & 14 & $S$ & $S$ & $S$ & $S$ & $S$ & $S$ & $S$ & $\mathrm{R}$ & $S$ & $S$ \\
\hline $270 / 06$ & A. baumannii & 51 & S. traqueal & 2006 & UTI adulto & 59 & $S$ & $S$ & $\mathrm{R}$ & $\mathrm{R}$ & $S$ & $\mathrm{R}$ & $\mathrm{R}$ & $\mathrm{R}$ & $\mathrm{R}$ & $\mathrm{R}$ \\
\hline $316 / 06$ & A. baumannii & 51 & S. traqueal & 2006 & UTI adulto & 58 & $S$ & $S$ & $\mathrm{R}$ & $\mathrm{R}$ & $\mathrm{R}$ & $\mathrm{R}$ & $\mathrm{R}$ & $\mathrm{R}$ & $\mathrm{R}$ & $\mathrm{R}$ \\
\hline $327 / 06$ & A. baumannii & 51 & Urina & 2006 & Pronto socorro & 69 & $\mathrm{~S}$ & $\mathrm{R}$ & $\mathrm{R}$ & $\mathrm{R}$ & $\mathrm{R}$ & $\mathrm{R}$ & $\mathrm{R}$ & $\mathrm{R}$ & $S$ & $S$ \\
\hline $345 / 06$ & A. baumannii & 51 & Urina & 2006 & Clínica médica & 80 & $\mathrm{~S}$ & $\mathrm{R}$ & $\mathrm{R}$ & $\mathrm{R}$ & $\mathrm{R}$ & $\mathrm{R}$ & 1 & $\mathrm{R}$ & $S$ & $\mathrm{~S}$ \\
\hline $346 / 06$ & A. baumannii & 51 & Escara & 2006 & Clínica cirúrgica & 33 & $\mathrm{~S}$ & $\mathrm{~S}$ & $\mathrm{R}$ & $\mathrm{R}$ & $\mathrm{R}$ & $\mathrm{R}$ & $\mathrm{R}$ & $\mathrm{R}$ & $\mathrm{R}$ & $\mathrm{R}$ \\
\hline $347 / 06$ & A. baumannii & 51 & S. orofaringe & 2006 & Clínica pediátrica & meses & $S$ & $S$ & $S$ & $S$ & $S$ & $S$ & $S$ & $S$ & $S$ & $S$ \\
\hline $364 / 06$ & A. baumannii & 51 & Urina & 2006 & SEMI & 74 & $\mathrm{~S}$ & $\mathrm{R}$ & $\mathrm{R}$ & $\mathrm{R}$ & $\mathrm{R}$ & $\mathrm{S}$ & $\mathrm{R}$ & $\mathrm{S}$ & $\mathrm{S}$ & $\mathrm{S}$ \\
\hline $372 / 06$ & A. baumannii & 51 & P. inguinal & 2006 & Clínica médica & 76 & $\mathrm{~S}$ & $\mathrm{R}$ & $\mathrm{R}$ & $\mathrm{R}$ & $\mathrm{S}$ & $\mathrm{R}$ & $\mathrm{R}$ & $\mathrm{S}$ & $\mathrm{S}$ & $\mathrm{S}$ \\
\hline $373 / 06$ & A. baumannii & 51 & Escara & 2006 & Clínica médica & 72 & $\mathrm{~S}$ & $\mathrm{R}$ & $\mathrm{R}$ & $\mathrm{R}$ & $\mathrm{S}$ & $\mathrm{R}$ & $\mathrm{R}$ & $\mathrm{S}$ & $\mathrm{S}$ & $\mathrm{S}$ \\
\hline $375 / 06$ & A. baumannii & 51 & Sangue & 2006 & UTI adulto & 70 & $\mathrm{~S}$ & $\mathrm{R}$ & $\mathrm{R}$ & $\mathrm{R}$ & $\mathrm{R}$ & $\mathrm{R}$ & $\mathrm{R}$ & $\mathrm{R}$ & $\mathrm{S}$ & $\mathrm{S}$ \\
\hline $407 / 06$ & A. gen. 3 & $\ldots$ & S. traqueal & 2006 & UTI neonatal & 0 & $\mathrm{~S}$ & $\mathrm{~S}$ & $\mathrm{~S}$ & $\mathrm{~S}$ & $\mathrm{~S}$ & $\mathrm{~S}$ & $\mathrm{~S}$ & $\mathrm{~S}$ & $\mathrm{~S}$ & $\mathrm{~S}$ \\
\hline $435 / 06$ & A. baumannii & 51 & P. axilar & 2006 & UTI adulto & 78 & $\mathrm{~S}$ & $\mathrm{R}$ & $\mathrm{R}$ & $\mathrm{R}$ & $\mathrm{S}$ & $\mathrm{R}$ & 1 & $S$ & $\mathrm{~S}$ & $\mathrm{~S}$ \\
\hline $454 / 06$ & A. baumannii & 51 & P. axilar & 2006 & Clínica médica & 72 & $\mathrm{R}$ & $\mathrm{R}$ & 1 & $\mathrm{R}$ & $\mathrm{R}$ & $S$ & $\mathrm{R}$ & $S$ & $\mathrm{R}$ & $\mathrm{R}$ \\
\hline $460 / 06$ & A. gen. $13 \mathrm{TU}$ & $\ldots$ & S. traqueal & 2006 & Clínica pediátrica & 1 & $S$ & $S$ & $S$ & $S$ & $S$ & $S$ & $S$ & $S$ & $S$ & $S$ \\
\hline $465 / 06$ & A. baumannii & 51 & Urina & 2006 & Clínica médica & 54 & $\mathrm{~S}$ & $\mathrm{~S}$ & $S$ & $S$ & $\mathrm{~S}$ & $S$ & $\mathrm{~S}$ & $S$ & $\mathrm{~S}$ & $\mathrm{~S}$ \\
\hline $490 / 06$ & A. baumannii & 51 & P. cateter & 2006 & UTI adulto & 60 & $S$ & $\mathrm{R}$ & $\mathrm{R}$ & $\mathrm{R}$ & $\mathrm{R}$ & $\mathrm{R}$ & 1 & $\mathrm{R}$ & $S$ & $S$ \\
\hline $500 / 06$ & A. baumannii & 51 & LBA & 2006 & UTI adulto & 76 & $\mathrm{~S}$ & $\mathrm{R}$ & $\mathrm{R}$ & $\mathrm{R}$ & $\mathrm{R}$ & $\mathrm{R}$ & $\mathrm{R}$ & $\mathrm{R}$ & $\mathrm{S}$ & $\mathrm{S}$ \\
\hline $501 / 06$ & A. gen. 3 & $\ldots$ & S. orofaringe & 2006 & Berçario & meses & $S$ & $S$ & $S$ & $S$ & 1 & I & $S$ & $S$ & $S$ & $S$ \\
\hline $506 / 06$ & A. baumannii & 51 & Urina & 2006 & Pronto socorro & 79 & $S$ & $\mathrm{R}$ & $\mathrm{R}$ & $\mathrm{R}$ & $\mathrm{R}$ & $\mathrm{R}$ & 1 & $\mathrm{R}$ & $S$ & $S$ \\
\hline $541 / 06$ & A. baumannii & 51 & S. dreno & 2006 & UTI adulto & 86 & $S$ & $\mathrm{R}$ & $\mathrm{R}$ & $\mathrm{R}$ & $\mathrm{R}$ & $\mathrm{R}$ & 1 & $\mathrm{R}$ & $S$ & $S$ \\
\hline $589 / 06$ & A. baumannii & 51 & S. traqueal & 2006 & UTI adulto & 53 & $S$ & $\mathrm{R}$ & $\mathrm{R}$ & $\mathrm{R}$ & $\mathrm{R}$ & $\mathrm{R}$ & $\mathrm{R}$ & $\mathrm{R}$ & $S$ & $S$ \\
\hline $599 / 06$ & A. gen. $13 \mathrm{TU}$ & ausente & S. traqueal & 2006 & UTI adulto & 59 & $\mathrm{~S}$ & $\mathrm{~S}$ & $\mathrm{R}$ & $\mathrm{S}$ & $S$ & $\mathrm{~S}$ & $\mathrm{~S}$ & $\mathrm{R}$ & $\mathrm{S}$ & $\mathrm{S}$ \\
\hline $600 / 06$ & A. baumannii & 51 & LBA & 2006 & UTI adulto & 77 & $S$ & $\mathrm{R}$ & $\mathrm{R}$ & $\mathrm{R}$ & $\mathrm{R}$ & $\mathrm{R}$ & $\mathrm{R}$ & $\mathrm{R}$ & $S$ & $S$ \\
\hline $609 / 06$ & A. baumannii & 51 & LBA & 2006 & UTI adulto & 66 & $\mathrm{~S}$ & $\mathrm{R}$ & $\mathrm{R}$ & $\mathrm{R}$ & $\mathrm{R}$ & $\mathrm{R}$ & $\mathrm{R}$ & $\mathrm{R}$ & $\mathrm{S}$ & $\mathrm{S}$ \\
\hline $615 / 06$ & A. baumannii & 23,51 & S. ferida & 2006 & UTI adulto & 26 & 1 & $\mathrm{R}$ & $\mathrm{R}$ & $\mathrm{R}$ & 1 & $\mathrm{R}$ & $\mathrm{R}$ & $\mathrm{R}$ & $\mathrm{S}$ & $\mathrm{R}$ \\
\hline $630 / 06$ & A. baumannii & 23,51 & Urina & 2006 & UTI adulto & 81 & $\mathrm{R}$ & 1 & $\mathrm{R}$ & $\mathrm{R}$ & $\mathrm{S}$ & 1 & $\mathrm{R}$ & $\mathrm{R}$ & $\mathrm{R}$ & $\mathrm{R}$ \\
\hline $635 / 06$ & A. baumannii & 51 & Urina & 2006 & Ambulatório & 77 & $S$ & $S$ & $S$ & $S$ & $S$ & $S$ & $S$ & $S$ & $S$ & $S$ \\
\hline
\end{tabular}




\begin{tabular}{|c|c|c|c|c|c|c|c|c|c|c|c|c|c|c|c|c|}
\hline Número & identificação & OXAs & Amostra & Ano & Clínica & idade & SAM & FEP & CAZ & CIP & AK & $\mathrm{CN}$ & TZP & SXT & IPM & MEM \\
\hline $638 / 06$ & A. gen. 3 & $\ldots$ & Sangue & 2006 & UTI neonatal & meses & $S$ & $S$ & I & $S$ & $S$ & $S$ & $S$ & $\mathrm{R}$ & $S$ & $S$ \\
\hline $640 / 06$ & A. gen. $13 \mathrm{TU}$ & $\ldots$ & Urina & 2006 & Pronto socorro & 34 & $S$ & $S$ & $S$ & $\mathrm{~S}$ & $S$ & $S$ & $S$ & $S$ & $\mathrm{~S}$ & $\mathrm{~S}$ \\
\hline $646 / 06$ & A. gen. 3 & $\ldots$ & S. membro & 2006 & Clínica pediátrica & dias & $S$ & $S$ & $S$ & $S$ & $S$ & $S$ & $S$ & $S$ & $S$ & $S$ \\
\hline $649 / 06$ & A. baumannii & 51 & S. traqueal & 2006 & UTI Pediatria & 7 & $S$ & $\mathrm{R}$ & $\mathrm{R}$ & $\mathrm{R}$ & $\mathrm{R}$ & $\mathrm{R}$ & $\mathrm{R}$ & $\mathrm{R}$ & $S$ & $S$ \\
\hline $656 / 06$ & A. gen. $13 \mathrm{TU}$ & $\ldots$ & Sangue & 2006 & Clínica médica & 92 & $S$ & $S$ & 1 & $S$ & $S$ & $S$ & $S$ & $S$ & $S$ & $S$ \\
\hline $657 / 06$ & A. gen. 3 & $\ldots$ & Sangue & 2006 & Clínica cirúrgica & 22 & $S$ & $S$ & $S$ & $S$ & $S$ & $S$ & $S$ & $S$ & $S$ & $S$ \\
\hline $668 / 06$ & A. baumannii & 51 & S. traqueal & 2006 & UTI adulto & 42 & $S$ & $S$ & 1 & $S$ & $\mathrm{~S}$ & $S$ & $S$ & $S$ & $\mathrm{~S}$ & $S$ \\
\hline $669 / 06$ & A. baumannii & 51 & S. traqueal & 2006 & UTI adulto & 55 & $\mathrm{R}$ & 1 & $\mathrm{R}$ & $\mathrm{R}$ & $\mathrm{R}$ & $S$ & $\mathrm{R}$ & $\mathrm{R}$ & $S$ & $S$ \\
\hline $671 / 06$ & A. baumannii & 51 & Urina & 2006 & Clínica médica & 74 & $S$ & $\mathrm{R}$ & $\mathrm{R}$ & $\mathrm{R}$ & $\mathrm{R}$ & $\mathrm{R}$ & $\mathrm{R}$ & $\mathrm{R}$ & $S$ & $S$ \\
\hline $674 / 06$ & A. gen. $13 \mathrm{TU}$ & $\ldots$ & P. cateter & 2006 & Clínica pediátrica & meses & $S$ & $S$ & $S$ & $S$ & $S$ & $S$ & $S$ & $S$ & $S$ & $S$ \\
\hline $683 / 06$ & A. baumannii & 51 & S. traqueal & 2006 & UTI adulto & 82 & $S$ & $\mathrm{R}$ & $\mathrm{R}$ & $\mathrm{R}$ & $\mathrm{R}$ & 1 & $\mathrm{R}$ & $\mathrm{R}$ & $\mathrm{S}$ & $\mathrm{S}$ \\
\hline $688 / 06$ & A. baumannii & 51 & P. cateter & 2006 & Clínica cirúrgica & 73 & $S$ & $\mathrm{R}$ & $\mathrm{R}$ & $\mathrm{R}$ & $\mathrm{R}$ & 1 & $\mathrm{R}$ & $\mathrm{R}$ & $S$ & $S$ \\
\hline $001 / 07$ & A. baumannii & 51 & S. traqueal & 2007 & Clínica médica & 35 & $\mathrm{R}$ & $\mathrm{R}$ & $\mathrm{R}$ & $\mathrm{R}$ & $\mathrm{R}$ & $\mathrm{R}$ & $\mathrm{R}$ & $\mathrm{R}$ & $S$ & $S$ \\
\hline 010/07 & A. gen. 3 & $\ldots$ & Urina & 2007 & UTI Pediatria & 0 & $S$ & $S$ & $S$ & $S$ & $S$ & $S$ & 1 & $S$ & $S$ & $S$ \\
\hline $034 / 07$ & A. baumannii & 51 & Sangue & 2007 & UTI Pediatria & 1 & $S$ & $S$ & $S$ & $S$ & $S$ & $S$ & $S$ & $S$ & $S$ & $S$ \\
\hline $036 / 07$ & A. baumannii & 51 & Sangue & 2007 & UTI adulto & 72 & $S$ & $\mathrm{R}$ & $\mathrm{R}$ & $\mathrm{R}$ & $\mathrm{R}$ & $\mathrm{R}$ & $\mathrm{R}$ & $\mathrm{R}$ & $\mathrm{S}$ & $\mathrm{S}$ \\
\hline $039 / 07$ & A. gen. 3 & diferente & S. traqueal & 2007 & UTI adulto & 57 & $S$ & $S$ & $S$ & $S$ & $S$ & $S$ & $S$ & $S$ & $\mathrm{~S}$ & $S$ \\
\hline $053 / 07$ & A. baumannii & 51 & urina & 2007 & UTI adulto & 17 & $S$ & $\mathrm{R}$ & $\mathrm{R}$ & $\mathrm{R}$ & $\mathrm{R}$ & $\mathrm{R}$ & $\mathrm{R}$ & $S$ & $S$ & $\mathrm{R}$ \\
\hline $070 / 07$ & A. gen. 3 & $\ldots$ & S. traqueal & 2007 & UTI adulto & 62 & $S$ & $S$ & $S$ & $S$ & $S$ & $S$ & $S$ & $\mathrm{R}$ & $S$ & $S$ \\
\hline $084 / 07$ & A. baumannii & 51 & S. traqueal & 2007 & UTI adulto & 76 & $\mathrm{R}$ & $\mathrm{R}$ & $\mathrm{R}$ & $\mathrm{R}$ & $\mathrm{R}$ & $\mathrm{R}$ & $S$ & $\mathrm{R}$ & $S$ & $S$ \\
\hline 085/07 & A. baumannii & 51 & S. traqueal & 2007 & UTI adulto & 60 & $S$ & $\mathrm{R}$ & $\mathrm{R}$ & $\mathrm{R}$ & $\mathrm{R}$ & $\mathrm{R}$ & $\mathrm{R}$ & $\mathrm{R}$ & $S$ & $S$ \\
\hline $087 / 07$ & A. gen. 3 & $\ldots$ & Urina & 2007 & Pronto socorro & 74 & $S$ & $S$ & $\mathrm{~S}$ & $\mathrm{~S}$ & $S$ & $S$ & $S$ & $\mathrm{R}$ & $S$ & $S$ \\
\hline 090/07 & A. gen. 3 & $\ldots$ & S. traqueal & 2007 & UTI neonatal & 0 & $S$ & $S$ & $S$ & $S$ & $S$ & $S$ & 1 & $\mathrm{R}$ & $S$ & $S$ \\
\hline $105 / 07$ & A. baumannii & 51 & Urina & 2007 & Pronto socorro & 54 & $S$ & $\mathrm{R}$ & $\mathrm{R}$ & $\mathrm{R}$ & $\mathrm{R}$ & $\cdots$ & $\mathrm{R}$ & $\mathrm{R}$ & $\mathrm{S}$ & $S$ \\
\hline $107 / 07$ & A. gen. $13 \mathrm{TU}$ & $\ldots$ & LBA & 2007 & UTI Pediatria & 0 & $\mathrm{~S}$ & $\mathrm{~S}$ & $\mathrm{~S}$ & $\mathrm{~S}$ & $\mathrm{~S}$ & $S$ & $\mathrm{~S}$ & $\mathrm{R}$ & $\mathrm{S}$ & $\mathrm{S}$ \\
\hline $124 / 07$ & $A$. gen. $13 \mathrm{TU}$ & $\ldots$ & P. inguinal & 2007 & UTI Pediatria & 0 & $S$ & $\mathrm{~S}$ & $S$ & $\ldots$ & $\ldots$ & $\ldots$ & $\mathrm{S}$ & $S$ & $\mathrm{~S}$ & $\mathrm{~S}$ \\
\hline $154 / 07$ & A. baumannii & 51 & Sangue & 2007 & Pronto socorro & 48 & $\mathrm{R}$ & $\mathrm{R}$ & $\mathrm{R}$ & $\mathrm{R}$ & $\mathrm{R}$ & $\mathrm{R}$ & $\mathrm{R}$ & $\mathrm{R}$ & $\mathrm{S}$ & $S$ \\
\hline $157 / 07$ & A. baumannii & 51 & P. axilar & 2007 & Clínica médica & 56 & $S$ & $S$ & $S$ & $S$ & $S$ & $S$ & $S$ & $S$ & $S$ & $S$ \\
\hline $158 / 07$ & A. baumannii & 51 & S. traqueal & 2007 & UTI adulto & 59 & $\mathrm{R}$ & 1 & $\mathrm{R}$ & $\mathrm{R}$ & $\mathrm{R}$ & $\mathrm{R}$ & $\mathrm{R}$ & $S$ & $S$ & $S$ \\
\hline $163 / 07$ & A. baumannii & 51 & Urina & 2007 & Pronto socorro & 89 & $S$ & $S$ & $S$ & $\mathrm{R}$ & $S$ & $\mathrm{R}$ & $S$ & $\mathrm{R}$ & $S$ & $S$ \\
\hline $168 / 07$ & A. gen. $13 \mathrm{TU}$ & ausente & Sangue & 2007 & UTI adulto & 82 & $S$ & $S$ & $S$ & $S$ & $S$ & $S$ & $S$ & $S$ & $S$ & $S$ \\
\hline
\end{tabular}




\begin{tabular}{|c|c|c|c|c|c|c|c|c|c|c|c|c|c|c|c|c|}
\hline Número & identificação & OXAs & Amostra & Ano & Clínica & idade & SAM & FEP & CAZ & CIP & AK & $\mathrm{CN}$ & TZP & SXT & IPM & MEM \\
\hline $169 / 07$ & A. baumannii & 51 & S. orofaringe & 2007 & Clínica médica & 84 & $S$ & $\mathrm{R}$ & $\mathrm{R}$ & $\mathrm{R}$ & $\mathrm{R}$ & $\mathrm{R}$ & $\mathrm{R}$ & $\mathrm{R}$ & $S$ & $S$ \\
\hline $174 / 07$ & A. baumannii & 51 & Urina & 2007 & Clínica cirúrgica & 86 & $S$ & $\mathrm{R}$ & $\mathrm{R}$ & $\mathrm{R}$ & $\mathrm{R}$ & $\mathrm{R}$ & 1 & $\mathrm{R}$ & $S$ & $S$ \\
\hline $180 / 07$ & A. baumannii & 51 & Sangue & 2007 & UTI adulto & 80 & $S$ & $\mathrm{R}$ & $\mathrm{R}$ & $\mathrm{R}$ & $\mathrm{R}$ & $\mathrm{R}$ & $\mathrm{R}$ & $\mathrm{R}$ & $S$ & $S$ \\
\hline $188 / 07$ & A. baumannii & 51 & S. traqueal & 2007 & UTI adulto & 44 & $S$ & $\mathrm{R}$ & $\mathrm{R}$ & $\mathrm{R}$ & $\mathrm{R}$ & $\mathrm{R}$ & $\mathrm{R}$ & $\mathrm{R}$ & $S$ & $S$ \\
\hline $199 / 07$ & A. baumannii & 51 & S. traqueal & 2007 & UTI adulto & 66 & $\mathrm{~S}$ & $\mathrm{R}$ & $\mathrm{R}$ & $\mathrm{R}$ & $\mathrm{R}$ & $\mathrm{R}$ & $\mathrm{R}$ & $\mathrm{R}$ & $S$ & $S$ \\
\hline $200 / 07$ & A. gen. $13 \mathrm{TU}$ & $\ldots$ & S. orofaringe & 2007 & Berçario & 0 & $\mathrm{R}$ & $S$ & $S$ & $S$ & $\mathrm{~S}$ & $S$ & $S$ & $S$ & $S$ & $S$ \\
\hline $207 / 07$ & A. baumannii & 51 & P. axilar & 2007 & UTI adulto & 34 & $S$ & $\mathrm{R}$ & $\mathrm{R}$ & $\mathrm{R}$ & $\mathrm{R}$ & $\mathrm{R}$ & $\mathrm{R}$ & $\mathrm{R}$ & $S$ & $S$ \\
\hline $212 / 07$ & A. baumannii & 51 & S. traqueal & 2007 & UTI adulto & 78 & $S$ & $S$ & $S$ & $S$ & $\mathrm{~S}$ & $S$ & $S$ & $S$ & $S$ & $S$ \\
\hline $213 / 07$ & A. gen. $13 \mathrm{TU}$ & $\ldots$ & S. orofaringe & 2007 & Pronto socorro & 11 & $\mathrm{R}$ & $S$ & $S$ & $S$ & $S$ & $S$ & $\mathrm{R}$ & $S$ & $S$ & $S$ \\
\hline $214 / 07$ & A. gen. 3 & $\ldots$ & Celulite & 2007 & Clínica médica & 49 & $S$ & $S$ & $S$ & $S$ & $S$ & $S$ & $S$ & $S$ & $S$ & $S$ \\
\hline $215 / 07$ & A. baumannii & 51 & P. inguinal & 2007 & Clínica médica & 44 & $S$ & $\mathrm{R}$ & $\mathrm{R}$ & $\mathrm{R}$ & $\mathrm{R}$ & $\mathrm{R}$ & $\mathrm{R}$ & $\mathrm{R}$ & $S$ & $S$ \\
\hline $216 / 07$ & A. baumannii & 51 & Urina & 2007 & Pronto socorro & 62 & $S$ & $S$ & $S$ & $S$ & $S$ & $S$ & $S$ & $\mathrm{R}$ & $S$ & $S$ \\
\hline $227 / 07$ & A. baumannii & 51 & LBA & 2007 & UTI adulto & 55 & $S$ & $\mathrm{R}$ & $\mathrm{R}$ & $\mathrm{R}$ & $\mathrm{R}$ & $\mathrm{R}$ & $\mathrm{R}$ & $\mathrm{R}$ & $S$ & $S$ \\
\hline $237 / 07$ & A. baumannii & 51 & S. traqueal & 2007 & UTI adulto & 50 & $S$ & $\mathrm{R}$ & $\mathrm{R}$ & $\mathrm{R}$ & $\mathrm{R}$ & $\mathrm{R}$ & $\mathrm{R}$ & $\mathrm{R}$ & $S$ & $S$ \\
\hline $241 / 07$ & A. gen. 3 & $\ldots$ & S. traqueal & 2007 & UTI Pediatria & 0 & $S$ & $S$ & $S$ & $S$ & $S$ & $S$ & $S$ & $S$ & $S$ & $S$ \\
\hline $263 / 07$ & A. gen. $13 \mathrm{TU}$ & ausente & S. traqueal & 2007 & UTI adulto & 56 & $S$ & $\mathrm{R}$ & $\mathrm{R}$ & $S$ & $S$ & $S$ & $\mathrm{R}$ & $S$ & $S$ & $S$ \\
\hline $267 / 07$ & A. baumannii & 51 & S. traqueal & 2007 & UTI adulto & 55 & $S$ & $\mathrm{R}$ & $\mathrm{R}$ & $\mathrm{R}$ & $\mathrm{R}$ & $\mathrm{R}$ & $\mathrm{R}$ & $\mathrm{R}$ & $\mathrm{S}$ & $S$ \\
\hline $268 / 07$ & A. gen. $13 \mathrm{TU}$ & $\ldots$ & S. purulenta & 2007 & Berçario & -1 & $S$ & $S$ & $S$ & $S$ & $S$ & $S$ & $S$ & $S$ & $S$ & $S$ \\
\hline $271 / 07$ & A. gen. 13 TU & $\ldots$ & S. traqueal & 2007 & UTI Pediatria & 6 & $S$ & $\mathrm{~S}$ & $\mathrm{~S}$ & $S$ & $\mathrm{~S}$ & $S$ & $\mathrm{~S}$ & $\mathrm{~S}$ & $\mathrm{~S}$ & $\mathrm{~S}$ \\
\hline $278 / 07$ & A. baumannii & 51 & S. traqueal & 2007 & Semi & 29 & $\mathrm{I}$ & $\mathrm{R}$ & $\mathrm{R}$ & $\mathrm{R}$ & $\mathrm{R}$ & $\mathrm{R}$ & $\mathrm{R}$ & $\mathrm{R}$ & $\mathrm{S}$ & $\mathrm{S}$ \\
\hline $284 / 07$ & A. baumannii & 51 & S. ferida & 2007 & Clínica médica & 75 & $S$ & $\mathrm{R}$ & $\mathrm{R}$ & $\mathrm{R}$ & $S$ & $\mathrm{R}$ & $\mathrm{R}$ & $\mathrm{R}$ & $S$ & $S$ \\
\hline $290 / 07$ & A. baumannii & 51 & Escarro & 2007 & Semi & 71 & $\mathrm{~S}$ & $\mathrm{R}$ & $\mathrm{R}$ & $\mathrm{R}$ & $\mathrm{R}$ & $\mathrm{R}$ & $\mathrm{R}$ & $\mathrm{R}$ & $\mathrm{S}$ & $\mathrm{S}$ \\
\hline $298 / 07$ & A. baumannii & 51 & Urina & 2007 & Semi & 57 & $S$ & $\mathrm{R}$ & $\mathrm{R}$ & $\mathrm{R}$ & $\mathrm{R}$ & $\mathrm{R}$ & $\mathrm{R}$ & $\mathrm{R}$ & $S$ & $S$ \\
\hline $299 / 07$ & A. baumannii & 51 & Sangue & 2007 & UTI adulto & 54 & $\mathrm{~S}$ & $\mathrm{R}$ & $\mathrm{R}$ & $\mathrm{R}$ & $\mathrm{R}$ & $\mathrm{R}$ & $\mathrm{R}$ & $\mathrm{R}$ & $\mathrm{S}$ & $\mathrm{S}$ \\
\hline $303 / 07$ & A. baumannii & 51 & S. traqueal & 2007 & UTI adulto & 23 & $S$ & $\mathrm{R}$ & $\mathrm{R}$ & $\mathrm{R}$ & $\mathrm{R}$ & $\mathrm{R}$ & $\mathrm{R}$ & $\mathrm{R}$ & $S$ & $S$ \\
\hline $305 / 07$ & A. baumannii & 51 & S. traqueal & 2007 & UTI adulto & 79 & $\mathrm{~S}$ & $\mathrm{R}$ & $\mathrm{R}$ & $\mathrm{R}$ & $\mathrm{R}$ & $\mathrm{R}$ & $\mathrm{R}$ & $\mathrm{R}$ & $\mathrm{S}$ & $\mathrm{S}$ \\
\hline $315 / 07$ & A. baumannii & 51 & S. traqueal & 2007 & UTI adulto & 80 & $S$ & $\mathrm{R}$ & $\mathrm{R}$ & $\mathrm{R}$ & $\mathrm{R}$ & $\mathrm{R}$ & $\mathrm{R}$ & $S$ & $S$ & $S$ \\
\hline $317 / 07$ & A. baumannii & 51 & S. traqueal & 2007 & UTI adulto & 83 & $S$ & $\mathrm{R}$ & $\mathrm{R}$ & $\mathrm{R}$ & $\mathrm{R}$ & $\mathrm{R}$ & $\mathrm{R}$ & $\mathrm{R}$ & $S$ & $S$ \\
\hline $321 / 07$ & A. baumannii & 51 & LBA & 2007 & UTI adulto & 31 & $S$ & $S$ & $\mathrm{R}$ & $\mathrm{R}$ & $\mathrm{R}$ & $\mathrm{R}$ & $\mathrm{R}$ & $\mathrm{R}$ & $S$ & $S$ \\
\hline $327 / 07$ & A. baumannii & 51 & Urina & 2007 & Clínica cirúrgica & 78 & $S$ & $\mathrm{R}$ & $\mathrm{R}$ & $\mathrm{R}$ & $\mathrm{R}$ & $\mathrm{R}$ & $\mathrm{R}$ & $\mathrm{R}$ & $S$ & $S$ \\
\hline $338 / 07$ & A. gen. 3 & $\ldots$ & S. traqueal & 2007 & Pediatria & 0 & $S$ & $S$ & $S$ & $S$ & $S$ & $S$ & $S$ & $S$ & $S$ & $S$ \\
\hline
\end{tabular}




\begin{tabular}{|c|c|c|c|c|c|c|c|c|c|c|c|c|c|c|c|c|}
\hline Número & identificação & OXAs & Amostra & Ano & Clínica & idade & SAM & FEP & CAZ & CIP & AK & $\mathrm{CN}$ & TZP & SXT & IPM & MEM \\
\hline $339 / 07$ & A. baumannii & 51 & S. traqueal & 2007 & UTI adulto & 32 & $S$ & $S$ & $S$ & $S$ & $S$ & $S$ & $S$ & $S$ & $S$ & $S$ \\
\hline $339 / 07$ & A. baumannii & 51 & S. abdominal & 2007 & Clínica cirúrgica & 31 & $S$ & $S$ & $\mathrm{R}$ & $\mathrm{R}$ & $\mathrm{R}$ & $S$ & $\mathrm{R}$ & $\mathrm{R}$ & $\mathrm{S}$ & $\mathrm{S}$ \\
\hline $340 / 07$ & A. baumannii & 23,51 & S. ferida & 2007 & Clínica médica & 49 & S & $\mathrm{R}$ & $\mathrm{R}$ & $\mathrm{R}$ & $\mathrm{R}$ & $\mathrm{R}$ & $\mathrm{R}$ & $\mathrm{R}$ & $\mathrm{R}$ & $\mathrm{R}$ \\
\hline $347 / 07$ & A. gen. 3 & $\ldots$ & P. axilar & 2007 & Clínica médica & 53 & $\mathrm{~S}$ & $S$ & $S$ & $\mathrm{~S}$ & $S$ & $S$ & $\mathrm{~S}$ & $S$ & $\mathrm{~S}$ & $\mathrm{~S}$ \\
\hline $353 / 07$ & A. baumannii & 51 & S. traqueal & 2007 & UTI adulto & 69 & $S$ & $\mathrm{R}$ & $\mathrm{R}$ & $\mathrm{R}$ & $\mathrm{R}$ & $\mathrm{R}$ & $\mathrm{R}$ & $\mathrm{R}$ & $\mathrm{S}$ & $\mathrm{S}$ \\
\hline $355 / 07$ & A. baumannii & 51 & P. axilar & 2007 & Ambulatório & 10 & $S$ & $\mathrm{R}$ & $\mathrm{R}$ & $\mathrm{R}$ & $\mathrm{R}$ & $\mathrm{R}$ & $\mathrm{R}$ & $\mathrm{R}$ & $S$ & $S$ \\
\hline $361 / 07$ & A. baumannii & 51 & Urina & 2007 & Clínica cirúrgica & 83 & $S$ & $\mathrm{R}$ & $\mathrm{R}$ & $\mathrm{R}$ & $\mathrm{R}$ & $\mathrm{R}$ & $\mathrm{R}$ & $\mathrm{R}$ & $\mathrm{S}$ & $S$ \\
\hline $366 / 07$ & A. gen. $13 \mathrm{TU}$ & ausente & S. traqueal & 2007 & UTI adulto & 55 & $\mathrm{R}$ & $S$ & $S$ & $S$ & $S$ & $S$ & $\mathrm{R}$ & $S$ & $S$ & $S$ \\
\hline $399 / 07$ & A. baumannii & 51 & S. traqueal & 2007 & UTI adulto & 57 & $S$ & $S$ & $S$ & $S$ & $\mathrm{~S}$ & $S$ & $S$ & $S$ & $S$ & $S$ \\
\hline $426 / 07$ & A. baumannii & 51 & Escarro & 2007 & Clínica médica & 46 & $S$ & $S$ & $S$ & $S$ & $S$ & $S$ & $S$ & $S$ & $S$ & $S$ \\
\hline $428 / 07$ & A. baumannii & 23,51 & S. traqueal & 2007 & UTI adulto & 72 & 1 & $\mathrm{R}$ & $\mathrm{R}$ & $\mathrm{R}$ & 1 & $\mathrm{R}$ & $\mathrm{R}$ & $\mathrm{R}$ & $\mathrm{R}$ & $\mathrm{R}$ \\
\hline $433 / 07$ & A. gen. $13 \mathrm{TU}$ & ausente & P. cateter & 2007 & UTI adulto & 74 & $S$ & $S$ & $S$ & $S$ & $S$ & $S$ & $S$ & $S$ & $S$ & $S$ \\
\hline $434 / 07$ & A. gen. $13 \mathrm{TU}$ & ausente & Sangue & 2007 & UTI adulto & 31 & $\mathrm{R}$ & $S$ & $S$ & $S$ & $S$ & $S$ & $\mathrm{R}$ & $S$ & $S$ & $S$ \\
\hline $465 / 07$ & A. baumannii & 51 & P. axilar & 2007 & Clínica médica & 85 & $S$ & $\mathrm{R}$ & $\mathrm{R}$ & $\mathrm{R}$ & $\mathrm{R}$ & $S$ & $\mathrm{R}$ & $\mathrm{R}$ & $S$ & $S$ \\
\hline $470 / 07$ & A. baumannii & 51 & S. orofaringe & 2007 & Clínica médica & 84 & $S$ & $S$ & $S$ & $S$ & $S$ & $S$ & $S$ & $S$ & $S$ & $S$ \\
\hline $471 / 07$ & A. baumannii & 51 & S. traqueal & 2007 & UTI adulto & 63 & $S$ & $\mathrm{R}$ & $\mathrm{R}$ & $\mathrm{R}$ & $\mathrm{R}$ & $\mathrm{R}$ & $\mathrm{R}$ & $\mathrm{R}$ & $S$ & $S$ \\
\hline $495 / 07$ & A. baumannii & 51 & Urina & 2007 & Pronto socorro & meses & $S$ & $\mathrm{R}$ & $\mathrm{R}$ & $\mathrm{R}$ & $\mathrm{R}$ & $\mathrm{R}$ & $\mathrm{I}$ & $\mathrm{R}$ & $\mathrm{S}$ & $S$ \\
\hline $533 / 07$ & A. gen. $13 \mathrm{TU}$ & $\ldots$ & Urina & 2007 & Pronto socorro & 66 & $S$ & $S$ & $S$ & $S$ & $S$ & $S$ & $S$ & $S$ & $S$ & $S$ \\
\hline $566 / 07$ & A. gen. $13 \mathrm{TU}$ & $\ldots$ & S. ferida & 2007 & Pediatria & 10 & $S$ & $S$ & $S$ & $S$ & $S$ & $S$ & $S$ & $S$ & $S$ & $S$ \\
\hline $577 / 07$ & A. baumannii & 51 & Urina & 2007 & Pronto socorro & 89 & $S$ & $\mathrm{R}$ & $\mathrm{R}$ & $\mathrm{R}$ & $\mathrm{R}$ & $\mathrm{R}$ & $\mathrm{R}$ & $\mathrm{R}$ & $S$ & $S$ \\
\hline $623 / 07$ & A. baumannii & 23,51 & P. axilar & 2007 & Clínica médica & 52 & $\mathrm{I}$ & $\mathrm{R}$ & $\mathrm{R}$ & $\mathrm{R}$ & $\mathrm{R}$ & $\mathrm{R}$ & $\mathrm{R}$ & $\mathrm{R}$ & $\mathrm{R}$ & $\mathrm{R}$ \\
\hline $627 / 07$ & A. gen. $13 \mathrm{TU}$ & $\ldots$ & S. traqueal & 2007 & UTI Pediatria & dias & $S$ & $S$ & $\mathrm{~S}$ & $\mathrm{~S}$ & $S$ & $S$ & $\mathrm{~S}$ & $\mathrm{~S}$ & $S$ & $S$ \\
\hline $629 / 07$ & A. baumannii & 23,51 & S. traqueal & 2007 & UTI adulto & 69 & $\mathrm{R}$ & $\mathrm{R}$ & $\mathrm{R}$ & $\mathrm{R}$ & $\mathrm{R}$ & $\mathrm{R}$ & $\mathrm{R}$ & $\mathrm{R}$ & $\mathrm{R}$ & $\mathrm{R}$ \\
\hline $639 / 07$ & A. baumannii & 23,51 & S. traqueal & 2007 & UTI adulto & 45 & $S$ & $\mathrm{R}$ & $\mathrm{R}$ & $\mathrm{R}$ & $\mathrm{R}$ & $\mathrm{R}$ & $\mathrm{R}$ & $\mathrm{R}$ & $\mathrm{S}$ & $S$ \\
\hline $649 / 07$ & A. baumannii & 51 & S. traqueal & 2007 & Pronto socorro & 73 & $\mathrm{~S}$ & $\mathrm{R}$ & $\mathrm{R}$ & $\mathrm{R}$ & $\mathrm{R}$ & $\mathrm{R}$ & $\mathrm{R}$ & $\mathrm{R}$ & $\mathrm{S}$ & $S$ \\
\hline $651 / 07$ & A. baumannii & 23,51 & S. traqueal & 2007 & Semi & 80 & $\mathrm{I}$ & $\mathrm{R}$ & $\mathrm{R}$ & $\mathrm{R}$ & $\mathrm{R}$ & $\mathrm{R}$ & $\mathrm{R}$ & $\mathrm{R}$ & $\mathrm{R}$ & $\mathrm{R}$ \\
\hline $657 / 07$ & A. gen. $13 \mathrm{TU}$ & $\ldots$ & S. traqueal & 2007 & UTI Pediatria & 0 & $S$ & $\ldots$ & $S$ & $S$ & $S$ & $S$ & $S$ & $S$ & $S$ & $S$ \\
\hline $659 / 07$ & A. baumannii & 23,51 & Sangue & 2007 & Semi & 65 & $S$ & $\mathrm{R}$ & $\mathrm{R}$ & $\mathrm{R}$ & $\mathrm{R}$ & $\mathrm{R}$ & $\mathrm{R}$ & $\mathrm{R}$ & $\mathrm{R}$ & $\mathrm{R}$ \\
\hline $664 / 07$ & A. baumannii & 51 & S. traqueal & 2007 & UTI adulto & 34 & $S$ & $\ldots$ & $S$ & $S$ & $S$ & $S$ & $S$ & $S$ & $S$ & $S$ \\
\hline $672 / 07$ & A. baumannii & 51 & P. axilar & 2007 & UTI Pediatria & 0 & $S$ & $S$ & $S$ & $S$ & $S$ & $S$ & $S$ & $S$ & $S$ & $S$ \\
\hline $674 / 07$ & A. baumannii & 23,51 & S. traqueal & 2007 & UTI adulto & 45 & $S$ & $\mathrm{R}$ & $\mathrm{R}$ & $\mathrm{R}$ & $S$ & $S$ & $\mathrm{R}$ & $S$ & $\mathrm{R}$ & $\mathrm{R}$ \\
\hline
\end{tabular}




\begin{tabular}{|c|c|c|c|c|c|c|c|c|c|c|c|c|c|c|c|c|}
\hline Número & identificação & OXAs & Amostra & Ano & Clínica & idade & SAM & FEP & CAZ & CIP & AK & CN & TZP & SXT & IPM & MEM \\
\hline $728 / 07$ & A. baumannii & 51 & S. ferida & 2007 & Clínica médica & 79 & $\mathrm{R}$ & $\mathrm{R}$ & $\mathrm{R}$ & $\mathrm{R}$ & $S$ & $\mathrm{R}$ & $\mathrm{R}$ & $\mathrm{R}$ & $S$ & $S$ \\
\hline 0005/08 & A. baumannii & 23,51 & P. axilar & 2008 & Clínica médica & 84 & $\mathrm{R}$ & $\mathrm{R}$ & $\mathrm{R}$ & $\mathrm{R}$ & $\mathrm{R}$ & S & $\mathrm{R}$ & $\mathrm{R}$ & $\mathrm{R}$ & $\mathrm{R}$ \\
\hline 0008/08 & A. gen. $13 \mathrm{TU}$ & ausente & P. inguinal & 2008 & UTI adulto & 56 & $S$ & $S$ & $S$ & $S$ & $S$ & $S$ & $\mathrm{~S}$ & $\mathrm{R}$ & $\mathrm{S}$ & $S$ \\
\hline 0013/08 & A. baumannii & 23,51 & S. ocular & 2008 & UTI Pediatria & 2 & $\mathrm{R}$ & $\mathrm{R}$ & $\mathrm{R}$ & $\mathrm{R}$ & $\mathrm{R}$ & $S$ & $\mathrm{R}$ & $\mathrm{R}$ & $\mathrm{R}$ & $\mathrm{R}$ \\
\hline 0027/08 & A. baumannii & 51 & S. traqueal & 2008 & UTI adulto & 45 & $S$ & $\mathrm{R}$ & $\mathrm{R}$ & $\mathrm{R}$ & $\mathrm{R}$ & $S$ & $\mathrm{R}$ & $\mathrm{R}$ & $\mathrm{S}$ & $S$ \\
\hline 0033/08 & A. baumannii & 51 & P. axilar & 2008 & Clínica médica & 73 & $S$ & 1 & $\mathrm{R}$ & $\mathrm{R}$ & $\mathrm{R}$ & $S$ & $\mathrm{R}$ & $\mathrm{R}$ & $S$ & $S$ \\
\hline 0035/08 & A. baumannii & 23,51 & Escara & 2008 & Pronto socorro & 76 & $\mathrm{R}$ & $\mathrm{R}$ & $\mathrm{R}$ & $\mathrm{R}$ & $\mathrm{R}$ & $\mathrm{R}$ & $\mathrm{R}$ & $\mathrm{R}$ & $\mathrm{R}$ & $\mathrm{R}$ \\
\hline 0043/08 & A. baumannii & 51 & Sangue & 2008 & Semi & 82 & 1 & $\mathrm{R}$ & $\mathrm{R}$ & $\mathrm{R}$ & $\mathrm{R}$ & $\mathrm{R}$ & 1 & $\mathrm{R}$ & $S$ & $S$ \\
\hline $0050 / 08$ & A. gen. $13 \mathrm{TU}$ & $\ldots$ & S. orofaringe & 2008 & Clínica médica & 65 & $S$ & $S$ & $S$ & $S$ & $S$ & $S$ & $S$ & $S$ & $S$ & $S$ \\
\hline $0051 / 08$ & A. baumannii & 51 & S. traqueal & 2008 & UTI adulto & 75 & $S$ & $S$ & $S$ & $S$ & $S$ & $S$ & $S$ & $S$ & $S$ & $S$ \\
\hline $0055 / 08$ & A. gen. 3 & ausente & LBA & 2008 & UTI adulto & 37 & $S$ & $S$ & $S$ & $\mathrm{~S}$ & $S$ & $S$ & $S$ & $\mathrm{R}$ & $\mathrm{S}$ & $S$ \\
\hline $0076 / 08$ & A. baumannii & 51 & Urina & 2008 & Pronto socorro & 26 & $S$ & $S$ & $S$ & $S$ & $S$ & $S$ & $S$ & $S$ & $S$ & $S$ \\
\hline $0081 / 08$ & A. baumannii & 51 & P. axilar & 2008 & Pediatria & 16 & $\mathrm{~S}$ & $\mathrm{~S}$ & $S$ & $\mathrm{~S}$ & $\mathrm{~S}$ & $S$ & $\mathrm{~S}$ & $\mathrm{R}$ & $S$ & $S$ \\
\hline 0099/08 & A. baumannii & 51 & P. inguinal & 2008 & Clínica médica & 77 & $S$ & $\mathrm{R}$ & $\mathrm{R}$ & $\mathrm{R}$ & $\mathrm{R}$ & $\mathrm{R}$ & $\mathrm{R}$ & $\mathrm{R}$ & $S$ & $S$ \\
\hline $0105 / 08$ & A. baumannii & 51 & P. cateter & 2008 & UTI Pediatria & 10 & $S$ & $S$ & $S$ & $S$ & $S$ & $S$ & $S$ & $S$ & $S$ & $S$ \\
\hline 0106/08 & A. baumannii & 51 & S. traqueal & 2008 & UTI adulto & 50 & $S$ & $S$ & $S$ & $S$ & $S$ & $S$ & $S$ & $S$ & $S$ & $S$ \\
\hline $0118 / 08$ & A. baumannii & 51 & S. ferida & 2008 & Clínica cirúrgica & 57 & $S$ & $\mathrm{R}$ & $\mathrm{R}$ & $\mathrm{R}$ & $\mathrm{R}$ & $\mathrm{R}$ & $\mathrm{R}$ & $\mathrm{R}$ & $\mathrm{S}$ & $\mathrm{S}$ \\
\hline $0122 / 08$ & A. baumannii & 51 & S. traqueal & 2008 & UTI adulto & 48 & $S$ & $S$ & $S$ & $S$ & $S$ & $S$ & $\mathrm{R}$ & $\mathrm{R}$ & $S$ & $S$ \\
\hline $0144 / 08$ & A. baumannii & 23,51 & S. traqueal & 2008 & UTI adulto & 61 & $R$ & $\mathrm{R}$ & $\mathrm{R}$ & $\mathrm{R}$ & $\mathrm{S}$ & $\mathrm{S}$ & $\mathrm{R}$ & $S$ & $\mathrm{R}$ & $\mathrm{R}$ \\
\hline $0158 / 08$ & A. baumannii & 23,51 & P. axilar & 2008 & Clínica médica & 37 & $\mathrm{R}$ & $\mathrm{R}$ & $\mathrm{R}$ & $\mathrm{R}$ & $\mathrm{R}$ & $S$ & $\mathrm{R}$ & $S$ & $\mathrm{R}$ & $\mathrm{R}$ \\
\hline 0199/08 & A. gen. 3 & $\ldots$ & S. ferida & 2008 & UTI Pediatria & 0 & $S$ & $S$ & $S$ & $S$ & $S$ & $\mathrm{~S}$ & $S$ & $S$ & $S$ & $S$ \\
\hline $0219 / 08$ & A. baumannii & 51 & P. axilar & 2008 & Clínica médica & 86 & $S$ & $S$ & $\mathrm{~S}$ & $\mathrm{~S}$ & $S$ & $S$ & $S$ & $\mathrm{~S}$ & $S$ & $\mathrm{~S}$ \\
\hline $0233 / 08$ & A. baumannii & 23,51 & S. traqueal & 2008 & UTI adulto & 77 & $\mathrm{R}$ & $\mathrm{R}$ & $\mathrm{R}$ & $\mathrm{R}$ & $S$ & $S$ & $\mathrm{R}$ & $S$ & $\mathrm{R}$ & $\mathrm{R}$ \\
\hline $0242 / 08$ & A. baumannii & 51 & Abscesso & 2008 & Clínica cirúrgica & 46 & $S$ & $\mathrm{R}$ & $\mathrm{R}$ & $\mathrm{R}$ & $\mathrm{R}$ & $\mathrm{R}$ & $\mathrm{R}$ & $\mathrm{R}$ & $\mathrm{S}$ & $S$ \\
\hline $0244 / 08$ & A. baumannii & 23,51 & S. ferida & 2008 & UTI adulto & 77 & $\mathrm{R}$ & $\mathrm{R}$ & $\mathrm{R}$ & $\mathrm{R}$ & $S$ & $S$ & $\mathrm{R}$ & $S$ & $\mathrm{R}$ & $\mathrm{R}$ \\
\hline 0256/08 & A. baumannii & 23,51 & S. traqueal & 2008 & UTI adulto & 91 & $S$ & $\mathrm{R}$ & $\mathrm{R}$ & $\mathrm{R}$ & $\mathrm{S}$ & $\mathrm{S}$ & $\mathrm{R}$ & $S$ & $\mathrm{R}$ & $\mathrm{R}$ \\
\hline $0267 / 08$ & A. baumannii & 23,51 & S. traqueal & 2008 & UTI adulto & 65 & $\mathrm{R}$ & $\mathrm{R}$ & $\mathrm{R}$ & $\mathrm{R}$ & $\mathrm{S}$ & $S$ & $\mathrm{R}$ & $S$ & $\mathrm{R}$ & $\mathrm{R}$ \\
\hline 0270/08 & A. gen. $13 \mathrm{TU}$ & $\ldots$ & S. ferida & 2008 & Clínica obstétrica & 16 & $S$ & $S$ & $S$ & $S$ & $S$ & $S$ & $S$ & $S$ & $S$ & $S$ \\
\hline $0281 / 08$ & A. gen. $13 \mathrm{TU}$ & $\ldots$ & P. axilar & 2008 & Clínica cirúrgica & 21 & $S$ & $S$ & $S$ & $S$ & $S$ & $S$ & $\mathrm{R}$ & $S$ & $S$ & $S$ \\
\hline $0294 / 08$ & A. baumannii & 23,51 & S. traqueal & 2008 & UTI adulto & 75 & $S$ & $\mathrm{R}$ & $\mathrm{R}$ & $\mathrm{R}$ & $\mathrm{R}$ & $\mathrm{R}$ & $\mathrm{R}$ & $\mathrm{R}$ & $S$ & $S$ \\
\hline $0295 / 08$ & A. baumannii & 23,51 & LBA & 2008 & UTI adulto & 68 & $\mathrm{R}$ & $\mathrm{R}$ & $\mathrm{R}$ & $\mathrm{R}$ & $S$ & $S$ & $\mathrm{R}$ & $S$ & $\mathrm{R}$ & $\mathrm{R}$ \\
\hline
\end{tabular}




\begin{tabular}{|c|c|c|c|c|c|c|c|c|c|c|c|c|c|c|c|c|}
\hline Número & identificação & OXAs & Amostra & Ano & Clínica & idade & SAM & FEP & CAZ & CIP & AK & $\mathrm{CN}$ & TZP & SXT & IPM & MEM \\
\hline $0321 / 08$ & A. baumannii & 23,51 & S. traqueal & 2008 & UTI adulto & 77 & $\mathrm{R}$ & $\mathrm{R}$ & $\mathrm{R}$ & $\mathrm{R}$ & $S$ & $S$ & $\mathrm{R}$ & $S$ & $\mathrm{R}$ & $\mathrm{R}$ \\
\hline 0338/08 & A. baumannii & 23,51 & S. traqueal & 2008 & UTI adulto & 55 & I & $\mathrm{R}$ & $\mathrm{R}$ & $\mathrm{R}$ & $\mathrm{R}$ & $\mathrm{R}$ & $\mathrm{R}$ & $\mathrm{R}$ & $\mathrm{R}$ & $\mathrm{R}$ \\
\hline 0381/08 & A. baumannii & 23,51 & S. traqueal & 2008 & UTI adulto & 61 & $\mathrm{R}$ & $\mathrm{R}$ & $\mathrm{R}$ & $\mathrm{R}$ & $\mathrm{R}$ & $\mathrm{R}$ & $\mathrm{R}$ & $\mathrm{R}$ & $\mathrm{R}$ & $\mathrm{R}$ \\
\hline 0390/08 & A. baumannii & 51 & P. axilar & 2008 & Clínica médica & 43 & $S$ & $S$ & $S$ & $S$ & $S$ & $\ldots$ & $\mathrm{S}$ & $S$ & $S$ & $S$ \\
\hline $0421 / 08$ & A. baumannii & 51 & Urina & 2008 & Ambulatório & 55 & $S$ & $S$ & $S$ & $S$ & $S$ & $S$ & $\mathrm{~S}$ & $S$ & $\mathrm{~S}$ & $S$ \\
\hline 0449/08 & A. baumannii & 23,51 & S. orofaringe & 2008 & Clínica médica & 79 & $\mathrm{R}$ & $\mathrm{R}$ & $\mathrm{R}$ & $\mathrm{R}$ & $\mathrm{R}$ & $S$ & $\mathrm{R}$ & $S$ & $\mathrm{R}$ & $\mathrm{R}$ \\
\hline 0499/08 & A. baumannii & 51 & L. ascítico & 2008 & Semi & 38 & $S$ & $\mathrm{R}$ & $\mathrm{R}$ & $\mathrm{R}$ & $\mathrm{R}$ & $S$ & 1 & $\mathrm{R}$ & $\mathrm{S}$ & $S$ \\
\hline 0505/08 & A. baumannii & 51 & Sangue & 2008 & UTI adulto & 88 & $S$ & $\mathrm{R}$ & $\mathrm{R}$ & $\mathrm{R}$ & $\mathrm{R}$ & $S$ & $\mathrm{R}$ & $\mathrm{R}$ & $S$ & $S$ \\
\hline $0544 / 08$ & A. baumannii & 23,51 & Aspirado & 2008 & Clínica cirúrgica & 25 & $S$ & $\mathrm{R}$ & $\mathrm{R}$ & $\mathrm{R}$ & $\mathrm{R}$ & $\mathrm{R}$ & $\mathrm{R}$ & $\mathrm{R}$ & $\mathrm{R}$ & $\mathrm{R}$ \\
\hline $0552 / 08$ & A. baumannii & 51 & Sangue & 2008 & UTI adulto & 64 & $S$ & $\mathrm{R}$ & $\mathrm{R}$ & $\mathrm{R}$ & $\mathrm{R}$ & $S$ & $\mathrm{R}$ & $\mathrm{R}$ & $S$ & $S$ \\
\hline $0558 / 08$ & A. baumannii & 51 & P. cateter & 2008 & UTI adulto & 72 & $S$ & $\mathrm{R}$ & $\mathrm{R}$ & $\mathrm{R}$ & $\mathrm{S}$ & $S$ & $\mathrm{R}$ & $\mathrm{R}$ & $\mathrm{S}$ & $\mathrm{S}$ \\
\hline $0623 / 08$ & A. baumannii & 51 & P. axilar & 2008 & Clínica cirúrgica & 22 & $S$ & $S$ & $S$ & $S$ & $S$ & $S$ & $S$ & $S$ & $S$ & $S$ \\
\hline 0634/08 & A. baumannii & 23,51 & Escarro & 2008 & Clínica médica & 89 & $\mathrm{R}$ & $\mathrm{R}$ & $\mathrm{R}$ & $\mathrm{R}$ & $\mathrm{R}$ & $S$ & $\mathrm{R}$ & $\mathrm{R}$ & $\mathrm{R}$ & $\mathrm{R}$ \\
\hline 0642/08 & A. baumannii & 23,51 & S. traqueal & 2008 & UTI adulto & 58 & $\mathrm{R}$ & $\mathrm{R}$ & $\mathrm{R}$ & $\mathrm{R}$ & $S$ & $S$ & $\mathrm{R}$ & $S$ & $\mathrm{R}$ & $\mathrm{R}$ \\
\hline $0660 / 08$ & A. baumannii & 51 & LBA & 2008 & UTI adulto & 78 & $S$ & $\mathrm{R}$ & $\mathrm{R}$ & $\mathrm{R}$ & $\mathrm{R}$ & $S$ & $\mathrm{R}$ & $\mathrm{R}$ & $S$ & $S$ \\
\hline 0698/08 & A. gen. $13 \mathrm{TU}$ & ausente & S. traqueal & 2008 & UTI adulto & 25 & $S$ & $S$ & $S$ & $S$ & $S$ & $S$ & $S$ & $S$ & $S$ & $S$ \\
\hline $0733 / 08$ & A. baumannii & 23,51 & Urina & 2008 & Pronto socorro & 80 & $S$ & $\mathrm{R}$ & $\mathrm{R}$ & $\mathrm{R}$ & $\mathrm{R}$ & $\mathrm{R}$ & $\mathrm{R}$ & $\mathrm{R}$ & $\mathrm{R}$ & $\mathrm{R}$ \\
\hline $0750 / 08$ & A. baumannii & 51 & Urina & 2008 & Pronto socorro & 93 & $S$ & $\mathrm{R}$ & $\mathrm{R}$ & $\mathrm{R}$ & $\mathrm{R}$ & $S$ & $\mathrm{R}$ & $\mathrm{R}$ & $S$ & $S$ \\
\hline 0777/08 & A. baumannii & 23,51 & S. traqueal & 2008 & UTI adulto & 62 & $\mathrm{R}$ & $\mathrm{R}$ & $\mathrm{R}$ & $\mathrm{R}$ & $S$ & $S$ & $\mathrm{R}$ & $S$ & $\mathrm{R}$ & $\mathrm{R}$ \\
\hline $0811 / 08$ & A. gen. $13 \mathrm{TU}$ & ausente & S. traqueal & 2008 & UTI adulto & 50 & $S$ & $S$ & $S$ & $S$ & $S$ & $S$ & $S$ & $\mathrm{R}$ & $S$ & $S$ \\
\hline $0827 / 08$ & A. gen. 3 & $\ldots$ & P. axilar & 2008 & UTI Pediatria & 2 & $S$ & $S$ & $S$ & $S$ & $S$ & $\mathrm{~S}$ & $S$ & $\mathrm{R}$ & $S$ & $S$ \\
\hline $0828 / 08$ & A. baumannii & 51 & Urina & 2008 & Pronto socorro & 85 & $S$ & $\mathrm{R}$ & $\mathrm{R}$ & $\mathrm{R}$ & $\mathrm{R}$ & $S$ & 1 & $\mathrm{R}$ & $S$ & $S$ \\
\hline $0841 / 08$ & A. baumannii & 23,51 & S. traqueal & 2008 & UTI adulto & 43 & $\mathrm{R}$ & $\mathrm{R}$ & $\mathrm{R}$ & $\mathrm{R}$ & $\mathrm{R}$ & $\mathrm{R}$ & $\mathrm{R}$ & $\mathrm{R}$ & $\mathrm{R}$ & $\mathrm{R}$ \\
\hline $0847 / 08$ & A. gen. $13 \mathrm{TU}$ & $\ldots$ & S. purulenta & 2008 & UTI Pediatria & 6 & $S$ & $\mathrm{~S}$ & $\mathrm{~S}$ & $\mathrm{~S}$ & $\mathrm{~S}$ & $S$ & $\mathrm{~S}$ & $S$ & $\mathrm{~S}$ & $\mathrm{~S}$ \\
\hline $0851 / 08$ & A. baumannii & 23,51 & S. traqueal & 2008 & UTI adulto & 67 & $S$ & $S$ & $S$ & $S$ & $S$ & $S$ & $S$ & $S$ & $S$ & $S$ \\
\hline 0863/08 & A. baumannii & 51 & Sangue & 2008 & Clínica médica & 72 & $S$ & $\mathrm{R}$ & $\mathrm{R}$ & $\mathrm{R}$ & $\mathrm{R}$ & $\mathrm{S}$ & $\mathrm{R}$ & $\mathrm{R}$ & $\mathrm{S}$ & $\mathrm{S}$ \\
\hline 0880/08 & A. gen. $13 \mathrm{TU}$ & $\ldots$ & S. traqueal & 2008 & UTI Pediatria & meses & $S$ & $\mathrm{I}$ & 1 & $S$ & $S$ & $S$ & $\mathrm{R}$ & $\mathrm{R}$ & $S$ & $S$ \\
\hline 0881/08 & A. baumannii & 51 & P. inguinal & 2008 & Clínica médica & 71 & $S$ & $\mathrm{R}$ & $\mathrm{R}$ & $\mathrm{R}$ & $\mathrm{R}$ & $S$ & $\mathrm{R}$ & $S$ & $S$ & $S$ \\
\hline $0882 / 08$ & A. baumannii & 23,51 & S. traqueal & 2008 & UTI adulto & 78 & 1 & $\mathrm{R}$ & $\mathrm{R}$ & $\mathrm{R}$ & $S$ & $S$ & $\mathrm{R}$ & $S$ & $\mathrm{R}$ & $\mathrm{R}$ \\
\hline $0937 / 08$ & A. baumannii & 23,51 & LBA & 2008 & UTI adulto & 36 & $\mathrm{R}$ & $\mathrm{R}$ & $\mathrm{R}$ & $\mathrm{R}$ & $\mathrm{R}$ & $S$ & $\mathrm{R}$ & $S$ & $\mathrm{R}$ & $\mathrm{R}$ \\
\hline 0976/08 & A. baumannii & 51 & S. traqueal & 2008 & UTI adulto & 61 & $S$ & $S$ & $S$ & $S$ & $S$ & $S$ & $S$ & $S$ & $S$ & $S$ \\
\hline
\end{tabular}




\begin{tabular}{|c|c|c|c|c|c|c|c|c|c|c|c|c|c|c|c|c|}
\hline Número & identificação & OXAs & Amostra & Ano & Clínica & idade & SAM & FEP & CAZ & CIP & AK & $\mathrm{CN}$ & TZP & SXT & IPM & MEM \\
\hline 0986/08 & A. baumannii & 51 & P. inguinal & 2008 & Clínica médica & 46 & $S$ & $\mathrm{R}$ & $\mathrm{R}$ & $\mathrm{R}$ & $\mathrm{R}$ & $S$ & $\mathrm{R}$ & $\mathrm{R}$ & $S$ & $S$ \\
\hline 1019/08 & A. baumannii & 51 & S. traqueal & 2008 & UTI adulto & 76 & $S$ & $\mathrm{R}$ & $\mathrm{R}$ & $\mathrm{R}$ & $\mathrm{R}$ & $\mathrm{R}$ & $\mathrm{R}$ & $\mathrm{R}$ & $\mathrm{S}$ & $\mathrm{S}$ \\
\hline $1020 / 08$ & A. gen. 3 & $\ldots$ & S. traqueal & 2008 & UTI Pediatria & meses & $S$ & $S$ & $S$ & $S$ & $S$ & $S$ & $S$ & $S$ & $\mathrm{~S}$ & $S$ \\
\hline 0032/09 & A. gen. $13 \mathrm{TU}$ & $\ldots$ & P. axilar & 2009 & Pediatria & 10 & $S$ & $S$ & $S$ & $S$ & $\ldots$ & $S$ & $S$ & $S$ & $S$ & $S$ \\
\hline 0041/09 & A. baumannii & 23,51 & S. traqueal & 2009 & UTI adulto & 81 & $\mathrm{R}$ & $\mathrm{R}$ & $\mathrm{R}$ & $\mathrm{R}$ & $S$ & $S$ & $\mathrm{R}$ & $S$ & $\mathrm{R}$ & $\mathrm{R}$ \\
\hline 0047/09 & A. gen. $13 \mathrm{TU}$ & $\ldots$ & s. traqueal & 2009 & UTI neonatal & dias & $S$ & $S$ & $S$ & $S$ & $S$ & $S$ & $S$ & $S$ & $S$ & $S$ \\
\hline 0048/09 & A. baumannii & 24,51 & Urina & 2009 & Clínica médica & 84 & $S$ & $\mathrm{R}$ & $\mathrm{R}$ & $\mathrm{R}$ & $\mathrm{R}$ & $\mathrm{I}$ & $\mathrm{R}$ & $\mathrm{R}$ & $\mathrm{R}$ & $\mathrm{R}$ \\
\hline 0082/09 & A. baumannii & 51 & S. orofaringe & 2009 & Pronto socorro & 1 & $S$ & $S$ & $S$ & $S$ & $S$ & $S$ & $S$ & $S$ & $S$ & $S$ \\
\hline $0092 / 09$ & A. baumannii & 23,51 & Urina & 2009 & Clínica cirúrgica & 57 & $\mathrm{R}$ & $\mathrm{R}$ & $\mathrm{R}$ & $\mathrm{R}$ & $S$ & $S$ & $\mathrm{R}$ & $S$ & $\mathrm{R}$ & $\mathrm{R}$ \\
\hline 0095/09 & A. baumannii & 51 & S. traqueal & 2009 & UTI adulto & 68 & $S$ & $\mathrm{R}$ & $\mathrm{R}$ & $\mathrm{R}$ & $\mathrm{R}$ & $S$ & $\mathrm{R}$ & $\mathrm{R}$ & $S$ & $S$ \\
\hline $0102 / 09$ & A. baumannii & 51 & Sangue & 2009 & UTI adulto & 77 & $S$ & $\mathrm{R}$ & $\mathrm{R}$ & $\mathrm{R}$ & $\mathrm{R}$ & $S$ & $\mathrm{R}$ & $\mathrm{R}$ & $\mathrm{S}$ & $\mathrm{S}$ \\
\hline $0103 / 09$ & A. baumannii & 23,51 & Urina & 2009 & Semi & 77 & $\mathrm{R}$ & $S$ & $\mathrm{R}$ & $\mathrm{R}$ & $S$ & $S$ & $\mathrm{R}$ & $S$ & $\mathrm{R}$ & $\mathrm{R}$ \\
\hline 0114/09 & A. baumannii & 23,51 & S. traqueal & 2009 & UTI adulto & 49 & $\mathrm{R}$ & $\mathrm{R}$ & $\mathrm{R}$ & $\mathrm{R}$ & $S$ & $S$ & $\mathrm{R}$ & $S$ & $\mathrm{R}$ & $\mathrm{R}$ \\
\hline 0123/09 & A. baumannii & 51 & S. traqueal & 2009 & UTI adulto & 62 & $\mathrm{R}$ & $\mathrm{R}$ & $\mathrm{R}$ & $\mathrm{R}$ & $S$ & $S$ & $\mathrm{R}$ & $S$ & $\mathrm{R}$ & $\mathrm{R}$ \\
\hline $0124 / 09$ & A. baumannii & 51 & P. cateter & 2009 & UTI adulto & 53 & $\mathrm{R}$ & $\mathrm{R}$ & $\mathrm{R}$ & $\mathrm{R}$ & $S$ & $S$ & $\mathrm{R}$ & $S$ & $\mathrm{R}$ & $\mathrm{R}$ \\
\hline 0130/09 & A. baumannii & 51 & Urina & 2009 & Pronto socorro & 33 & $S$ & $S$ & $S$ & $S$ & $S$ & $S$ & $S$ & $S$ & $S$ & $S$ \\
\hline $0134 / 09$ & A. baumannii & 51 & S. traqueal & 2009 & UTI adulto & 68 & $S$ & $S$ & $S$ & $\mathrm{~S}$ & $\mathrm{~S}$ & $S$ & $S$ & $S$ & $S$ & $S$ \\
\hline $0135 / 09$ & A. baumannii & 51 & Urina & 2009 & Pronto socorro & 22 & $S$ & $S$ & $S$ & $S$ & $S$ & $S$ & $S$ & $S$ & $S$ & $S$ \\
\hline 0137/09 & A. baumannii & 51 & S. traqueal & 2009 & UTI Pediatria & meses & $S$ & $S$ & $S$ & $S$ & $S$ & $S$ & $S$ & $S$ & $S$ & $S$ \\
\hline $0146 / 09$ & A. baumannii & 23,51 & S. traqueal & 2009 & Clínica médica & 21 & $\mathrm{R}$ & $\mathrm{R}$ & $\mathrm{R}$ & $\mathrm{R}$ & $S$ & $S$ & $\mathrm{R}$ & $S$ & $\mathrm{R}$ & $\mathrm{R}$ \\
\hline 0160/09 & A. baumannii & 51 & Urina & 2009 & UTI adulto & 56 & $S$ & $\mathrm{R}$ & $\mathrm{R}$ & $\mathrm{R}$ & $\mathrm{R}$ & $S$ & $\mathrm{R}$ & $\mathrm{R}$ & $S$ & $S$ \\
\hline $0164 / 09$ & A. gen. $13 \mathrm{TU}$ & $\ldots$ & P. axilar & 2009 & Clínica cirúrgica & 67 & $S$ & $S$ & $\mathrm{~S}$ & $\mathrm{~S}$ & $S$ & $S$ & $S$ & $\mathrm{~S}$ & $S$ & $S$ \\
\hline 0170/09 & A. baumannii & 23,51 & S. traqueal & 2009 & UTI adulto & 86 & $S$ & $\mathrm{R}$ & $\mathrm{R}$ & $\mathrm{R}$ & $S$ & $S$ & $\mathrm{R}$ & $S$ & $\mathrm{R}$ & $\mathrm{R}$ \\
\hline $0178 / 09$ & A. baumannii & 23,51 & S. traqueal & 2009 & UTI adulto & 51 & $\mathrm{R}$ & $\mathrm{R}$ & $\mathrm{R}$ & $\mathrm{R}$ & $\mathrm{S}$ & 1 & $\mathrm{R}$ & $\mathrm{S}$ & $\mathrm{R}$ & $\mathrm{R}$ \\
\hline 0185/09 & A. baumannii & 51 & S. traqueal & 2009 & UTI adulto & 85 & $\mathrm{R}$ & $\mathrm{R}$ & $\mathrm{R}$ & $\mathrm{R}$ & $\mathrm{S}$ & 1 & $\mathrm{R}$ & $S$ & $\mathrm{R}$ & $\mathrm{R}$ \\
\hline 0189/09 & A. baumannii & 51 & S. traqueal & 2009 & UTI adulto & 58 & $\mathrm{R}$ & $\mathrm{R}$ & $\mathrm{R}$ & $\mathrm{R}$ & $\mathrm{S}$ & $\mathrm{S}$ & $\mathrm{R}$ & $S$ & $\mathrm{R}$ & $\mathrm{R}$ \\
\hline $0234 / 09$ & A. baumannii & 23,51 & outros & 2009 & Clínica médica & 60 & $\mathrm{~S}$ & $\mathrm{R}$ & $\mathrm{R}$ & $\mathrm{R}$ & $\mathrm{R}$ & $S$ & $\mathrm{R}$ & $S$ & $\mathrm{R}$ & $\mathrm{R}$ \\
\hline 0257/09 & A. baumannii & 51 & Urina & 2009 & Pronto socorro & 45 & $\mathrm{R}$ & $\mathrm{R}$ & $\mathrm{R}$ & $\mathrm{R}$ & $\mathrm{R}$ & $\mathrm{R}$ & $\mathrm{R}$ & $\mathrm{R}$ & $\mathrm{R}$ & $\mathrm{R}$ \\
\hline $0260 / 09$ & A. baumannii & 51 & S. traqueal & 2009 & Clínica médica & 68 & $S$ & $\mathrm{R}$ & $\mathrm{R}$ & $\mathrm{R}$ & $\mathrm{R}$ & $S$ & $\mathrm{R}$ & $\mathrm{R}$ & $S$ & $S$ \\
\hline $0264 / 09$ & A. baumannii & 51 & S. traqueal & 2009 & UTI adulto & 33 & $S$ & $\mathrm{R}$ & $\mathrm{R}$ & $\mathrm{R}$ & $S$ & $S$ & $\mathrm{R}$ & $\mathrm{R}$ & $S$ & $S$ \\
\hline 0275/09 & A. baumannii & 51 & P. cateter & 2009 & UTI adulto & 36 & $S$ & $\mathrm{R}$ & $\mathrm{R}$ & $\mathrm{R}$ & $S$ & $\mathrm{R}$ & $\mathrm{R}$ & $\mathrm{R}$ & $\mathrm{R}$ & $\mathrm{R}$ \\
\hline
\end{tabular}




\begin{tabular}{|c|c|c|c|c|c|c|c|c|c|c|c|c|c|c|c|c|}
\hline Número & identificação & OXAs & Amostra & Ano & Clínica & idade & SAM & FEP & CAZ & CIP & AK & $\mathrm{CN}$ & TZP & SXT & IPM & MEM \\
\hline 0278/09 & A. baumannii & 51 & FERIDA & 2009 & Semi & 74 & $S$ & $S$ & $\mathrm{R}$ & $\mathrm{R}$ & $\mathrm{R}$ & $\mathrm{R}$ & $\mathrm{R}$ & $\mathrm{R}$ & $\mathrm{R}$ & $\mathrm{R}$ \\
\hline 0297/09 & A. baumannii & 51 & S. orofaringe & 2009 & Semi & 51 & S & $\mathrm{R}$ & $\mathrm{R}$ & $\mathrm{R}$ & $\mathrm{R}$ & 1 & $\mathrm{R}$ & $\mathrm{R}$ & $\mathrm{R}$ & $\mathrm{R}$ \\
\hline 0299/09 & A. baumannii & 51 & S. traqueal & 2009 & UTI Pediatria & 0 & $S$ & $\mathrm{R}$ & $\mathrm{R}$ & $\mathrm{R}$ & $\mathrm{R}$ & $\mathrm{R}$ & $\mathrm{R}$ & $\mathrm{R}$ & $\mathrm{S}$ & $\ldots$ \\
\hline 0304/09 & A. baumannii & 51 & S. traqueal & 2009 & UTI Pediatria & 4 & $S$ & I & $\mathrm{R}$ & $\mathrm{R}$ & 1 & $\mathrm{R}$ & $\mathrm{S}$ & I & $S$ & $S$ \\
\hline 0305/09 & A. baumannii & 51 & P. cateter & 2009 & Clínica médica & 77 & $S$ & $\mathrm{R}$ & $\mathrm{R}$ & $\mathrm{R}$ & $\mathrm{R}$ & $\mathrm{R}$ & $\mathrm{R}$ & $\mathrm{R}$ & $\mathrm{S}$ & $S$ \\
\hline 0327/09 & A. baumannii & 51 & Urina & 2009 & UTI adulto & 43 & $S$ & $\mathrm{R}$ & $\mathrm{R}$ & $\mathrm{R}$ & $\mathrm{R}$ & $S$ & $\mathrm{R}$ & $\mathrm{R}$ & $S$ & $S$ \\
\hline 0329/09 & A. baumannii & 51 & Abscesso & 2009 & Berçario & meses & $S$ & $S$ & $S$ & $S$ & $\mathrm{~S}$ & $S$ & $S$ & $S$ & $\mathrm{~S}$ & $S$ \\
\hline 0330/09 & A. baumannii & 51 & LBA & 2009 & UTI adulto & 50 & $S$ & $\mathrm{R}$ & $\mathrm{R}$ & $\mathrm{R}$ & $S$ & $\mathrm{R}$ & $\mathrm{R}$ & $\mathrm{R}$ & $\mathrm{R}$ & $\mathrm{R}$ \\
\hline $0351 / 09$ & A. baumannii & 51 & s. traqueal & 2009 & UTI Pediatria & 0 & $S$ & $S$ & $S$ & $S$ & $S$ & $S$ & $S$ & $S$ & $S$ & $S$ \\
\hline 0358/09 & A. baumannii & 51 & M.inf & 2009 & Clínica cirúrgica & 75 & $S$ & $S$ & $S$ & $S$ & $S$ & $S$ & $S$ & $S$ & $S$ & $S$ \\
\hline $0362 / 09$ & A. baumannii & 51 & s. traqueal & 2009 & UTI adulto & 64 & $\mathrm{R}$ & $\mathrm{R}$ & $\mathrm{R}$ & $\mathrm{R}$ & $\mathrm{R}$ & $S$ & $\mathrm{R}$ & $\mathrm{R}$ & $\mathrm{R}$ & $\mathrm{R}$ \\
\hline $0363 / 09$ & A. baumannii & 51 & urina & 2009 & UTI adulto & 54 & $S$ & $\mathrm{R}$ & $\mathrm{R}$ & $\mathrm{R}$ & $\mathrm{R}$ & $S$ & $\mathrm{R}$ & $\mathrm{R}$ & $S$ & $S$ \\
\hline 0379/09 & A. baumannii & 51 & s. traqueal & 2009 & UTI adulto & 49 & $S$ & $\mathrm{R}$ & $\mathrm{R}$ & $\mathrm{R}$ & $\mathrm{R}$ & $S$ & $\mathrm{R}$ & $\mathrm{R}$ & $S$ & $S$ \\
\hline 0385/09 & A. baumannii & 23,51 & p. cateter & 2009 & Clínica médica & 54 & $\mathrm{R}$ & $\mathrm{R}$ & $\mathrm{R}$ & $\mathrm{R}$ & $\mathrm{R}$ & $S$ & $\mathrm{R}$ & $\mathrm{R}$ & $\mathrm{R}$ & $\mathrm{R}$ \\
\hline $0386 / 09$ & A. baumannii & 51 & s. traqueal & 2009 & UTI adulto & 66 & $S$ & $\mathrm{R}$ & $\mathrm{R}$ & $\mathrm{R}$ & $S$ & $S$ & $\mathrm{R}$ & $\mathrm{R}$ & $S$ & $S$ \\
\hline 0402/09 & A. baumannii & 51 & halu dir & 2009 & externo & 44 & $S$ & $S$ & $S$ & $S$ & $S$ & $S$ & $S$ & $S$ & $S$ & $S$ \\
\hline $0408 / 09$ & A. baumannii & 23,51 & Sangue & 2009 & UTI adulto & 79 & $\mathrm{R}$ & $\mathrm{R}$ & $\mathrm{R}$ & $\mathrm{R}$ & $\mathrm{R}$ & $S$ & $\mathrm{R}$ & $\mathrm{R}$ & $\mathrm{R}$ & $\mathrm{R}$ \\
\hline $0432 / 09$ & A. baumannii & 23,51 & s. traqueal & 2009 & UTI adulto & 60 & $\mathrm{R}$ & $\mathrm{R}$ & $\mathrm{R}$ & $\mathrm{R}$ & $\mathrm{R}$ & $S$ & $\mathrm{R}$ & $\mathrm{R}$ & $\mathrm{R}$ & $\mathrm{R}$ \\
\hline 0448/09 & A. baumannii & 51 & s. traqueal & 2009 & UTI adulto & 47 & $S$ & $\mathrm{R}$ & $\mathrm{R}$ & $\mathrm{R}$ & $\mathrm{R}$ & $S$ & $\mathrm{R}$ & $\mathrm{R}$ & $S$ & $S$ \\
\hline $0460 / 09$ & A. baumannii & 51 & p. cateter & 2009 & UTI adulto & 70 & $\mathrm{R}$ & $\mathrm{R}$ & $\mathrm{R}$ & $\mathrm{R}$ & $\mathrm{R}$ & $S$ & $\mathrm{R}$ & $\mathrm{R}$ & $\mathrm{R}$ & $\mathrm{R}$ \\
\hline 0475/09 & A. baumannii & 51 & prega axi & 2009 & UTI adulto & 85 & $S$ & $\mathrm{R}$ & $\mathrm{R}$ & $\mathrm{R}$ & $\mathrm{R}$ & $S$ & $\mathrm{R}$ & $\mathrm{R}$ & $S$ & $S$ \\
\hline $0501 / 09$ & A. gen. $13 \mathrm{TU}$ & $\ldots$ & prega axi & 2009 & externo & 49 & $S$ & $S$ & $\mathrm{~S}$ & $\mathrm{~S}$ & $S$ & $S$ & $S$ & $\mathrm{R}$ & $S$ & $\mathrm{~S}$ \\
\hline 0555/09 & A. baumannii & 23,51 & s. traqueal & 2009 & UTI adulto & 47 & $\mathrm{R}$ & $\mathrm{R}$ & $\mathrm{R}$ & $\mathrm{R}$ & $\mathrm{R}$ & $\mathrm{R}$ & $\mathrm{R}$ & $\mathrm{R}$ & $\mathrm{R}$ & $\mathrm{R}$ \\
\hline $0566 / 09$ & A. baumannii & 23,51 & s. traqueal & 2009 & UTI adulto & 28 & $\mathrm{R}$ & $\mathrm{R}$ & $\mathrm{R}$ & $\mathrm{R}$ & $\mathrm{R}$ & $\mathrm{R}$ & $\mathrm{R}$ & $\mathrm{R}$ & $\mathrm{R}$ & $\mathrm{R}$ \\
\hline 0577/09 & A. baumannii & 51 & s. traqueal & 2009 & UTI adulto & 85 & 1 & $\mathrm{R}$ & $\mathrm{R}$ & $\mathrm{R}$ & $\mathrm{R}$ & I & $\mathrm{R}$ & $\mathrm{R}$ & $\mathrm{R}$ & $\mathrm{R}$ \\
\hline 0595/09 & A. baumannii & 23,51 & s. traqueal & 2009 & UTI adulto & 40 & $\mathrm{I}$ & $\mathrm{R}$ & $\mathrm{R}$ & $\mathrm{R}$ & $\mathrm{R}$ & 1 & $\mathrm{R}$ & $\mathrm{R}$ & $\mathrm{R}$ & $\mathrm{R}$ \\
\hline $0602 / 09$ & A. baumannii & 51 & p. cateter & 2009 & UTI adulto & 17 & $S$ & $\mathrm{R}$ & $\mathrm{R}$ & $\mathrm{R}$ & $\mathrm{R}$ & $S$ & $\mathrm{R}$ & $\mathrm{R}$ & $\mathrm{R}$ & $\mathrm{R}$ \\
\hline 0603/09 & A. baumannii & 23,51 & s. traqueal & 2009 & UTI adulto & 84 & $\mathrm{R}$ & $\mathrm{R}$ & $\mathrm{R}$ & $\mathrm{R}$ & $\mathrm{R}$ & $S$ & $\mathrm{R}$ & $\mathrm{R}$ & $\mathrm{R}$ & $\mathrm{R}$ \\
\hline $0617 / 09$ & A. baumannii & 23,51 & S. traqueal & 2009 & UTI adulto & 54 & $\mathrm{R}$ & $\mathrm{R}$ & $\mathrm{R}$ & $\mathrm{R}$ & $\mathrm{R}$ & $S$ & $\mathrm{R}$ & $\mathrm{R}$ & $\mathrm{R}$ & $\mathrm{R}$ \\
\hline $0618 / 09$ & A. baumannii & 51 & P. axilar & 2009 & Pediatria & 6 & $S$ & $\mathrm{R}$ & $\mathrm{R}$ & $\mathrm{R}$ & $\mathrm{R}$ & 1 & $\mathrm{R}$ & $\mathrm{R}$ & $S$ & $S$ \\
\hline 0639/09 & A. baumannii & 23,51 & tornozelo & 2009 & UTI adulto & 78 & $\mathrm{R}$ & $\mathrm{R}$ & $\mathrm{R}$ & $\mathrm{R}$ & $\mathrm{R}$ & $S$ & $\mathrm{R}$ & $\mathrm{R}$ & $\mathrm{R}$ & $\mathrm{R}$ \\
\hline
\end{tabular}




\begin{tabular}{|c|c|c|c|c|c|c|c|c|c|c|c|c|c|c|c|c|}
\hline Número & identificação & OXAs & Amostra & Ano & Clínica & idade & SAM & FEP & CAZ & CIP & AK & $\mathrm{CN}$ & TZP & SXT & IPM & MEM \\
\hline 0655/09 & A. baumannii & 51 & p. inguinal & 2009 & UTI adulto & 24 & $S$ & $S$ & $S$ & $S$ & $S$ & $S$ & $S$ & $S$ & $S$ & $S$ \\
\hline 0657/09 & A. baumannii & 51 & Sangue & 2009 & UTI adulto & 35 & S & $S$ & $S$ & $S$ & $S$ & S & S & $S$ & S & S \\
\hline 0659/09 & A. baumannii & 23,51 & S. traqueal & 2009 & UTI adulto & 82 & $\mathrm{R}$ & $\mathrm{R}$ & $\mathrm{R}$ & $\mathrm{R}$ & $\mathrm{R}$ & 1 & $\mathrm{R}$ & $\mathrm{R}$ & $\mathrm{R}$ & $\mathrm{R}$ \\
\hline 0660/09 & A. baumannii & 23,51 & S. traqueal & 2009 & UTI adulto & 74 & $\mathrm{R}$ & $\mathrm{R}$ & $\mathrm{R}$ & $\mathrm{R}$ & $\mathrm{R}$ & 1 & $\mathrm{R}$ & $\mathrm{R}$ & $\mathrm{R}$ & $\mathrm{R}$ \\
\hline 0661/09 & A. baumannii & 23,51 & Sangue & 2009 & UTI adulto & 49 & $\mathrm{R}$ & $\mathrm{R}$ & $\mathrm{R}$ & $\mathrm{R}$ & $\mathrm{R}$ & $S$ & $\mathrm{R}$ & $\mathrm{R}$ & $\mathrm{R}$ & $\mathrm{R}$ \\
\hline 0667/09 & A. gen. $13 \mathrm{TU}$ & $\ldots$ & S. traqueal & 2009 & UTI adulto & 28 & $S$ & $S$ & $S$ & $S$ & $S$ & $S$ & $S$ & $S$ & $S$ & $S$ \\
\hline 0674/09 & A. baumannii & 23,51 & s. traqueal & 2009 & UTI adulto & 87 & $\mathrm{R}$ & $\mathrm{R}$ & $\mathrm{R}$ & $\mathrm{R}$ & $\mathrm{R}$ & $S$ & $\mathrm{R}$ & $\mathrm{R}$ & $\mathrm{R}$ & $\mathrm{R}$ \\
\hline 0689/09 & A. baumannii & 23,51 & p. cateter & 2009 & Pediatria & 2 & $\mathrm{R}$ & $\mathrm{R}$ & $\mathrm{R}$ & $\mathrm{R}$ & $\mathrm{R}$ & $S$ & $\mathrm{R}$ & $\mathrm{R}$ & $\mathrm{R}$ & $\mathrm{R}$ \\
\hline 0690/09 & A. baumannii & 23,51 & s. traqueal & 2009 & UTI adulto & 75 & $\mathrm{R}$ & $\mathrm{R}$ & $\mathrm{R}$ & $\mathrm{R}$ & $\mathrm{R}$ & 1 & $\mathrm{R}$ & $\mathrm{R}$ & $\mathrm{R}$ & $\mathrm{R}$ \\
\hline 0694/09 & A. baumannii & 51 & s. orofaringe & 2009 & Clínica médica & 85 & $S$ & $S$ & $S$ & $\mathrm{R}$ & $S$ & $S$ & 1 & $\mathrm{R}$ & $S$ & $S$ \\
\hline 0705/09 & A. baumannii & 51 & sangue & 2009 & UTI adulto & 85 & $S$ & $\mathrm{R}$ & $\mathrm{R}$ & $\mathrm{R}$ & $\mathrm{R}$ & $S$ & $\mathrm{R}$ & $\mathrm{R}$ & $\mathrm{S}$ & $S$ \\
\hline $0713 / 09$ & A. baumannii & 23,51 & s. traqueal & 2009 & UTI adulto & 23 & $\mathrm{R}$ & $\mathrm{R}$ & $\mathrm{R}$ & $\mathrm{R}$ & $\mathrm{R}$ & $S$ & $\mathrm{R}$ & $\mathrm{R}$ & $\mathrm{R}$ & $\mathrm{R}$ \\
\hline 0714/09 & A. baumannii & 51 & p. cateter & 2009 & Clínica médica & 48 & $S$ & $S$ & $\mathrm{R}$ & $\mathrm{R}$ & 1 & $\mathrm{R}$ & $\mathrm{R}$ & $\mathrm{R}$ & $\mathrm{R}$ & $\mathrm{R}$ \\
\hline 0727/09 & A. baumannii & 23,51 & s. traqueal & 2009 & UTI adulto & 35 & $\mathrm{R}$ & $\mathrm{R}$ & $\mathrm{R}$ & $\mathrm{R}$ & $\mathrm{R}$ & $S$ & $\mathrm{R}$ & $\mathrm{R}$ & $\mathrm{R}$ & $\mathrm{R}$ \\
\hline $0742 / 09$ & A. baumannii & 23,51 & p.inguinal & 2009 & Clínica médica & 42 & $\mathrm{R}$ & $\mathrm{R}$ & $\mathrm{R}$ & $\mathrm{R}$ & $S$ & $\mathrm{R}$ & $\mathrm{R}$ & $\mathrm{R}$ & $\mathrm{R}$ & $\mathrm{R}$ \\
\hline 0749/09 & A. baumannii & 23,51 & Sangue & 2009 & Clínica médica & 46 & $\mathrm{R}$ & $\mathrm{R}$ & $\mathrm{R}$ & $\mathrm{R}$ & 1 & $S$ & $\mathrm{R}$ & $\mathrm{R}$ & $\mathrm{R}$ & $\mathrm{R}$ \\
\hline $0772 / 09$ & A. gen. 3 & $\ldots$ & s. traqueal & 2009 & UTI adulto & 81 & $S$ & $S$ & $S$ & $S$ & $S$ & $S$ & $S$ & $S$ & $S$ & $S$ \\
\hline 0798/09 & A. baumannii & 23,51 & S. traqueal & 2009 & UTI adulto & 45 & $\mathrm{R}$ & $\mathrm{R}$ & $\mathrm{R}$ & $\mathrm{R}$ & $\mathrm{R}$ & $S$ & $\mathrm{R}$ & $\mathrm{R}$ & $\mathrm{R}$ & $\mathrm{R}$ \\
\hline 0804/09 & A. baumannii & 23,51 & S. traqueal & 2009 & UTI adulto & 72 & $\mathrm{R}$ & $\mathrm{R}$ & $\mathrm{R}$ & $\mathrm{R}$ & $\mathrm{R}$ & $S$ & $\mathrm{R}$ & $\mathrm{R}$ & $\mathrm{R}$ & $\mathrm{R}$ \\
\hline $0805 / 09$ & A. baumannii & 23,51 & S. orofaringe & 2009 & UTI adulto & 75 & $\mathrm{R}$ & $\mathrm{R}$ & $\mathrm{R}$ & $\mathrm{R}$ & $\mathrm{R}$ & $S$ & $\mathrm{R}$ & $\mathrm{R}$ & $\mathrm{R}$ & $\mathrm{R}$ \\
\hline 0820/09 & A. baumannii & 23,51 & Urina & 2009 & externo & 83 & $S$ & $\mathrm{R}$ & $\mathrm{R}$ & $\mathrm{R}$ & $\mathrm{R}$ & $S$ & $\mathrm{R}$ & $\mathrm{R}$ & 1 & $\mathrm{R}$ \\
\hline $0826 / 09$ & A. baumannii & 51 & P. cateter & 2009 & Clínica médica & 41 & $S$ & $S$ & $\mathrm{~S}$ & $\mathrm{~S}$ & $S$ & $S$ & $S$ & $\mathrm{~S}$ & $S$ & $S$ \\
\hline 0876/09 & A. baumannii & 23,51 & osso & 2009 & UTI adulto & 56 & $\mathrm{R}$ & $\mathrm{R}$ & $\mathrm{R}$ & $\mathrm{R}$ & $\mathrm{R}$ & $S$ & $\mathrm{R}$ & $\mathrm{R}$ & $\mathrm{R}$ & $\mathrm{R}$ \\
\hline $0886 / 09$ & A. baumannii & 23,51 & S. traqueal & 2009 & UTI adulto & 91 & $\mathrm{R}$ & $\mathrm{R}$ & $\mathrm{R}$ & $\mathrm{R}$ & $\mathrm{R}$ & $S$ & $\mathrm{R}$ & $\mathrm{R}$ & $\mathrm{R}$ & $\mathrm{R}$ \\
\hline $0887 / 09$ & A. baumannii & 23,51 & sangue & 2009 & UTI adulto & 37 & $\mathrm{R}$ & $\mathrm{R}$ & $\mathrm{R}$ & $\mathrm{R}$ & $\mathrm{R}$ & $S$ & $\mathrm{R}$ & $\mathrm{R}$ & $\mathrm{R}$ & $\mathrm{R}$ \\
\hline 0896/09 & A. baumannii & 23,51 & S. traqueal & 2009 & UTI adulto & 78 & $\mathrm{R}$ & $\mathrm{R}$ & $\mathrm{R}$ & $\mathrm{R}$ & $\mathrm{R}$ & $\mathrm{S}$ & $\mathrm{R}$ & $\mathrm{R}$ & $\mathrm{R}$ & $\mathrm{R}$ \\
\hline 0914/09 & A. baumannii & 51 & sangue & 2009 & UTI adulto & 64 & $S$ & $\mathrm{R}$ & $\mathrm{R}$ & $\mathrm{R}$ & $\mathrm{R}$ & 1 & $\mathrm{R}$ & $\mathrm{R}$ & $S$ & $S$ \\
\hline 0921/09 & A. baumannii & 23,51 & S. traqueal & 2009 & UTI adulto & 88 & $\mathrm{R}$ & $\mathrm{R}$ & $\mathrm{R}$ & $\mathrm{R}$ & $\mathrm{R}$ & $\mathrm{R}$ & $\mathrm{R}$ & $\mathrm{R}$ & $\mathrm{R}$ & $\mathrm{R}$ \\
\hline $0937 / 09$ & A. baumannii & 23,51 & sangue & 2009 & UTI adulto & 56 & $\mathrm{R}$ & $\mathrm{R}$ & $\mathrm{R}$ & $\mathrm{R}$ & $\mathrm{R}$ & $S$ & $\mathrm{R}$ & $\mathrm{R}$ & $\mathrm{R}$ & $\mathrm{R}$ \\
\hline 0986/09 & A. baumannii & 23,51 & S. traqueal & 2009 & UTI adulto & 67 & $S$ & $\mathrm{R}$ & $\mathrm{R}$ & $\mathrm{R}$ & $\mathrm{R}$ & 1 & $\mathrm{R}$ & $\mathrm{R}$ & $\mathrm{R}$ & $\mathrm{R}$ \\
\hline 0997/09 & A. baumannii & 24,51 & Urina & 2009 & Pronto socorro & 84 & $S$ & $\mathrm{R}$ & $\mathrm{R}$ & $\mathrm{R}$ & $\mathrm{R}$ & $\mathrm{R}$ & $\mathrm{R}$ & $\mathrm{R}$ & $\mathrm{R}$ & $\mathrm{R}$ \\
\hline
\end{tabular}




\begin{tabular}{|c|c|c|c|c|c|c|c|c|c|c|c|c|c|c|c|c|}
\hline Número & identificação & OXAs & Amostra & Ano & Clínica & idade & SAM & FEP & CAZ & CIP & AK & $\mathrm{CN}$ & TZP & SXT & IPM & MEM \\
\hline 0998/09 & A. baumannii & 23,51 & S. traqueal & 2009 & UTI adulto & 49 & $\mathrm{R}$ & $\mathrm{R}$ & $\mathrm{R}$ & $\mathrm{R}$ & $\mathrm{R}$ & I & $\mathrm{R}$ & $\mathrm{R}$ & $\mathrm{R}$ & $\mathrm{R}$ \\
\hline $1003 / 09$ & A. baumannii & 23,51 & sangue & 2009 & UTI adulto & 77 & $\mathrm{R}$ & $\mathrm{R}$ & $\mathrm{R}$ & $\mathrm{R}$ & $\mathrm{R}$ & $\mathrm{S}$ & $\mathrm{R}$ & $\mathrm{R}$ & $\mathrm{R}$ & $\mathrm{R}$ \\
\hline $1007 / 09$ & A. baumannii & 23,51 & sangue & 2009 & UTI adulto & 34 & $\mathrm{R}$ & $\mathrm{R}$ & $\mathrm{R}$ & $\mathrm{R}$ & $\mathrm{R}$ & $S$ & $\mathrm{R}$ & $\mathrm{R}$ & $\mathrm{R}$ & $\mathrm{R}$ \\
\hline $1011 / 09$ & A. baumannii & 23,51 & Abscesso & 2009 & UTI adulto & 37 & $\mathrm{R}$ & $\mathrm{R}$ & $\mathrm{R}$ & $\mathrm{R}$ & $\mathrm{R}$ & I & $\mathrm{R}$ & $\mathrm{R}$ & $\mathrm{R}$ & $\mathrm{R}$ \\
\hline $1022 / 09$ & A. baumannii & 51 & s. gastrico & 2009 & Pediatria & meses & $\mathrm{S}$ & $S$ & $S$ & $S$ & $S$ & $S$ & $\mathrm{~S}$ & $S$ & $S$ & $S$ \\
\hline $1023 / 09$ & A. baumannii & 51 & P. cateter & 2009 & UTI adulto & 46 & $\mathrm{R}$ & $\mathrm{R}$ & $\mathrm{R}$ & $\mathrm{R}$ & $\mathrm{R}$ & I & $\mathrm{R}$ & $\mathrm{R}$ & $\mathrm{R}$ & $\mathrm{R}$ \\
\hline $1025 / 09$ & A. baumannii & 23,51 & sangue & 2009 & UTI adulto & 60 & $\mathrm{R}$ & $\mathrm{R}$ & $\mathrm{R}$ & $\mathrm{R}$ & $\mathrm{R}$ & $S$ & $\mathrm{R}$ & $\mathrm{R}$ & $\mathrm{R}$ & $\mathrm{R}$ \\
\hline $1044 / 09$ & A. baumannii & 23,51 & S. traqueal & 2009 & UTI adulto & 38 & $\mathrm{R}$ & $\mathrm{R}$ & $\mathrm{R}$ & $\mathrm{R}$ & $\mathrm{R}$ & $S$ & $\mathrm{R}$ & $\mathrm{R}$ & $\mathrm{R}$ & $\mathrm{R}$ \\
\hline $1049 / 09$ & A. gen. $13 \mathrm{TU}$ & $\ldots$ & sangue & 2009 & Pediatria & 4 & $S$ & $S$ & $S$ & $S$ & $S$ & $S$ & $S$ & $S$ & $S$ & $S$ \\
\hline $1050 / 09$ & A. baumannii & 23,51 & S. traqueal & 2009 & UTI adulto & 78 & I & $\mathrm{R}$ & $\mathrm{R}$ & $\mathrm{R}$ & $\mathrm{R}$ & $\mathrm{R}$ & $\mathrm{R}$ & $\mathrm{R}$ & $\mathrm{R}$ & $\mathrm{R}$ \\
\hline $1086 / 09$ & A. baumannii & 51 & osso & 2009 & Ambulatório & 60 & $S$ & $S$ & $S$ & $S$ & $S$ & $S$ & $S$ & $S$ & $S$ & $S$ \\
\hline $1091 / 09$ & A. baumannii & 51 & ulcera & 2009 & Ambulatório & 68 & $S$ & $\mathrm{R}$ & $\mathrm{R}$ & $\mathrm{R}$ & $\mathrm{R}$ & $\mathrm{R}$ & $\mathrm{R}$ & $\mathrm{R}$ & $S$ & $S$ \\
\hline $1092 / 09$ & A. baumannii & 51 & P. cateter & 2009 & UTI adulto & 26 & $S$ & $S$ & $S$ & $S$ & $S$ & $S$ & $S$ & $S$ & $S$ & $S$ \\
\hline $1093 / 09$ & A. baumannii & 23,51 & S. ferida & 2009 & Clínica médica & 53 & $\mathrm{R}$ & $\mathrm{R}$ & $\mathrm{R}$ & $\mathrm{R}$ & $\mathrm{R}$ & $S$ & $\mathrm{R}$ & $\mathrm{R}$ & $\mathrm{R}$ & $\mathrm{R}$ \\
\hline $1099 / 09$ & A. baumannii & 23,51 & S. traqueal & 2009 & UTI adulto & 74 & 1 & $\mathrm{R}$ & $\mathrm{R}$ & $\mathrm{R}$ & $S$ & $\mathrm{R}$ & $\mathrm{R}$ & $\mathrm{R}$ & $\mathrm{R}$ & $\mathrm{R}$ \\
\hline $1101 / 09$ & A. baumannii & 23,51 & S. traqueal & 2009 & UTI adulto & 82 & $\mathrm{R}$ & $\mathrm{R}$ & $\mathrm{R}$ & $\mathrm{R}$ & $\mathrm{R}$ & $S$ & $\mathrm{R}$ & $\mathrm{R}$ & $\mathrm{R}$ & $\mathrm{R}$ \\
\hline $1129 / 09$ & A. baumannii & 23,51 & S. traqueal & 2009 & UTI adulto & 65 & $\mathrm{R}$ & $\mathrm{R}$ & $\mathrm{R}$ & $\mathrm{R}$ & $\mathrm{R}$ & $S$ & $\mathrm{R}$ & $\mathrm{R}$ & $\mathrm{R}$ & $\mathrm{R}$ \\
\hline $1137 / 09$ & A. baumannii & 23,51 & S. traqueal & 2009 & UTI adulto & 47 & $\mathrm{R}$ & $\mathrm{R}$ & $\mathrm{R}$ & $\mathrm{R}$ & $\mathrm{R}$ & $S$ & $\mathrm{R}$ & $\mathrm{R}$ & $\mathrm{R}$ & $\mathrm{R}$ \\
\hline $003 / 10$ & A. baumannii & 23,51 & P. axilar & 2010 & UTI Pediatria & 1 & $\mathrm{R}$ & $\mathrm{R}$ & $\mathrm{R}$ & $\mathrm{R}$ & $\mathrm{R}$ & $S$ & $\mathrm{R}$ & $\mathrm{R}$ & $\mathrm{R}$ & $\mathrm{R}$ \\
\hline $013 / 10$ & A. baumannii & 23,51 & S. traqueal & 2010 & UTI adulto & 42 & $\mathrm{R}$ & $\mathrm{R}$ & $\mathrm{R}$ & $\mathrm{R}$ & $\mathrm{R}$ & $\mathrm{S}$ & $\mathrm{R}$ & $\mathrm{R}$ & $\mathrm{R}$ & $\mathrm{R}$ \\
\hline $014 / 10$ & A. baumannii & 23,51 & Sangue & 2010 & UTI adulto & 42 & $\mathrm{R}$ & $\mathrm{R}$ & $\mathrm{R}$ & $\mathrm{R}$ & $\mathrm{R}$ & $S$ & $\mathrm{R}$ & $\mathrm{R}$ & $\mathrm{R}$ & $\mathrm{R}$ \\
\hline $057 / 10$ & A. baumannii & 23,51 & Secreção & 2010 & UTI adulto & 92 & $\mathrm{~S}$ & $\mathrm{R}$ & $\mathrm{R}$ & $\mathrm{R}$ & $\mathrm{R}$ & $\mathrm{I}$ & $\mathrm{R}$ & $\mathrm{R}$ & $\mathrm{R}$ & $\mathrm{R}$ \\
\hline $069 / 10$ & A. baumannii & 51 & Empiema & 2010 & Clínica médica & 75 & $S$ & $\mathrm{R}$ & $\mathrm{R}$ & $\mathrm{R}$ & $\mathrm{R}$ & $S$ & $\mathrm{R}$ & $\mathrm{R}$ & $S$ & $S$ \\
\hline $079 / 10$ & A. baumannii & 23,51 & Biópsia & 2010 & UTI adulto & 60 & $\mathrm{R}$ & $\mathrm{R}$ & $\mathrm{R}$ & $\mathrm{R}$ & $\mathrm{R}$ & $\mathrm{I}$ & $\mathrm{R}$ & $\mathrm{R}$ & $\mathrm{R}$ & $\mathrm{R}$ \\
\hline $082 / 10$ & A. baumannii & 51 & Urina & 2010 & UTI adulto & 68 & $\mathrm{R}$ & $\mathrm{R}$ & $\mathrm{R}$ & $\mathrm{R}$ & $\mathrm{R}$ & $\mathrm{R}$ & $\mathrm{R}$ & $\mathrm{R}$ & $S$ & $S$ \\
\hline $085 / 10$ & A. baumannii & 23,51 & S. traqueal & 2010 & UTI adulto & 82 & $\mathrm{R}$ & $\mathrm{R}$ & $\mathrm{R}$ & $\mathrm{R}$ & $\mathrm{R}$ & $\mathrm{R}$ & $\mathrm{R}$ & $\mathrm{R}$ & $\mathrm{I}$ & 1 \\
\hline $117 / 10$ & A. gen. $13 \mathrm{TU}$ & $\ldots$ & P. cateter & 2010 & Clínica obstétrica & 24 & $S$ & $S$ & $S$ & $S$ & $S$ & $S$ & $S$ & $S$ & $S$ & $S$ \\
\hline $118 / 10$ & A. baumannii & 23,51 & s. ferida & 2010 & UTI adulto & 73 & $\mathrm{R}$ & $\mathrm{R}$ & $\mathrm{R}$ & $\mathrm{R}$ & $\mathrm{R}$ & I & $\mathrm{R}$ & $\mathrm{R}$ & $\mathrm{R}$ & $\mathrm{R}$ \\
\hline $122 / 10$ & A. baumannii & 51 & P. cateter & 2010 & Clínica cirúrgica & 84 & $S$ & $S$ & $S$ & $S$ & $S$ & $S$ & 1 & $S$ & $S$ & $S$ \\
\hline $127 / 10$ & A. baumannii & 23,51 & S. traqueal & 2010 & UTI adulto & 57 & $S$ & $\mathrm{R}$ & $\mathrm{R}$ & $\mathrm{R}$ & $\mathrm{R}$ & $S$ & $\mathrm{R}$ & $\mathrm{R}$ & I & $\mathrm{R}$ \\
\hline $128 / 10$ & A. baumannii & 51 & s. ferida & 2010 & Clínica médica & 88 & $S$ & $S$ & $S$ & $S$ & $S$ & $S$ & $S$ & $S$ & $S$ & $S$ \\
\hline
\end{tabular}




\begin{tabular}{|c|c|c|c|c|c|c|c|c|c|c|c|c|c|c|c|c|}
\hline Número & identificação & OXAs & Amostra & Ano & Clínica & idade & SAM & FEP & CAZ & CIP & AK & $\mathrm{CN}$ & TZP & SXT & IPM & MEM \\
\hline $148 / 10$ & A. baumannii & 23,51 & LBA & 2010 & UTI adulto & 75 & $\mathrm{R}$ & $\mathrm{R}$ & $\mathrm{R}$ & $\mathrm{R}$ & $\mathrm{R}$ & $S$ & $\mathrm{R}$ & $\mathrm{R}$ & $\mathrm{R}$ & $\mathrm{R}$ \\
\hline $158 / 10$ & A. gen. 3 & $\ldots$ & secreção coto & 2010 & UTI neonatal & dias & $S$ & $S$ & $S$ & $\mathrm{~S}$ & $S$ & $S$ & $S$ & $S$ & $S$ & $S$ \\
\hline $159 / 10$ & A. baumannii & 23,51 & S. traqueal & 2010 & UTI adulto & 53 & $\mathrm{R}$ & $\mathrm{R}$ & $\mathrm{R}$ & $\mathrm{R}$ & $\mathrm{R}$ & $S$ & $\mathrm{R}$ & $\mathrm{R}$ & $\mathrm{R}$ & $\mathrm{R}$ \\
\hline $169 / 10$ & A. baumannii & 23,51 & Sangue & 2010 & UTI adulto & 68 & $S$ & $\mathrm{R}$ & $\mathrm{R}$ & $\mathrm{R}$ & $\mathrm{R}$ & $S$ & $\mathrm{R}$ & $\mathrm{R}$ & $\mathrm{R}$ & $\mathrm{R}$ \\
\hline $172 / 10$ & A. baumannii & 51 & S. traqueal & 2010 & UTI adulto & 31 & $S$ & $\mathrm{R}$ & $\mathrm{R}$ & $\mathrm{R}$ & $S$ & 1 & I & $\mathrm{R}$ & $\mathrm{S}$ & $S$ \\
\hline $175 / 10$ & A. baumannii & 23,51 & Urina & 2010 & UTI adulto & 50 & $S$ & $\mathrm{R}$ & $\mathrm{R}$ & $\mathrm{R}$ & $\mathrm{R}$ & $\mathrm{R}$ & $\mathrm{R}$ & $\mathrm{R}$ & $\mathrm{R}$ & $\mathrm{R}$ \\
\hline $178 / 10$ & A. baumannii & 51 & Sangue & 2010 & Clínica médica & 51 & $S$ & $\mathrm{R}$ & $\mathrm{R}$ & $\mathrm{R}$ & $\mathrm{R}$ & $\mathrm{R}$ & $\mathrm{R}$ & $\mathrm{R}$ & $S$ & $S$ \\
\hline $218 / 10$ & A. baumannii & 23,51 & Sangue & 2010 & UTI adulto & 81 & 1 & $\mathrm{R}$ & $\mathrm{R}$ & $\mathrm{R}$ & $\mathrm{R}$ & $S$ & $\mathrm{R}$ & $\mathrm{R}$ & $\mathrm{R}$ & $\mathrm{R}$ \\
\hline $237 / 10$ & A. baumannii & 23,51 & Sangue & 2010 & UTI adulto & 44 & $\mathrm{R}$ & $\mathrm{R}$ & $\mathrm{R}$ & $\mathrm{R}$ & $\mathrm{R}$ & $S$ & $\mathrm{R}$ & $\mathrm{R}$ & $\mathrm{R}$ & $\mathrm{R}$ \\
\hline $249 / 10$ & A. baumannii & 23,51 & S. traqueal & 2010 & UTI adulto & 72 & $\mathrm{R}$ & $\mathrm{R}$ & $\mathrm{R}$ & $\mathrm{R}$ & $\mathrm{R}$ & $S$ & $\mathrm{R}$ & $\mathrm{R}$ & $\mathrm{R}$ & $\mathrm{R}$ \\
\hline $251 / 10$ & A. baumannii & 23,51 & S. traqueal & 2010 & UTI adulto & 54 & $\mathrm{R}$ & $\mathrm{R}$ & $\mathrm{R}$ & $\mathrm{R}$ & $\mathrm{R}$ & $S$ & $\mathrm{R}$ & $\mathrm{R}$ & $\mathrm{R}$ & $\mathrm{R}$ \\
\hline $253 / 10$ & A. baumannii & 23,51 & Prega & 2010 & UTI adulto & 63 & $\mathrm{R}$ & $\mathrm{R}$ & $\mathrm{R}$ & $\mathrm{R}$ & $\mathrm{R}$ & $S$ & $\mathrm{R}$ & $S$ & $\mathrm{R}$ & $\mathrm{R}$ \\
\hline $254 / 10$ & A. baumannii & 51 & Prega & 2010 & Pediatria & $11 \mathrm{~m}$ & $S$ & $S$ & $S$ & $S$ & $S$ & $S$ & $S$ & $S$ & $\mathrm{~S}$ & $S$ \\
\hline $258 / 10$ & A. baumannii & 23,51 & S. traqueal & 2010 & UTI adulto & 23 & $\mathrm{R}$ & $\mathrm{R}$ & $\mathrm{R}$ & $\mathrm{R}$ & $\mathrm{R}$ & $S$ & $\mathrm{R}$ & $S$ & $\mathrm{R}$ & $\mathrm{R}$ \\
\hline $279 / 10$ & A. baumannii & 51 & S. traqueal & 2010 & Clínica médica & 41 & $S$ & $S$ & $S$ & $S$ & $S$ & $S$ & $S$ & $S$ & $S$ & $S$ \\
\hline $282 / 10$ & A. baumannii & 23,51 & Prega & 2010 & UTI adulto & 37 & $\mathrm{R}$ & $\mathrm{R}$ & $\mathrm{R}$ & $\mathrm{R}$ & $\mathrm{R}$ & $S$ & $\mathrm{R}$ & $\mathrm{R}$ & $\mathrm{R}$ & $\mathrm{R}$ \\
\hline $290 / 10$ & A. baumannii & 23,51 & s. orofaringe & 2010 & Clínica médica & 43 & $\mathrm{R}$ & $\mathrm{R}$ & $\mathrm{R}$ & $\mathrm{R}$ & $\mathrm{R}$ & $S$ & $\mathrm{R}$ & $\mathrm{R}$ & $\mathrm{R}$ & $\mathrm{R}$ \\
\hline $308 / 10$ & A. baumannii & 23,51 & s. ferida & 2010 & UTI adulto & 77 & $\mathrm{R}$ & $\mathrm{R}$ & $\mathrm{R}$ & $\mathrm{R}$ & $\mathrm{R}$ & $\mathrm{R}$ & $\mathrm{R}$ & $\mathrm{R}$ & $\mathrm{R}$ & $\mathrm{R}$ \\
\hline $309 / 10$ & A. baumannii & 23,51 & S. traqueal & 2010 & UTI adulto & 60 & $\mathrm{R}$ & $\mathrm{R}$ & $\mathrm{R}$ & $\mathrm{R}$ & $\mathrm{R}$ & $S$ & $\mathrm{R}$ & $\mathrm{R}$ & $\mathrm{R}$ & $\mathrm{R}$ \\
\hline $311 / 10$ & A. baumannii & 23,51 & Prega & 2010 & UTI adulto & 81 & $S$ & $\mathrm{R}$ & $\mathrm{R}$ & $\mathrm{R}$ & $\mathrm{R}$ & $\mathrm{R}$ & $\mathrm{R}$ & $\mathrm{R}$ & $\mathrm{R}$ & $\mathrm{R}$ \\
\hline $325 / 10$ & A. baumannii & 23,51 & Prega & 2010 & UTI adulto & 81 & $\mathrm{R}$ & $\mathrm{R}$ & $\mathrm{R}$ & $\mathrm{R}$ & $\mathrm{R}$ & $S$ & $\mathrm{R}$ & $\mathrm{R}$ & $\mathrm{R}$ & $\mathrm{R}$ \\
\hline $330 / 10$ & A. baumannii & 51 & S. traqueal & 2010 & UTI adulto & 71 & $S$ & $\mathrm{~S}$ & $\mathrm{~S}$ & $\mathrm{~S}$ & $\mathrm{~S}$ & $S$ & $S$ & $S$ & $\mathrm{~S}$ & $S$ \\
\hline $352 / 10$ & A. baumannii & 23,51 & P. cateter & 2010 & UTI adulto & 60 & $\mathrm{R}$ & $\mathrm{R}$ & $\mathrm{R}$ & $\mathrm{R}$ & $\mathrm{R}$ & $S$ & $\mathrm{R}$ & $\mathrm{R}$ & $\mathrm{R}$ & $\mathrm{R}$ \\
\hline $362 / 10$ & A. baumannii & 23,51 & Urina & 2010 & Clínica cirúrgica & 51 & $\mathrm{R}$ & $\mathrm{R}$ & $\mathrm{R}$ & $\mathrm{R}$ & $\mathrm{R}$ & $S$ & $\mathrm{R}$ & $\mathrm{R}$ & $\mathrm{R}$ & $\mathrm{R}$ \\
\hline $369 / 10$ & A. baumannii & 23,51 & S. traqueal & 2010 & UTI adulto & 76 & $\mathrm{R}$ & $\mathrm{R}$ & $\mathrm{R}$ & $\mathrm{R}$ & $\mathrm{R}$ & $\mathrm{S}$ & $\mathrm{R}$ & $\mathrm{S}$ & $\mathrm{R}$ & $\mathrm{R}$ \\
\hline $420 / 10$ & A. baumannii & 23,51 & S. traqueal & 2010 & UTI adulto & 79 & $\mathrm{R}$ & $\mathrm{R}$ & $\mathrm{R}$ & $\mathrm{R}$ & $\mathrm{R}$ & $S$ & $\mathrm{R}$ & $S$ & $\mathrm{R}$ & $\mathrm{R}$ \\
\hline $423 / 10$ & A. baumannii & 23,51 & S. traqueal & 2010 & UTI adulto & 27 & $\mathrm{R}$ & $\mathrm{R}$ & $S$ & $\mathrm{R}$ & $\mathrm{R}$ & $S$ & $\mathrm{R}$ & $\mathrm{R}$ & $\mathrm{R}$ & $\mathrm{R}$ \\
\hline $424 / 10$ & A. baumannii & 51 & S. traqueal & 2010 & UTI adulto & 71 & $\mathrm{R}$ & $\mathrm{R}$ & $S$ & $\mathrm{R}$ & $\mathrm{R}$ & 1 & $\mathrm{R}$ & $\mathrm{R}$ & $S$ & $S$ \\
\hline $429 / 10$ & A. baumannii & 23,51 & S. traqueal & 2010 & UTI adulto & 72 & $\mathrm{R}$ & $\mathrm{R}$ & $S$ & $\mathrm{R}$ & $\mathrm{R}$ & $S$ & $\mathrm{R}$ & $\mathrm{R}$ & $\mathrm{R}$ & $\mathrm{R}$ \\
\hline $434 / 10$ & A. baumannii & 23,51 & S. traqueal & 2010 & UTI adulto & 80 & $\mathrm{R}$ & $\mathrm{R}$ & $\mathrm{R}$ & $\mathrm{R}$ & $\mathrm{R}$ & $S$ & $\mathrm{R}$ & $\mathrm{R}$ & $\mathrm{R}$ & $\mathrm{R}$ \\
\hline $441 / 10$ & A. baumannii & 23,51 & S. traqueal & 2010 & Semi & 68 & $\mathrm{R}$ & $\mathrm{R}$ & $\mathrm{R}$ & $\mathrm{R}$ & $\mathrm{R}$ & $S$ & $\mathrm{R}$ & $\mathrm{R}$ & $\mathrm{R}$ & $\mathrm{R}$ \\
\hline
\end{tabular}




\begin{tabular}{|c|c|c|c|c|c|c|c|c|c|c|c|c|c|c|c|c|}
\hline Número & identificação & OXAs & Amostra & Ano & Clínica & idade & SAM & FEP & CAZ & CIP & AK & $\mathrm{CN}$ & TZP & SXT & IPM & MEM \\
\hline $454 / 10$ & A. baumannii & 51 & S. purulenta & 2010 & UTI Pediatria & $10 \mathrm{~m}$ & $S$ & $S$ & $S$ & $\mathrm{~S}$ & $\mathrm{~S}$ & $S$ & $S$ & $S$ & $S$ & $S$ \\
\hline $456 / 10$ & A. baumannii & 23,51 & S. traqueal & 2010 & UTI adulto & 40 & $S$ & $\mathrm{R}$ & $\mathrm{R}$ & $\mathrm{R}$ & $\mathrm{R}$ & I & $\mathrm{R}$ & $\mathrm{R}$ & $\mathrm{R}$ & $\mathrm{R}$ \\
\hline $459 / 10$ & A. baumannii & 51 & S. traqueal & 2010 & Clínica médica & 52 & $S$ & $\mathrm{R}$ & $\mathrm{R}$ & $\mathrm{R}$ & $\mathrm{R}$ & $\mathrm{R}$ & $\mathrm{R}$ & $\mathrm{R}$ & $S$ & $S$ \\
\hline $474 / 10$ & A. baumannii & 23,51 & S. traqueal & 2010 & UTI adulto & 53 & $\mathrm{R}$ & $\mathrm{R}$ & $\mathrm{R}$ & $\mathrm{R}$ & $\mathrm{R}$ & $S$ & $\mathrm{R}$ & $\mathrm{R}$ & $\mathrm{R}$ & $\mathrm{R}$ \\
\hline $491 / 10$ & A. gen. 3 & $\ldots$ & S. orofaringe & 2010 & Clínica médica & 69 & $S$ & $S$ & $S$ & $S$ & $S$ & $S$ & $\mathrm{~S}$ & $S$ & $S$ & $S$ \\
\hline $492 / 10$ & A. baumannii & 51 & escara & 2010 & Clínica médica & 68 & S & $S$ & $S$ & $S$ & $\mathrm{~S}$ & $S$ & $S$ & $S$ & $S$ & $S$ \\
\hline $511 / 10$ & A. baumannii & 23,51 & S. traqueal & 2010 & UTI adulto & 47 & $\mathrm{R}$ & $\mathrm{R}$ & $\mathrm{R}$ & $\mathrm{R}$ & $\mathrm{R}$ & $\mathrm{S}$ & $\mathrm{R}$ & $\mathrm{R}$ & $\mathrm{R}$ & $\mathrm{R}$ \\
\hline $512 / 10$ & A. baumannii & 23,51 & S. traqueal & 2010 & UTI adulto & 54 & $\mathrm{R}$ & $\mathrm{R}$ & $\mathrm{R}$ & $\mathrm{R}$ & $\mathrm{R}$ & $S$ & $\mathrm{R}$ & $\mathrm{R}$ & $\mathrm{R}$ & $\mathrm{R}$ \\
\hline $524 / 10$ & A. baumannii & 23,51 & S. traqueal & 2010 & UTI adulto & 48 & $\mathrm{R}$ & $\mathrm{R}$ & $\mathrm{R}$ & $\mathrm{R}$ & $\mathrm{R}$ & $S$ & $\mathrm{R}$ & $\mathrm{R}$ & $\mathrm{R}$ & $\mathrm{R}$ \\
\hline $525 / 10$ & A. baumannii & 51 & Secreção & 2010 & Pediatria & 1 & $S$ & $S$ & $S$ & $S$ & $S$ & $S$ & $S$ & $S$ & $S$ & $S$ \\
\hline $545 / 10$ & A. baumannii & 23,51 & S. traqueal & 2010 & UTI adulto & 59 & $\mathrm{R}$ & $\mathrm{R}$ & $\mathrm{R}$ & $\mathrm{R}$ & $\mathrm{R}$ & $S$ & $\mathrm{R}$ & $\mathrm{R}$ & $\mathrm{R}$ & $\mathrm{R}$ \\
\hline $547 / 10$ & A. baumannii & 23,51 & s. tibia & 2010 & Clínica cirúrgica & 57 & $\mathrm{R}$ & $\mathrm{R}$ & $\mathrm{R}$ & $\mathrm{R}$ & $\mathrm{R}$ & $S$ & $\mathrm{R}$ & $\mathrm{R}$ & $\mathrm{R}$ & $\mathrm{R}$ \\
\hline $560 / 10$ & A. baumannii & 23,51 & S. traqueal & 2010 & UTI adulto & 59 & $\mathrm{R}$ & $\mathrm{R}$ & $\mathrm{R}$ & $\mathrm{R}$ & $\mathrm{R}$ & $S$ & $\mathrm{R}$ & $\mathrm{R}$ & $\mathrm{R}$ & $\mathrm{R}$ \\
\hline $564 / 10$ & A. baumannii & 23,51 & Urina & 2010 & Semi & 38 & $\mathrm{R}$ & $\mathrm{R}$ & $\mathrm{R}$ & $\mathrm{R}$ & $\mathrm{R}$ & $S$ & $\mathrm{R}$ & $S$ & $\mathrm{R}$ & $\mathrm{R}$ \\
\hline $576 / 10$ & A. baumannii & 51 & S. traqueal & 2010 & UTI adulto & 31 & $S$ & $S$ & $S$ & $S$ & $S$ & $S$ & $S$ & $S$ & $S$ & $S$ \\
\hline $577 / 10$ & A. baumannii & 51 & S. traqueal & 2010 & UTI adulto & 63 & $S$ & $S$ & $S$ & $S$ & $S$ & $S$ & $S$ & $S$ & $S$ & $S$ \\
\hline $594 / 10$ & A. baumannii & 23,51 & s. orofaringe & 2010 & Clínica médica & 80 & $\mathrm{R}$ & $\mathrm{R}$ & $\mathrm{R}$ & $\mathrm{R}$ & $\mathrm{R}$ & $S$ & $\mathrm{R}$ & $\mathrm{R}$ & $\mathrm{R}$ & $\mathrm{R}$ \\
\hline $604 / 10$ & A. baumannii & 51 & S. traqueal & 2010 & UTI adulto & 26 & $\mathrm{~S}$ & $\mathrm{~S}$ & $\mathrm{~S}$ & $\mathrm{~S}$ & $\mathrm{~S}$ & $\mathrm{~S}$ & $\mathrm{~S}$ & $\mathrm{~S}$ & $\mathrm{~S}$ & $\mathrm{~S}$ \\
\hline $605 / 10$ & A. baumannii & 23,51 & S. traqueal & 2010 & UTI adulto & 87 & $\mathrm{R}$ & $\mathrm{R}$ & $\mathrm{R}$ & $\mathrm{R}$ & $\mathrm{R}$ & $S$ & $\mathrm{R}$ & $\mathrm{R}$ & $\mathrm{R}$ & $\mathrm{R}$ \\
\hline $620 / 10$ & A. baumannii & 51 & LBA & 2010 & Clínica médica & 75 & $S$ & $S$ & $\mathrm{~S}$ & $\mathrm{~S}$ & $\mathrm{~S}$ & $\mathrm{~S}$ & $\mathrm{~S}$ & $\mathrm{~S}$ & $\mathrm{~S}$ & $\mathrm{~S}$ \\
\hline $626 / 10$ & A. baumannii & 51 & osso sacral & 2010 & Clínica cirúrgica & 38 & $S$ & $\mathrm{R}$ & $\mathrm{R}$ & $\mathrm{R}$ & $\mathrm{R}$ & $S$ & $\mathrm{R}$ & $\mathrm{R}$ & $S$ & $S$ \\
\hline $634 / 10$ & A. gen. 3 & $\ldots$ & S. traqueal & 2010 & UTI adulto & 74 & $\mathrm{~S}$ & $\mathrm{~S}$ & $\mathrm{~S}$ & $\mathrm{~S}$ & $\mathrm{~S}$ & $\mathrm{~S}$ & $\mathrm{~S}$ & $\mathrm{~S}$ & $\mathrm{~S}$ & $\mathrm{~S}$ \\
\hline $652 / 10$ & A. gen. $13 \mathrm{TU}$ & $\ldots$ & p. axilar & 2010 & Clínica cirúrgica & 34 & $S$ & $S$ & $S$ & $S$ & $S$ & $S$ & $S$ & $S$ & $S$ & $S$ \\
\hline $654 / 10$ & A. baumannii & 51 & Urina & 2010 & Clínica cirúrgica & 42 & $S$ & $\mathrm{~S}$ & $\mathrm{~S}$ & $\mathrm{~S}$ & $\mathrm{~S}$ & $\mathrm{~S}$ & $\mathrm{~S}$ & $S$ & $\mathrm{~S}$ & $S$ \\
\hline $656 / 10$ & A. baumannii & 23,51 & hemo & 2010 & Clínica médica & 72 & $\mathrm{R}$ & $\mathrm{R}$ & $\mathrm{R}$ & $\mathrm{R}$ & $\mathrm{R}$ & $S$ & $\mathrm{R}$ & $\mathrm{R}$ & $\mathrm{R}$ & $\mathrm{R}$ \\
\hline $696 / 10$ & A. baumannii & 23,51 & S. traqueal & 2010 & UTI adulto & 77 & I & $\mathrm{R}$ & $\mathrm{R}$ & $\mathrm{R}$ & $\mathrm{R}$ & $\mathrm{S}$ & $\mathrm{R}$ & $\mathrm{R}$ & $\mathrm{R}$ & $\mathrm{R}$ \\
\hline $701 / 10$ & A. baumannii & 23,51 & S. traqueal & 2010 & UTI adulto & 65 & $\mathrm{R}$ & $\mathrm{R}$ & $\mathrm{R}$ & $\mathrm{R}$ & $\mathrm{R}$ & $S$ & $\mathrm{R}$ & $\mathrm{R}$ & $\mathrm{R}$ & $\mathrm{R}$ \\
\hline $704 / 10$ & A. baumannii & 23,51 & I. ascítico & 2010 & UTI Pediatria & 1 & $\mathrm{R}$ & $\mathrm{R}$ & $\mathrm{R}$ & $\mathrm{R}$ & $\mathrm{R}$ & $S$ & $\mathrm{R}$ & $\mathrm{R}$ & $\mathrm{R}$ & $\mathrm{R}$ \\
\hline $707 / 10$ & A. gen. $13 \mathrm{TU}$ & $\ldots$ & urina & 2010 & Pronto socorro & 69 & $S$ & $S$ & $S$ & $S$ & $S$ & $S$ & $S$ & $S$ & $S$ & $S$ \\
\hline $717 / 10$ & A. baumannii & 23,51 & S. traqueal & 2010 & Clínica médica & 82 & $\mathrm{R}$ & $\mathrm{R}$ & $\mathrm{R}$ & $\mathrm{R}$ & $\mathrm{R}$ & $S$ & $\mathrm{R}$ & $\mathrm{R}$ & $\mathrm{R}$ & $\mathrm{R}$ \\
\hline $725 / 10$ & A. baumannii & 23,51 & S. traqueal & 2010 & UTI adulto & 79 & $\mathrm{R}$ & $\mathrm{R}$ & $\mathrm{R}$ & $\mathrm{R}$ & $\mathrm{R}$ & $S$ & $\mathrm{R}$ & $\mathrm{R}$ & $\mathrm{R}$ & $\mathrm{R}$ \\
\hline
\end{tabular}




\begin{tabular}{|c|c|c|c|c|c|c|c|c|c|c|c|c|c|c|c|c|}
\hline Número & identificação & OXAs & Amostra & Ano & Clínica & idade & SAM & FEP & CAZ & CIP & AK & CN & TZP & SXT & IPM & MEM \\
\hline $726 / 10$ & A. baumannii & 23,51 & S. traqueal & 2010 & UTI adulto & 89 & $\mathrm{R}$ & $\mathrm{R}$ & $\mathrm{R}$ & $\mathrm{R}$ & $\mathrm{R}$ & $\mathrm{S}$ & $\mathrm{R}$ & $\mathrm{R}$ & $\mathrm{R}$ & $\mathrm{R}$ \\
\hline $729 / 10$ & A. baumannii & 51 & S. traqueal & 2010 & UTI Pediatria & 10 & $\mathrm{~S}$ & $S$ & $S$ & $S$ & $\mathrm{~S}$ & $\mathrm{~S}$ & $S$ & $S$ & $S$ & $S$ \\
\hline $766 / 10$ & A. baumannii & 23,51 & s. traqueal & 2010 & UTI adulto & 76 & $\mathrm{R}$ & $\mathrm{R}$ & $\mathrm{R}$ & $\mathrm{R}$ & $\mathrm{R}$ & $S$ & $\mathrm{R}$ & $\mathrm{R}$ & $\mathrm{R}$ & $\mathrm{R}$ \\
\hline $767 / 10$ & A. baumannii & 23,51 & S. traqueal & 2010 & UTI Pediatria & 56 & $\mathrm{R}$ & $\mathrm{R}$ & $\mathrm{R}$ & $\mathrm{R}$ & $\mathrm{R}$ & $S$ & $\mathrm{R}$ & $\mathrm{R}$ & $\mathrm{R}$ & $\mathrm{R}$ \\
\hline $777 / 10$ & A. baumannii & 51 & p. inguinal & 2010 & Pediatria & 1 & $S$ & $S$ & $S$ & $S$ & $S$ & $S$ & $S$ & $S$ & $S$ & $S$ \\
\hline $779 / 10$ & A. baumannii & 51 & urina & 2010 & Pronto socorro & 39 & $S$ & $S$ & $S$ & $S$ & $S$ & $S$ & $S$ & $S$ & $S$ & $S$ \\
\hline $782 / 10$ & A. baumannii & 23,51 & S. traqueal & 2010 & UTI adulto & 38 & $\mathrm{R}$ & $\mathrm{R}$ & $\mathrm{R}$ & $\mathrm{R}$ & $\mathrm{R}$ & $S$ & $\mathrm{R}$ & $\mathrm{R}$ & $\mathrm{R}$ & $\mathrm{R}$ \\
\hline $790 / 10$ & A. baumannii & 23,51 & s. gastrotomia & 2010 & UTI Pediatria & $11 \mathrm{~m}$ & $\mathrm{R}$ & $\mathrm{R}$ & $\mathrm{R}$ & $\mathrm{R}$ & $\mathrm{R}$ & $S$ & $\mathrm{R}$ & $\mathrm{R}$ & $\mathrm{R}$ & $\mathrm{R}$ \\
\hline $811 / 10$ & A. baumannii & 23,51 & s. traqueal & 2010 & UTI Pediatria & $10 \mathrm{~m}$ & $\mathrm{R}$ & $\mathrm{R}$ & $\mathrm{R}$ & $\mathrm{R}$ & $\mathrm{R}$ & $\mathrm{S}$ & $\mathrm{R}$ & $\mathrm{R}$ & $\mathrm{R}$ & $\mathrm{R}$ \\
\hline $819 / 10$ & A. baumannii & 23,51 & osso & 2010 & Clínica cirúrgica & 50 & $\mathrm{R}$ & $\mathrm{R}$ & $\mathrm{R}$ & $\mathrm{R}$ & $\mathrm{R}$ & $S$ & $\mathrm{R}$ & $\mathrm{R}$ & $\mathrm{R}$ & $\mathrm{R}$ \\
\hline $821 / 10$ & A. baumannii & 23,51 & urina & 2010 & Pronto socorro & 73 & $\mathrm{~S}$ & $\mathrm{R}$ & $\mathrm{R}$ & $\mathrm{R}$ & $\mathrm{R}$ & 1 & $\mathrm{R}$ & $\mathrm{R}$ & $\mathrm{R}$ & $\mathrm{R}$ \\
\hline $837 / 10$ & A. baumannii & 23,51 & s. traqueal & 2010 & UTI adulto & 53 & $\mathrm{R}$ & $\mathrm{R}$ & $\mathrm{R}$ & $\mathrm{R}$ & $\mathrm{R}$ & $\mathrm{S}$ & $\mathrm{R}$ & $\mathrm{R}$ & $\mathrm{R}$ & $\mathrm{R}$ \\
\hline $850 / 10$ & A. baumannii & 23,51 & s. traqueal & 2010 & UTI adulto & 39 & $\mathrm{R}$ & $\mathrm{R}$ & $\mathrm{R}$ & $\mathrm{R}$ & $\mathrm{R}$ & $\mathrm{S}$ & $\mathrm{R}$ & $\mathrm{R}$ & $\mathrm{R}$ & $\mathrm{R}$ \\
\hline $867 / 10$ & A. baumannii & 23,51 & S. traqueal & 2010 & Clínica médica & 60 & $\mathrm{R}$ & $\mathrm{R}$ & $\mathrm{R}$ & $\mathrm{R}$ & $\mathrm{R}$ & $\mathrm{S}$ & $\mathrm{R}$ & $\mathrm{R}$ & $\mathrm{R}$ & $\mathrm{R}$ \\
\hline $869 / 10$ & A. baumannii & 23,51 & S. traqueal & 2010 & UTI Pediatria & 1 & $\mathrm{R}$ & $\mathrm{R}$ & $\mathrm{R}$ & $\mathrm{R}$ & $\mathrm{R}$ & $\mathrm{S}$ & $\mathrm{R}$ & $\mathrm{R}$ & $\mathrm{R}$ & $\mathrm{R}$ \\
\hline $872 / 10$ & A. baumannii & 23,51 & s. traqueal & 2010 & UTI adulto & 55 & $\mathrm{R}$ & $\mathrm{R}$ & $\mathrm{R}$ & $\mathrm{R}$ & $\mathrm{R}$ & $\mathrm{S}$ & $\mathrm{R}$ & $\mathrm{R}$ & $\mathrm{R}$ & $\mathrm{R}$ \\
\hline $884 / 10$ & A. baumannii & 51 & s. traqueal & 2010 & UTI Pediatria & 1 & $\mathrm{~S}$ & $\mathrm{~S}$ & $\mathrm{~S}$ & $\mathrm{~S}$ & $\mathrm{~S}$ & $\mathrm{~S}$ & $\mathrm{~S}$ & $\mathrm{~S}$ & $\mathrm{~S}$ & $\mathrm{~S}$ \\
\hline $885 / 10$ & A. baumannii & 51 & s. traqueal & 2010 & UTI Pediatria & $5 m$ & $S$ & $S$ & $S$ & $S$ & $S$ & $S$ & $S$ & $S$ & $S$ & $S$ \\
\hline $921 / 10$ & A. baumannii & 23,51 & s. ferida & 2010 & Clínica cirúrgica & 40 & $S$ & $S$ & $S$ & $\mathrm{R}$ & $\mathrm{S}$ & $\mathrm{R}$ & $S$ & $S$ & $S$ & $S$ \\
\hline $926 / 10$ & A. baumannii & 23,51 & s. traqueal & 2010 & UTI adulto & 61 & $\mathrm{R}$ & $\mathrm{R}$ & $\mathrm{R}$ & $\mathrm{R}$ & $\mathrm{R}$ & $S$ & $\mathrm{R}$ & $\mathrm{R}$ & $\mathrm{R}$ & $\mathrm{R}$ \\
\hline $937 / 10$ & A. baumannii & 23,51 & LBA & 2010 & Clínica médica & 66 & $\mathrm{~S}$ & $\mathrm{R}$ & $\mathrm{R}$ & $\mathrm{R}$ & $\mathrm{R}$ & $\mathrm{R}$ & $\mathrm{R}$ & $\mathrm{R}$ & $\mathrm{R}$ & $\mathrm{R}$ \\
\hline
\end{tabular}

Siglas:

SAM - ampicilina/sulbactam

FEP - cefepima

CAZ - ceftazidima

CIP - ciprofloxacino

AK - amicacina

$\mathrm{CN}$ - gentamicina

TZP - piperacilina/tazobactam

SXT - sulfametoxazol/trimetopim

IMP - imipenem

MEM - meropenem 
Anexo 2 - Relação das três cepas de cada espécie clínica do complexo ACB analisadas nos ensaios de "quorum sensing" adesão bacteriana

\begin{tabular}{|c|c|c|c|c|c|c|c|c|c|c|c|c|c|c|c|c|}
\hline Número & identificação & OXAs & Amostra & Ano & Clínica & idade & SAM & FEP & CAZ & CIP & AK & $\mathrm{CN}$ & TZP & SXT & IPM & MEM \\
\hline $407 / 06$ & A. gen. 3 & $\ldots$ & S. traqueal & 2006 & UTI neonatal & dias & $S$ & $S$ & $S$ & $S$ & $S$ & $S$ & $S$ & $S$ & $S$ & S \\
\hline $657 / 06$ & A. gen. 3 & $\ldots$ & Sangue & 2006 & Clínica cirúrgica & 22 & $S$ & $S$ & $S$ & $S$ & $S$ & $S$ & $S$ & $S$ & $S$ & $S$ \\
\hline $070 / 07$ & A. gen. 3 & $\ldots$ & S. traqueal & 2007 & UTI adulto & 62 & $S$ & $S$ & $S$ & $S$ & $S$ & $S$ & $S$ & $\mathrm{R}$ & $S$ & $S$ \\
\hline $267 / 05$ & A.gen.13TU & $\ldots$ & S. traqueal & 2005 & UTI adulto & 64 & $S$ & $S$ & $S$ & $S$ & $S$ & $S$ & $S$ & $S$ & $S$ & $S$ \\
\hline $160 / 06$ & A. gen.13TU & ausente & LBA & 2006 & UTI adulto & 66 & $\mathrm{~S}$ & $\mathrm{~S}$ & I & $\mathrm{S}$ & $\mathrm{S}$ & $\mathrm{S}$ & $\mathrm{S}$ & $\mathrm{S}$ & $\mathrm{S}$ & $\mathrm{S}$ \\
\hline $434 / 07$ & A.gen.13TU & ausente & Sangue & 2007 & UTI adulto & 31 & $\mathrm{R}$ & $S$ & $S$ & $S$ & $S$ & $S$ & $\mathrm{R}$ & $S$ & $S$ & $S$ \\
\hline $344 / 05$ & A. baumannii & 51 & LBA & 2005 & UTI adulto & 87 & $\mathrm{~S}$ & I & $\mathrm{R}$ & $\mathrm{S}$ & $\mathrm{R}$ & $\mathrm{S}$ & I & $\mathrm{S}$ & $\mathrm{S}$ & $\ldots$ \\
\hline $589 / 06$ & A. baumannii & 51 & S. traqueal & 2006 & UTI adulto & 53 & $\mathrm{~S}$ & $\mathrm{R}$ & $\mathrm{R}$ & $\mathrm{R}$ & $\mathrm{R}$ & $\mathrm{R}$ & $\mathrm{R}$ & $\mathrm{R}$ & $\mathrm{S}$ & $S$ \\
\hline $428 / 07$ & A. baumannii & 23,51 & S. traqueal & 2007 & UTI adulto & 72 & 1 & $\mathrm{R}$ & $\mathrm{R}$ & $\mathrm{R}$ & 1 & $\mathrm{R}$ & $\mathrm{R}$ & $\mathrm{R}$ & $\mathrm{R}$ & $\mathrm{R}$ \\
\hline
\end{tabular}

Siglas:

SAM - ampicilina/sulbactam

FEP - cefepima

CAZ - ceftazidima

CIP - ciprofloxacino

AK - amicacina

$\mathrm{CN}$ - gentamicina

TZP - piperacilina/tazobactam

SXT - sulfametoxazol/trimetopim

IMP - imipenem

MEM - meropenem 
Anexo 3 - Relação das dez cepas de cada espécie clínica do complexo ACB avaliadas nos ensaios de biofilme

\begin{tabular}{|c|c|c|c|c|c|c|c|c|c|c|c|c|c|c|c|c|}
\hline Número & identificação & OXAs & Amostra & Ano & Clínica & idade & SAM & FEP & CAZ & CIP & AK & CN & TZP & SXT & IPM & MEM \\
\hline $022 / 05$ & A. gen. 3 & $\ldots$ & urina & 2005 & Pronto socorro & 90 & $S$ & $S$ & $S$ & $S$ & $S$ & $S$ & $S$ & $S$ & $S$ & $S$ \\
\hline $407 / 06$ & A. gen. 3 & $\ldots$ & s. traqueal & 2006 & UTI neonatal & dias & $S$ & $S$ & $S$ & $S$ & $S$ & $\mathrm{~S}$ & $S$ & $\mathrm{~S}$ & $S$ & $S$ \\
\hline $657 / 06$ & A. gen. 3 & $\ldots$ & sangue & 2006 & Clínica cirúrgica & 22 & $S$ & $S$ & $S$ & $S$ & $S$ & $S$ & $S$ & $S$ & $S$ & $\mathrm{~S}$ \\
\hline 070/07 & A. gen. 3 & $\ldots$ & s.traqueal & 2007 & UTI adulto & 62 & $S$ & $S$ & $S$ & $S$ & $S$ & $S$ & $S$ & $\mathrm{R}$ & $S$ & $S$ \\
\hline $347 / 07$ & A. gen. 3 & $\ldots$ & p. axilar & 2007 & Clínica médica & 53 & $S$ & $S$ & $S$ & $S$ & $S$ & $S$ & $S$ & $S$ & $S$ & $S$ \\
\hline $0055 / 08$ & A. gen. 3 & $\ldots$ & LBA & 2008 & UTI adulto & 37 & $S$ & $S$ & $S$ & $S$ & $S$ & $S$ & $S$ & $\mathrm{R}$ & $S$ & $S$ \\
\hline $0827 / 08$ & A. gen. 3 & $\ldots$ & p. axilar & 2008 & UTI Pediatria & 2 & $S$ & $S$ & $S$ & $S$ & $S$ & $S$ & $S$ & $\mathrm{R}$ & $S$ & $S$ \\
\hline $0772 / 09$ & A. gen. 3 & $\ldots$ & s. traqueal & 2009 & UTI adulto & 81 & $S$ & $S$ & $S$ & $S$ & $S$ & $S$ & $S$ & $S$ & $S$ & $S$ \\
\hline $158 / 10$ & A. gen. 3 & $\ldots$ & s. traqueal & 2010 & UTI neonatal & dias & $S$ & $S$ & $S$ & $S$ & $S$ & $S$ & $S$ & $S$ & $S$ & $S$ \\
\hline $634 / 10$ & A. gen. 3 & $\ldots$ & secreção coto & 2010 & UTI adulto & 74 & $S$ & $S$ & $S$ & $S$ & $S$ & $\mathrm{~S}$ & $\mathrm{~S}$ & $S$ & $S$ & $S$ \\
\hline $267 / 05$ & A.gen.13TU & $\ldots$ & s. traqueal & 2005 & UTI adulto & 64 & $S$ & $S$ & $S$ & $S$ & $S$ & $S$ & $S$ & $S$ & $S$ & $S$ \\
\hline $160 / 06$ & A. gen.13TU & $\ldots$ & LBA & 2006 & UTI adulto & 66 & $S$ & $S$ & $\mathrm{I}$ & $S$ & $S$ & $S$ & $S$ & $S$ & $S$ & $S$ \\
\hline $674 / 06$ & A. gen.13TU & $\ldots$ & p. cateter & 2006 & Clínica pediátrica & meses & $\mathrm{S}$ & $S$ & $\mathrm{~S}$ & $\mathrm{~S}$ & $\mathrm{~S}$ & $\mathrm{~S}$ & $\mathrm{~S}$ & $\mathrm{~S}$ & $\mathrm{~S}$ & $\mathrm{~S}$ \\
\hline $168 / 07$ & A.gen.13TU & $\ldots$ & sangue & 2007 & UTI adulto & 31 & $\mathrm{~S}$ & $S$ & $\mathrm{~S}$ & $S$ & $\mathrm{~S}$ & $\mathrm{~S}$ & $\mathrm{~S}$ & $\mathrm{~S}$ & $\mathrm{~S}$ & $\mathrm{~S}$ \\
\hline $434 / 07$ & A.gen.13TU & $\ldots$ & sangua & 2007 & UTI adulto & 56 & $\mathrm{R}$ & $S$ & $S$ & $S$ & $S$ & $S$ & $\mathrm{R}$ & $\mathrm{S}$ & $S$ & $\mathrm{~S}$ \\
\hline $0008 / 08$ & A. gen.13TU & $\ldots$ & p. inguinal & 2008 & UTI adulto & 56 & $S$ & $S$ & $S$ & $S$ & $S$ & $S$ & $S$ & $\mathrm{R}$ & $S$ & $S$ \\
\hline $0847 / 08$ & A.gen.13TU & $\ldots$ & s. purulenta & 2008 & UTI Pediatria & 6 & $S$ & $S$ & $S$ & $S$ & $S$ & $S$ & $S$ & $S$ & $S$ & $S$ \\
\hline $0047 / 09$ & A.gen.13TU & $\ldots$ & s. traqueal & 2009 & UTI neonatal & dias & $S$ & $S$ & $S$ & $S$ & $S$ & $S$ & $S$ & $S$ & $S$ & $S$ \\
\hline $117 / 10$ & A.gen.13TU & $\ldots$ & p. cateter & 2010 & Clínica obstétrica & 24 & $S$ & $S$ & $S$ & $S$ & $S$ & $S$ & $S$ & $S$ & $S$ & $S$ \\
\hline $707 / 10$ & A.gen.13TU & $\ldots$ & urina & 2010 & Pronto socorro & 69 & $\mathrm{~S}$ & $S$ & $S$ & $S$ & $S$ & $S$ & $\mathrm{~S}$ & $S$ & $\mathrm{~S}$ & $\mathrm{~S}$ \\
\hline $346 / 05$ & A. baumannii & 51 & s. traqueal & 2005 & UTI adulto & 78 & $S$ & $\mathrm{R}$ & $\mathrm{R}$ & $\mathrm{R}$ & $\mathrm{R}$ & $\mathrm{R}$ & 1 & $\mathrm{R}$ & $S$ & $\mathrm{~S}$ \\
\hline $182 / 06$ & A. baumannii & 51 & urina & 2006 & Ambulatório & 69 & $S$ & $S$ & $S$ & $\mathrm{R}$ & $S$ & $S$ & $S$ & $S$ & $S$ & $S$ \\
\hline $454 / 06$ & A. baumannii & 51 & p. axilar & 2006 & Clínica médica & 72 & $\mathrm{R}$ & $\mathrm{R}$ & 1 & $\mathrm{R}$ & $\mathrm{R}$ & $\mathrm{S}$ & $\mathrm{R}$ & $\mathrm{S}$ & $\mathrm{R}$ & $\mathrm{R}$ \\
\hline 034/07 & A. baumannii & 51 & sangue & 2007 & UTI Pediatria & 1 & $S$ & $S$ & $S$ & $S$ & $S$ & $S$ & $S$ & $S$ & $S$ & $S$ \\
\hline 0144/08 & A. baumannii & 23,51 & s. traqueal & 2008 & UTI adulto & 61 & $\mathrm{R}$ & $\mathrm{R}$ & $\mathrm{R}$ & $\mathrm{R}$ & $S$ & $S$ & $\mathrm{R}$ & $S$ & $\mathrm{R}$ & $\mathrm{R}$ \\
\hline $0390 / 08$ & A. baumannii & 51 & p. axilar & 2008 & Clínica médica & 43 & $S$ & $S$ & $S$ & $S$ & $S$ & $\ldots$ & $S$ & $S$ & $S$ & $S$ \\
\hline $0130 / 09$ & A. baumannii & 51 & urina & 2009 & Pronto socorro & 33 & $S$ & $S$ & $S$ & $S$ & $S$ & $S$ & $S$ & $S$ & $S$ & $S$ \\
\hline $0460 / 09$ & A. baumannii & 51 & p. cateter & 2009 & UTI adulto & 70 & $\mathrm{R}$ & $\mathrm{R}$ & $\mathrm{R}$ & $\mathrm{R}$ & $\mathrm{R}$ & $S$ & $\mathrm{R}$ & $\mathrm{R}$ & $\mathrm{R}$ & $\mathrm{R}$ \\
\hline $576 / 10$ & A. baumannii & 51 & s. traqueal & 2010 & UTI adulto & 31 & $S$ & $S$ & $S$ & $S$ & $S$ & $S$ & $S$ & $S$ & $S$ & $S$ \\
\hline $926 / 10$ & A. baumannii & 23,51 & s. traqueal & 2010 & UTI adulto & 61 & $\mathrm{R}$ & $\mathrm{R}$ & $\mathrm{R}$ & $\mathrm{R}$ & $\mathrm{R}$ & $S$ & $\mathrm{R}$ & $\mathrm{R}$ & $\mathrm{R}$ & $\mathrm{R}$ \\
\hline
\end{tabular}




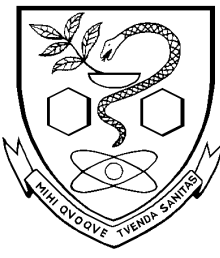

\section{UNIVERSIDADE DE SÃO PAULO}

Faculdade de Ciências Farmacêuticas

Departamento de Análises Clínicas e Toxicológicas

\section{DECLARAÇÃO}

Declaramos que o projeto "Caracterização molecular e fenotípica de amostras bacterianas do complexo Acinetobacter calcoaceticus-Acinetobacter baumannii" dispensa aprovação por comitê de ética pois não envolve seres humanos e animais.

\section{Elizabeth Harummyy Takagi}

Profa. Titular. Marina B. Martinez

São Paulo, 07 de junho de 2011

Av. Prof. Lineu Prestes, $n^{\circ}$ 580, Bloco 17 - Cidade Universitária - CEP 05508900 - São Paulo - SP

Fone: (011) 3818-3661/3818-3642 - Fax (011) 3813-2197 